Doctorado en Geografía

Facultad de Humanidades y Cs. de la Educación

Universidad Nacional de La Plata

\title{
Consolidación de cadenas globales de valor y desarrollo de clusters locales: el caso de la maquinaria agrícola en Argentina.
}

Autor: Federico Langard

Director: Pablo José Lavarello

Director de Beca CONICET: Graciela Elena Gutman 


\section{Agradecimientos}

Finalmente luego de un largo camino, que por momentos se hizo arduo, me llega la muy grata tarea de elaborar los agradecimientos a quienes hicieron posible la presente tesis. Intentaré expresar la gratitud que siento a riesgo de no enunciarlo de forma totalmente justa y en su real dimensión, a todas las personas e instituciones que han estado presentes de distintas maneras durante este trabajo de tesis. Esta tesis, sin dudas, no hubiese sido factible de otra manera.

En este sentido, quiero agradecer: a Pablo J. Lavarello y a Graciela E. Gutman por el compromiso, preocupación, generosidad y dedicación como directores de este trabajo de investigación, y por su paciente tarea docente, a Etel por hacer del mundo el mejor de los mundos, a aquellos amigos, pares en el trabajo de investigación, que fueron espíritu, comprensión, discusión, lectura, ayuda y diversión en esta apasionante actividad, Juan Pablo Del Rio, Mariana Relli y Diego Arturi. A Luis por su generosa asistencia en momentos cruciales. Nuevamente a Juan Pablo Del Rio por su incansable y admirable pasión por las formas.

Quiero destacar que la elaboración de este estudio no podría haberse llevado a cabo sin los recursos otorgados por el Consejo Nacional de Investigaciones Científicas y Técnicas y el Centro de Estudios Urbanos y Regionales, sede de mí trabajo. Asimismo, contribuyó y fuertemente la Universidad Nacional de General Sarmiento a través del proyecto PEC A-26, FLACSO-IDRC.

No puedo dejar de expresar mi gratitud a mí familia Cocó, Manucho, Eleonora y Mariana, y a mis amigos, con quienes crecí, su incondicionalidad y alegría: Berna, Juli, Manu, Memo, Nico, Poty y Tincho. 


\section{Índice}

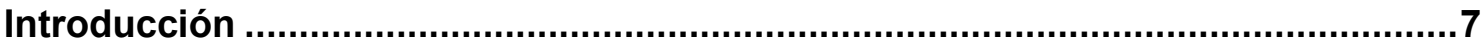

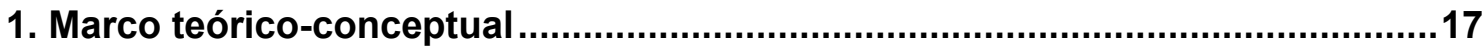

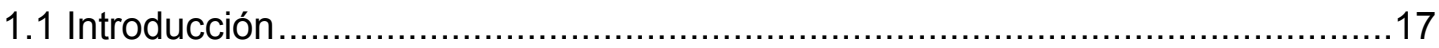

1.2. Los aportes del estructuralismo latinoamericano para el estudio de las

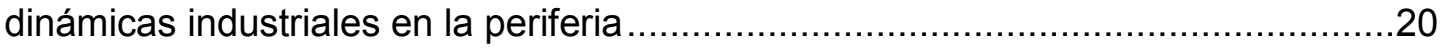

1.2.1. La importancia del concepto centro-periferia .........................................22

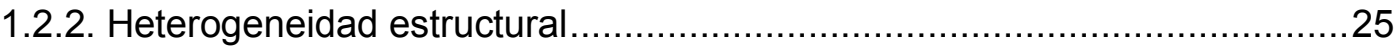

1.2.3. Una perspectiva holista: la dependencia ..........................................27

1.3. Los puentes entre el estructuralismo latinoamericano y la literatura de los

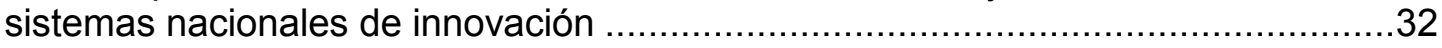

1.3.1. El Cambio estructural y las industrias difusoras del progreso técnico ........33

1.3.2. Enfoque de los Sistemas Nacionales de Innovación (SNI) ........................37

1.4. Crisis del régimen de acumulación de postguerra y nuevas formas de organización de la producción a nivel internacional .............................................40

1.5. Las nuevas lógicas espaciales de la producción industrial ............................47

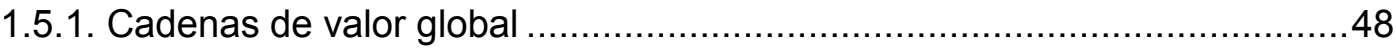

1.5.2. Las dinámicas locales: Aglomeraciones productivas, clusters y distritos

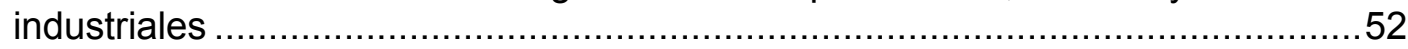

1.6. Recapitulación. Los aportes de la teoría del desarrollo y la geografía económica al estudio de la maquinaria agrícola en Argentina ...............................................57

2. Desarrollo histórico del sector argentino de maquinaria agrícola ...................62

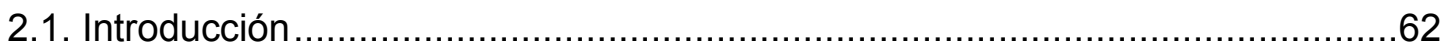

2.2. Orígenes y localización del sector de maquinaria agrícola argentino...............64

2. 3. Nuevo rol del Estado como dinamizador y promotor del sector de maquinaria

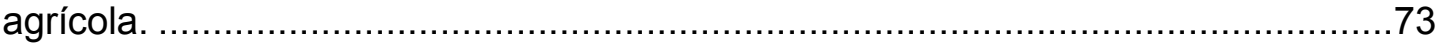

2.4. Cambio regresivo estructural. Reestructuración de la industria .......................82

2.4.1. Profundización de la desestructuración productiva ................................93

2.5. Nuevo proceso de sustitución de importaciones ........................................102

2.6. Cambios en el manejo agronómico de la siembra y su incidencia en el mercado

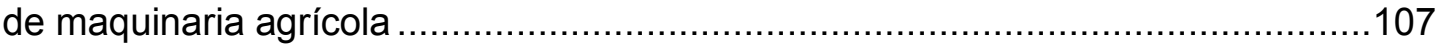

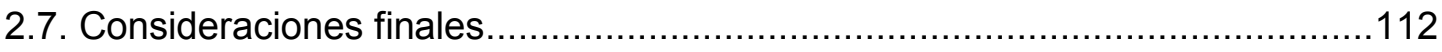

3. Estructura del comercio mundial de maquinaria agrícola.............................118

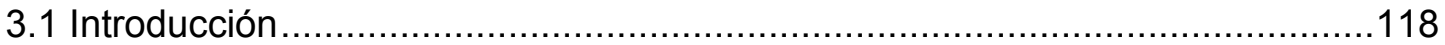

3.2. Configuración mundial del comercio de maquinaria agrícola .........................120 
3.2.1. Empresas que dominan el mercado internacional de maquinaria agrícola120

3.2.2 Países que dominan el mercado mundial de maquinaria agrícola 124

3.3 La concentración del capital y la estrategia competitiva de las empresas transnacionales

3.3.1. Las estrategias de las empresas transnacionales en Argentina y América del Sur.

3.3.2 Los cambios en la política industrial en el período posdevaluación en el país y las estrategias sectoriales. 139

3.4 Inserción de Argentina en el mercado internacional

3.5 Consecuencias de la estructura mundial del comercio de maquinaria agrícola en Argentina 146

4. Configuración territorial y organización empresarial

4.1. Introducción.

4.2. Organización espacial de la industria de maquinaria agrícola 152

4.3 Delimitación territorial del área de estudio 154

4.4 Estructura de los distintos segmentos de la industria en la región de estudio..156

4.5. Configuración de relaciones proveedor - usuario. 160

4.6. Aprendizajes sistémicos en la industria de maquinaria agrícola argentina 167

4.7. Desarrollo de competencias endógenas en torno a la organización de la producción

4.7.1. Tipo de equipamiento para la producción 174

4.7.2 Sistemas de organización productiva del trabajo 178

4.7.3. Cultura hacia la calidad y la mejora continua . 181

4.8. Estrategias de las empresas transnacionales de maquinaria agrícola en Argentina

4.8.1. Articulación de la estrategia local de las compañías y la estrategia global187

4.8.2. Esquema de producción. Organización del proceso de trabajo 191

4.8.3. Impactos sobre el entramado productivo local 193

4.8.4. Innovación y desarrollo. Vinculaciones con el SNI 195

4.9 Conclusión. 196

Conclusión 203

Referencias bibliográficas 216

Otras fuentes 231

Índice de abreviaturas 233

Índice de figuras. 
Introducción 


\section{Introducción}

La industria de maquinaria agrícola argentina tiene una larga trayectoria vinculada desde sus inicios al desarrollo de la agricultura pampeana argentina. En tanto, su localización, concentrada en las provincias de Santa Fe y Córdoba, se vincula a la zona de producción agrícola originaria del país, donde la demanda fue desde un principio cuantitativamente más importante y cualitativamente más dinámica. Específicamente la región se encuentra ubicada en el este de Córdoba y el centro-sur de Santa Fe (ver mapa N², capítulo 4).

Las firmas productoras de maquinaria agrícola se encuentran aglomeradas territorialmente en relación directa con el desarrollo histórico y geográfico de la agricultura del país. Esta industria nace en respuesta a las necesidades de las formas de producción agrícola en la región centro argentina, en primera instancia como talleres de reparación de maquinaria importada y, posteriormente, como productores que adaptan, copian y fabrican los productos más complejos tecnológicamente. Es de este modo que se inicia, por lo general, la industria de bienes de capital en los países "subdesarrollados" (Nagao y Chudnovsky, 1987).

Esta industria de equipos provee de maquinaria al sector agropecuario y, este hecho, le confiere a la industria un rasgo muy particular dentro de la industria de bienes de capital; en primer lugar, porque en la economía argentina predominan los sectores de recursos naturales intensivos (Cimoli, et al., 2005) y, en segundo lugar, es una industria que interviene en el proceso de innovación en el sector agropecuario (Pavitt, 1984).

Ahora bien, la producción de maquinaria agrícola ${ }^{1}$ en el país atravesó, a lo largo de los años, por sucesivas etapas de crecimiento y contracción asociadas a las dinámicas macroeconómicas y sectoriales. A partir de mediados de la década de 1970, años en que la producción de maquinaria agrícola llegó a tener los niveles más altos de producción, comenzó (con fuertes fluctuaciones) una caída general de estos niveles, caída que fue acompañada de cierre de empresas con la consecuente pérdida de empleo sectorial (Huici, 1988; García, 1999). Hacia la década de 1990 esta

\footnotetext{
1 Por industria de maquinaria agrícola identificamos al conjunto de empresas que, en la Argentina, fabrican algún equipo agrícola. El sector es muy amplio y heterogéneo por lo que metodológicamente se identifican distintos segmentos: tractores, cosechadoras, pulverizadoras, implementos agrícolas, agropartes y sembradoras.
} 
industria poseía una capacidad instalada muy inferior a la que tenía en el decenio de 1980.

La década de 1990 se caracterizó por adoptar los principios del denominado "Consenso de Washington". Esto se vio reflejado en la apertura externa comercial y unilateral del país, en las privatizaciones, en la reestructuración del Estado, en la desregulación de la economía y de los mercados en general (Basualdo, 2003).

Durante los primeros años de la década de 1990, tras diez años de malos resultados, la demanda argentina de equipos agrícolas se recuperó, bajo el impulso de la suba de los precios de los cereales y las oleaginosas, que fueron superiores a los registrados en la década de 1980 . El aumento de la demanda y el tipo de regulación económica de la época permitieron que aumentara la penetración de equipos importados en las ventas locales (Baruj et al., 2005). ${ }^{2}$ La regulación económica y las estrategias de las compañías transnacionales tuvieron, en esta etapa, una sincronía armónica.

Es en este período, las compañías transnacionales reestructuraron su situación en el país. Como hecho destacado de la reorganización de las empresas transnacionales, se observó la deslocalización de la producción integral de equipos, fundamentalmente, los segmentos de producto de cosechadoras y de tractores. Como consecuencia de ello, estas firmas concentraron la producción en Brasil para abastecer, desde allí, la región del MERCOSUR ${ }^{3}$ (Chudnovsky y Castagno, 2003). Por su parte, algunas de las filiales locales de las empresas transnacionales se reconvirtieron de fabricantes de productos finales (tractores y cosechadoras), a sólo productoras de partes e importadoras de las máquinas completas. Varios autores (García, 1999; Baruj et al., 2005; Pellegrini, 2005; Rougier, 2006) concuerdan con que la reorganización de las compañías transnacionales de maquinaria agrícola en Argentina se hizo en función de una reestructuración de las firmas a nivel mundial.

En la década de 1990, Argentina dejó atrás la etapa denominada "industria por sustitución de importaciones" (ISI) y las empresas transnacionales abandonaron la forma de operar a través de "filiales réplica"4, forma de producir que habían adoptado

\footnotetext{
2 Hacia finales de la década, según estimaciones del INDEC el aumento de maquinaria agrícola importada llega a cubrir el $50 \%$ en tractores y cosechadoras del mercado local, mayoritariamente proveniente de Brasil. A partir de 1997 las multinacionales comienzan a retirarse del mercado local, como fabricantes y concentran la producción en Brasil. En Argentina John Deere y Deutz continúan la fabricación de motores que luego exportan a Brasil para equipar los tractores y cosechadoras que desde allí son importados.

${ }^{3}$ EI MERCOSUR entró en vigencia a partir del 1 de enero de 1995.

${ }^{4}$ La "filial réplica", produce domésticamente las líneas de producto de la casa matriz y de otras filiales adaptando los procesos de producción originales en escalas menores (downscaling). En el marco de una estrategia "multidoméstica" u "horizontal", centraliza las actividades de I\&D en la casa matriz (esto es, sus
} 
en mercados protegidos. En cuanto a ello, algunas de estas compañías comenzaron a operar en el país a través de "filiales racionalizadas" ${ }^{5}$ y otras sólo importaron sus equipos finales.

De acuerdo con lo dicho, la estrategia de las firmas transnacionales cambió en Argentina en la década de 1990 debido a las transformaciones organizacionales a nivel internacional, aunque fue necesaria la modificación de la regulación económica a escala nacional para que esto sucediera con la potencia que lo hizo. Estos cambios explican, en alguna medida, la emergencia en el país de las cadenas globales de valor de la maquinaria agrícola, en el marco de una estrategia global o regional (sudamericana) de las empresas transnacionales. A su vez, estas transformaciones generaron, en el país, un déficit sectorial externo de carácter estructural. Como se verá en el desarrollo de la tesis dicha problemática puede interpretarse como una de las manifestaciones centrales en los debates centro - periferia y dependencia en los que anclamos, en parte, nuestro abordaje teórico-metodológico.

Ahora bien, a comienzos de la década de 2000 tras la profunda crisis económica del país y el consecuente fin de la paridad cambiaria (año 2002), se produjo una nueva modificación de la regulación económica. En tanto para el período, el sector agrícola profundizó la adopción de nuevas prácticas agronómicas de cultivo y la utilización de nueva tecnología con el consecuente aumento de la producción ${ }^{6}$. A escala global, esta década (la de 2000), se destacó por la evolución favorable de los precios de los commodities agropecuarios, con una marcada influencia sobre la demanda de equipos agrícolas. En este nuevo escenario, la industria de maquinaria agrícola sufrirá una importante reconfiguración tras un período histórico de estancamiento, cuya manifestación dará lugar a una serie de particularidades que serán analizadas a lo largo de esta tesis.

Cabe señalar que la industria de maquinaria agrícola argentina estuvo estancada y con severos retrocesos durante 25 años (1977 - 2002). Diferentes trabajos publicados que dan cuenta de este período, describen una tendencia general de caída de la actividad y pérdida de capacidades adquiridas en el transcurso de más de 80

ventajas de propiedad) limitando al espacio doméstico las actividades tecnológicas de adaptación de proceso y producto (Lavarello, 2004).

${ }^{5} \mathrm{La}$ "filial racionalizada o especializada", las empresas multinacionales reestructuran o cierran las filiales réplica que resultaran en deseconomías de escala a nivel internacional. La especialización en una etapa específica de la cadena de valor (especialización de proceso) o en la producción de un reducido número de líneas de producto (especialización por línea de producto) son las alternativas de racionalización frecuentemente llevadas adelante (Lavarello, 2004).

\footnotetext{
${ }^{6}$ Pasó de 35 millones de toneladas de granos en 1994 a 97 millones en 2012 (SAGyP, 2013).
} 
años de desarrollo. Hacia el año 2002, la industria de maquinaria agrícola tenía serias dificultades para funcionar, algunos de sus segmentos de productos más complejos tecnológicamente, como tractores y cosechadoras, habían dejado de producirse en el país. Si bien es cierto, que las cifras de producción de maquinaria agrícola se fueron recomponiendo en el período 2002-2010, no todos los segmentos de producto alcanzaron los niveles promedio de la década de 1990.

El nuevo contexto favorable que se generó después de 2002 ha permitido que la industria de maquinaria agrícola se recupere, pero de forma dispar, por segmento de equipo ${ }^{7}$. Más allá de las variables globales que inciden en la industria de maquinaria agrícola argentina existen particularidades locales que han intervenido en el desenvolvimiento de los distintos segmentos de producto. En torno a ello, diversos estudios de caso realizados en Argentina demuestran, que la interacción entre los cambios en el sistema agronómico, impulsados por nuevos paquetes biotecnológicos y por la industria de maquinaria agrícola, con una amplia acumulación de competencias metal-mecánicas durante la industrialización sustitutiva de importaciones, han permitido al sector ser uno de los pocos eslabonamientos resultantes del actual perfil de especialización agrícola en la industria manufacturera (Chudnovsky y Castaño, 2003; García, 2005, 2007; Baruj et al., 2005; Hybel, 2005; Lavarello, et al., 2008). Sin embargo, al interior de la industria de maquinaria agrícola nos interesa destacar que se han evidenciado dinámicas muy heterogéneas desde el punto de vista de su inserción internacional, de su productividad, de la presencia de empresas transnacionales y de la acumulación de capacidades tecno-productivas (Lavarello, Silva y Langard, 2009).

Esta heterogeneidad ${ }^{8}$, concebida teóricamente por el estructuralismo latinoamericano como rasgo característico de todas las economías latinoamericanas, se encuentra presente en la estructura de la industria de maquinaria agrícola argentina. La mencionada estructura posee una fuerte influencia por el tipo de empresas que compone cada segmento de producto. Las compañías transnacionales se concentran en la producción de tractores y $\operatorname{cosechadoras}^{9}$, con altos niveles de productividad relativos, mientras que el resto de los equipos ${ }^{10}$ es producido por

\footnotetext{
7 Se considera en este trabajo de tesis, la siguiente clasificación por segmento de producto dentro de la industria de maquinaria agrícola: tractores, cosechadoras, implementos agrícolas, pulverizadoras, sembradoras, agropartes.

${ }^{8}$ En referencia al concepto de heterogeneidad ver capítulo 1.

${ }^{9}$ Existen empresas nacionales productoras de tractores y cosechadoras, no obstante cuentan con una cuota menor de mercado.

${ }^{10}$ Las máquinas aquí referidas son: pulverizadoras, sembradoras, implementos agrícolas y agropartes.
} 
pequeñas y medianas empresas (PyME) de capital nacional, con diferentes niveles de productividad relativos.

En este sentido, algunos de los interrogantes que pondremos en juego en relación a esta dimensión de análisis, son: ¿cuál ha sido la configuración industrial de los distintos segmentos de producción? ¿Hasta qué punto las diversas trayectorias se traducen en dinámicas diferenciadas de vinculación en el territorio y en la acumulación de competencias endógenas por parte de las empresas? En otras palabras, consideramos importante analizar las diferentes formas de organizar la producción espacialmente, ya sean PyME nacionales o firmas transnacionales, y sus consecuencias a nivel económico, como así también, en la forma de estructurar el territorio ${ }^{11}$.

En un contexto, en el cual la producción de maquinaria agrícola es una de las industrias de bienes de capital más importante del país, el objetivo general de esta tesis es analizar el desenvolvimiento de la industria de maquinaria agrícola argentina, en el período 2001 - 2010. Nuestro interés en esta industria radica en su capacidad potencial, histórica y actual, para contrarrestar los altos niveles de dependencia extranjera sectorial. Tres ejes fundamentales ordenan el recorte de nuestro objeto de estudio: el primero de ellos, la trayectoria histórica de la industria de maquinaria agrícola argentina; el segundo, la inserción del país y de esta industria en el contexto internacional; y el tercero, articula los dos ejes anteriores con la lectura de la estructura productiva de esta industria y su vinculación con el territorio.

Los objetivos específicos de la investigación son: a) analizar las características de la trayectoria de la industria de maquinaria agrícola argentina. Para ello, se hará hincapié en las condiciones de surgimiento, consolidación, restructuración y situación reciente de esta industria. b) Exhibir la estructura de la industria de maquinaria agrícola a nivel mundial, a efectos de identificar los países y las empresas dominantes en la organización del mercado internacional. c) Analizar la influencia de los actores internacionales en el país y en la industria de maquinaria agrícola nacional, como así también, el rol que desempeña el país en el mercado internacional. d) Identificar las distintas configuraciones productivas que asume cada segmento de producto dentro de la industria de maquinaria agrícola argentina. e) Caracterizar las estructuras productivas de las empresas por segmento de producto y el tipo de vinculación que generan con el territorio.

${ }^{11}$ Con respecto a la idea de "estructurar el territorio", nos referiremos en esta tesis a la forma en que una trama productiva se configura y articula en el espacio nacional. 
Nuestra principal hipótesis, es que existen dinámicas globales y locales que reproducen la heterogeneidad propia de un país periférico. La cual se expresa en las estrategias productivas y territoriales de los distintos tipos de empresas de la industria de maquinaria agrícola. Las lógicas globales de las empresas transnacionales tienden a desarticular la producción local y su relación con el territorio se encuentra determinada por una mayor movilidad geográfica del capital, mientras que las dinámicas locales en la que coexisten firmas PyME, tienden a articular la producción local y estructurar el territorio, al desarrollar vínculos con el SNI.

Para dar cuenta de ello, se propone una estrategia metodológica cualicuantitativa que articula tres niveles analíticos: i) a nivel global, se realiza un análisis de la estructura que adquiere el mercado mundial de maquinaria agrícola y de la trayectoria de esta industria en el país; ii) a nivel micro, analizaremos la organización de la producción de las firmas por segmento de producto (tractores y cosechadoras, pulverizadoras, sembradoras, implementos agrícolas y agropartes); iii) a nivel meso, se identifica el desarrollo de vinculaciones a escala regional entre: empresas de maquinaria agrícola (con vinculaciones de tipo horizontal y vertical), empresas de maquinaria agrícola e instituciones (públicas y privadas) y empresas de maquinaria agrícola y productores agropecuarios (proveedor/usuario).

Desde este abordaje, será necesario comprender cuáles son las formas en las que las compañías de capital extranjero organizan la producción en el territorio y como lo hacen las PyME de capital nacional. A este respecto, se exploran las distintas estructuras de producción por segmento de equipo, así como también, el tipo de desarrollo territorial que cada segmento genera. El desarrollo territorial es analizado metodológicamente a partir de la configuración espacial que la industria adopta, tomando como parámetros teóricos los conceptos de cluster y cadena global de valor.

Con tal objetivo, instrumentaremos una perspectiva que combina el análisis de información secundaria a nivel documental y bibliográfico con el trabajo de campo. Con el fin de analizar la trayectoria histórica y reciente de la industria, se ha recurrido a fuentes de información secundaria (bibliográfica y estadística). A partir de ellas se realizó un proceso de análisis a efectos de caracterizar la industria de maquinaria agrícola en Argentina desde sus comienzos a finales del s. XIX hasta el año 2010. Esto nos ha permitido establecer las características centrales de esta industria en el país y sus condicionantes de crecimiento.

El estudio del comportamiento del mercado internacional requirió de una profunda revisión bibliográfica y el análisis de bases estadísticas de organismos 
internacionales. Por último, la caracterización estructural de la industria de maquinaria agrícola demandó de la articulación de dos instrumentos: se realizaron encuestas estructuradas en profundidad para trabajar a efectos de exhibir la organización de la producción interna y las vinculaciones locales-regionales, nacionales e internacionales $\mathrm{y}$, complementariamente, se utilizaron las entrevistas, realizadas por Lavarello y Hecker (2010), a las empresas transnacionales que producen en el país a partir de un esquema de cadena de valor global. ${ }^{12}$

La lectura sobre la forma de organizar la producción interna a la empresa y en el territorio fue clave, a la hora de realizar un análisis de las fortalezas productivas y de la capacidad de estructurar o desestructurar el entramado productivo. El análisis conjunto de la lectura transversal de la trayectoria histórica de la industria de maquinaria agrícola, enmarcado por el desenvolvimiento externo de la misma, permitirá observar y explicar los heterogéneos comportamientos por segmento de producto (sembradoras, pulverizadoras, tractores y cosechadoras, implementos agrícolas, agropartes).

La estructura de la tesis se organizará en cuatro capítulos, cada uno de los cuales se encontrará divido en varias secciones.

En el primer capítulo, de naturaleza teórico-metodológica, introduciremos la discusión del problema estructural en la matriz productiva de los países periféricos. Para tal fin, se revisarán una serie de debates teóricos que configuran el estado de la cuestión del problema de la estructura productiva de los países de América Latina en el contexto de la división internacional del trabajo y la relación centro-periferia. Luego, se inspeccionará el enfoque de heterogeneidad estructural y de dependencia. Todos estos conceptos dan el encuadre más amplio y general de la problemática a tratar. A partir de lo antes dicho y siguiendo con la línea de pensamiento estructuralista, cronológicamente hablando, realizaremos algunas aclaraciones respecto del giro de dicho pensamiento en la década de 1980. En este sentido, consideraremos el concepto de núcleo endógeno de desarrollo un elemento clave, que vinculado a la idea de sistema nacional de innovación, se erigen como posibles artífices del cambio estructural. Por su parte, para abordar la dimensión territorial y pensar la relación entre la industria de maquinaria agrícola y el espacio geográfico, se introducen las ideas de los campos conceptuales de cluster y cadena global de valor. Ideas fuerza que se

12 En el caso de las encuestas estructuradas se realizaron en el marco de un proyecto colectivo (ver Proyecto Redes de Conocimiento en tramas productivas: Generación, circulación y apropiación del conocimiento y creación de ventajas competitivas en seis tramas de la Argentina. Componente Maquinaria Agrícola. PEC A-26 FLACSO-IDRC. Proyecto A26 IDRC-FLACSO México. En www.continentedigital.org.). Las entrevistas realizadas a las empresas transnacionales fueron hechas por Lavarello y Hecker para el ministerio de economía de la nación (ver Lavarello y Hecker, 2010). 
ajustan, en parte, al comportamiento de la industria de maquinaria agrícola en la Argentina.

En el segundo capítulo, se reconstruirán las principales transformaciones de la historia de la industria de maquinaria agrícola en la Argentina, desde principios del siglo XX hasta la década de 2000. El objetivo, de este capítulo, será examinar el desarrollo cronológico de esta industria en el país, donde quedará expuesta la importancia de la trayectoria de la industria de maquinaria agrícola conjuntamente con los efectos de la política nacional y sectorial en la mencionada industria. Además en este capítulo, se evidenciarán las capacidades y fortalezas de la industria de maquinaria agrícola Argentina. De hecho, la mirada histórica pone en tensión la relación entre políticas públicas, PyME y empresas transnacionales. En este sentido, las transformaciones de esta industria en la década de 1990, enmarcada en los importantes cambios en el tipo de regulación macroeconómica, supondrán un agravamiento de esta tensión con: la deslocalización de la producción de las empresas transnacionales hacia Brasil y el cierre de la mayoría de las líneas de producción de empresas nacionales de equipos agrícolas autopropulsados. A partir de la década de 2000, daremos cuenta de que la industria de maquinaria agrícola argentina adquirirá una lógica con rasgos específicos a la época y, a su vez, revelará características persistentes en el tiempo.

En el tercer capítulo, exhibiremos de forma estilizada el comportamiento del mercado de la industria de maquinaria agrícola a escala internacional. Donde encontraremos un amplio dominio de empresas transnacionales de países centrales y, a su vez, la supremacía de estos países sobre el mercado global. En referencia a ello, estableceremos la posición que Argentina ocupa a nivel mundial, en cuanto a producción y mercado. El país tiene relativa importancia en el mercado mundial como consumidor de sofisticados equipos. Esto genera, en parte, una vinculación fuertemente asimétrica del país con el mundo en su vinculación con el mercado internacional de maquinaria agrícola, dando como resultado una relación estructuralmente deficitaria. No obstante ello, comprobaremos que algunos de los segmentos de producto de la industria de maquinaria agrícola han mostrado en la década de 2000 capacidad para competir en mercados externos.

El cuarto capítulo introducirá la lectura de la organización de la producción en las empresas. Al mismo tiempo, se desagregará el análisis de la industria de maquinaria agrícola por segmento de producto. Es entonces, que a partir de esta clasificación se establecerá la correspondiente trama de abastecimiento y vinculaciones por segmento, que nos abrirá los caminos para estudiar el anclaje territorial de la industria. Esto 
significa que sin perder de vista la referencia a la escala micro de la empresa distinguiremos los vínculos territoriales ya sean locales (regionales), nacionales o internacionales. En este punto, nos interesará reconstruir la trama de relaciones mercantiles y no mercantiles, en la que haremos siempre la diferenciación entre PyME y empresas grandes, y entre firmas locales y extranjeras. El punto central del capítulo resaltará qué segmento de producto obtiene la mayor eficiencia e indagaremos sobre sus causas, ya sea que estas estén vinculadas con la forma de organizar la producción "puertas adentro" o con la configuración en el territorio o con ambas. La configuración de la producción en el territorio nos plantea una doble tensión: la primera de ellas entre la aglomeración territorial de empresas y el cluster, en la que consideramos a esta última forma de organización territorial como una instancia superadora de la mera aglomeración; la segunda tensión, opera en la relación cadena de valor global en contraposición al cluster, en este caso, indagaremos los efectos en el territorio por parte de la cadena de valor global en oposición a la supuesta estructuración y homogeneización generada por las vinculaciones de tipo cluster. 
CAPÍTULO 1 


\section{Marco teórico-conceptual}

\subsection{Introducción}

Durante las últimas décadas la economía mundial ha experimentado cambios en la organización de la producción fruto del aumento en los flujos del comercio y de capitales, y de una mayor apertura comercial, con tendencia a la concentración y centralización de las empresas a nivel mundial. Esto ha generado un escenario mundial más interdependiente, con nuevos y cambiantes marcos regulatorios. Se ha desarrollado una nueva configuración en el que las empresas transnacionales han modificado su estrategia y organización espacial. Ello se ve reflejado, entre muchos otros aspectos, en nuevos modos de distribuir en el espacio las funciones productivas por parte de las empresas. Estudiar estas dinámicas exige diferenciar las estrategias de las compañías trasnacionales de las PyME dada sus fuertes asimetrías en la capacidad de despliegue territorial. El primer grupo de empresas ha consolidado nuevas formas de organización que han dado lugar al despliegue de cadenas globales de valor y el segundo grupo, ha tenido éxito variable en la conformación de aglomeraciones sectoriales y territoriales como forma de responder al nuevo escenario.

Dos ejes analíticos organizan este capítulo. El primero se centra en la revisión de autores y conceptos de la escuela de pensamiento estructuralista latinoamericano. Enfocado desde su pertinencia para el abordaje de la visión de desarrollo de las naciones latinoamericanas. El segundo se refiere a los desafíos metodológicos que presenta el análisis conjunto de las lógicas espaciales y sectoriales de la industria. Finalmente, en la recapitulación, se sintetiza lo expuesto y se plantea el grupo central de conceptos y teorías que se utilizan para desarrollar el argumento de la tesis.

Al inicio del capítulo, explicitamos como eje central para la comprensión de la dinámica de ciertos acontecimientos socio-económicos y espaciales globales la diferenciación entre centro y periferia, introducida en el año 1949 por Raúl Prebish en el debate latinoamericano sobre subdesarrollo. En el marco del modelo centro-periferia elaborado por este autor y adoptado por la CEPAL, el autor Aníbal Pinto, en la década de 1960, desarrolla el concepto de "heterogeneidad estructural", que hace hincapié en las diferencias internas del desarrollo, entre un sector moderno y uno denominado sector tradicional "atrasado".

La "heterogeneidad estructural" es expresión del subdesarrollo de América Latina. Encontramos que las causas de dicha heterogeneidad tienen relación directa 
con las asimetrías entre centros y periferias capitalistas, y consecuentemente son los factores externos poderosos determinantes del subdesarrollo.

En forma simultánea, otros autores avanzaron en el estudio del carácter dependiente de las economías latinoamericanas, que obstaculizaba el proceso de modernización de América Latina. A partir de la visión de Sunkel (1970) se advierte que la implantación de subsidiarias o filiales extranjeras no produce un sistema integrado con la economía local y, que por el contrario, tienden a desintegrar el entramado local existente, realimentando de manera dinámica la situación de centroperiferia. Este enfoque nos invita a pensar y estudiar la desestructuración espacial generada al interior de nuestros países a partir de la intervención de las empresas transnacionales, en el conjunto del sistema económico mundial y nacional.

El enfoque centro-periferia, el de heterogeneidad estructural y el de dependencia condensan parte del núcleo central del pensamiento estructuralista. Esta matriz de ideas elabora un conjunto homogéneo de conceptos (originales y originarias de países periféricos) que consideran y ponderan las causas externas como fundantes del subdesarrollo de los países de América Latina.

La superación de la "condición periférica" suponía, en opinión de los pioneros de la literatura de la CEPAL (Prebisch, Pinto y Sunkel, entre otros), una modalidad propia de introducir el progreso técnico, de distribuir el ingreso y de relacionarse con el resto del mundo. Con independencia y audacia, esa producción contribuyó al diseño de una identidad ideológica para la región en su conjunto. Este campo conceptual nos brinda un respaldo teórico sobre el funcionamiento de la dinámica global y sus efectos sociales, económicos y territoriales.

La visión estructuralista posterior a la década de 1980, emerge ligada a la transformación producida en el esquema de organización de la producción industrial a nivel mundial, en los problemas encontrados por la industrialización de América Latina, el débil perfil exportador y en el avance del endeudamiento. El interés por la temática del desarrollo económico, en sus esferas productivas y distributivas, tiene su expresión más clara en la búsqueda del progreso técnico endógeno y el cambio estructural.

Esta problemática se incorpora explícitamente en los escritos teóricos de Fajnzylber de la década de 1980 y 1990, con el concepto de núcleo endógeno ${ }^{13}$. El autor plantea en ese marco la centralidad de los sectores "engineering products" que

${ }^{13} \mathrm{El}$ concepto de "núcleo endógeno" se refiere a las capacidades internas para iniciar un nuevo proceso de industrialización en América Latina, basado en el desarrollo de ciertas ramas industriales específicas. Este concepto involucra crecimiento y creatividad propios del país, requisitos esenciales para lograr el empleo productivo y la equidad. 
corresponde a la metalmecánica ${ }^{14}$, en el proceso de cambio estructural (Fanjzylber, 1992, pp. 26). De esta manera se evidencia un "puente" entre la literatura de los sistemas nacionales de innovación (SNI) y los problemas del desarrollo. Considerado, en esta tesis, el concepto de núcleo endógeno de desarrollo, como parte de una segunda etapa del estructuralismo, que nos permite profundizar el estudio de las dinámicas sectoriales de las industrias de bienes de capital, en el presente caso con el análisis de la actividad productora de maquinaria agrícola en Argentina. Dinámica industrial de gran importancia en procesos de cambio estructural en países que parten de una especialización productiva asociada a la exportación de materias primas de origen agropecuario.

Cabe interrogarse en qué medida este marco conceptual desarrollado en el esquema del régimen de acumulación de la postguerra permite ser aplicado al estudio de las dinámicas sectoriales frente al agotamiento del esquema de producción "fordista", desde finales de la década de 1960. Teniendo en cuenta que éste constituye uno de los hechos históricos que modelan el pensamiento estructuralista a partir de los años 90, es necesario indagar como conciliar la diversidad de abordajes sobre las nuevas formas espaciales ${ }^{15}$ de organización de la actividad económica. Dando respuesta a los nuevos desafíos de productividad y competitividad, emergen nuevas formas de organizar la producción en el territorio. En este sentido, destacamos una tensión en la literatura entre los trabajos que hacen hincapié por un lado, en el estudio de las aglomeraciones productivas, denominadas clusters por cierta literatura que analizaremos en el presente capítulo y por el otro, aquellos autores que basándose en el estudio de la reestructuración a nivel global de las estructuras productivas han desarrollado el concepto de cadenas globales de valor. Como se discutirá en este capítulo, esta ambivalencia a nivel teórico no hace más que reflejar una tensión existente entre las lógicas de acumulación a nivel global y las dinámicas territoriales locales reproduciendo a nivel sectorial la polaridad centro-periferia. Si bien, estos abordajes presentan límites analíticos en relación a los enfoques más generales sobre la internacionalización del capital, permiten estudiar en forma concreta las estrategias empresariales en la industria de maquinaria y sus efectos sobre el territorio.

\footnotetext{
${ }^{14}$ Estos sectores agrupan a los bienes de capital y los equipos de transporte más los electrodomésticos.

15 Si bien en la tradición geográfica el "territorio" tiene una connotación vinculada al poder y el "espacio" está más relacionado a un sentido filosófico más amplio en tanto contiene objetos, sujetos, acciones y representaciones simbólicas. Nosotros tomaremos estas nociones de manera indistinta (Ver Haesbaert, 2009).
} 


\subsection{Los aportes del estructuralismo latinoamericano para el estudio de las dinámicas industriales en la periferia}

El estructuralismo latinoamericano tiene sus fundamentos en la producción de un cuerpo analítico orientado al examen del subdesarrollo en América Latina. Prebisch, considerado el "padre" de este cuerpo teórico, genera un diagnóstico de los inconvenientes estructurales de Latinoamérica, que restringen el desenvolvimiento productivo de nuestros países. Este marco teórico-conceptual propone los siguientes déficits estructurales a corregir:

Cuadro №1. Diagnóstico de los déficits estructurales de Latinoamérica

\begin{tabular}{|c|c|}
\hline $\begin{array}{c}\text { Características de la matriz productiva } \\
\text { de América Latina }\end{array}$ & $\begin{array}{l}\text { Incidencia en la industrialización y el } \\
\text { crecimiento }\end{array}$ \\
\hline Baja diversidad productiva & $\begin{array}{l}\text { Necesidad de inversiones simultáneas en } \\
\text { muchos sectores. Proceso muy exigente en } \\
\text { materia de ahorro, inversión y divisas } \\
\text { extranjeras }\end{array}$ \\
\hline Especialización en agricultura y minería & $\begin{array}{l}\text { Limitada capacidad para generar divisas } \\
\text { externas debido a la baja demanda mundial de } \\
\text { exportaciones y al deterioro de los términos de } \\
\text { intercambio, así como a la fuerte demanda de } \\
\text { divisas generada por la elevada elasticidad } \\
\text { ingreso de las importaciones }\end{array}$ \\
\hline $\begin{array}{l}\text { Marcada heterogeneidad tecnológica. } \\
\text { Coexistencia de sectores de alta } \\
\text { productividad y de sectores con } \\
\text { abundante ocupación de mano de obra a } \\
\text { niveles próximos a los de subsistencia }\end{array}$ & $\begin{array}{l}\text { Baja productividad promedio y reducido } \\
\text { excedente como proporción del ingreso }\end{array}$ \\
\hline $\begin{array}{l}\text { Institucionalidad inadecuada y falta de } \\
\text { capacidad empresarial }\end{array}$ & $\begin{array}{l}\text { Baja propensión a ahorrar e invertir, } \\
\text { insuficiente acumulación de capital y progreso } \\
\text { técnico (parte del excedente se desperdicia en } \\
\text { consumo superfluo e inversiones } \\
\text { improductivas) }\end{array}$ \\
\hline
\end{tabular}

Fuente: Bielchowsky (2006).

Prebisch (1949) se basaba en la identificación de este conjunto de problemas estructurales de la periferia (latinoamericana) para construir su análisis del crecimiento, el desarrollo periférico y las relaciones centro-periferia. Este enfoque le daba al desarrollo industrial una importancia superlativa, que fijaba las pautas de 
comprensión de cuáles eran los obstáculos que se necesitaban sortear para lograr superar la situación periférica.

Entonces, se dirigía la atención, por primera vez, hacia las relaciones asimétricas entre centros y periferias capitalistas, permitiendo poner en evidencia los factores externos del subdesarrollo, hasta entonces fuera del debate político del desarrollo.

Sobre estas bases se articuló una matriz de pensamiento nacida en los países latinoamericanos. Una de las tesis centrales del estructuralismo, del período de posguerra, es que se impedía que la periferia retuviera los frutos de su progreso técnico, como consecuencia del carácter altamente atomizado de los sectores primarios característicos de la periferia y la rigidez a la baja de los precios asociado al tipo monopolista de los sectores industriales ubicados en los países centrales. Como consecuencia de estas asimetrías se explicaba la tendencia al deterioro de los términos de intercambio en perjuicio de los países subdesarrollados.

Debemos destacar que la CEPAL (como representante principal de la teoría estructuralista) basa el sistema analítico de estudio de la problemática de los países subdesarrollados o periféricos en el método "histórico-estructural". Este método permite una fértil interacción de los enfoques deductivo e histórico-interpretativo, ocupándose de la trayectoria de los agentes e instituciones y de diálogo permanente entre las formulaciones teóricas y los cambios históricos (Bielchowsky ${ }^{16}, 2009$ ).

El estructuralismo de posguerra, se establece en un momento histórico con ciertas particularidades en el escenario latinoamericano y mundial. Latinoamérica comenzaba la búsqueda de una matriz de producción basada en una industria propia, proceso denominado ISI. ${ }^{17}$

El comercio internacional estaba dominado por el comercio intersectorial de manufactura-materia prima. El perfil de la inversión extranjera directa no favorecía una inserción a los flujos de comercio intraindustrial. A partir de fines de la década de 1940, el capital transnacional a través de la inversión extranjera directa se establecía en los países periféricos en la búsqueda de nuevos mercados, instalando "filiales réplica" ${ }^{18}$. Comportamiento que respondía, en parte, a la existencia de barreras que protegían la producción local y, en parte, a las estrategias de las casas matrices que

\footnotetext{
${ }^{16}$ Este autor realiza una pormenorizada revisión de las ideas de la CEPAL que se toman como base en este apartado.

17 Se podrá objetar que el proceso comienza en Argentina a en la tercera década del siglo XX en forma espontánea, pero las políticas decididamente activas para el desarrollo industrial comienzan en 1945.

18 Filial réplica: produce los mismos productos que en el país de origen, o una canasta de ellos, desaprovechando economías de escala.
} 
buscaban valorizar capital excedente. Por otro lado, como consecuencia de la caída de los términos del intercambio la base exportadora latinoamericana de productos primarios perdía capacidad de compra de productos industriales extranjeros, generando recurrentes crisis en los balances de pago. Esto conformaba en gran medida la relación "necesaria" entre países desarrollados y países subdesarrollados para reproducir el sistema económico mundial de centro-periferia.

\subsubsection{La importancia del concepto centro-periferia}

Las nociones de centro y periferia están referidas a las distintas características de estos dos tipos de formaciones capitalistas y a las relaciones asimétricas existentes entre ellas.

En la perspectiva aquí adoptada el carácter central de una formación depende de la constitución de un sistema industrial, que permita al capital orientar, conforme a sus necesidades, el desarrollo de las fuerzas productivas.

Existe una diferenciación conceptual entre ambos tipos de formaciones (centroperiferia) que la podemos encontrar en los trabajos seminales de Prebisch (1949) en "El desarrollo económico de América Latina y algunos de sus principales problemas" y en trabajos sucesivos de Celso Furtado (1964) en "Desarrollo y Subdesarrollo", en Fernando Fanjzylber (1987) en "La industrialización de América Latina: de la "caja negra" al "casillero vacío." y en Cimoli et al. (2005) "Heterogeneidad estructural, asimetrías tecnológicas y crecimiento en América Latina", con renovada vigencia. Estos términos conllevan implícita la idea de un sistema mundial jerarquizado, que debemos tener presente al momento de analizar las posibilidades y los caminos al desarrollo ${ }^{19}$ de los países latinoamericanos.

A partir de los cambios en las formaciones capitalistas centrales, luego de la década de 1970 y en el modo de acumulación dominante en escala mundial que estos países impulsaron, se determinaron transformaciones más o menos amplias en el conjunto de la periferia y en su articulación con las economías centrales. Esas transformaciones no son necesariamente similares en toda la periferia, ya que el alcance y la naturaleza de las mismas dependen de las condiciones económicas y sociales específicas de cada país y de las características de las clases dominantes (y de las alianzas de gobierno en cada país periférico). Estas relaciones resultan claves

${ }^{19}$ Contraponiéndose a la teoría ortodoxa de convergencia (Barro y Salas-i-Martin, 1995) que supone la nivelación de todos los países a partir del libre comercio. 
para comprender disparidades entre países, entre espacios sub-nacionales y entre regiones supranacionales.

Cardoso y Faletto (1969), definen los términos subdesarrollo y desarrollo, llegando con ello al entendimiento del sistema centro-periferia. El subdesarrollo existe en relación a los países desarrollados, sus sistemas productivos tienen diferencias y son distintas, también, las funciones que desempeñan en una misma estructura económica internacional, vinculados entre sí a través del mercado mundial.

Los países subdesarrollados se caracterizan, como vimos en el cuadro $\mathrm{N}^{0} 1$, por un sistema económico con predominio del sector primario ${ }^{20}$, fuerte concentración de la renta, poca diversidad del sistema productivo y preeminencia del mercado externo sobre el interno. Estas características suponen, además, un tipo de relación con el mercado mundial, configurado a partir de la articulación entre las clases dominantes internas y la estructura de poder internacional, que permite que esta situación se reproduzca.

Si bien existen muchas variables y determinantes en el análisis causal del subdesarrollo, desde este enfoque teórico (Estructuralismo Latinoamericano) hay un núcleo significativo de procesos que definen esta situación: i) imposibilidad de acceso a la tecnología, ii) dificultad de acceso al financiamiento, e iii) inestabilidad macroeconómica y falta de independencia para manejar la economía. Desde luego este diagnóstico tiene un nivel de generalización y abstracción que se debe ir reduciendo a medida que avanzamos sobre el cuerpo teórico.

Prosiguiendo con la idea de centro-periferia, supone ésta una constante divergencia entre los países centrales y los periféricos, en razón de estructuras productivas diferentes, los primeros ostentan, a grandes rasgos, entramados productivos relativamente homogéneos y diversificados, mientras que los segundos poseen un sistema de producción heterogéneo y especializado. Los países centrales elaboran una amplia gama de productos con las mejores prácticas, altos niveles de productividad e innovación permanente. Estos bienes poseen una alta elasticidad de

\footnotetext{
20 Los países centrales tienen rendimientos crecientes a escala, porque se intensifican en actividades donde el aumento de factores disminuye los costos medios por producto, en el caso de los países pobres especializados en la producción y exportación de recursos naturales, las actividades primarias no admiten mayor carga de factores tendiendo a rendimientos decrecientes (Reinert, 2007). Si bien esto es discutible, es esperable que a largo plazo sea cierto. La idea principal de Reinert es mostrar la importancia de cuáles son los grandes sectores en que se especializa cada país. En general se reconoce que la elasticidad ingreso de la demanda es menor para la mayoría de los productos primarios que para los productos manufacturados que son intensivos en conocimientos. Que la elasticidad de ingresos de la demanda de productos primarios, sea menor significa que, para un determinado incremento en el ingreso mundial, el balance de pagos del país en desarrollo automáticamente se deteriorará (Cimoli, 2009).
} 
ingresos de la demanda en contraposición a las características generales de los productos de los países periféricos, cuyos rasgos se definen por las características opuestas a los productos y procesos de los países centrales. Esto no implica que en los países periféricos no se adopten técnicas de muy alta productividad, pero ocurre sólo en ciertos sectores, de allí, en parte, la heterogeneidad del sistema.

Por otro lado el cambio tecnológico en los países periféricos, mayoritariamente se instrumenta a favor de una baja de precios y no en términos colusivos ${ }^{21}$, nos basamos aquí en la interpretación de Reinert (2007). La redistribución de los beneficios del cambio tecnológico y el aumento de productividad no se reflejan en aumentos nominales de salario. Los incrementos de productividad a través de mejoras tecnológicas, de los sectores primarios se manifiestan en la forma de precios más bajos, en el modo clásico, mientras que, por igual razón, los incrementos de productividad de los productores de bienes industriales se manifiestan de manera colusoria, en la forma de salarios más altos (Reinert, op cit.).

Prebisch no consideraba factible cambiar la estructura internacional del comercio, que determina la estructura productiva interna de los países periféricos, por lo tanto, el cambio estructural debía ser endógeno. Esta línea de pensamiento supone que una de las formas de acceder a la transformación de la estructura productiva, es industrializar la economía. Dejar de producir exclusivamente materias primas, de bajo valor agregado y comenzar un proceso de diversificación y producción de productos más complejos.

En este sentido, los estudios empíricos indican, en efecto, que la convergencia de los niveles de ingreso por habitante se ha dado en forma puntual y se ha limitado a los países del sudeste asiático (Cimoli y Porcile, 2009). Este conjunto limitado de países (Corea del Sur y Taiwan) ha logrado avanzar, bajo modalidades muy diferentes, en procesos de cambio estructural liderado por las exportaciones manufactureras. Proceso que ha sido posible en el marco de una sistemática y férrea política industrial y de un mercado internacional en el que predomina el comercio intrasectorial e intrafirma dominado por empresas transnacionales. ${ }^{22}$ Más allá de estos casos excepcionales, la expansión externa de los países centrales se basa en productos de alto contenido tecnológico y servicios internacionalmente transables,

\footnotetext{
${ }^{21}$ El modo colusorio de distribución de las ganancias derivadas del cambio tecnológico, debido a que las fuerzas del país productor (capital, mano de obra y gobierno) en la práctica 'coluden' -aunque no en el sentido de conspirar- para apropiarse de estas ganancias. Este mecanismo operará si el cambio técnico es acompañado por la creación de barreras de entrada, donde los rendimientos crecientes son el mecanismo clave.

22 Otros determinantes han intervenido en este proceso, de características políticas internas y externas, sociales y culturales.
} 
mientras que los países de América Latina siguen con un perfil, mayoritariamente, exportador de materias primas asociado a la primera división del trabajo, incursionando en el comercio de componentes manufactureros de menor intensidad tecnológica.

Entre los factores que explican esta nueva dinámica de comercio intrafirma de manufacturas ocupa un lugar central el rol jugado por la reconfiguración de las estrategias de las empresas trasnacionales, desde una forma de organización "second best" frente al comercio, hacia una nueva modalidad de internacionalización en el que las estrategias y las formas de organización son concebidas a escala global (Michalet, 1985; Lavarello, 2004). Esta nueva forma de organización, a diferencia de la transnacionalización de postguerra, explica que las productividades laborales en la periferia, converjan con los países centrales. Situación que al no ser acompañada por una convergencia en los salarios reales posibilita recomponer la rentabilidad de las empresas a nivel global.

Si bien, los países periféricos, actualmente, pueden exportar una mayor proporción de bienes industriales, el mercado internacional sigue siendo un espacio fuertemente asimétrico en el que los países centrales y sus capitales juegan un rol clave en su estructuración, creando formas de apropiación y normas de control sobre la denominada "globalización" productiva (propiedad intelectual, desregulación de los mercados financieros, restricción a la migración de personas).

En definitiva, si bien las formas de apropiación mercantiles pasan a ser reemplazadas por la extensión a nivel global de relaciones directas de acumulación, la noción centro-periferia mantiene vigencia, en la medida que incorpore el rol de las empresas transnacionales, lo que permite establecer bajo su estructura de conceptos un marco teórico coherente.

\subsubsection{Heterogeneidad estructural}

La literatura de la CEPAL de los años 1950 señaló a la heterogeneidad estructural como uno de los condicionantes internos a los procesos de desarrollo de los países de América Latina.

En este sentido, Prebisch (1949) mostró que uno de los aspectos que diferencia la estructura periférica de la de los países centrales es su mayor especialización y su mayor grado relativo de heterogeneidad.

No obstante, fue Aníbal Pinto (1976) quien profundizo la tesis de la heterogeneidad estructural. Este autor indagó el concepto en contraposición a la 
evolución más armónica que se produce en los países del centro. Allí el crecimiento de los distintos sectores tiende a la homogeneidad y existen sectores que impulsan al resto de la economía. La heterogeneidad estructural supone un rezago de productividad del trabajo entre actividades modernas y atrasadas, en los países de la periferia.

En América Latina existen distintas situaciones de heterogeneidad estructural. En forma esquemática los podemos dividir en dos segmentos: los países cuyo sector exportador está disociado totalmente del aparato productivo del país y actúa como enclave (países centroamericanos productores de bananas, café, cacao); y un segundo grupo de países, que exporta bienes que se vinculan en mayor medida con el resto del sistema productivo del país (países del cono sur productores de cereales y carne, exportados y consumidores internamente).

Se puede observar que Pinto (op cit.), elaboró su tesis en vistas de comprender las limitaciones de las políticas del período de ISI en América Latina. El desarrollo de la industrialización modificó sensiblemente el cuadro de heterogeneidad antes descripto. La llamada diversificación "hacia adentro", llevó a la aparición de un sector no exportador modernizado, con niveles de productividad iguales al del sistema o superiores. Este proceso se produjo en los países que lograron entrar en la segunda etapa de la industrialización, incursionando en la producción nacional de bienes de consumo duradero y bienes intermedios, basados en tecnologías modernas y de mayor densidad de capital.

En una primera instancia se supuso que como sucedió en el centro, donde sectores líderes "arrastraron" hacia un aumento de la productividad al resto, en niveles más o menos homogéneos, la industria homogeneizaría las economías periféricas. Se concebía que el polo generado, alrededor de la industria y proyectado hacia adentro, cumpliría una misión homogeneizadora similar a la registrada en el centro.

Como sostiene Pinto (1976 pp.109), tal afirmación se vio opacada por los resultados:

1.El nivel de desarrollo no se aceleró y no fue capaz de autosostenerse.

2. La dependencia del exterior había cambiado sus características, pero continuaba y en algunos puntos se había exacerbado (endeudamiento, enajenación de las decisiones de política económica, subordinación tecnológica, extranjerización de actividades básicas).

3. Gran parte de la población y de la estructura productiva habían quedado marginados del avance en el "polo moderno". Se había manifestado una triple 
concentración de los resultados del progreso técnico: en lo social, en los estratos económicos y en lo regional.

4. No existe una tendencia natural a rectificar el rumbo.

En resumen la capacidad de diseminar el progreso por parte del sector moderno hacia el resto de la economía había sido discreto. Según este autor, el pivote del crecimiento debía enfocarse en la profundización del progreso técnico, en la ampliación del mercado interno, en la homogeneización del sistema, en el desarrollo de un mayor grado de autonomía, para generar una capacidad de auto-sustentación respecto de factores externos.

Hacia fines de 1960 y principios de 1970, como consecuencia del creciente ingreso a la región de capitales extranjeros a través de empresas transnacionales y el progresivo proceso de sujeción a ellas, se planteó el abordaje de la heterogeneidad estructural y el debate sobre el carácter dependiente del proceso de modernización latinoamericano.

\subsubsection{Una perspectiva holista: la dependencia ${ }^{23}$}

El enfoque o la visión estructuralista de la dependencia se encuentra asociado, directamente, a una de las formas de articulación a nivel global contenido en el concepto de centro-periferia.

El sistema socio-económico de los países periféricos (también el de los países centrales) posee componentes estructurales internos y externos que los definen. Entre los primeros encontramos la dotación de recursos naturales y de población, las instituciones políticas, estratos socio-políticos, ideologías, como así también las políticas estatales. En cuanto a los elementos estructurales externos se consideran todas las instituciones que ofician en la vinculación política, económica, social y

${ }^{23}$ Compartimos la aclaración que menciona Bielschowsky (1998, p34), que la teoría de la dependencia y el concepto dependencia utilizado por el estructuralismo (este es explicado en el apartado 2.3 de este capítulo) son cosas distintas. Si bien la teoría de la dependencia es un emergente del estructuralismo latinoamericano, está se presenta de forma crítica al estructuralismo. Gunder Frank y Ruy Marini fueron algunos de sus expositores más destacados. Estos autores consideran la dependencia y el subdesarrollo como categorías estructurales que corresponden al modo de producción capitalista y sólo se superan con la abolición del sistema.

En términos generales el concepto dependencia como característica estructural de las economías latinoamericanas es utilizado tanto por dependentistas como por estructuralistas, con la diferencia que los primeros niegan explícitamente la posibilidad de desarrollo capitalista en los países de la periferia. Los estructuralistas reconocen las posibilidades de desarrollo capitalista periférico subrayando, sin embargo, la forma dependiente que adopta en relación con los países centrales. En este sentido se expresan los escritos de Cardoso y Faletto (1969). Por otro lado Pinto (1976) reconoce la dependencia tecnológica de los países latinoamericanos, la cual es factible superar con esfuerzos de inversión en los sectores correctos. 
cultural de los países de la periferia con los países del centro. La estructura interna de los países periféricos en relación con los países centrales definen la estructura global del sistema y en consecuencia constituyen el marco de referencia dentro del cual se produce el funcionamiento del sistema nacional y su proceso de transformación estructural (Sunkel, 1970).

El proceso de cambio estructural, explicará Sunkel (1970), se genera por dos vías, una como relación directa del funcionamiento y crecimiento interno del país y la otra asociada a cambios externos de la economía mundial. Es esta última la que prevalece en el desencadenamiento y aceleración de los procesos de transformación estructural.

De acuerdo con el enfoque estructuralista, el desarrollo y el subdesarrollo son caras de un mismo proceso, ambos son históricamente simultáneos y están vinculados funcionalmente. Uno de los resultados notorios de este proceso es la polarización, primero a nivel mundial entre países centrales (países industriales, avanzados) y países periféricos (países de base de producción primaria y atrasados); y en segundo lugar hacia el interior de los países periféricos se generan, paralelamente, estructuras disociadas y polarizadas. Sunkel (op cit.) destaca que los países desarrollados en virtud de su capacidad endógena de crecimiento dominan el escenario mundial y los países subdesarrollados son dependientes. Esto también aplica entre regiones al interior de un mismo país.

Los países latinoamericanos comienzan el que se suponía era el camino emancipador de la industrialización, posteriormente a la gran crisis y a la segunda guerra mundial (con diferentes características), pero no por ello logran una dinámica endógena de desarrollo. Al igual que el período previo, de crecimiento hacia afuera (primario exportador), el período ISI constituye un esquema, con diferencias importantes, de inserción de países subdesarrollados en el sistema mundial. La industrialización se realizó (en el período ISI) necesariamente con ayuda externa en muchos de sus pasos, tecnología, recursos humanos, insumos, etc.; ello supone diferentes costos y consecuencias ${ }^{24}$. Sunkel (op cit.), consideraba que nos

\footnotetext{
${ }^{24}$ Las consecuencias para Sunkel del modelo son ya conocidas: a) monoexportación expandiendo al sector tradicional; b) impulso dinámico de la economía proveniente del exterior; c) centros de decisión fundamentalmente externos en cuanto a financiamiento, políticas económicas, conocimiento científico y tecnológico, acceso a los mercados internacionales; d) tendencia persistente y cada vez más aguda al endeudamiento externo y a la desnacionalización de la industria nacional; e) amenaza de que el proceso de integración latinoamericana favorezca principalmente a la empresa multinacional extra-latinoamericana y liquide definitivamente la empresa privada nacional en Aca. Latina al crear mediante la integración de los mercados y de la liberación del comercio condiciones en que la empresa nacional no sólo queda desfavorecida sino incapacitada de obtener protección del Estado nacional; f) ampliación acumulativa de las brechas entre nuestros países y los desarrollados.
} 
encontrabamos en pleno proceso de incorporación a una nueva modalidad del modelo centro-periferia, del cual se creía que la industrialización por sustitución de importaciones nos estaba liberando.

Dentro de la preocupación por el desarrollo retomamos a Sunkel (1970) y en adelante exponemos algunas de sus tesis más relevantes. Este autor actualiza el concepto centro-periferia. Retoma las teorías de Myrdal, Singer, Prebisch entre otros para exponer lo que él denomina las teorías "retardatarias" en alusión a la traducción de backwash término empleado por Myrdal. El subdesarrollo está vinculado a la generación de una polarización mundial entre países centrales y periféricos. Esta se produce porque: a) los sectores de producción primaria para la exportación, generalmente bajo control o propiedad de subsidiarias extranjeras, tienden a convertirse en actividades de tipo enclave, con escasos encadenamientos en la economía local; b) el empeoramiento de los términos del intercambio; c) la naturaleza monopólica de la exportación de las materias primas, por parte de una subsidiaria extranjera, implica la salida de un exceso de utilidades.

El autor critica la excesiva preponderancia dada a la relación centro-periferia a partir del comercio de productos primarios, como si fuese esta la única forma de interrelación. Dejando fuera una serie de presiones y condicionantes que ejercen sobre los países de la periferia los países centrales. En relación a ello el autor advierte que la industrialización en los países de la periferia se dio necesariamente con provisión de ciertos componentes como: mano de obra especializada, maquinarias y equipos, y capacidad tecnológica proveniente de los países centrales. En la medida, que el proceso industrializador supera las primeras fases, la necesidad de los componentes antes mencionados y en consecuencia la dependencia se agudiza. El "ingrediente" tecnológico de mayor complejidad en la segunda etapa industrializadora, se incorpora en la matriz productiva a través de subsidiarias extranjeras, patentes, licencias y adaptaciones o desarrollos locales de tecnología. Luego del proceso de industrialización, la estructura sigue estando conformada por países dominantes y dependientes, con la incorporación de las corporaciones transnacionales como actor destacado.

En este punto nos interesa particularmente la advertencia de Sunkel, ya en la década de 1970, sobre la importancia de quienes estaban modelando la estructura 
internacional de relaciones. Las estrategias de las empresas transnacionales tienen implicancias en el comercio y en la evolución de los términos de intercambio. ${ }^{25}$

La tesis principal de Sunkel (1970) en el texto: Desarrollo, subdesarrollo, dependencia, marginación y desigualdades espaciales; hacia un enfoque totalizante, eje de este apartado del capítulo es que, el proceso de polarización internacional entre países "ricos" y "pobres" descripto hasta aquí; genera que la estructura interna de los países periféricos, también se polarice.

En el plano interno se tiende en un extremo, a una división en espacios físicos, grupos sociales, actividades económicas avanzadas y modernas; y en el otro espacios físicos, grupos sociales y actividades económicas atrasadas y dependientes. La decadencia o el auge de una región dentro de un país periférico se encuentre asociada, en mayor o menor medida, al grado de vinculación que tengan sus actividades económicas con los países centrales. El subdesarrollo y la dependencia son consecuencias manifiestas del proceso general de evolución del sistema capitalista internacional. Por lo tanto es necesario para comprender el proceso de formación y generación de subdesarrollo, tener una visión del funcionamiento y de las transformaciones estructurales del sistema a nivel global.

La relación entre países subdesarrollados y desarrollados no es únicamente productiva y de comercio, existen vínculos entre un sector minoritario de la población de los países subdesarrollados y una porción mayoritaria de los países desarrollados. Esta relación está dada por los niveles de ingreso y el tipo de consumo que esos ingresos permiten en unos y otros países. Existe un continuo homogéneo, de sectores sociales, que comparten niveles de ingresos, consumos culturales, niveles y tipo de consumo ${ }^{26}$, entre una minoría de la periferia y sectores mayoritarios de la población en los países centrales.

La capacidad de grupos o sectores sociales en los países periféricos de captar altos ingresos está relacionado a su vinculación directa con 1) actividades de alta productividad, generalmente asociada al complejo primario exportador; 2) transferencias de ingresos de las actividades de alta productividad; 3) explotación monopólica de mercados de factores o productos en sectores de baja productividad.

\footnotetext{
${ }^{25}$ Ciertos estudios sostienen que cerca de un tercio del comercio mundial corresponde a intercambios al interior de las empresas multinacionales tanto entre filiales como entre filiales y casas matrices (Diken, 2001). Este tipo de comercio ha ganado espacio en Latinoamérica a partir de una mayor apertura.

${ }^{26}$ Fajnzylber (1983) considera que este tipo de consumo "imitativo" ha sido una de las causas del pobre desempeño productivo de los países periféricos. Este fenómeno introduce serias distorsiones en la estructura de la demanda y en la asignación de recursos de inversión público y privado, transfiriendo recursos a las empresas transnacionales y estas a su vez al exterior.
} 
En ese sentido un grupo de la sociedad asociado a la matriz productiva internacional de altos niveles de productividad y otro grupo, que, a través, de transferencia política institucional o explotación monopólicas de mercado obtienen altos ingresos. Es el conjunto homogéneo de consumo imitativo de los países centrales del que habla Fajnzylber (1983) y que en parte frena el proceso industrializador.

Hasta aquí se intenta comprender de qué manera la modalidad de inserción internacional desestructura la organización económica nacional y regional de los países periféricos. Este proceso es llevado a cabo internacionalmente por corporaciones transnacionales con el aporte de los Estados de los países centrales donde esas empresas se asientan. La estrategia principal a largo plazo de estas empresas es la homogeneización del consumo a nivel internacional, implantando subsidiarias en los países periféricos que provean esa demanda maximizando ganancias. Si bien, esto supone aportes de capital y transferencia de tecnología, ambos procesos son relativos, el aporte de capital es revertido (remesas de utilidades, pago de regalías, asistencia técnica) o nunca efectuado a través de maniobras financieras (financiado con recursos locales) y las transferencias tecnológicas son escasas, generalmente se consumen nuevas técnicas pero no se adaptan, ni se producen localmente.

De este modo nos parece importante resaltar que en definitiva el sistema mundial ejerce sobre las naciones periféricas su influencia y son las empresas transnacionales los agentes, que al expandirse, desestructuran las economías nacionales de estos países. La implantación de subsidiarias o filiales extranjeras escasamente dan origen a un complejo industrial integrado con el resto de la economía local, por el contrario tienden a desintegrar el entramado local existente superando competitivamente a cualquier oponente a través de escala, tecnología y organización más eficiente, proveyéndose, además, desde el exterior.

Como párrafo final de esta sección, es importante remarcar que el papel central que juegan las vinculaciones externas de nuestros países, en la estructuración y transformación de las economías latinoamericanas, establece también una relación directa con las manifestaciones espaciales que se generan hacia el interior de nuestros países. En el siguiente apartado se da lugar a las elaboraciones conceptuales de CEPAL, posteriores a los cambios paradigmáticos de mediados de 1970, en el sistema capitalista a nivel mundial. 


\subsection{Los puentes entre el estructuralismo latinoamericano y la literatura de los sistemas nacionales de innovación}

A partir de los años '80, como consecuencia de los procesos de liberalización financiera y comercial entre los países de la región, los problemas de restricción externa se vieron agudizados. La excesiva deuda externa era una muestra ineludible de esta nueva etapa. Los problemas de escasez de divisas no sólo se explicaban por los problemas estructurales de una inserción internacional periférica sino, que también, por la creciente carga de la deuda externa. La década de 1980 se denominó "la década perdida", debido a la caída del ingreso per cápita regional originada, en parte, por estas nuevas restricciones al crecimiento. El trabajo de la CEPAL estuvo condicionado por el contexto de los ajustes recesivos practicados en gran parte de los países de la región.

Este período, promovió un nuevo escenario, para los desarrollos teóricos estructuralistas. Luego del estructuralismo de posguerra, la caída del modelo ISI y el aparente fracaso de la teoría, se reanudó el debate en los años '80 de los postulados estructuralistas, denominado "neoestructuralismo" según Stulwark (2005) y Bielchowsky (2009). Una de las ideas fundamentales de esta nueva etapa de la CEPAL, es el planteo de la necesidad de la incorporación deliberada y sistemática del progreso técnico al proceso productivo, que permita un aumento sostenido y generalizado de los salarios. Ahora, la importancia del perfil de las exportaciones pasa a estar en el centro de las discusiones, entonces, los países de Latinoamérica deben especializarse en bienes cuya producción necesite uso intensivo de conocimiento.

Como se discutirá en esta sección, el mayor énfasis en las cuestiones de cambio tecnológico va a nutrirse de la discusión que se estaba dando en forma paralela en Estados Unidos y Europa por la pérdida de competitividad de estas economías frente a Japón. En este marco surge el concepto de "competitividad estructural", que a diferencia de la competitividad que se focaliza en ajustar costos, se centra en la capacidad de los países de establecer un sistema nacional de innovación estructurado en fuertes articulaciones de las industrias usuarias con sus proveedores y con la infraestructura de ciencia y tecnología (Lundvall, 1992; Dalum, 1992).

Como particularidad para los países de la región, el énfasis en el progreso técnico basado en la acumulación de conocimientos tiene como objetivo la transformación estructural de los países latinoamericanos para quebrar la persistente heterogeneidad. 


\subsubsection{El Cambio estructural y las industrias difusoras del progreso técnico}

Afirma Fajnzylber (1983) que la expresión más clara de la precariedad industrial en América Latina es la presencia, indiscriminada, de empresas transnacionales definiendo el perfil industrial del continente. Existe en estos países una fragilidad industrial referida al contenido del "núcleo de desarrollo endógeno"27. La promoción industrial ${ }^{28}$ proviene de los años 30 y los magros resultados apuntan a una débil estructura industrial. Este diagnóstico es explicado por la inexistencia de un sector industrial que lidere la construcción de un "núcleo endógeno", capaz de adaptar, innovar y competir internacionalmente en una serie de sectores productivos.

Algunos autores (Fajnzylber 1983, Cardoso y Faletto, 1969) consideran que ciertos sectores industriales tienen la virtud de generar y difundir el conocimiento, que inducen hacia un cambio estructural sustentable en el tiempo, uno de estos sectores es el de bienes de capital. La confluencia de estas ideas con la literatura neoschumpeteriana dio lugar a un rico trabajo empírico que buscó identificar las fuentes y usos intersectoriales del progreso técnico. En este sentido Pavitt (1984) señaló en su clásico trabajo "Patrones sectoriales de cambio tecnológico: hacia una taxonomía y una teoría" que existen distintos patrones sectoriales de cambio tecnológico. Mientras ciertas actividades -como la agricultura- se caracterizan por la dependencia de fuentes externas de tecnología, otras juegan un rol clave en la generación y difusión del cambio tecnológico. Por un lado, industrias escala intensivas que realizan esfuerzos de ingeniería, y por el otro, industrias basadas en la ciencia y de proveedores especializados que juegan un rol clave en la difusión de progreso técnico. Entre los proveedores especializados, Lavarello y Goldstein (2011) en base a Pavitt señalan, a partir del estudio de caso de las maquinarias agrícolas en Argentina, que al interior de una misma industria de bienes de capital pueden existir ramas caracterizadas por su carácter escala intensivo con una baja propensión a realizar esfuerzos innovativos en los países de la región y otras ramas de proveedores especializados con el potencial de realizar innovaciones de producto a partir de la interacción con los usuarios en una extensa gama de aplicaciones. De allí, nuestro interés en la comprensión del sector productor de maquinaria agrícola como referente más acotado del sector de bienes de capital.

\footnotetext{
27 Uno de los objetivos principales de la aplicación del modelo de desarrollo endógeno es fomentar y establecer una sociedad capaz de contener en si misma los modos y medios de producción necesarios para cubrir la necesidades básicas y ampliadas de las personas que la integran, mediante la implementación de una serie de estrategias endogenizadoras que influyan lo cultural, lo económico, lo educacional y el uso e invención de tecnología.

${ }^{28}$ En este sentido Fajnzylber (1983) se expresa por la baja articulación entre componentes sectoriales y la alta extranjerización del sector.
} 
En la actualidad la industria de bienes de capital incorpora los adelantos de la microelectrónica, entre los cuales se destacan los mecanismos de control y precisión que otorgan flexibilidad y ahorro de tiempos muertos a la producción. Este es uno de los desafíos en la carrera tecnológica que la periferia deberá superar para disminuir la brecha que la separa del centro. ${ }^{29}$ No obstante, como sostienen Lavarello y Goldstein (2011), si bien las nuevas revoluciones tecnológicas de las TICs. plantean desafíos a las industrias de bienes de capital, las mismas no llegan a poner en cuestión el rol nodal de esta industria.

La importancia del desarrollo de una industria de bienes de capital está dada por dos características centrales: por un lado, la necesidad de superar los desequilibrios externos recurrentes y la dependencia tecnológica respecto de los países centrales; y por otro, los bienes de capital actúan como generadores y difusores del cambio tecnológico (Cimoli, et al. 2005). Según esta concepción, el cambio tecnológico, en ciertos sectores, es el impulsor del cambio estructural. Un país especializado en la producción y exportación de materias primas puede garantizar ingresos altos per cápita por un plazo no muy largo de tiempo, mientras que el crecimiento es perdurable si se generan los encadenamientos hacia adelante y hacia atrás, siempre teniendo en cuenta que ciertos sectores crean más encadenamientos que otros. Las exportaciones de materia prima pueden generar una alternativa hacia el desarrollo o al subdesarrollo según se la oriente.

Reforzando dicha argumentación, Mistral (1979) muestra la influencia del sector de bienes de capital en el desarrollo de los países, a partir de un análisis de las estructuras de comercio exterior y la composición de los esquemas productivos de seis naciones industrializadas. Estos países controlan el mercado interno de los bienes de producción, que utilizan como plataforma para impulsar el sector a nivel internacional. Esto les permite la formación de capital de forma autónoma y durante períodos prolongados.

En este mismo sentido Fagerberg (1992) analiza la importancia del control selectivo del mercado interno para el desarrollo de complementariedades entre empresas de diferentes sectores. El vínculo entre firmas "aguas arriba y abajo" determina en parte la competitividad/ventaja comparativa de las empresas en el mercado mundial. Desde esta visión se considera que si un país exporta exitosamente ciertos bienes (primarios) y quienes producen estos bienes compran tecnología a otros sectores de la economía del país, debería esperarse que este último sector también

${ }^{29}$ Esta idea remite a la concepción de Perez (2001) de la frontera tecnológica como un blanco móvil. 
fuera competitivo internacionalmente. Por lo tanto, se supone que el desarrollo de un producto que tiene éxito en el mercado interno probablemente lo tenga en el externo, para ello es condición necesaria que la demanda interna sea sofisticada y exigente.

Las tesis de estos dos autores (Mistral y Fagerberg) nos muestran la importancia de integrar nacionalmente la industria de bienes de capital. Este proceso será posible en la medida que un Estado Nación tenga la voluntad y la posibilidad de controlar y direccionar la matriz tecnológica dentro de los límites (protegidos) del mercado interno. Estos estudios señalaron una regularidad histórica de países que avanzaron en procesos de cambio estructural. La literatura estructuralista mostró que la debilidad de los encadenamientos internos constituye el principal limitante en la reproducción de una estructura económica diversificada y homogénea (Hirschman, 1958).

En definitiva, el neoestructuralismo continua expresando dos aspectos que creemos centrales, la situación de los países en el contexto internacional (comercio externo) y la estructura interna como elemento necesariamente funcional del entramado de relaciones centro-periferia. Romper la relación desventajosa y de supeditación con los países centrales implica realizar un cambio estructural. Por un lado, se deben sortear los determinantes externos y por otro lado, modificar internamente las relaciones de fuerza que operan en contrario a un cambio en los aspectos estructurales del aparato productivo (Cardoso y Faletto, 1969).

Al seguir con la línea argumental, es posible resaltar que según estos autores, la acumulación de capital debe tener un mayor componente de sectores que permitan controlar y desarrollar tecnología de los medios de producción propia. En este sentido encontramos dos vertientes, una más vinculada a la creación y generación de capacidades endógenas con un alto componente nacional y otra más cercana al desarrollo de tecnología a partir del vínculo con los grandes "jugadores" internacionales.

Por su parte, la generación de dichas capacidades resultaría de procesos de adopción y asimilación de tecnología extranjera acompañada de cambios en la estructura productiva. Según refiere Ocampo (2004), la dinámica estructural responde a dos fuerzas que interaccionan, la innovación y las complementariedades, pero en los países periféricos no se genera, o no es esperable que se generen nuevas tecnologías sino la adopción de las ya maduras de los países centrales. Por lo tanto, en los países en desarrollo las "innovaciones" dependen de las transferencias que se hagan desde los países industrializados. 
Desde el punto de vista de Cimoli y Porcile (2009), en el intento de revertir la heterogeneidad estructural y la dependencia tecnológica, la clave está en el desarrollo endógeno de sectores fundamentales en la difusión de conocimiento. Los autores basándose en los desarrollos de Kaldor, consideran que el sector manufacturero proporciona rendimientos crecientes y permite la generación de aprendizajes tecnológicos a partir de la expansión de la demanda. La creciente participación de la industria en valor añadido total generaría efectos secundarios, hacia atrás, hacia delante y externalidades tecnológicas, que a su vez acelerarían la acumulación de capital y el crecimiento. Este proceso se vería reforzado por el continuo desarrollo de nuevas industrias y nuevos conocimiento si la demanda y la inversión en nuevos productos se mantuvieran.

Ambas visiones (Ocampo op. cit. y Cimoli y Porcile op. cit.) proponen el cambio estructural y ambas se articulan con una concepción en la que se pone en juego la necesidad de superar la heterogeneidad interempresarial o industrial estructural.

El carácter estructural de la heterogeneidad está asociado no tanto a la existencia de diferencias entre productividades sino a su persistencia. En este sentido cabe interrogarse sobre cuáles son los motivos que explican esta persistencia ( $\mathrm{y} / \mathrm{o}$ profundización). Esta persistencia se debe a la lenta y desigual difusión del progreso técnico a escala nacional e internacional. Por un lado la I\&D de las grandes empresas se concentra en los países de la denominada "tríada" (Arocena y Sutz, 1999) y por otro lado, a nivel nacional los sectores exportadores de mayor productividad, cercanos a la frontera tecnológica internacional, no "irradian" hacia el resto de los sectores sus avances en materia innovativa (Abeles, Lavarello y Montagu, 2012). Acordamos con Lavarello (2004) que en países con una fuerte especialización en sectores intensivos en recursos naturales, como es el caso de Argentina, los sectores agrícologanadero y agrícolaindustrial han funcionado como receptores de innovación extranjera (en gran medida) y no han desarrollado en profundidad la cadena proveedora "hacia delante y hacia atrás".

El estudio del sector de la maquinaria agrícola nos permite avanzar en el conocimiento del grado de encadenamientos entre las actividades dinámicas insertas en sistemas globales con el entramado local. El enfoque teórico de los sistemas nacionales de innovación profundiza, muy asociados a la visión de desarrollo endógeno y cambio de la estructura productiva, el análisis de la centralidad del sector de bienes de capital. 


\subsubsection{Enfoque de los Sistemas Nacionales de Innovación (SNI)}

El concepto de SNI emerge a finales de la década de los '80 y rápidamente adquiere relevancia académica. Autores como Freeman (1982), Nelson (1993) y Lundvall (1992), son pioneros en desarrollar el enfoque de SNI, basados en los resultados de investigaciones empíricas llevadas a cabo en los países centrales.

Desde esta visión, el espacio en el que emerge la innovación es el Estado Nación. Desde la perspectiva de Lundvall (1992) la innovación sería el resultado de aprendizajes en el sistema entre proveedores y usuarios. La existencia de proveedores locales y usuarios sofisticados en los procesos de innovación es un determinante clave para la emergencia de un sistema nacional de innovación. Lundvall (1992) resalta las relaciones entre productores y usuarios, ya que estos generan códigos de comunicación y la fluidez de esa comunicación va a influir en el sistema de innovación. La durabilidad y la densidad en la comunicación son puntos claves en relaciones de aprendizaje interactivo. Estas interacciones pueden ser tanto formales como informales. La cultura, la distancia geográfica, los factores organizacionales y los espacios económicos pueden funcionar como barreras o coadyuvantes para la fluidez del mencionado aprendizaje interactivo. El autor destaca la centralidad de los espacios nacionales en los sistemas de innovación.

En este sentido, el SNI se apoya en dos pilares: en primer lugar, en las características del sistema educativo, de la infraestructura de ciencia tecnología y las instituciones de política tecnológica, que constituyen (bajo distintos grados de coherencia) las fuentes de externalidades sistémicas. En segundo lugar, las bases sobre las que descansa el SIN, comprende la forma en que las firmas y otras organizaciones capturan estas externalidades a partir de relaciones no mercantiles e interacciones sistémicas (Storper, 1997; Abeles, Lavarello y Montagu, 2012). Para comprender este segundo pilar se debe estudiar la calidad de la cooperación y los eslabonamientos entre las distintas firmas. Aún si una gran parte de las relaciones entre firmas son de mercado, existen subsistemas de relaciones relativamente estables que funcionan como canales de información conectando a los productores de tecnología y a sus usuarios. ${ }^{30}$ Digamos pues, que la idea fuerza de este enfoque es un concepto "relacional".

Los autores Arocena y Sutz (1999) leen el concepto desde la perspectiva de los países de América Latina. Desde este punto de vista, los SNI latinoamericanos están

\footnotetext{
${ }^{30}$ Esta noción se profundiza en apartados subsiguientes del presente capítulo.
} 
moldeados por una inserción en la economía internacional basada en recursos naturales. El componente tecnológico resulta relativamente escaso y es mayoritariamente importado. Ante el hecho de que menos del $1 \%{ }^{31}$ de las actividades innovativas realizadas en el extranjero por las empresas más grandes del mundo están localizadas fuera de la "tríada", los países periféricos deben construir un SNI sólido en el marco de una estrategia de desarrollo endógeno. La relevancia de la estructura del sistema de producción nacional radica en que las relaciones intranacionales son generalmente mejores que las internacionales, ya que están menos sujetas a filtros y distorsiones que en el caso (interfirma) de las relaciones internacionales.

La argumentación de este enfoque (SNI), en relación al desarrollo, hace fuerte hincapié en la tradición productiva vigente en cada país asociada al sistema nacional de innovación. Desde esta perspectiva se sostiene que los cambios de productos y de procesos (innovación) siguen trayectorias determinadas, en gran medida, por patrones de producción y de comercio heredados (Dalum, 1992). La estructura productiva de cada país es reflejo de su historia y esto tiene importancia.

Entorno a ello, autores como Arocena y Sutz (1999), Dalum (1992) y Andersen (1992) coinciden en la importancia del sector de bienes de capital en la estructura productiva de un país y en el desarrollo de los SNI. Es este sector y su interdependencia con la producción de bienes intermedios y bienes finales, el que logra introducir cambios de forma exitosa en la matriz productiva nacional.

En este mismo sentido, la explicación del atraso tecnológico en el aparato productivo en los países subdesarrollados, considera Rosenberg (2003), se debe a la falta de desarrollo de un sector de bienes de capital, estos países se abastecen de maquinaria y equipo en el mercado externo. Según este autor, esto implicó, para los países periféricos, la falta de desarrollo de las habilidades tecnológicas y de los conocimientos de los cuales depende el sistema técnico. Esto se refiere principalmente a las actividades de aprendizaje microeconómicos tales como el uso de los equipos, el desarrollo de habilidades de ingeniería en la transformación de la maquinaria y la adaptación de los productos finales a condiciones ambientales específicas. Los factores más significativos que favorecen este proceso incluyen el nivel de capacitación de la fuerza de trabajo, las habilidades y la competencia técnica de los ingenieros y los diseñadores en los artefactos mecánicos. No de una manera aislada sino de una forma sistémica.

31 Ver Chasnais (1992); y Patel y Pavitt (1991) 
Un enfoque sistémico, que más allá de la cibernética, se apoye en la estructura económica determinada históricamente requiere analizar el perfil de especialización sectorial de cada Estado Nación. Luego, es posible identificar la estructura económica analizando la composición sectorial a partir de la taxonomía de Pavitt (1984), ya mencionada en el anterior apartado, sobre cuatro grupos sectoriales industriales: (i) "los sectores dominados por proveedores", donde las innovaciones se generan en forma exógena, en bienes de capital y bienes intermedios, (ii) "los proveedores especializados", que ofrecen equipos e instrumentos y confían en sus estructuras de innovación formales (departamentos de ingeniería y laboratorios de $I+D$ ), más un aprendizaje basado en las relaciones entre usuarios y productores, (iii) "los sectores de escala intensivos", cuya capacidad innovadora se basa en la adopción de equipos innovadores, el diseño de productos complejos, la explotación de las economías de escala y la capacidad de dominar las organizaciones complejas y el último grupo, (iv) "basados en ciencia", cuyas oportunidades innovadoras están más directamente vinculadas con los avances en la investigación.

Consideramos de importancia esta taxonomía en el marco del desarrollo de un segundo trabajo de Pavitt junto a Pattel (1991), donde revitalizan el rol que juega aún en la actualidad la innovación en bienes de capital del sector metalmecánico, el cual atraviesa y sirve de soporte al resto de los sectores, a muchos de los cuales se los conceptualiza como la vanguardia de la innovación. Como ilustra Dalum (1992) en su trabajo sobre los cambios en el perfil sectorial de especialización de los países de la OCDE, todo proceso de desarrollo parte de sectores tradicionales y va avanzando hacia una especialización en sectores de ingeniería intensivos asimilables a los proveedores especializados de la taxonomía de Pavitt.

Al inicio de todo proceso de cambio estructural, predominará el sector i), de la taxonomía de Pavitt (1984), en la estructura productiva. En países especializados en la exportación de recursos naturales, el sector primario representa a este tipo de actividades que estarán influidas por las innovaciones de los otros tres sectores, los cuales generan la mayor parte del cambio tecnológico. Esto no supone que en países especializados en sectores primarios la productividad de ese sector no sea alta, pero da por cierto que el dominio de la tecnología es externo, teniendo consecuencias a largo plazo para el crecimiento, ya que se asocia con una elasticidad de bajos ingresos de la demanda de las mercancías que el país puede producir competitivamente (Abeles, Lavarello, Montagu, 2013).

En este sentido Andersen (1992) reafirma la centralidad en el proceso de innovación de las relaciones de aprendizaje productor de bienes de capital - usuario a 
escala nacional. Es aquí donde la estructura productiva debe producir el quiebre en su heterogeneidad interna, generando el cambio tecnológico cualitativo en su sistema productivo.

En el siguiente apartado avanzamos sobre los cambios en la producción industrial acaecidos en la década de 1970, ellos nos dan cuenta de las transformaciones producidas al interior de las fábricas, y en las relaciones interempresarias. Estos cambios sucedidos en los países del centro están vinculados a la caída del régimen de acumulación fordista. Si bien no han tenido repercusión sobre el campo conceptual estructuralista de manera directa, el estructuralismo da cuenta de la modificación de ciertas configuraciones de producción que son de nuestro interés.

\subsection{Crisis del régimen de acumulación de postguerra y nuevas formas de organización de la producción a nivel internacional}

El período en el cual se desarrollan los enfoques estructuralistas, estaban asociados a un tipo especial de producción industrial, estilo fordista - taylorista32 y a una forma particular de regulación, el keynesianismo. Con fuertes disparidades en la implementación organizacional entre el centro y la periferia, en el primero se desarrolló plenamente y en el segundo se hizo en forma dependiente y subdesarrollada. En los países periféricos, el desarrollo del capitalismo industrial tuvo serios limitantes, entre los que se cuenta la dificultad de avanzar en un proceso endógeno de diversificación manufacturera, al mismo tiempo, que se consolidaron patrones de consumo similares a lo de los países centrales en los sectores modernos de la población, como consecuencia de la alta concentración del ingreso.

A principios y mediados de la década de 1970, el modelo de crecimiento económico vigente a nivel internacional se cedió progresivamente. Se produjo a nivel mundial una crisis en el modelo de crecimiento y una de las manifestaciones evidentes de lo que estaba ocurriendo (crisis capitalista de los '70), fue la disminución de la tasa de ganancia de las empresas de los países desarrollados, particularmente en los Estados Unidos. El fenómeno más influyente en este proceso lo constituyó, sin duda,

32 De manera resumida podemos decir que el fordismo es una forma de organizar la producción. Con aumento de la división del trabajo. Producción en masa. Profundización del control de los tiempos productivos del obrero. Reducción de costos. Necesariamente el modelo fordista de producción comprendía además para su realización de dos instituciones: la negociación colectiva de contratos laborales y salarios, y del Estado benefactor (quien redistribuye rentas) (Lipietz, 1994). 
el agotamiento de los rendimientos crecientes del sistema productivo imperante, esto produjo una desaceleración de la productividad, al mismo, tiempo que se generalizaban y profundizaban las instituciones centradas en el reparto de las ganancias de productividad (Boyer 2007, Setterfield, 2005). El menor crecimiento interrumpió, lo que varios autores han llamado, el círculo virtuoso de la estabilidad de las décadas previas, expresado, este proceso, en la retroalimentación entre el aumento de la producción y la capacidad de los consumidores para absorberlo, basado en políticas keynesianas (Boyer, 2007).

En este contexto la acumulación flexible aparece como una forma de organización del trabajo para regenerar mecanismos, que permitan recomponer los rendimientos crecientes y los márgenes de ganancias, en el marco de normas de consumo más estratificadas y segmentadas. Al mismo tiempo las grandes empresas transnacionales buscaban recomponer sus ganancias a partir de la fragmentación internacional de aquellas fases más maduras del proceso productivo. En este sentido Harvey (2008) y Dicken (2001) señalan que en parte esta mutación se traduce en la mudanza de los sitios de producción tradicionales del mundo desarrollado a sitios con menos tradición de lucha obrera y menos derechos laborales, recreando así ganancias y acumulación de capital.

La organización del capitalismo varía y se ajusta a través de la diversificación, la movilidad geográfica, la flexibilidad de los mercados de trabajo, de los procesos laborales y de los mercados de consumo, todo esto acompañado por fuertes dosis de innovación institucional, productiva y tecnológica. Lejos de emerger un nuevo modelo productivo, se asiste a la coexistencia de procesos flexibles con procesos escala intensivos.

Tal coexistencia plantea una fuerte tensión entre los análisis que hacen hincapié en la ruptura del modelo productivo previo y uno nuevo, con estudios que admiten un nuevo modelo, pero que señalan que existen elementos de continuidad. Distintos trabajos señalan un proceso (aún hoy inconcluso) de transición entre el fordismo y una nueva configuración tecno-productiva. En este sentido Perez y Freeman (2003), de tradición neoschumpeteriana, dan cuenta de los ciclos económicos poniendo especial énfasis en la inversión y sus fluctuaciones como causas preponderantes de las crisis y los auges económicos. La dinámica de la acumulación de capital se explica por factores asociados directamente a la caída de un viejo paradigma tecnológico ${ }^{33}$ y el

${ }^{33}$ Cambios en los paradigmas tecno-económicos: Son cambios tecnológicos tan drásticos que afectan al conjunto de la economía. Afectan los costos de producción, insumos, las condiciones, y distribución. Son vendavales de destrucción creación. Son paradigmas tecnoproductivos asociados a un marco normativo institucional, que surge después de los cambios estructurales. 
ascenso de uno nuevo que permite recrear las condiciones para la acumulación ampliada del capital. En cada nuevo paradigma existe un factor clave ${ }^{34}$, que le es vital en su desarrollo. Cuando la productividad del viejo paradigma no da respuesta a las necesidades del capital, es cuando los altos riesgos se toman y son justificados, es entonces, que operan las transformaciones. En este sentido es que se explican los cambios en la década de 1970 con la emergencia de nuevas formas de organizar la producción que reemplazan la especialización en la línea de montaje. Según los autores Piore y Sabel (1984) se generaron dos posibilidades de superar la crisis (desde mediados de los 70 quiebre en los modelos de producción) una era la profundización de la producción en serie y otra era avanzar sobre la especialización flexible, con cambios complementarios en la tecnología y las instituciones que la regulan.

Como sostiene Coriat (1990), hacia el interior de la fábrica, es necesario distinguir entre las innovaciones tecnológicas de las innovaciones organizacionales. Refiere este autor que las innovaciones organizacionales preceden a las innovaciones tecnológicas, que a partir de los años '70 involucran el desarrollo de medios de trabajo que incorporan la electrónica. Los cambios organizacionales, ocurridos en el mencionado contexto se sustentan sobre tres principios interdependientes:

1. Establecimiento de grupos de trabajo, "islotes", que administran un conjunto homogéneo de tareas.

2. Transformación de una sóla línea de montaje unidireccional, a una red de minilíneas.

3. Reemplazo de la cinta transportadora con tiempos fijos, por carretillas que se desplazan por la red con ritmos flexibles.

Si bien estas medidas no involucran necesariamente cambio tecnológico, liberan un enorme potencial de productividad y de flexibilidad en las organizaciones productivas. Se trata de innovaciones organizacionales mayores que generarán las bases organizacionales donde la electrónica tendrá gran impacto.

Estas nuevas formas de organización posibilitan responder a una demanda menos estable y más segmentada. A diferencia de la fabricación de productos elaborados en serie, aquí predomina la producción en lotes chicos con calidad y

\footnotetext{
${ }^{34}$ Es un insumo que presenta las siguientes características: bajo costo relativo y decreciente, oferta ilimitada del mismo, y potencial claro de incorporación en todos o varios sectores de la economía directa o indirectamente.
} 
diferenciación. Este nuevo desafío concierne tanto a las empresas de los sectores tradicionales de demanda estancada o decreciente como a las dedicadas a productos nuevos de demanda creciente y donde la innovación de proceso o producto es constante. Si bien la producción en serie a bajo costo continúa prevaleciendo, en adelante la oferta deberá hacer frente al cambio y a la diferenciación de la demanda. De ello resulta la necesidad de líneas flexibles, es decir capaces de fabricar productos diferentes sin una mayor reorganización.

La tesis que propone Coriat (1990), es que en este contexto de importantes innovaciones organizacionales las tecnologías de la información (informática, electrónica, telecomunicaciones y robótica) constituyen las tecnologías claves del nuevo sistema. Sistema que se hará transversal a todo el aparato productivo, incorporándose a todos los procesos de trabajo mediados por bienes de capital. De esta forma se constituye una nueva trayectoria tecnológica ${ }^{35}$ basada en la automatización programable.

Estas situaciones han suscitado dos respuestas la integración y la búsqueda de flexibilidad de las líneas productivas. La integración se refiere a eliminar los tiempos muertos y las nuevas tecnologías tienen un doble efecto sobre este proceso, en primer lugar la disminución de costos de producción, al intensificar la productividad de las máquinas al sincronizar sus trabajos y elimina así los tiempos muertos. En segundo término se pueden optimizar la circulación de insumos, generando ahorros en capital circulante. En cuanto a la flexibilidad de las líneas productivas, Coriat (op cit.) destaca que la flexibilidad técnica no involucra la eliminación de la escala sino la generación de nuevas escalas mínimas. Una empresa necesita una escala mínima para incorporar equipamiento flexible y por otro lado, para que este sea rentable debe existir un mercado que capte esa escala mínima. Para invertir en nuevo equipamiento la empresa debe conquistar nuevos mercados y los conquistará bajando precios, lo que se logrará con la nueva inversión.

Otra forma de alcanzar escalas mínimas de producción rentables, es generar la capacidad de producir un surtido de multiproductos, escalas de variedad. De esta manera la flexibilidad aparece como un instrumento capaz de disminuir los costos

\footnotetext{
35 Una trayectoria tecnológica está constituida por una serie orientada y acumulativa de innovaciones sucesivas. Las condiciones socioeconómicas en las cuales se forman esas trayectorias, favorecen de hecho un proceso de selección de innovaciones, que hace que entre varias líneas de desarrollo se seleccionen sólo algunas de ellas. La nueva trayectoria tecnológica (automatización) prevé la eliminación de tiempos muertos en relación a la máquina y no en el trabajo vivo, estandarte del taylorismo.
} 
unitarios medios y de reducir riesgos al distribuirlos en una canasta de productos ${ }^{36}$. Estas son ciertas ventajas que decididamente aportó la producción flexible.

En este sentido, Coriat (op. cit.) supone que en la especialización flexible, las ganancias de productividad descansan sobre la explotación de las economías de escalas estáticas, pero por encima de todo de las economías de variedad. La capacidad de fabricar de manera diferenciada una variedad de productos favorece ajustes instantáneos a las fluctuaciones de la composición de la demanda y puede así permitir a una empresa, incluso de tamaño limitado, competir con la gran empresa fordista dedicada a un único producto indiferenciado.

La especialización flexible sólo es posible si el ciclo del producto es corto, impidiendo que puedan ponerse en práctica estrategias de economías de escala. Únicamente requerimientos de series cortas, sobre productos de demanda ${ }^{37}$ inestable o de renovación rápida pueden comprometer la búsqueda de economías de escala de las grandes empresas.

Desde una perspectiva diferente, Piore y Sabel (1984), sostienen que la especialización flexible involucra la búsqueda de calidad y variedad (diferenciación) y triunfa sobre el efecto cantidad (escala). Para estos autores, a diferencia de Coriat (op cit) es posible alcanzar la especialización flexible sin un requisito de tamaño. Son las tecnologías de la información (principalmente microelectrónica) las que favorecen la mayor flexibilidad, el hardware se adapta mediante un software a una variedad de situaciones que facilitan la producción de pequeñas cantidades, hay una tendencia a crear líneas de series cortas.

La producción se resuelve con nuevas tecnologías y nuevas prácticas, la coordinación y gobierno de los mercados se efectúa de manera familiar o comunal, se crean lazos de responsabilidad. Se presenta un nuevo esquema de producción que si bien está asociado al nuevo esquema dentro de la fábrica, tiene un componente de relación interempresaria y comunal muy fuerte.

La competencia es entre distintas comunidades, la confección de Milán, París y Nueva York compiten entre sí, el resultado es la innovación. Se limita la competencia por salario y condiciones de trabajo, volcándola únicamente hacia la innovación. El

\footnotetext{
${ }^{36}$ Con respecto a la producción de multiproductos, existe economía de variedad si una misma empresa que produce dos bienes de manera conjunta, es capaz de fabricarlos a menor costo, que dos empresas que los producen por separado.

${ }^{37}$ Hay dos estrategias la pasiva, esperar que la demanda transmita sus gustos o requerimientos y, la activa ir reemplazando el producto antes de que termine su ciclo.
} 
sistema de especialización flexible está pensado, por los autores (Piore y Sabel, op cit.) a escala nacional con estructuras comunitarias de regulación y con provisión de los soportes de investigación y desarrollo, al igual que la formación de los trabajadores, sólo por parte del Estado.

Ahora bien, uno de los puntos importantes que nos interesa rescatar del desarrollo teórico de Piore y Sabel es la centralidad de la PyME en la organización industrial de un sistema flexible de producción.

Según la literatura italiana ${ }^{38}$ sobre las aglomeraciones productivas de PyME se establecen dos tesis desde el plano teórico:

La primera consiste en que bajo condiciones precisas y bien determinadas, las nuevas normas de competencia (de bienes diferenciados e inestabilidad de la demanda) pueden favorecer el surgimiento relativamente durable de nuevas formas productivas que asocien, en el caso de la producción de bienes especificados, empresas de dimensiones pequeñas y medianas, capaces de competir eficazmente con las grandes empresas, aún a escala internacional.

De acuerdo a la segunda tesis, las prácticas industriales nuevas, y a los análisis a los que han dado lugar, confirman que a las concatenaciones clásicas del fordismo: gran empresa - integración vertical - economías de escala - constitución de barreras oligopolísticas a la entrada; se mezclan y añaden concatenaciones nuevas: pequeñas y medianas empresas contratistas - cooperación horizontal - economías de variedad - constitución de nichos monopolísticos por rápida capacidad de ajuste a las variaciones de la demanda.

En numerosos casos al combinar los beneficios de las economías de escala con efectos de variedad o economías de organización renovada y el empleo de tecnologías flexibles contribuyen a una consolidación de las barreras de entrada. Esta nueva configuración industrial ha permitido generar nuevas estructuras emergentes de localización de las plantas industriales y nuevas posibilidades de competencia no oligopólicas.

Hay que tener en cuenta que Piore y Sabel, hacen su estudio y generan sus conclusiones a partir de lo que sucedía en el norte exitoso, rico e industrial de Italia a finales de los '70 y principios de los '80. Sin embargo, los autores aventuran que en una economía internacional unificada (globalización) la nueva división del trabajo se podría basar en deslocalizar la producción en serie hacia el "tercer mundo" y localizar

38 Pietrobelli y Rabelloti (2005), Becatini (1994, 2004), Garofoli (2002), entre otros. 
los sistemas artesanales con mejoras tecnológicas en el primero, desarrollando la oportunidad de frenar el declive de la producción en serie. La variación producida en las configuraciones espaciales de producción entre el período fordista y el posfordista modifican las lógicas espaciales y dan cuenta de ciertas especificidades locales.

En forma similar, Lipietz (1994) sostiene desde una perspectiva diferente ${ }^{39}$ que luego de la crisis fordista se produce en términos espaciales un proceso de reaglomeración de las firmas industriales y esas aglomeraciones pueden dividirse en dos: por un lado se ubica el trabajo intelectual de las empresas (administrativas, marketing, investigación, diseño, y desarrollo) y por otro lado, el trabajo manual. La primer forma se concentra en los países centrales y la segunda en los periféricos. Una característica importante es que en la forma de trabajo de los países centrales los obreros tienen una relación de mayor libertad en su lugar de trabajo que permite que el operario se sienta comprometido con los objetivos de la firma generando aumentos de productividad e innovación, mientras que la de los países periféricos sólo se buscan aumentos de productividad a través de un mayor control (taylorista). Esta tipología está asociada también a diferentes ramas de la industria. En los países del centro se concentran las ramas de mayor complejidad tecnológica y en contraposición las ramas de producción más simple (ensamble) se ubican en la periferia. El autor considera que esto contribuye a reproducir las relaciones asimétricas entre el centro y la periferia.

En definitiva el nuevo esquema productivo se articula como veremos a continuación con distintas lógicas espaciales de producción, de las que recuperamos dos de ellas, las que nos son más relevantes en nuestro análisis. Por un lado, una lógica global que traslada del centro a la periferia aquellas etapas de las cadenas globales de valor de los procesos productivos regidas por las formas fordistastayloristas de producción y, por el otro, una lógica territorial que organiza la producción en forma flexible aprovechando las ventajas de aglomeración.

\footnotetext{
39 Cabe destacar que Lipietz hace hincapié en otra dimensión de la flexibilidad, hace foco sobre las relaciones laborales. Luego distingue entre flexibilidad interna asociada al proceso de trabajo y flexibilidad externa asociada a la posibilidad de despedir trabajadores con bajos costos. Considera que la flexibilidad externa es menor en los lugares donde el trabajador tiene una alta calificación, salarios elevados, e importantes derechos laborales y es posible que en estos países la flexibilidad interna sea mayor dada la posibilidad de difundir las nuevas normas de producción flexible. En el otro extremo la situación de mayor flexibilidad externa se produce donde los obreros de baja calificación, cobran reducidos salarios y tienen muy pocos derechos laborales, pero en donde la posibilidades de introducir polivalencia o trabajos en células es mucho menor. El autor considera que se genera un trade - off entre la flexibilidad interna y externa a escala nacional y por rama de actividad.
} 


\subsection{Las nuevas lógicas espaciales de la producción industrial}

En la siguiente sección indagamos los enfoques teóricos que profundizan el estudio de la organización territorial de la producción industrial. Específicamente se hace énfasis en los análisis al respecto, posteriores a los cambios producidos en los modos de producción entre 1970 y 1980. En este sentido, se realizará en principio una revisión de ciertos conceptos provenientes de la geografía, recorriendo un camino que va desde un mayor nivel de abstracción teórico hacia la operacionalización de ciertos conceptos.

El recorrido propuesto toma como eje el concepto de organización territorial40 de manera articulada con los enfoques teóricos de cadenas de valor global, cluster y aglomeración territorial de industrias.

Durante las últimas décadas, la organización espacial de la producción industrial se ha modificado como resultado de un conjunto de transformaciones profundas en las condiciones de acumulación y de circulación del capital. Entre estas transformaciones se destacan la emergencia de nuevos paradigmas tecnológicos y organizativos (analizados en la sección previa); los cambios en los flujos comerciales y de capitales a nivel internacional, resultantes de la profundización de los procesos de globalización y del recrudecimiento de la competencia en los mercados mundiales. Inciden, también, el "acortamiento" de las distancias y las nuevas formas de coordinación y governance de la producción. Si se habla de transformaciones profundas se deben mencionar, además, los nuevos contextos regulatorios a nivel local, regional e internacional ${ }^{41}$. El resultante de estas transformaciones se ha traducido, entre otros aspectos, en dinámicas de incorporación-desplazamiento de espacios industriales; nuevos patrones de localización industrial; desarticulación - articulación de cluster locales y consolidación de cadenas globales de valor ${ }^{42}$.

A partir de de Coraggio (1987), introducimos el tema y ciertos conceptos a utilizar. En términos de este autor, existe una distinción esencial entre el concepto de configuración territorial y organización territorial. La primera de las nociones alude exclusivamente a la proyección de los objetos sobre la superficie terrestre haciendo abstracción de las relaciones y mediaciones sociales que intervienen entre estos.

\footnotetext{
40 Para ver en detalle una revisión sobre estos conceptos se puede ver Arturi (2007) y Fernandez et al. (2008).

${ }^{41}$ Mayor apertura a partir de los acuerdos en el GATT y OMC.

42 El concepto de cadena de valor se refiere, a las articulaciones que se establecen, a partir de las relaciones del tipo cliente/proveedor o insumo/producto, a lo largo de etapas estrechamente asociadas entre sí para la elaboración de un determinado bien.
} 
Ahora bien, si la configuración territorial está generada, mediada y sostenida por procesos sociales ${ }^{43}$, se puede decir, entonces, que es una organización territorial o espacial. ${ }^{44}$ En este sentido se establecen relaciones donde los procesos sociales y las configuraciones territoriales se determinan mutuamente y de forma dialéctica.

Diversos autores (Massey, 1984; Santos y Silveira, 2001; Coraggio, 1987), consideran que la organización espacial es el resultado de los procesos sociales, pero la organización espacial y la configuración espacial a su vez afectan al desenvolvimiento de estos procesos. Es decir, lo espacial no es sólo un resultado sino también parte de la explicación. Cuando la configuración territorial está generada, mediada y sostenida por procesos sociales como lo son la producción y la innovación existe una organización espacial determinada. En este sentido es parte del interés de esta tesis, analizar cómo se manifiesta la tensión entre la lógica estructurante del territorio asociadas a la aglomeración productiva y el cluster; y por otro lado, las lógicas desestructurantes de la cadena global de valor.

La reorganización de los espacios industriales ha generado la necesidad y el desafío de producir nuevos instrumentos teóricos, que den cuenta de una visión dinámica y compleja de las relaciones industria-territorio. Acorde a ello se profundiza en las próximas secciones, por su importancia en nuestro objeto de estudio, ciertos enfoques del campo conceptual que se ocupan de la articulación espacial de la actividad económica: el enfoque de cadenas global de valor y el de cluster.

\subsubsection{Cadenas de valor global}

Siguiendo el abordaje histórico-estructural del estructuralismo es importante destacar que en el momento en que Prebisch y los otros pioneros de este enfoque hacen sus estudios seminales, la internacionalización del capital se encontraba aún subordinada a la lógica de los intercambios internacionales de bienes y servicios. Desde los años '70, el comercio pasaría a estar subordinado a la lógica de la internacionalización productiva expresada en las estrategias globales de las grandes transnacionales (Michalet, 1985). A partir de los años '80, con la desrelgulación financiera, las grandes empresas transnacionales replantearían su estrategia de producción (Chesnais, 1994; Lavarello, 2004; Abeles, Lavarello y Montagu, 2011). En el marco de los mencionados procesos se experimenta una fuerte reestructuración

\footnotetext{
${ }^{43}$ Se entiende aquí por proceso social una secuencia de eventos recurrentes, que implican permanencia de condiciones y por lo tanto estructura y posibilidad de reproducción.

44 En esta tesis se utiliza el concepto de espacio geográfico desarrollado por Santos (2000, 1990). Es importante destacar que se maneja aquí como sinónimo de territorio.
} 
espacial de la producción industrial, que se explica por la relevancia que ha asumido durante las últimas décadas el concepto de cadena global de valor, resultante de la creciente desintegración internacional de ciertos procesos productivos por parte de grandes corporaciones.

Este concepto, ampliamente adoptado por una prolífica bibliografía, permite analizar en forma concreta las formas de coordinación o de gobernanza que pueden asumir las relaciones directas entre agentes de las cadenas productivas en un proceso de división vertical del trabajo. En este marco, el mercado es sólo una de las formas de coordinación posible en la que los intercambios entre proveedores y clientes independientes no van más allá de las transacciones mercantiles. En el otro extremo, las relaciones jerárquicas implican vinculaciones explícitas de coordinación sobre el proceso productivo, basadas en la propiedad de las empresas proveedoras por parte de la líder. Entre medio de estos dos extremos existe un continuo de formas de coordinación en el que las redes (networks) son la forma más desarrollada, donde tienen lugar las complementariedades entre proveedores y compradores que operan con niveles tecnológicos similares. No obstante, existen una variedad de formas cuasi-jerárquicas en las que existen fuertes asimetrías de poder en la cadena, ya que las empresas líderes son las encargadas de diseñar el producto y transmitir las especificaciones correspondientes a su núcleo de proveedores, las compañías líderes controlan también los mercados de venta (Humphrey y Schmitz, 2002).

En sus orígenes, el concepto de cadena global de valor se fundó en una visión dinámica en la que era posible sostener que las formas de coordinación predominantes variaban en relación a la etapa de los ciclos tecnológicos y económicos que atraviesa cada tecnología (Hopkins y Wallerstein, 1986). Cuando el ciclo económico está en su fase expansiva se incrementa la integración vertical y declina en las fases recesivas reduciendo el número de filiales externas. En el caso del ciclo tecnológico, cuando una innovación acaba de ocurrir tiende a concentrarse la producción (donde se producen los adelantos tecnológicos), debido a la imposibilidad de poder replicar el proceso. Cuando el adelanto o innovación tecnológica está difundida es factible desintegrar los procesos productivos.

En sus versiones más recientes, este enfoque busca fundamentar, desde un abordaje individualista metodológico, inspirado en el concepto de "costos de transacción" 45 , las opciones a partir de agentes con racionalidad limitada entre una extensa gama de formas de coordinación intermedias entre el mercado y la jerarquía.

${ }^{45}$ Este concepto se puede profundizar en Williamson (1989). 
Las mismas resultan de la elección racional bajo condiciones de incertidumbre, lo que permite a los autores de este enfoque (CGV), encontrar un micro-fundamento a las hipótesis de la inserción subordinada de la periferia al núcleo transnacionalizado (expuesta en el apartado 2.3 de este capítulo) desarrollada, ésta, en forma previa a los cambios de la década de 1970.

Desde una perspectiva estática, se parte de una situación inicial en la que las corporaciones concentran en sus casas matrices las actividades principales: innovación, estrategias de marketing y segmentos de mayor valor agregado, mientras que reubican en países periféricos otras funciones como servicios genéricos y la producción a gran escala. Al respecto de la globalización y las cadenas de valor de los países centrales, ciertos autores consideran que los segmentos de producción de dichas cadenas de valor que se relocalizan en países periféricos, llevan a especializar a los países pobres en eslabones de producción de baja complejidad, que pueden ser deslocalizados desde los países centrales porque ya no hay campo para la innovación en dichos segmentos.

La bibliografía que estudia las cadenas de valor global, considera a estas como una oportunidad de ingreso a los mercados de los países centrales por parte de los países periféricos. Las empresas de estos últimos países tienen la posibilidad, al ser parte de uno de los eslabones de la cadena, de obtener aprendizajes tecnológicos (catching up) transferidos por las grandes corporaciones, cerrando, de esta manera la brecha tecnológica existente entre empresas de países centrales y periféricos.

Desde el punto de vista del análisis empírico de las formas de coordinación, los parámetros críticos para la gobernanza de la cadena de valor son fundamentalmente la definición del producto -qué se va a producir- y la definición de los procesos de producción -cómo se va a producir- aunque existen otros dos parámetros (tiempo y cantidad) que también definen el proceso de producción (Humprey y Schmitz, 2002). Podríamos adicionar ciertas preguntas que se nos plantea como relevantes, en dónde se va a producir y cuál va a ser la vinculación con el territorio local.

A pesar del excesivo interés en las explicaciones estáticas de las configuraciones territoriales, estas aproximaciones teóricas logran poner el énfasis en las formas de coordinación concretas en que se sustentan las dinámicas generales de acumulación. De esta manera permiten explicar las diferencias entre distintas formas de cadenas globales y de redes globales de producción y comercialización, señalando, en línea con la literatura de desarrollo regional, que los centros de comando se encuentran en empresas transnacionales crecientemente "desterritorializadas" (De Mattos, 1989). 
Esto significa que la lógica de las estrategias del capital transnacional no tiene ningún tipo de compromiso territorial más allá de los costos hundidos en el proceso de inversión que las casas matrices buscan delegar a los proveedores. De este modo, en la medida que logran reducir su grado de inmovilización del capital se asegura el predominio de la lógica del capital en su forma más reducida (Dinero-Dinero') (Lavarello, 2004). De esta manera limitan las potencialidades de los desarrollos endógenos locales o regionales, cuando éstos quedan sujetos al accionar de la empresa matriz (Gutman y Gorestein, 2003).

Aunque se busque dar un fundamento microeconómico a las formas de coordinar las relaciones de producción, el objeto del análisis sigue siendo las relaciones directas de acumulación y la comprensión del sistema jerárquico de capitales, donde el mayor poder económico y las capacidades competitivas de un número reducido de empresas que operan a escala internacional imponen el ritmo de acumulación al conjunto del subsistema (Gutman y Gorestein, 2003), más allá de las restricciones impuestas por el espacio geográfico. En este contexto, las lógicas espaciales quedan subordinadas a las estrategias sectoriales-globales, de las firmas líderes transnacionales (Humphrey y Schmitz, 2001; Gereffi et.al, 2005).

En resumen, este enfoque teórico nos permite explicar a partir de las estrategias de los agentes individuales - en este caso empresas transnacionales y proveedoresla reproducción del esquema de centro-periferia. Existe, claro, una polarización a nivel internacional, pero también a nivel interno que será ilustrada empíricamente en el capítulo 4 de la tesis, donde se estudiará el comportamiento de dos de las principales empresas transnacionales de tractores que cuentan con filiales en Argentina.

Una cadena de valor global tiende, como atributo general, a la polarización internacional, donde las capacidades (o los eslabones) que generan más valor se mantienen en los países centrales y se traslada hacia los países de la periferia los procesos de producción de ensamble con métodos fordistas. A su vez es dable pensar que este proceso genera polarización interna en el país huésped. Se establece un vínculo acotado al "hinterland" de la empresa, desestructurando el entramado productivo local (Gutman y Gorestein, 2003).

Se puede establecer cierta tensión entre este tipo de configuración espacial de producción, con actores preponderantemente transnacionales y esquemas de producción más horizontales, donde todo el proceso productivo o gran parte se encadena en el territorio nacional. Estos últimos son conocidos como clusters, nos detendremos en la próxima sección del capítulo para una revisión de dicho concepto. 


\subsubsection{Las dinámicas locales: Aglomeraciones productivas, clusters y distritos industriales}

Distintos autores, desde perspectivas teóricas diferentes han señalado que no existe un único tipo de respuesta de las industrias en términos de su configuración espacial (Pietrobelli y Rabelotti, 2005; Porter, 1999; Ramos, 1999). Desde una perspectiva de la economía de la innovación, que difiere del abordaje estático de la cadena de valor global, ciertos autores han sostenido que existen distintos tipos de organizaciones territoriales dependiendo de las capacidades internas acumuladas y de su grado de articulación intersectorial sobre una base territorial (Yoguel, Borello y Erbes, 2006). En los casos en los que las empresas cuentan con inversiones y esfuerzos tecnológicos, incluyendo el desarrollo de articulaciones intersectoriales en el espacio territorial, es muy factible que su ámbito de desarrollo sea en su territorio inmediato. En él las firmas crearán una estructura de confianza, mercantil y no mercantil, para producir a partir de encadenamientos locales (territorialmente cercanos).

Independientemente de la magnitud de información y conocimiento codificado disponible en una economía, si este no se relaciona a través de la estructura de vinculaciones no mercantiles estables con los conocimientos tácitos incorporados en las capacidades de los ingenieros y trabajadores de las firmas, los países quedan entrampados en un sendero de bajo crecimiento (Lundvall, 1992). La cercanía territorial y la trayectoria de trabajo conjunto generan un tráfico informal de información y conocimiento. El territorio no se configura como resultado de decisiones deliberadas de los agentes sino que emerge de las interacciones en los sistemas.

Desde una perspectiva empírica, y apoyándose en estudios de caso, Porter (1999) es quien primero introduce el concepto de cluster definiéndolo como concentraciones geográficas de empresas e instituciones interconectadas, que actúan en determinado campo. Partiendo de una visión centrada en los procesos competitivos, define al cluster como una fuente de ventajas competitivas que incluye una amplia gama de industrias y otras entidades relacionadas que son importantes para competir internacionalmente. En su conocido diamante de las "ventajas competitivas" incorpora entre uno de los principales determinantes de la competitividad a los proveedores de insumos críticos como: componentes, equipos, servicios y proveedores de infraestructura especializada. También, resalta la existencia de clientes sofisticados, canales de comercialización, fabricantes de productos complementarios y empresas que operan en industrias relacionadas. Muchos clusters incluyen organismos gubernamentales y otras instituciones, tales como universidades 
y agencias encargadas de fijar normas. Por otra parte los límites de un cluster están definidos por los enlaces y complementariedades de las industrias e instituciones que resultan críticas para competir.

Básicamente estaríamos hablando de una forma particular de aglomeración territorial de firmas sectorialmente especializada en la que podríamos identificar una región autosuficiente. Las empresas compiten y cooperan entre sí logrando una eficiencia colectiva en el territorio que los agentes de forma individual no podrían obtener. Este es un esquema ideal en el estudio de aglomeraciones territoriales de industrias, en el que debemos hacer para cada caso una lectura particular acerca de las características técnicas según el momento histórico y el lugar (Fernandez et al. 2008).

Uno de los aspectos esenciales a resaltar es que los clusters no están formados solamente por flujos mercantiles de bienes y servicios sino también por un intenso intercambio de información, conocimientos y expertise tecnológico (Gomez Minujín, 2005; Humprhey y Schmitz, 1995). Este es un aspecto fundante en las corrientes de pensamiento evolucionista y de sistemas locales de innovación (Lundvall, 1992; Naclerio et al. 2010).

De igual manera, Storper (2003) sostiene que la innovación por proximidad es un elemento central para explicar las dinámicas microeconómicas y territoriales. Destaca que, frecuentemente, la innovación es el resultado complejo de interacciones entre escala, especialización y flexibilidad en el contexto de la proximidad. Las aglomeraciones industriales facilitan procesos dinámicos, como los cambios tecnológicos localizados. Esto nos recuerda, una vez más, la capacidad de innovación en circuitos locales (y sectoriales) de producción.

En forma simultánea al concepto de clusters surge la noción de distrito industrial, basado en algunas localidades industriales de Italia (Becattinti, 1990). Este concepto parte de los primeros escritos de Marshall, quien sostiene que para que una aglomeración de empresas conforme un distrito industrial es necesario que la población de firmas se integre con la comunidad local de personas, reserva de cultura, valores y normas sociales adaptadas por un proceso de industrialización desde abajo (bottom-up). El componente social, siguiendo esta línea, es central para el modelo italiano de distritos industriales.

Según Becattini (1990), el origen y el desarrollo de un distrito industrial, no es simplemente el resultado "local" del encuentro entre algunos extractos socio-culturales de una comunidad, elementos históricos y naturales de un área geográfica y 
características técnicas de un proceso de producción, si no es, por sobre todas las cosas, el resultado de un proceso dinámico de interacción entre división e integración del trabajo, de aumento de la demanda y de formación de una red permanente de relaciones entre el distrito y el mercado externo.

Todas las características descriptas por Marshall en el modelo de distrito industrial son resumibles en el concepto de aglomeración, que no se limita a la localización estratégica de las empresas individuales, sino de la externalidad positiva derivada de la presencia conjunta de empresas especializadas y servicios dedicados a ellas (Becattini, 1987).

Luego, ambas concepciones (cluster y distrito industrial), muy cercanas entre sí, consideran fundamental la forma particular de organizar la producción y conseguir a partir de los vínculos e integración en un mismo territorio, economías externas y creación de conocimiento para la innovación, bases fundamentales de la competitividad. Esta competitividad ${ }^{46}$ está conferida entonces no por el costo más bajo de la mano de obra ${ }^{47}$, ni por la integración vertical, sino por la integración en un mismo territorio.

No obstante, un aspecto que debemos destacar, a partir de la literatura, es que los distritos industriales están conformados por PyME únicamente y los clusters, son aglomerados productivos más heterogéneos y existen distintos tipos, ya sea, que estén formados sólo PyME o PyME articuladas con empresas grandes (Pietrobelli y Rabelloti, 2005). Las dinámicas territoriales de los clusters resultan de las relaciones de conflicto y cooperación entre empresas de distinto origen de capital, tamaño y capacidades tecnológicas. Este aspecto es muy importante al momento de destacar el tipo de desarrollo territorial del conglomerado de firmas, ya que generalmente las grandes empresas transnacionales (o grupos extra-territoriales) pueden desarrollar redes internas o coordinar redes externas de conocimiento que trascienden el espacio territorial mientras que las PyME deben apelar a la proximidad para el desarrollo de conocimiento interactivo (Yoguel y Borello, 2001).

La idea central como denominador común de estos enfoques es la del territorio como "un conjunto que interactúa". Las firmas dejan de ser objeto de estudio individual en el marco de "la nueva competencia territorial". Los agentes, las instituciones, las

46 La concentración geográfica permite o coadyuva a la existencia de recursos humanos calificados, relaciones entre proveedores y clientes con una fuerte circulación de información, la existencia de una fuerte identidad sociocultural que facilita la confianza mutua entre agentes. Estas cualidades permite bajos costos de transacción y genera economías externas.

47 Storper y Walker (1982) consideran que el factor más relevante en la elección de la localización de las industrias por parte de los capitalistas es el costo de la mano de obra. 
normas, la comunidad social donde se desenvuelven junto con el espacio natural, ya no constituyen externalidades sino elementos directos del proceso competitivo. Podría sostenerse que el concepto de cluster incluye al de distrito industrial entendiendo a éste último como un caso particular que emerge a partir de procesos de abajo hacia arriba endógenos al territorio.

Es importante destacar que tanto el enfoque de cluster como el de distrito industrial hacen abstracción de los cambios previamente señalados en la organización de la producción. En este sentido, Amin y Robins (1994) advierten que durante la transición del fordismo al posfordismo se ha producido una profunda reestructuración de los territorios, y las aglomeraciones industriales (clusters, distritos industriales) se han convertido en símbolos de ello. Para estos autores las fases sucesivas de acumulación dan origen a una superposición de distintos tipos de organización y estructuras industriales.

Estos enfoques de aglomeraciones productivas se apoyan, dirán estos autores, esencialmente sobre las nociones de confianza, cooperación y fidelidad entre actores locales dando por supuesta la fuerza de la región para competir internacionalmente en forma aislada de las dinámicas globales de acumulación. Esto conduce a aislar la región en relación al marco internacional en el que se desarrolla no sólo la competencia sino también la expansión de los espacios transnacionales. La economía local no puede ser vista más que como un nodo de una red económica mundial, la pérdida de autonomía está en relación directa con la capacidad que posean las empresas transnacionales para integrar a las regiones en sus estrategias y formas de organización concebidas a escala global.

En este sentido Fernandez et al. (2008) identifican cuatro límites ${ }^{48}$ o inconsistencias en el entramado conceptual de los distritos industriales o clusters provenientes de los países centrales. El primero de los límites está asociado a la ambigüedad con la que se definen los términos de este campo conceptual, tornando impreciso dos aspectos en el momento del abordaje empírico a) las delimitaciones espaciales y b) los aspectos constitutivos funcionales que en este marco se toman como referencia. En segundo término los autores consideran que la literatura subestima la vinculación externa de las aglomeraciones industriales, sobrestimando las capacidades locales. No se somete a las aglomeraciones a situaciones reales de contacto directo con competencia, proveeduría, clientes, política, componentes sociales externos, ya sean nacionales o extranjeras. El tercer límite, de la mayor parte

${ }^{48}$ Fernandez et al. (2008) hablan de "fallas". 
de la literatura especializada, lo encuentran en la exposición idealizada de las aglomeraciones donde no existen ni heterogeneidades ni conflictos hacia el interior de las mismas. El cuarto y último "límite" encontrado en el andamiaje teórico de las aglomeraciones productivas, es no tener en debida cuenta la relación entre clusters competitivos económicamente y la mejora en la calidad de vida intra-territorial. ${ }^{49} \mathrm{O}$ sea, no sólo encontrar en las aglomeraciones productivas un medio de aumento de competitividad sino también un mejoramiento de las condiciones de vida de la población en su conjunto.

Debemos destacar y remarcar, además, ya para finalizar, que una aglomeración territorial productiva puede ser o no un tipo de organización espacial de tipo cluster. En este sentido hacemos hincapié en que una aglomeración territorial productiva posee una configuración espacial como la definida para el cluster por la literatura, empresas e industrias colocalizadas. No obstante, esto no implica necesariamente, que cualquier aglomeración territorial productiva sea un cluster. Es decir que a partir de la literatura citada, se puede establecer que una aglomeración territorial productiva puede ser un cluster, según sea el tipo y calidad de la organización espacial que posea.

En este sentido, Storper y Harrison definen aglomeración territorial de industrias como:

“...un conjunto de unidades de producción reunidas en un territorio bien delimitado, como la ciudad o la región. Estos aglomerados territoriales están muy frecuentemente, pero no necesariamente, orientados hacia un mismo sector de actividades. A su vez, pueden estar constituidos ya sea por unidades que pertenecen a un sólo $y$ determinado sistema input-output, y por lo tanto estrechamente interdependientes. En este último caso la división social del trabajo (...) se produce en forma localizada. Allí donde las relaciones entre unidades son estrechas y localizadas, es posible que aparezca un cluster" (1994:258).

Teniendo en cuenta estos elementos y a fin de analizar la organización del espacio productivo para el caso de la maquinaría agrícola, es necesario interrogarse si estamos en presencia en la región de estudio de un cluster o si se trata sólo una aglomeración territorial de industrias. De esta manera será posible realizar un contraste entre el concepto de cluster como situación "ideal" y un simple conjunto de

${ }^{49}$ Aspecto, este último, que excede los alcances de esta tesis 
empresas co-localizadas, cuyo ejemplo más extremo es el parque industrial donde no existe ni especialización ni nexos fluidos entre firmas.

\subsection{Recapitulación. Los aportes de la teoría del desarrollo y la geografía económica al estudio de la maquinaria agrícola en Argentina}

Desde el abordaje estructuralista adoptado en esta tesis, el carácter periférico de la economía argentina, al igual que la mayor parte de los países de América Latina, ha sido resultado de un largo proceso histórico, en el cual se han alternado diferentes modelos de acumulación con sus respectivas formas de regulación; se define de esta manera una particular división espacial del trabajo y perfil productivo.

Este proceso se ha expresado, en diferentes formas: a través de la estructura sectorial de la producción, tipo y composición del comercio exterior, los grados de productividad, capacitación de la mano de obra, y el nivel tecnológico.

Como se discutió en este capítulo, la teoría estructuralista pone énfasis en las restricciones propias y externas para la acumulación local de capital en ciertos sectores específicos, que son claves. De esta forma, se abre el debate sobre las posibilidades que posee un país periférico de cambiar su especialización productiva, la cual, desde esta teoría, es considerada una traba en las posibilidades de desarrollo de los países latinoamericanos.

Destacamos o diferenciamos dos momentos del enfoque teórico estructuralista. El primero de ellos aborda los temas centrales del desarrollo de manera de abarcar el sistema como un todo y el segundo, se centra sobre el concepto de núcleo endógeno.

Del primer "momento" del estructuralismo destacamos los conceptos centroperiferia, heterogeneidad estructural y el enfoque de la dependencia. Estas ideas nos ayudan a elaborar un marco referencial holista sobre cuestiones vinculadas al desarrollo.

El primero de estos conceptos da cuenta de un sistema jerárquico de naciones a nivel mundial, vinculado a la matriz productiva de cada país. Esta idea contempla el concepto de heterogeneidad estructural que nos revela diferencias de productividad entre sectores dentro de cada país de la periferia. Si bien, el desarrollo de la industrialización, con la llamada diversificación "hacia adentro" (lleva a la aparición de un sector no exportador modernizado, con niveles de productividad iguales al del sistema o superiores), modifica sensiblemente el cuadro de heterogeneidad estructural, genera, también un nuevo escenario de centro-periferia. No son ya sólo los 
términos de intercambio los principales causantes de una estructura jerárquica de naciones, sino, además, se adiciona la necesidad de la provisión de ciertos componentes como: mano de obra especializada, maquinarias, equipos y capacidad tecnológica, todo proveniente de los países centrales.

Es aquí donde el concepto de dependencia nos muestra que luego del período de industrialización latinoamericano persiste una estructura económica mundial con países dominantes y países dominados, en la cual, las corporaciones transnacionales son vectores de dominación que manejan el componente tecnológico. A nivel social, económico y territorial se produce una polarización estructural. Dicha perspectiva contiene y engloba los conceptos de centro-periferia y de heterogeneidad. Este es el eje del cuerpo teórico estructuralista, y nos permite acceder a un entramado conceptual que visibiliza procesos que existen, determinan y operan en un país de capitalismo periférico.

El segundo "momento" del estructuralismo (o neoestructuralismo), a partir de una lectura crítica del proceso industrializador del período ISI en Latinoamérica y cambios contextuales mediante ${ }^{50}$, avanza sobre un nuevo enfoque. Este nuevo enfoque, se encuentra orientado a desarrollar el estudio de ciertos sectores con complejidad (tecnológica) creciente y con un fuerte componente de innovación local, que intenta reducir la brecha tecnológica, que separa el centro de la periferia. El redireccionamiento del enfoque estructuralista reduce la escala de la perspectiva y de la problematización y hace hincapié sobre el concepto de núcleo endógeno. Podemos decir que, a grandes rasgos, la teoría "resigna" en este último período gran parte de su matriz analítica totalizante $u$ holista, soslayando ciertos temas que le pertenecían en la agenda de discusión del desarrollo. Más allá de esto, el enfoque del desarrollo endógeno nos permite aprehender, desde un concepto intermedio asociado a los sistemas nacionales de innovación la importancia de la creación ${ }^{51}$ tecnológica y de la innovación como factor de competitividad vis a vis los costos laborales.

La falta de desarrollo de ciertos sectores en los procesos de industrialización de América Latina frenaron los eslabonamientos hacia atrás en la cadena de producción, que cerraron la posibilidad, en muchos casos, de dominar el proceso productivo completo. Aspecto que reproduce el carácter especializado y heterogéneo de las estructuras de los países periféricos, aún de los que alcanzaron un grado de desarrollo intermedio hasta mediados de los años '70.

\footnotetext{
50 Preeminencia del capital financiero sobre el industrial, el peso de la deuda sobre las naciones latinoamericanas, las políticas de ajuste, la modificación de los modelos de producción.

51 Creación expresada aquí como sinónimo de innovación
} 
El concepto de desarrollo endógeno y el de los sistemas nacionales de innovación consideran a los sectores de bienes de capital centrales en el desarrollo del aparato productivo. Dichos enfoques hacen hincapié en la centralidad de estos sectores dada la importancia de los aprendizajes proveedor-usuario como estrategia innovadora.

Son estos aportes que nos permiten poner en primer plano y analizar las condiciones de competitividad asociadas a la innovación, en un sector de bienes de capital vinculado a la producción de materias primas. Estos enfoques son reforzados por autores que analizaron las diferencias entre patrones sectoriales de innovación, mostrando que los sectores proveedores especializados (maquinaria y equipo) juegan un rol crucial en la difusión intersectorial del progreso técnico.

A partir de mediados de la década de 1970, la idea de integración nacional de los procesos productivos va a ser puesta en tensión frente a los cambios ocurridos en las formas de producción industrial. Al interior de la fábrica, se flexibilizan los "tiempos muertos" y las relaciones interindustriales se modifican. Esto produce un nuevo escenario mundial y una nueva configuración espacial de la producción. Desde la perspectiva de los autores que analizaron los procesos de cambio en los sistemas productivos, es posible comprender la nueva dinámica de centro-periferia. Los países del centro reestructuran su industria hacia la producción automatizada y "artesanal" acompañada de innovación, diseño y desarrollo; la periferia recibe la industria de ensamble en masa bajo nuevas formas de coordinación en las cadenas de valor globales. Sólo en aquellos casos en los que las dinámicas territoriales logran articular procesos innovativos vinculadas a usuarios locales es posible apreciar procesos de desarrollo endógeno.

Esta modalidad productiva que el centro "exporta", genera dos tendencias territoriales, por un lado la cadena de valor global, y por otro clusters. La primera de estas tendencias nos permite preguntarnos, sí a partir de una cadena de valor global específica (tractores) la reproducción de la situación de dependencia internacional, permite cierto grado de up-graiding; y generar posibilidades de reducción de la polarización y heterogeneidad interna. La segunda tendencia asocia la cadena de valor de la maquinaria agrícola a un territorio, que le imprime características locales. Dentro de ese marco, es esperable que la producción local de maquinaria agrícola se vincule con el sistema nacional de innovación. Esto nos habilita a observar las estrategias PyME nacionales vis a vis las estrategias territoriales de las compañías transnacionales. 
Al respecto, se hará hincapié en la heterogeneidad y desestructuración generada en el entramado productivo sectorial y del aglomerado productivo de maquinaria agrícola por parte de las empresas transnacionales. A partir de la falta del desarrollo local de ciertos procesos y eslabones de la cadena de valor (I+D como ejemplo). La no integración local de ciertos eslabonamientos hacia atrás en la cadena de producción cierra la posibilidad en muchos casos de dominar el proceso productivo completo. Aunado a ello, existe la posibilidad de que a partir de la potencia productiva y económica, las empresas transnacionales capturen también en el mediano plazo la cadena de valor y el mercado de productos que, por su especificidad local, se mantiene abastecido por PyME de capital nacional, muy integradas en el territorio.

En función de todo esto, retomamos el interrogante de nuestra tesis, que es si en la industria de maquinaria agrícola se reproducen (o amplifican) las tendencias centroperiferia en ciertos sectores fordistas con plantas de ensamble de tractores y al mismo tiempo se evidencia un proceso de aglomeración productiva de estilo cluster, con PyME especializadas, con fuertes heterogeneidades e idiosincrasias locales, que compensan (o tienen el potencial de compensar al menos localizadamente) esta tendencia. 
CAPÍTULO 2 


\section{Desarrollo histórico del sector argentino de maquinaria agrícola}

\subsection{Introducción}

En el presente capítulo se hace un análisis del desenvolvimiento del sector productor de maquinaria agrícola en la República Argentina, durante el siglo pasado (s.XX) y el comienzo del actual. Para ello se hizo una exhaustiva revisión de la bibliografía existente y se tomaron, además, fuentes estadísticas de divulgación.

Al hacer un análisis histórico, que nos permitirá identificar las condiciones que intervienen en el desarrollo del sector productor de maquinaria agrícola, encontramos que existen variables de importancia para explicar el desempeño del mismo. A este respecto, observamos como la política económica y el ciclo macroeconómico nacional han afectado tanto el desempeño de las firmas productoras de maquinaria agrícola como la demanda de estos equipos. Por su parte, las políticas económicas sectoriales (créditos, protección arancelaria, incentivos y subsidios) estuvieron orientadas de acuerdo a visiones políticas - ideológicas, según se considerara estratégico o no, al sector industrial en general y a la industria de maquinaria agrícola en particular. Esto se encuentra en relación directa con las coaliciones de gobierno que estuvieran al frente del desarrollo de dichas políticas.

Las políticas sectoriales tienen la posibilidad de incidir en dos sentidos: por un lado, en el incremento de la demanda de equipos, con la intensión de mecanizar el sector agrario y por otro lado, en la promoción directa de la producción de máquinas. Esto no significa que ambas políticas no se dictasen en simultáneo y fuesen, a su vez, complementarias. Entorno a la demanda de maquinaria, esta estuvo durante toda su historia influenciada por los precios internacionales agropecuarios (en ciertos períodos desde el Estado se logra aislar a la industria de esta influencia) y también, por los ciclos de reposición de la maquinaria, que en gran medida están determinados por períodos de restricciones de acceso y etapas de aumento en la capacidad de compra.

En los últimos 20 años se produjeron cambios de relevancia en los manejos agronómicos en la producción agrícola, que han involucrado transformaciones en las características del sector productor de maquinaria agrícola. Esto ha repercutido en la estructura de la industria de maquinaria agrícola, dando un impulso renovador a la capacidad innovadora de un sector tecnológicamente maduro.

Ahora bien, el capítulo refleja estos procesos dividido en 4 etapas históricas, que son, a su vez, los respectivos segmentos del capítulo: 
1. Una primera etapa (1900 - 1930), que consideramos se destaca por la producción "artesanal" o de "prototipos", que le permitirá a la industria hacer un proceso de aprendizaje en cuestiones vinculadas al desarrollo de tecnología. Este proceso de aprendizaje estará muy vinculado a relaciones de proveedor-usuario. En el período antes dicho es en el cual, se formarán gran parte de las firmas productoras de maquinaria agrícola, proceso que estará relacionado con los productores agrarios instalados en Córdoba y Santa Fe. Este vínculo influirá, fuertemente, en la localización de las empresas y en los modos en que los talleres de reparaciones se convertirán en industria.

2. La segunda etapa (1930 - 1976), tiene como rasgo distintivo el desarrollo industrial, con crecimiento casi ininterrumpido en: producción, número de establecimientos, cantidad de trabajadores, integración de procesos, desarrollo de productos y complejidad tecnológica. En este período, la industria de maquinaria agrícola articulará los esfuerzos tecnológicos previos con el decidido apoyo del Estado. Es entonces, cuando los talleres de reparación y adaptación se desarrollarán como una industria de bienes de capital proveedora del sector agropecuario. En este período se incorpora, a demás, el capital transnacional en la producción de tractores, complementando la oferta nacional de equipos.

3. Período denominado de "reestructuración regresiva"52 (1976 - 2002), luego de una crisis iniciada a finales de 1977 , se inició una nueva etapa para la industria de maquinaria agrícola. Este período fue mucho más inestable en cuanto a producción y desarrollo evolutivo del sector. Se desarticuló la cadena de producción y se sustituyó paulatinamente la producción nacional por producción extranjera. En esta etapa comenzaron a desarrollarse cambios de importancia en los sistemas agronómicos de cultivo, que permitirán luego generar desarrollos locales innovadores en algunos segmentos de equipos agrícolas.

4. En el período 2002 - 2010 que podemos denominar como un nuevo período ISI. Se asiste a una nueva expansión del sector, con características en las cuales nos detendremos con mayor énfasis. Vinculado este crecimiento a un cambio en los modos de regulación macroeconómica, al aumento internacional de los precios de los granos y en la profundización de los métodos agronómicos de producción agrícola basados en la siembra directa-semillas transgénicas - herbicidas-maquinaria.

52 Ver Azpiazu, Basualdo y Nochteff (1990). 
Las conclusiones condensan el proceso evolutivo del sector, y en él se presentan algunas consideraciones y evidencias de importancia para nuestro trabajo de tesis, como así también, algunos interrogantes, que son un preámbulo del próximo capítulo.

\subsection{Orígenes y localización del sector de maquinaria agrícola argentino}

La literatura dedicada al estudio del sector de maquinaria agrícola, le confiere a la industria de maquinaria agrícola argentina un papel marginal en el período que transcurre entre finales del siglo XIX hasta finales de la década de 1940 (Rougier, 2006; Wimer Romero, 2010, Bil, 2011). Si bien, los empresarios locales conseguían importantes avances y logros en lo que se refiere a innovación y desarrollo de productos, no lograban tener peso sobre la provisión de maquinaria agrícola en el mercado interno. Este se abastecía mayoritariamente de equipos importados. Hasta finales de la década de 1940, la industria local de maquinaria era básicamente "artesanal" y de poca envergadura. Cuando hablamos de "artesanal" hacemos referencia a la fabricación de forma no seriada y con parámetros fordista, poseía, además, un componente de diseño propio creativo-innovador. Si bien es cierto, que existían algunas empresas con procesos y niveles de producción importantes eran minoría.

Las características excepcionales agro-ecológicas ${ }^{53}$ del país, y la falta de trabajadores en períodos críticos como la cosecha, fueron determinantes geohistóricos de la necesidad de mecanizar el agro argentino. En épocas tempranas, esta situación propició la creación de talleres de reparación (adaptación y mejora) de los equipos de maquinaria agrícola importada.

\footnotetext{
53 La región pampeana argentina es una planicie, que limita al sur con la Patagonia, al este con la costa atlántica, al norte con la región chaco - pampeana y al oeste con las sierras pampeanas, sus características edáficas y climatológicas la determinan como una de las regiones con mayor aptitud agrícola ganadera del mundo. Se genera de forma natural pasturas no celulósicas aptas para el consumo del ganado vacuno y ovino, y las condiciones climáticas admite sin mayores labores el cultivo de cereales y oleaginosas (trigo, maíz, soja, girasol, sorgo, etc) al secano.
} 
Cuadro No2. Desarrollos de maquinaria agrícola en Argentina (1900-1945)

\begin{tabular}{|c|c|c|c|c|}
\hline Empresa & $\begin{array}{l}\text { Año } \\
\text { inicio } \\
\text { tareas }\end{array}$ & Equipo & $\begin{array}{c}\text { Características del proceso de } \\
\text { desarrollo del equipo }\end{array}$ & $\begin{array}{l}\text { Localidad- } \\
\text { Provincia }^{54}\end{array}$ \\
\hline Senor & 1900 & $\begin{array}{l}\text { Máquina corta trilla de } \\
\text { arrastre }\end{array}$ & $\begin{array}{l}\text { Taller de herrería que se dedica al } \\
\text { arreglo de maquinas agrícolas y a la } \\
\text { fabricación de carruajes de tracción a } \\
\text { sangre. Posteriormente comienzan a } \\
\text { trabajar en la trilla de cereales en parvas } \\
\text { con trilladoras accionadas con motor a } \\
\text { vapor, incentivo éste que los lleva, en } \\
\text { 1920, a construir una maquina corta trilla } \\
\text { de arrastre. Este resultado les permite en } \\
\text { el año } 1921 \text { encarar la fabricación de } \\
\text { este tipo de maquinarias con el nombre } \\
\text { de Senor. }\end{array}$ & $\begin{array}{c}\text { San Vicente - Santa } \\
\text { Fe }\end{array}$ \\
\hline Rotania & 1915 & $\begin{array}{l}\text { Elementos para maquinas } \\
\text { trilladoras de vapor. La } \\
\text { fabricación de maquinas } \\
\text { corta trillas de arrastre a } \\
\text { caballo o a tractor. } \\
\text { "Espigadora-Trilladora con } \\
\text { adaptabilidad de un tren } \\
\text { automotriz en el rodado } \\
\text { delantero". }\end{array}$ & $\begin{array}{l}\text { Taller de reparación de maquinas } \\
\text { agrícolas. A su vez se dedicaban a la } \\
\text { explotación agrícola con este tipo de } \\
\text { maquinas trillando parvas de trigo y lino. }\end{array}$ & Sunchales - Santa Fe \\
\hline Susana & 1917 & $\begin{array}{l}\text { Primera corta trilla nacional } \\
\text { (traccionada por caballos, } \\
\text { pero con motor } \\
\text { incorporado). Fabricación } \\
\text { de cosechadoras, } \\
\text { enfardadoras y demás } \\
\text { implementos agrícolas. }\end{array}$ & Taller mecánico de motores a vapor. & Susana - Santa Fe \\
\hline $\begin{array}{l}\text { Santiago } \\
\text { Puzzi y } \\
\text { Cia. }\end{array}$ & 1917 & $\begin{array}{l}\text { Cosechadoras de tracción a } \\
\text { sangre }\end{array}$ & $\begin{array}{l}\text { Santiago Puzzi, pasa de chacarero a } \\
\text { tallerista de reparaciones de trilladoras a } \\
\text { vapor (con taller mecánico propio), } \\
\text { donde construye la mencionada } \\
\text { trilladora. }\end{array}$ & $\begin{array}{l}\text { Colonia Clusellas - } \\
\text { Santa Fe } \\
\text { Josefina - Santa Fe } \\
\text { San Francisco - } \\
\text { Córdoba }\end{array}$ \\
\hline Vassalli & 1935 & $\begin{array}{l}\text { Cosechadoras adaptadas- } \\
\text { cosechadoras automotrices }\end{array}$ & $\begin{array}{l}\text { Taller - herrería. Vassalli se dedica en } \\
\text { un primer momento a reformar maquinas } \\
\text { de agricultores de la zona y luego a } \\
\text { desarrollar un modelo de diseño propio. }\end{array}$ & $\begin{array}{l}\text { Cañada del Ucle - } \\
\text { Santa Fe } \\
\text { Firmat - Santa Fe }\end{array}$ \\
\hline Bernardín & 1923 & $\begin{array}{l}\text { Cosechadoras de arrastre. } \\
\text { Luego de } 1930, \text { lanza al } \\
\text { mercado su primer modelo } \\
\text { automotriz. }\end{array}$ & Pequeña industria. & $\begin{array}{c}\text { San Vicente - Santa } \\
\text { Fe }\end{array}$ \\
\hline
\end{tabular}

Continua en la siguiente página

54 En los casos necesarios primero se menciona la primer ubicación y en segundo la localización definitiva. 


\begin{tabular}{|c|c|c|c|c|}
\hline Empresa & $\begin{array}{l}\text { Año } \\
\text { inicio } \\
\text { tareas }\end{array}$ & Equipo & $\begin{array}{c}\text { Características del proceso de } \\
\text { desarrollo del equipo }\end{array}$ & $\begin{array}{l}\text { Localidad- } \\
\text { Provincia }^{55}\end{array}$ \\
\hline Druetta & 1923 & $\begin{array}{l}\text { Recolector de cereales que } \\
\text { previamente se cortaba para } \\
\text { su secado y que quedaba en } \\
\text { hileras en el campo, luego, ya } \\
\text { seco, este cereal era posible } \\
\text { levantarlo. }\end{array}$ & $\begin{array}{l}\text { Druetta trabajó como tallerista en campo } \\
\text { reparando cosechadoras. Pocos años } \\
\text { después, ya instalado en Buenos Aires y } \\
\text { en la campaña de cosecha de trigo año } \\
1929 / 30, \text { probó con éxito otra invención } \\
\text { suya, la autocosechadora de cereales } \\
\text { con plataforma de corte al frente. Este } \\
\text { modelo de maquina automotriz fue la } \\
\text { primera en el mundo en su tipo, siendo } \\
\text { contemporáneo de Rotania en la } \\
\text { creación de maquinas con transmisión } \\
\text { de mando propio a las ruedas motoras. }\end{array}$ & Totoras - Santa Fe \\
\hline $\begin{array}{l}\text { Daniele y } \\
\text { Cía. }\end{array}$ & 1927 & Cosechadoras & $\begin{array}{l}\text { Comienza como taller de reparaciones } \\
\text { de maquinarias importadas. En ese } \\
\text { trabajo y en paralelo comenzaron a } \\
\text { diseñar técnicamente sus propios } \\
\text { modelos de máquinas. Construyen su } \\
\text { primera cosechadora con el nombre B y } \\
\text { A Fiorito. }\end{array}$ & $\begin{array}{l}\text { Seeber - Córdoba } \\
\text { Porteña - Córdoba }\end{array}$ \\
\hline $\begin{array}{l}\text { Araus } \\
\text { Hnos. }\end{array}$ & 1942 & Cosechadoras automotrices & $\begin{array}{l}\text { Instalan un taller Araus Hnos. para } \\
\text { fabricar máquinas cosechadoras de } \\
\text { cereales y juntadora de maíz } \\
\text { automotrices. }\end{array}$ & $\begin{array}{c}\text { Armstrong - Santa Fe } \\
\text { Noetinger - Córdoba }\end{array}$ \\
\hline $\begin{array}{l}\text { RYCSA } \\
\text { (Rosatti y } \\
\text { Cristofaro } \\
\text { S.A.) }\end{array}$ & 1942 & Cosechadoras y enfardadoras & $\begin{array}{l}\text { Druetta vende su fábrica e inicia una } \\
\text { nueva con nuevos socios. }\end{array}$ & $\begin{array}{l}\text { Ciudadela y en } \\
\text { Arrecifes - Bs. As. }\end{array}$ \\
\hline
\end{tabular}

Fuente: elaboración propia en base a Buratovich (2010).

Los equipos importados, que tuvieron en esta época una participación mayoritaria en el mercado de la República Argentina, necesitaban, en muchos casos, ser readaptados para su uso a las condiciones locales. Estas adaptaciones, que se destacaron por sus avances tecnológicos y de vanguardia, devendrían, algunas de ellas, en producciones industriales. En 1878 en Esperanza, Santa Fe, Nicolás Schneider inició la fabricación de arados, los primeros del país, está localidad es considerada por los santafesinos como la primer colonia agrícola del país. Para la misma época, los hermanos Rosso, en Leones, Córdoba; Sode en Tres Arroyos, Buenos Aires y Juan y Emilio Senor en San Vicente, Santa Fe, produjeron trilladoras propulsadas por caballos. En 1910, Juan Istilart en Tres Arroyos, Buenos Aires produjo trilladoras impulsadas a vapor. En 1927, se desarrolló en Sunchales, Santa Fe una de las primeras cosechadoras automotrices a nivel mundial, creada por los hermanos

55 En los casos necesarios primero se menciona la primer ubicación y en segundo la localización definitiva. 
Rotania de origen italiano, cuya patente es otorgada en 1929. Se fabrican 5 máquinas, de las que 4 quedan en el país y 1 se exporta a Estados Unidos.

La interacción entre los productores agropecuarios y los talleres que elaboraban la maquinaria fue decisiva en el avance innovativo del sector. Los desarrollos estaban basados en los requerimientos de la demanda. La inventiva e ingenio, que los fabricantes de equipos volcaban a los desarrollos locales eran semejantes a los hechos en países que iban a la vanguardia en el tema, como Estados Unidos (Rougier, 2006).

Los avances logrados en la producción de maquinaria comenzaron con base en la reparación, adaptación y mejora de la maquinaria importada. Un proceso necesario para desarrollar cualquier industria de bienes de capital (Nagao y Chudnovsky, 1984).

En este sentido, la interacción con los productores agropecuarios generaron innovaciones que resolvieron limitantes al uso de los equipos importados en la región e iban un paso más allá produciendo modificaciones que derivaban, algunas veces, en nuevos equipos (innovaciones incrementales de productos ${ }^{56}$ ), situándose a la par de la innovación sectorial a nivel mundial. En los talleres se generó un capital de conocimientos que sentó las bases de la posterior industria nacional de maquinaria agrícola. Aunque por otro lado, debemos decir que la producción local de maquinaria agrícola ${ }^{57}$ no incidía aún, de manera decisiva, en la provisión de equipos agrícolas en el mercado interno.

A este respecto, debemos remitirnos al trabajo doctoral de Bil (2011) quien considera que la industria de maquinaria agrícola no alcanzó los estándares medios de competitividad a nivel mundial, y por lo tanto, ésta tuvo problemas para desarrollarse a nivel nacional y desde luego no pudo ingresar al mercado internacional; donde ya existían empresas especializadas con varias décadas de historia y de acumulación de conocimiento y de capital. ${ }^{58}$

\footnotetext{
56 Las innovaciones incrementales son las mejoras sucesivas a los productos y procesos existentes, que se producen cuando se agrega (o quita, o combina, o resta, o suplanta) una parte a un producto o servicio. Las innovaciones incrementales son las mejoras sucesivas a los productos y procesos existentes. Desde un punto de vista económico, este tipo de cambio es el que origina el aumento general de productividad, observable en las estadísticas. La dinámica evolutiva de cada tecnología particular se caracteriza por frecuentes incrementos en eficiencia técnica, productividad y precisión de los procesos y por cambios regulares en los productos para conseguir mejor calidad, reducir costos o ampliar la gama de usos (Freeman y Perez, 2003).

${ }^{57}$ Hacia 1914, los datos del censo mostraban que la industria argentina se concentraba en algunas ramas como alimentos, materiales para la construcción y textiles con un $66 \%$ del valor bruto de la producción industrial; la industria metalmecánica representaba sólo un $4 \%$ del valor bruto la producción industrial (Neffa, 1996).

58 Una de las respuestas que encuentra Bil a los límites en la acumulación del sector en Argentina en el período 1875 - 1940 es: en primer lugar, la "llegada tarde" de la industria Argentina, perdiendo mercado
} 
Por otro lado, no se debe menospreciar el grado de apertura que tenía la economía Argentina en la época (agroexportadora). En ese sentido debemos decir que Estados Unidos tuvo una elevada protección arancelaria, las industrias de Estadounidenses fueron las más protegidas del mundo desde 1816 hasta 1945 (Chang, 2003). Es nuestra opinión que el pobre desenvolvimiento del sector de maquinaria agrícola argentino ha tenido muy probablemente múltiples factores y no sólo uno o dos, en el período entre fines de s.XIX y 1940.

Ahora bien, el paulatino desarrollo del sector de maquinaria agrícola de comienzos del siglo XX, tiene como principales factores explicativos:

1. cierta protección "natural" debida a las distancias de los mercados oferentes especialmente Estados Unidos. ${ }^{59}$

2. La especialización argentina internacional a partir de la excepcionalidad agroecológica en productos agrícolas (cereales) y pecuarios (vacuno y ovino) en la región pampeana generaron rentas ${ }^{60}$ que permitían una demanda constante de equipos. ${ }^{61}$

3. Las características de la inmigración, es un factor explicativo hasta ahora no enunciado por la bibliografía especializada. A la República Argentina llegaron inmigrantes, que por cuyos perfiles podríamos agrupar de esta manera: un grupo mayoritario de agricultores de las zonas mediterráneas de Italia y España y otro de países ya industrializados (Francia, Checoslovaquia, Suiza, Bélgica, Luxemburgo, Alemania inclusive del norte de Italia), con mayor nivel

\footnotetext{
frente a las importaciones de la industria estadounidense. En segundo término, la dificultad de aprovisionamiento de insumos siderúrgicos y metalúrgicos y la inexistencia de una industria auxiliar fueron limitantes severos para el desarrollo adecuado del sector. La consecuencia de ambas cuestiones fue una producción muy reducida (baja escala), más costosa e ineficiente que la estadounidense, y una organización laboral no acorde a las mejores prácticas de las plantas más grandes, también estadounidense. Si bien acordamos con la segunda tesis, donde se considera que la escasez de insumos básicos para la producción se transformó en un obstáculo, no estamos de acuerdo con la primera de ellas; en la que se considera que la producción Argentina haya comenzado "tarde". Por un lado como hemos visto en el cuadro $\mathrm{N}^{\circ} 1$ son muchos los talleres que comienzan a producir entre principios de 1900 y 1940, más de los que aquí se detallan (y en trabajos del mismo Damián Bil del 2008 se analizan fábricas con inicio previo al 1900). Por otro lado Brasil comenzó más "tarde" que Argentina en el desarrollo de la industria de maquinaria agrícola y tuvo un mejor desempeño exportador y relativo éxito, para citar un ejemplo en contrario. Si consideramos además que Claas de Alemania empresa líder en cosechadoras, lanza al mercado la primera cosechadora de arrastre hecha en Alemania en 1936 y en 1953 la automotriz (en: www.claas.de, 2012), no podemos decir que Argentina haya comenzado tarde. En todo caso más allá de que podamos admitirlo como cierto, esto demuestra que, el comienzo tardío no ha sido un determinante severo en el proceso de acumulación de capital sectorial.

${ }^{59}$ A partir de 1914, se suma, que como consecuencia de la I Guerra Mundial se generan restricciones externas en la importación de equipos.

${ }^{60} \mathrm{El}$ concepto de "renta" aquí utilizado es el que se desprende del desarrollado por Harvey (1982).

${ }^{61}$ La especialización, además de generar excedentes, ha sido uno de los motivos motivo también para el impedimento de la industrialización.
} 
de instrucción formal y conocimientos necesarios para la producción manufacturera (IPEC, 2008). Ambos grupos, fueron actores sociales determinantes en el desarrollo del proceso de articulación entre industria proveedora de equipos agrícolas y la actividad agrícola misma.

La relación entre la localización de las colonias agrícolas de inmigrantes europeos y la industria de maquinaria agrícola estructuraron con fuerza la configuración territorial de producción de maquinaria agrícola. En el siguiente mapa se observa la región de asentamiento de las colonias agrícolas ${ }^{62}$ por departamento y por años de comienzo aproximado de colonización, que se corresponde con la región de mayor desarrollo de talleres de reparación y producción de maquinaria agrícola para la época.

La estructura de las explotaciones agropecuarias argentinas en este período se conformaban a grandes rasgos de la siguiente manera: la provincia de Buenos Aires concentraba grandes estancias cuya tenencia y propiedad estaba en manos de pobladores locales que alternaban ganado vacuno y ovino según la conveniencia de precios (muy relacionado con la distancia al puerto y con posterioridad con la expansión de los frigoríficos); en Córdoba, en Santa $\mathrm{Fe}^{63}$ y en, menor medida, Entre Ríos, el Estado y sectores privados propiciaron colonias agrícolas, donde se instalaron en su mayoría los inmigrantes europeos, con explotaciones en promedio de 300ha (Giberti, 1988). Fue en esta región (ver mapa №1) donde se concentraron la mayoría de los talleres de maquinaria agrícola antes mencionados (con excepción de Istilart y Sode, que lo hacen en Buenos Aires).

La población inmigrante tuvo un doble rol: por un lado, fue el actor agrario que mayoritariamente demandó maquinaria agrícola ${ }^{64}$ y por otro lado, fue el agente que inició el proceso de reparación, adaptación e incluso fabricación e innovación de equipos agrícolas.

\footnotetext{
62 En Argentina hubo distintos proyectos de colonización rural con inmigración europea, para más detalle se puede consultar Wolf y Patriarca (1991).

${ }^{63}$ Esto fue posible gracias a la expansión del Ferrocarril, que permitió expandir la frontera agrícola a tierras marginales, no por su aptitud agrícola sino por su distancia del puerto y del principal mercado de consumo. La distribución de la tierra estuvo siempre muy restringida por el poder de la clase terrateniente local que impedían una mayor distribución de las tierras (Rofman y Romero, 1974). En el futuro esta situación será un limitante en el aumento de la productividad agropecuaria medida por hectárea (Giberti, 1988, Barsky et al, 1988)

64 La promulgación de la ley de Prenda Agraria en 1914 tuvo importantes consecuencias para el sector y para los inmigrantes que venían con muy poco capital para invertir. En cuanto a los fabricantes e importadoras de maquinarias, esta legislación inauguró un sistema de venta que dura hasta hoy en la región pampeana. Este consiste en vender a crédito la maquinaria y mantenerla prendada mientras persista la obligación (Lódola - Angeletti, 2004).
} 
Mapa №1. Localización de las primeras colonias agrícolas en las provincias de Córdoba y Santa Fe, según período de colonización.

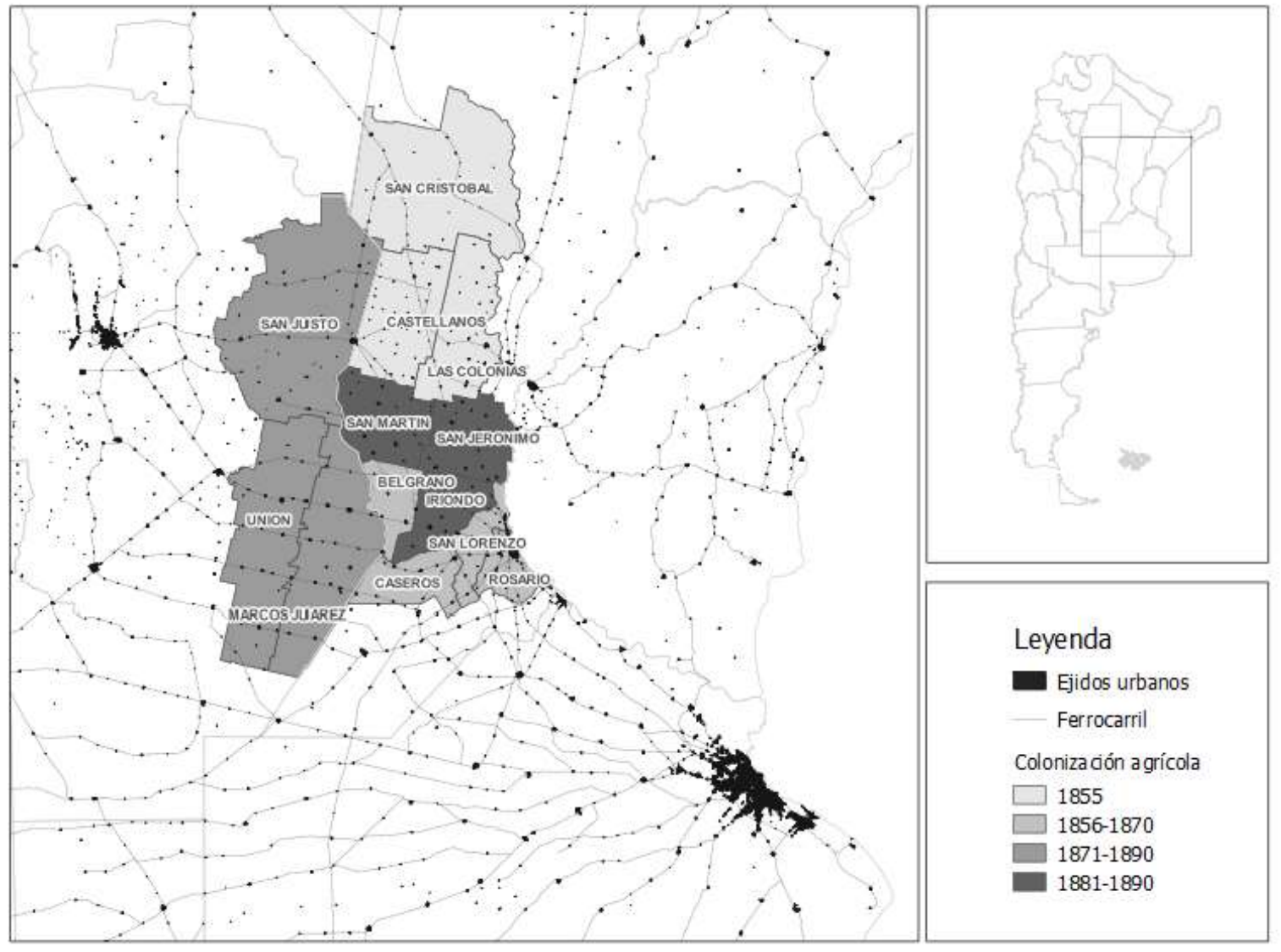

Fuente: elaboración propia en base a IPEC (2008).

La provincia de Buenos Aires, tuvo una estructura agraria diferente a la de las provincias de Santa Fe, Entre Ríos y Córdoba, debido a la forma de ocupación territorial, esto influyó para que recién a partir de mediados de 1920 la producción agraria comience a tener relevancia en Buenos Aires. ${ }^{65}$ Los grandes estancieros de Buenos Aires (ganaderos) arrendaban parte de sus campos a inmigrantes descapitalizados, por término de tres años y bajo sus condiciones (Giberti, 1988). En la provincia de Buenos Aires comienza de forma tardía (en relación con las otras provincias pampeanas) a intensificarse el uso de la maquinaria agrícola, que se abasteció sistemáticamente con importaciones, sin mayores inconvenientes. Es por ello, que Buenos Aires ${ }^{66}$ no tuvo desarrollo de industrias de maquinaria agrícola, no

${ }^{65}$ Como consecuencia de bajas en los precios del ganado (Giberti, 1988).

${ }^{66}$ A excepción de la región sur de la provincia de Bs. As., por ejemplo Tres Arroyos donde se ubica una importante colonia de agricultores de Europa del Norte y donde surge una empresa pionera en la producción de maquinaria agrícola, Istilart. 
por lo menos, en el nivel que poseyeron Santa Fe y Córdoba, pese a ser la provincia con el producto industrial más alto en ese momento.

Durante toda la década de 1920, la producción agrícola creció y como consecuencia de ello la demanda de maquinaria agrícola y de mano de obra fue en aumento. La oferta de mano de obra era un factor crítico durante el período de cosecha, al punto que el salario atraía trabajadores de Europa, que aprovechaban la contra estación hemisférica (Barsky, 1988).

Este período en Argentina, estuvo guiado por las exportaciones de productos agropecuarios, bienes que lideraron el crecimiento del país de forma ininterrumpida ${ }^{67}$ De hecho, la mayor parte de la economía argentina se articuló alrededor del sector. No obstante, la crisis mundial de 1930, que afectó la marcha de la economía en general, comprometió la producción agropecuaria negativamente, los cereales tuvieron precios muy por debajo del promedio de la década de 1920 para su exportación. Como consecuencia de ello, el Estado creó un ente ${ }^{68}$ encargado de intervenir en el mercado de granos, denominado Comisión Nacional de Granos y Elevadores, este organismo público tenía como propósito sostener un precio mínimo de los granos y limitar las áreas sembradas. El Estado lograba, de esta forma, asegurar la renta agraria (Rofman y Romero, 1974), alejándose, a su vez, de un rol "pasivo" en políticas económicas. A partir de la crisis se generaron políticas industriales de protección, primero como reacción al esquema internacional generalizado de proteccionismo y luego como concepción consciente dirigida a la promoción de la actividad industrial local.

A modo de síntesis, podemos decir y revalorizar esta etapa (1900 - 1930) en varios sentidos, primero reconocer la importancia del desarrollo relativamente temprano y casi autónomo del sector de maquinaria agrícola, dando respuesta a las características territoriales de producción con innovaciones incrementales locales en maquinaria agrícola importada. Por otro lado, es importante destacar, que la forma, en que la industria de maquinaria agrícola, se configuró espacialmente se encuentra vinculada directamente a la distribución de las corrientes inmigratorias europeas en colonias agrícolas. Este proceso creó una región territorialmente concentrada de empresas de equipos agrícolas, a partir del círculo "virtuoso" que se generó entre talleristas y productores agrarios. Si bien es cierto, que existía la habilidad artesanal de

${ }^{67}$ EI PBI argentino creció durante 1900 a 1930 un promedio anual de 4,5\%, la población lo hacía al 3,3\%. La industria que más creció en este período fue la de insumos, bienes durables y maquinaria (Neffa, 1996).

68 Otras medidas de importancia a nivel político económico: se eliminó la Caja de conversión de la moneda, con paridad patrón oro al control de cambios y se creó el Banco Central. Se hizo un estricto control de importaciones, que favoreció a los productores locales, tendiente a equilibrar la balanza de pagos (Rofman y Romero, 1974). 
desarrollar diseños propios acorde a las necesidades locales, por otro lado, la capacidad de dar el "salto" hacia la conformación de una industria en serie con características fordistas estaba muy disminuida.

Este es un momento crucial en el cual los países periféricos tuvieron la posibilidad de generar un proceso de industrialización a partir del estadío en el desarrollo del paradigma metalmecánico ${ }^{69}$. Debemos considerar, también, que los distintos segmentos de equipos agrícolas se encontraban en diferentes etapas del ciclo de producto. Por decir un ejemplo, los arados estaban en una fase de madurez, pero cosechadoras autopropulsadas en una fase inicial, al igual que tractores. Argentina conseguía en estos últimos productos ciertos logros, pero eso no alcanzaba para el desarrollo industrial del sector. Al respecto recordemos, que una de las primeras cosechadoras autopropulsadas del mundo se hizo en el país y se patentó internacionalmente, pero sólo se produjeron 5 unidades. Esto nos permite inferir que en el país existían capacidades tecnológicas que no se articulaban como proceso industrial.

Una de las causas de que el sector de fabricación de maquinaria agrícola se mantuviera en un estado latente (talleres) y no llegara a transformarse en industria al estilo fordista, en el que se incluyera un proceso de acumulación de capital ampliado, pudo ser la ausencia de promoción estatal de la actividad en Argentina. Aunque, el país llegó a tener 2500 talleres de reparación y de fabricación de implementos en este período, nunca alcanzó el desarrollo que para estos años tenía esta misma industria en Estados Unidos, donde las plantas alcanzaron escalas mucho mayores, lo cual marcó una de la diferencias más importantes.

En definitiva, la primer sección de este capítulo da respuesta a la pregunta de ¿cómo surgió la actividad productora de maquinaria agrícola en el país, sin apoyo estatal y con una fuerte competencia externa ${ }^{70}$ ?

Ahora bien, hacia 1930 y con más fuerza y definición hacia mediados de 1940, comienza una nueva etapa, donde el rol del Estado comienza a ser visualizado como determinante en el proceso de industrialización. En 1930, el Estado actuó con una estrategia defensiva frente al nuevo escenario internacional y luego en 1940, con un Estado proactivo, se intentó generar las condiciones del cambio estructural de la matriz productiva.

\footnotetext{
69 Para ver en detalle el concepto de paradigma tecnoeconómico, examinar Perez (2001).

70 Si como dato central sabemos que para la década de 1920 Argentina era el primer importador de equipos a nivel mundial (Bil, 2011).
} 


\section{3. Nuevo rol del Estado como dinamizador y promotor del sector de maquinaria agrícola.}

Luego de la crisis mundial de 1930, el Estado argentino instrumentó una serie de medidas, que dieron impulso a la industrialización (en general) del país. Más allá de la creación de la Junta Reguladora de Granos, ya mencionada, se comenzó a regular la importación de bienes, para ello se elevaron los aranceles a las compras externas.

Estas medidas fortalecieron la actividad productora de maquinaria agrícola, a su vez, el mercado interno se encontraba en expansión debido a: por un lado, la ingente necesidad de reemplazar mano de obra rural que migraba internamente con dirección "campo - ciudad", y por otro lado, al aumento de los precios de los granos, que se registraba ya hacia 1933. La escasez de mano de obra rural ${ }^{71}$ siguió siendo un factor crítico, el productor intentó, entonces, resolver el problema a través de la incorporación de maquinaria (Lodola y Fossati, 2002).

Por otra parte, los autores Lodola y Fossati (2002) describen un proceso interesante que sucede en esta época con mayor intensidad. Este proceso es el aumentó en la cantidad de prestadores de servicios agropecuarios, conocidos como contratistas72, cuya existencia comienza a principios de siglo en Argentina. Este aumento sucede como consecuencia de la compra, por parte de los productores arrendatarios (básicamente de la provincia de Buenos Aires) de equipos como forma de capitalizarse, y luego debido a una serie de cambios institucionales y contractuales de carácter político, pierden su condición de arrendatarios. De esta manera, sin tierra y con maquinaria, venden sus servicios a los dueños de las tierras. Avanzado el siglo $X X$, los contratistas se convertirán en el principal actor del sector agropecuario demandante de maquinaria agrícola.

Hacia finales de la década de 1930, pese a la protección arancelaria, que había instrumentado el Estado argentino, no existía aún una verdadera sustitución de importaciones. En este sentido el sector de producción de maquinaria agrícola producía algo menos de 500 cosechadoras y 1.275 sembradoras, la escala era relativamente baja comparada con la Estadounidense y no podía competir internacionalmente (Bil, 2011).

\footnotetext{
71 Pese a ello los salarios se mantuvieron bajos, con la salvedad de los períodos de cosecha ya mencionados.

72 Definimos a las empresas de servicios agropecuarios (contratistas) como aquellas unidades económicas (personas o sociedades), propietarias de tierra o no, que regularmente brindan, en forma autónoma, servicios de maquinarias o de personal (no profesionales) a una explotación agropecuaria y por lo cual reciben un pago específico (en dinero o en especie) (Lódola y Fossati 2002). Se puede clasificar a los mismos, de acuerdo al factor de producción que ofrecen, en contratistas de maquinarias o contratistas de mano de obra; nos referiremos en este trabajo a contratistas de maquinaria.
} 
Por otro lado, para esa época (finales de la década de 1930) se llegó al límite de la frontera física agropecuaria ${ }^{73}$, y con ello se alcanzó el límite del crecimiento de la producción agrícola y ganadera ${ }^{74}$. No obstante, la industria de maquinaria agrícola estaba asociada al sector más dinámico de la economía Argentina, esto le confería pese a sus límites muchas ventajas. El país tuvo una demanda en ascenso de maquinaria agrícola durante los años de la II Guerra Mundial (1939-1945), con una oferta que se restringía debido al conflicto bélico. La producción de maquinaria agrícola se retrajo en Estados Unidos, como consecuencia de que este país transformó su industria para la producción de armamento.

Mientras tanto, en Argentina en 1944, se estableció "El Estatuto del Peón" de los trabajadores rurales, en un proceso de sindicalización de la mano de obra rural, que culminó en 1949 con la instrumentación legal de dicho estatuto, que establecía entre otras cosas la limitación del trabajo familiar en la explotación agropecuaria, ley que restringía aún más la cantidad de mano de obra rural. Esto incentivaba la mecanización de las explotaciones, que sumado al apoyo decidido del Estado, que financiando líneas de crédito a tasas negativas y a largo plazo, hicieron crecer mucho la demanda (Lódola y Angeletti, 2004).

Durante este período (los años de la Segunda Guerra Mundial y los inmediatamente posteriores), los implementos agrícolas tuvieron un fuerte crecimiento en la producción nacional, esto fue consecuencia de una demanda sostenida en el mercado interno. La mayor simpleza de los implementos agrícolas (frente a otros equipos) hizo innecesaria la provisión de insumos importados para su producción, por lo que no tuvo restricciones de este tipo para su crecimiento. Como muestra del avance del desarrollo que tuvo el segmento de implementos agrícolas, en el año 1944 la empresa Mainero en Bell Ville, Córdoba, desarrolla el primer cabezal del país para la cosecha de girasol (fue uno de los primeros a nivel mundial). La intención era clara, sustituir mano de obra. Los requerimientos de los productores agrícolas orientaban la innovación de los productores de equipos.

Por otro lado la fabricación de cosechadoras que era altamente demandante de insumos importados para su ensamblaje, no avanzó en su capacidad productiva durante estos años. La producción de tractores todavía no se había iniciado en el país

\footnotetext{
${ }^{73}$ El $80 \%$ de la tierra de la región pampeana estaba dedicada a la cría de ganado el $20 \%$ restante tenía uso agrícola (Neffa, 1996).

${ }^{74}$ La forma de producción agropecuaria en Argentina era extensiva, por lo tanto el sector no podía aumentar la producción sin incorporar nuevas tierras. Para lograr nuevos aumentos de producción era necesario invertir en tecnología y maquinaria para por un lado transformar las explotaciones de un modo de producción extensivo a uno intensivo y por otro para seguir incorporando tierras con menores aptitudes para la explotación agropecuaria.
} 
(Lajer et al., 2006), esto estaba sumamente ligado a la inexistencia de industria automotriz nacional (Bil, 2011).

Durante el lapso que duró la segunda gran guerra, se produjo una restricción de oferta. Por un lado, había incentivos para la compra de maquinaria agrícola, pero por otro lado, las posibilidades de importarla eran casi nulas, esta situación generó un "cuello de botella" para el aumento de la mecanización agraria, que se resolvería años más tarde a partir de la articulación entre Estado e industria.

En este sentido, en 1946 se creó el IAPI ${ }^{75}$ (Instituto Argentino de Promoción del Intercambio), y con él se da un paso de importancia en la resolución de las necesidades financieras de la industria. El organismo estaba encargado de comerciar los productos exportables (principalmente granos y carne) argentinos y transferir ingresos del sector agropecuario al industrial.

A partir de $1949^{76}$, se generan una serie de hechos, que fueron disparadores de un nuevo escenario para la producción nacional de maquinaria agrícola. El crecimiento de la economía generó la necesidad de aumentar los volúmenes exportables, para evitar la restricción externa que se producía durante los años de expansión del PBI industrial (la industria demandaba la mayor parte de las divisas para importar tecnología). Esto podría ser factible a partir de un aumento de la productividad de los sectores agropecuarios generadores de divisas. Desde el Estado se impulsó la mecanización agraria como método más eficiente para lograr el necesario crecimiento de la productividad por hectárea. Un ejemplo de ello, fue una gran innovación nacional, la plataforma de recolección de maíz, que significó un avance de importancia para la cosecha del cultivo, que necesitaba entre 600 mil a 800 mil trabajadores temporarios. El avance se logró a partir de desarrollos simultáneos de Vassalli y Giubergia, el primero en Firmat y el segundo en Santa Fe. Esto sucedió a principios de 1950, con apoyo e incentivo del gobierno. La necesidad de obtener la cosecha en tiempo y forma hizo intervenir al Estado, que visualizó esta fase de la producción granaria como un cuello de botella a resolver. Los proyectos de Vassalli y Giubergia (el gobierno les pide a estas dos empresas aceleren los mismos) son acompañados con créditos "blandos" de importancia aportados por el Banco Industrial.

\footnotetext{
${ }^{75}$ Lo desactiva en 1955 la autodenominada Revolución Libertadora.

${ }^{76}$ Desde ese año hay un apoyo sistemático para la producción rural entre los que se encuentra el plan trienal destinado a la mecanización agraria que permitía y otorgaba permisos para importar MA, y una rebaja de 2 puntos en la tasa de interés para el crédito agrario. Se incluye a todo el espectro de la estructura rural (Girbal-Blacha et al., 2001).
} 
En esta nueva etapa, el Estado mucho más activo en políticas sectoriales comenzó a dictar normas para el desarrollo de la industria de maquinaria agrícola. En 1949, el gobierno nacional, por decreto 12.109/49, suspende el arancel a la importación de maquinaria agrícola. Esta medida favorecía la mecanización agraria pero iba en contra de la producción local de estos equipos. En contra de esta medida, el empresariado local (mayoritariamente los productores de implementos agrícolas) presionó al gobierno para que se cierre la importación y se apoye la producción nacional. En un primer momento, las empresas de maquinaria agrícola nacionales sólo consiguieron apoyo financiero, con intereses del $4 \%^{77}$ (Lajer et al, op cit.).

Los intentos de organizar una industria de maquinaria agrícola nacional tuvieron oposición interna en los sectores agropecuarios. La Sociedad Rural Argentina (SRA) y otras organizaciones rurales desestimaron el proyecto de instalar plantas de tractores en el país (y presionaron en contrario), bajo los argumentos de la presunta menor calidad y el mayor precio de los posibles fabricantes locales. La estrategia gubernamental fue aumentar el otorgamiento de créditos subsidiados a los productores agropecuarios, transfiriéndoles recursos para la compra de equipos. De esta forma el sector agropecuario cesó en sus reclamos (Schvarzer, 1996).

A partir de 1951, hubo, desde el Estado, una nueva postura hacia la actividad, ese mismo año se declara a la industria de maquinaria agrícola de "interés nacional". Esto se produce porque no bastaba con aumentar la productividad agropecuaria a través de la mecanización para acrecentar la generación de divisas ${ }^{78}$, sino que también, había que ahorrarlas a través de la producción local de equipos. El Estado ${ }^{79}$ decidió, ahora sí, impedir el ingreso de equipos extranjeros, fijó cuotas y tipos de cambio diferenciales para la maquinaria agrícola no producida en el país, y liberó la importación de insumos necesarios para producir maquinaria nacional. Estas medidas producen una rápida sustitución de importaciones en toda la gama de herramientas agrícolas (implementos agrícolas y cosechadoras), a excepción de los tractores que aún no eran fabricados en el país, como ya se dijo.

La República Argentina no podía hacer frente a las inversiones necesarias en algunos sectores industriales, y tampoco contaba con la tecnología necesaria. Esto fue generando cierto consenso a nivel nacional de la necesidad de abrir la producción a las empresas transnacionales para que instalen filiales en el país. Para hacer frente al

\footnotetext{
77 Tasa real negativa.

${ }^{78}$ Esto se asocia a la restricción externa vinculada al proceso llamado stop and go, ver Kosakof (2007)

${ }^{79}$ Esto se produce en el marco del $1^{\circ}$ Plan Quinquenal y en vistas de su profundización a partir del $2^{\circ}$ que contemplaba con mucho mayor énfasis la producción de bienes de capital (Girbal-Blacha et al. op cit.)
} 
temor de que la entrada de empresas extranjeras desplazara a las firmas locales, desde el Estado se direccionó la inversión y se seleccionó el sector y los tipos de emprendimientos que llevarían adelante las empresas transnacionales. En este período las empresas transnacionales, originarias generalmente de los países centrales, buscaban oportunidades en otros mercados (ante la caída de la demanda en los propios mercados), proceso que intentaba recrear las tasas de ganancia, que iban disminuyendo en sus mercados domésticos (Schvarzer, 1996). Hacia 1953, se promulgó la ley 14.122 referida a la inversión extranjera directa (IED), la misma promovía la inversión IED en el sector de metalmecánica. Cuatro meses después se abrió la licitación para instalar una fábrica de tractores en el país.

El Estado, a través de Industrias Argentinas Metalmecánicas del Estado (IAME) empresa asociada a la Fábrica Militar de Aviones (FMA), comienza la fabricación local de tractores en asociación con FIAT Spa. de Italia, que era proveedora de la FMA. Se le otorga a la nueva empresa un préstamo del Banco Industrial y un mercado interno totalmente protegido. En 1954, se refuerza la política de incentivos y el Estado nacional: promulga el "Régimen de la industria del tractor", llamó a licitación para que cuatro empresas líderes se instalen en el país para producir localmente y abastezcan el mercado interno, y además se fijó cuotas de producción según la necesidad del mercado, prohibió importar tractores con las características de los producidos en el territorio nacional y sólo pudieron importar unidades completas ${ }^{80}$ las empresas ganadoras de la licitación. Las empresas que ganaron la licitación fueron FIAT Concord, Deutz, Hanomag y FAHR.

El escenario para las empresas de tractores volvió a cambiar en 1958, cuando asume un gobierno que promueve una política de atracción de IED, en desmedro, de una mayor calidad en el tipo inversión. Se modificó, entonces, el régimen de la industria del tractor, ahora se permitiría el establecimiento, en el país, de toda empresa que cumpliese con los requisitos de integración de partes y componentes nacionales. En 1959, se dio por terminado con los cupos de producción (Lajer et al, op cit.). Al año siguiente, se produjeron en el país 20.000 tractores anuales, se logró, en el término de 7 años, abastecer el mercado interno con un porcentaje de integración de componentes nacionales cercano al $95 \%$.

Con estas medidas se resolvía un dilema de índole económico político, que se refería a la controversia entre asegurar el mercado de forma monopólica a una sola empresa ya instalada en el país (asociada al Estado argentino), con capacidad para

80 Esto les permitía completar el cupo que poseían de producción en la fase inicial, hasta que pudieran cumplir con el cupo con producción nacional, el plazo eran los 3 primeros años. 
producir la cantidad necesaria para el mercado interno y con capacidad para exportar, con economías de escala de planta; o se aumentaban los costos medios por unidad al reducir las escalas de planta, y el mercado se resolvía de manera oligopólica con el ingreso de más productores destinados a abastecer exclusivamente el mercado interno ${ }^{81}$. Finalmente se optó por esta última opción y 4 empresas se repartieron un mercado de 12.000 unidades promedio por año, magnitud que podría haber sido atendida por una sola empresa de planta eficiente, siendo sus costos un $30 \%$ menores que los que tenían las 4 empresas juntas (Schvarzer, 1996).

El Estado, pese a los cambios de gobierno, seguía una línea política, era productor de maquinaria agrícola y generador de incentivos para la demanda de maquinaria agrícola con créditos a tasas negativas y a largo plazo (Rougier, op cit.).

En 1963, hubo un cambio de gobierno que exhibió una visión distinta de la política implementada en los últimos años, se fijó desde el Estado ${ }^{82}$ en cuatro la cantidad de empresas que podían producir tractores, estas eran (luego de fusiones y adquisiciones en el plano global): Deutz, FIAT, John Deere, y Massey Ferguson. Ese mismo año dejó de producir la Dirección Nacional de Fabricaciones e Investigaciones Aeronáuticas (DINFIA ex IAME) el tractor Pampa, del cual se produjeron 3760 unidades entre 1953 y 1963.

La fabricación nacional de cosechadoras observó un desarrollo diferente. Argentina llegó a tener en el país más de 38 fábricas dedicadas a la producción de cosechadoras en el período que comprende desde la década de 1920 hasta finales de la década de 1950. Algunas de estas fábricas fueron de gran importancia industrial y comercial, y no sólo vendían sus máquinas dentro del país, sino que, además, las exportaban. A partir de las estadística del año 1965, las 21 fábricas en actividad en ese momento (12 en la provincia de Santa Fe y 9 en la provincia de Córdoba), produjeron más de 4.500 unidades (Buratovich, 2010).

En síntesis, el sector de maquinaria agrícola argentino se conformaba de esta manera: el segmento productor de implementos agrícolas y cosechadoras eran PYME que evolucionaban, de los primeros talleres de reparación, adaptación y mejora de la maquinaria agrícola importada ${ }^{83}$, ubicados en el corazón agrícola del país, descriptos

\footnotetext{
81 Las deseconomías de escala, que generó la estructura oligopólica en las firmas transnacionales, impedía que estas fueran competitivas en el exterior.

82 Hay un cambio en la idea de desarrollo del gobierno de Frondizi basado en IED, al nuevo gobierno de Illia (1963), mucho más cercano a posturas ideológicas basadas en el desarrollo de corte nacional.

${ }^{83}$ En estos dos subsectores (cosechadoras e implementos) las empresas han tenido bajas barreras a la entrada (con respecto a tractores), por el tipo de tecnología relativamente sencilla y mercados cautivos, estos últimos son los inmediatamente cercanos geográficamente (García, 1999).
} 
en la sección anterior. Por su parte, fue precisa la participación activa del Estado y de empresas transnacionales para completar la gama de equipos de producción nacional. Las fábricas de tractores se instalaron en las ciudades de Córdoba, Rosario y Gran Buenos Aires, sin necesidad de estar cerca de los productores agropecuarios, porque la inspiración del diseño y desarrollo tecnológico de estas empresas procedía del exterior, aunque los modelos producidos localmente iban rezagados con los producidos en países como Estados Unidos y Canadá (Huici, 1988). A partir de la década de 1960 la industria nacional logró abastecer al 100\% la demanda local, que fue en constante aumento ${ }^{84}$ hasta 1977.

Este aumento tuvo una particularidad y es que la demanda de maquinaria agrícola creció en Argentina en un período (1940 y 1965) en el que el sector agropecuario sufrió un estancamiento en la producción ${ }^{85}$, con precios agrícolas bajos (a excepción de la campaña 1961-62) y desplazamiento de muchas producciones agrícolas hacia producciones de ganadería ${ }^{86}$ (Barsky et al. op cit.). Hubo un importante reemplazo de trabajo humano y animal por trabajo mecánico, no obstante, no aumentó la productividad del sector ${ }^{87}$. El sector agropecuario sufrió además tres años consecutivos de sequías: 1949-50-51. Pese a ello, durante el período en cuestión existe una demanda fuerte y en ascenso de maquinaria agrícola ${ }^{88}$, estimulada por el crédito a tasas negativas y las políticas de promoción de incorporación de tecnología por parte del Estado (Giberti, 1988).

Las medidas estatales permitieron independizar al sector agropecuario de los vaivenes que su actividad pudiera sufrir en relación a bajas en los precios internacionales de los granos y a las condiciones climáticas, estabilizando la demanda del sector de equipos. El mecanismo en esencia fue la transferencia de recursos desde el Estado hacia el sector primario en forma de créditos subsidiados.

84 En 1972 se produce un estancamiento de la demanda de cosechadoras, que se revierte en el año siguiente, y el Estado subsidia algunas empresas para que no quiebren mediante créditos (Lajer, 2006)

${ }^{85}$ Algunos trabajos académicos hablan de factores relacionados con la estructura agraria, relacionado con el tipo de producción extensiva y otros trabajos lo relacionan con los tipos de políticas agropecuarias (ver Barsky, op cit.).

${ }^{86}$ Esta actividad demanda menor cantidad de equipos

${ }^{87}$ Se acelera la mecanización de la producción rural, se pasa de 21.500 tractores antes de la Segunda Guerra Mundial a 84.000 en 1960. Se sustituyó trabajo humano y animal pero no se aumentó la productividad por hectárea. Para cultivar una hectárea de trigo las horas hombre bajaron $73 \%$ y $83 \%$ para cultivar una hectárea de maíz entre 1930- 40 y 1960-65 según datos del INTA, a su vez un trabajo de la CEPAL indica que la producción media por hectárea es igual en ambos períodos (Giberti, 1988).

88 La falta de aumento de productividad por hectárea del sector sumada al aumento de la población, disminuyen los saldos exportables de productos agropecuarios. Estas irregularidades de tipo cíclicas en el sector agropecuario generaban crisis recurrentes en la balanza de pagos, debiendo el Estado devaluar y aumentar los precios internos para restablecer el superávit nacional. Es un período caracterizado por aumento de salario real, y disminución de las tasas de ganancia empresarial. Tipo de cambio alto. Con un crecimiento del PBI promedio del 6\% anual entre 1953 y 1974. 
Por otra parte, la excepcional aptitud agrícola de las tierras, seguía generando una elevada renta agraria, pese al bajo crecimiento de la productividad por hectárea. Esto desincentivaba, en parte, a los productores a incorporar cambios tecnológicos 89 que permitieran hacer de las explotaciones extensivas, explotaciones intensivas. Los productores agropecuarios eran superados en productividad por hectárea, por productores de Australia y Estados Unidos y esto generaba una erosión en la competitividad agraria local frente a los productores extranjeros. La tarea del INTA es destacada, por varios autores, como fundamental en la generación y difusión de las más eficientes prácticas productivas, que pese a la reticencia de los productores, poco a poco y en vista de los resultados, se incorporaron (Barsky, 1988). ${ }^{90}$

A partir del año 1965 se comenzó a verificar un cambio en el tipo de producción agropecuaria, se transformó la forma exclusivamente extensiva ${ }^{91}$ de producción con la incorporación de métodos de producción de tipo intensivo. La adopción masiva de maquinaria agrícola comienza a dar sus frutos, la productividad por hectárea se aproxima a la de Australia y Estados Unidos. Los cambios tecnológicos generaron, a su vez, aumento en el tamaño de las explotaciones medias, que buscaron conseguir rendimientos acordes a los requerimientos de la maquinaria agrícola. ${ }^{92} \mathrm{El}$ mayor uso de maquinaria agrícola y el aumento del tamaño de las explotaciones producen expulsión de mano de obra rural, incrementando también la productividad por trabajador.

Por otro lado, el sector productor de maquinaria agrícola sufrió, a partir de 1965 y hasta el año 1969, una caída de la demanda. Esta situación llegó al punto de generar grandes dificultades financieras en muchas de las empresas líderes. En este sentido, el Estado ayudó a recomponer las finanzas de dichas firmas a través de préstamos del Banco Nacional de Desarrollo. La situación se modificó, a partir de 1972, produciéndose un aumento de la demanda interna de maquinaria agrícola, con reposición, por parte de los productores y contratistas agrícolas, del equipamiento que había quedado obsoleto.

Las empresas de maquinaria agrícola tuvieron, en la década de 1960 y hasta mitad de 1970, un continuado aumento en sus exportaciones contando para ello con

\footnotetext{
${ }^{89}$ A nivel mundial se producía el cambio denominado revolución verde, que Argentina tardó en adoptar y nunca lo hizo completamente (Bisang, 2001).

90 Los cambios tecnológicos más importantes están relacionados con: semillas híbridas mejoradas de mayor rendimiento, supresión del rodeo equino (aumento de superficie disponible), utilización masiva de plaguicidas y herbicidas, y mecanización (Barsky, 1988).

91 Siempre se trata en esta tesis del sector agropecuario de la región pampeana.

92 Hay un aumento en el uso de los servicios de contratistas.
} 
apoyo estatal (subsidio directo que comenzó a ser importante a partir del año 1964) (Rougier, op cit.). La exportación constante y en aumento, durante este período fue un hecho novedoso para el sector. Dando muestras de cierta madurez y competitividad a nivel externo. ${ }^{93}$

Durante todo este período, se observó un crecimiento general de la economía, alternando con años de crisis, con caída del PBI, y principalmente del PBI industrial, debido a la recurrente restricción externa ${ }^{94}$ (se importa más de lo que se exporta). En 1975, se produjo una fuerte devaluación y una escalada inflacionaria de proporciones considerables. La devaluación benefició al sector agropecuario en sus ingresos por exportaciones, y pese a ciertos desequilibrios internos se mantuvieron los créditos para la compra de maquinaria agrícola, a tasa fija (y negativa) y con elevados niveles inflacionarios. Es entonces, que hacia 1977 se generó un récord de ventas de maquinaria agrícola debido al subsidio y transferencia de recursos desde el Estado, a través de la tasa real negativa en los créditos estatales (Huici, et al. op. cit.; Lajer et al. op. cit.; Lódola y Angelleti op. cit.).

A modo de síntesis podemos decir que la intervención estatal estructuró al sector y esto permitió sustituir el total de las importaciones del rubro. Los modos de regulación que se fijaron, a partir de 1945 y con posterioridad, tuvieron como objetivo obtener conductas microeconómicas destinadas a generar un cambio estructural en el aparato productivo del país.

Gracias a las capacidades adquiridas en el período previo al de sustitución de importaciones, fue factible desarrollar la industria sin grandes esfuerzos en transferencia de tecnología externa, compra de licencias o necesidad de inversiones de capital extranjero en producción, a excepción del segmento de tractores.

Las políticas de intervención estatal ${ }^{95}$ lograron, en cierta medida, despegar el efecto de elasticidad cruzada entre precios de los granos y maquinaria agrícola, que tuvieron una influencia muy fuerte, a partir de la desregulación de los mercados en épocas posteriores a la hasta aquí descripta.

\footnotetext{
${ }^{93}$ El subsector tractores pasó a exportar el 5,7\% de su producción en 1970-1972 y tuvo un punto máximo histórico del 19,4\% para el trienio 1973-75 (Huici, 1984). La magnitud que había cobrado la exportación de tractores en la primera mitad de los años setenta demostró la viabilidad de su producción, a pesar de ciertos atrasos tecnológicos que tenía al momento (Rancanello, 2010).

94 En estas crisis conocidas como "stop and go" los distintos gobiernos han optado por devaluar la moneda local para reestablecer el equilibrio externo.

95 Si bien el período 1955 a 1975 se caracterizó por inestabilidad política y macroeconómica, Schvarzer (1996) rescata como positivo el apoyo estatal de instituciones medias a la industria: compre nacional, oficinas sectoriales que establecían tarifas aduaneras, protección a los fabricantes locales amenazados por la competencia externa, normas técnicas con el mismo objetivo, una cantidad mayor de bancos que otorgaban créditos, además del Banco Nacional de Desarrollo.
} 
Es sustantiva, también, la intervención estatal en la introducción de mejoras de innovación productiva en el sector agrícola-ganadero. Esto permitió aumentar la productividad por hectárea y por trabajador. Gran parte del aumento de la productividad mencionada se debe indudablemente al mayor uso de la maquinaria agrícola. El Estado tiene, a demás, una participación activa en el desarrollo innovativo de productos necesarios para la cosecha y en la organización junto al capital transnacional de la importante industria del tractor.

Hacia el final de la década de 1970, Argentina pareció acceder al dominio de las industrias metalmecánicas de equipos agrícolas, una industria madura (fase 3 y 4 del paradigma tecno-económico96) que permitiría según Perez (2001) incorporarse al nuevo paradigma tecno-productivo vinculado a las tecnologías de la microelectrónica. El esfuerzo hecho hasta aquí tiene una "suma positiva", con empresas de capitales nacionales que alcanzaron estándares de internacionales de producto, con alguna distancia a la frontera tecnológica. Ciertos segmentos de producto y partistas quedaron en manos de empresas transnacionales, como tractores y motores. Tampoco se lograron desarrollar importantes economías de escala, ni incorporar tecnologías de procesos de producción (Bil, 2011), o mejor dicho se hizo de forma muy heterogénea.

A partir del golpe de Estado de 1976 comenzó un período de reestructuración para la economía en general y la industria en particular. Esta nueva etapa, que durará 25 años, tendrá características regresivas para la industria de capitales nacionales.

\subsection{Cambio regresivo estructural. Reestructuración de la industria}

En marzo de 1976, se produjo en la República Argentina un golpe de Estado y asumió el gobierno una junta militar que modificó el modo de regulación de la economía. ${ }^{97}$ Bajo el supuesto de que un Estado sobredimensionado con exceso de funciones, exceso de gastos e ineficiente y los altos salarios en la economía, generan inflación y distorsión en los precios relativos, se adoptaron cambios estructurales en la economía. Estos cambios intentaron desregular la economía y disciplinar a los trabajadores, quienes habían adquirido cierto poder a través de los sindicatos durante el período ISI (Industria por Sustitución de Importaciones). De acuerdo con ello, el gobierno militar decidió alentar una "economía de libre mercado", que el discurso

96 Ver Perez (2001)

${ }^{97}$ El régimen militar implementó medidas económicas bajo un fuerte control coercitivo de la sociedad. 
oficial aseguraba solucionaría los problemas económicos del país. En consecuencia, modificarán, de manera estructural, el modo de acumulación del capital: de una lógica productiva a una lógica financiera.

En torno a las medidas más relevantes que se dispusieron, se pueden mencionar las siguientes: la eliminación de los créditos a tasa fija y la introducción de la indexación como método de ajuste a los saldos de deuda. También, se redujeron aranceles $^{98}$ a la importación de bienes de capital y de consumo, no se alentaron desde el Estado, ni de forma directa ni indirecta, a las industrias que habían progresado en la fase anterior: maquinaria, equipos electrónicos, máquinas de oficina y de bienes de capital; se sustituyó su producción por importaciones (Neffa, 1996). Se liberalizaron los precios, se controlaron salarios ${ }^{99}$ y se apreció el tipo de cambio.

De esta manera, el gobierno incrementó las tasas de ganancia del sector privado, aunque de forma selectiva. ${ }^{100}$ Se liberalizó el sector financiero y se incrementaron las tasas de interés, generando condiciones de ganancias superiores en este sector que en el sector productivo. Este nuevo proceso de reformas económicas y políticas genera una gran inestabilidad macroeconómica, altas tasas de inflación, sucesivas devaluaciones, caída en la tasa de inversión, del salario, del crecimiento industrial ${ }^{101} \mathrm{y}$ del PBI global (Kosakoff y Ramos, 2005).

En este sentido, el nuevo rumbo de la política económica del país afectó el desenvolvimiento de la industria de maquinaria agrícola. A comienzos de la década de 1970 la demanda y fabricación de maquinaria agrícola tuvo un período de crecimiento, con índices récord de producción y de exportación, que terminó hacia el cuarto trimestre del año 1977. En consecuencia cambió el escenario para el sector productor de maquinaria agrícola, esto se aprecia de forma singular en la sugestiva cita que Rougier (2006:15) hace de Roque Vassalli ${ }^{102}$ para definir dicha época:

"En una oportunidad el entonces ministro Martínez de Hoz me concede una audiencia donde le expongo detalladamente las dificultades

\footnotetext{
${ }^{98}$ En promedio los aranceles bajan a nivel nominal del $94 \%$ al $53 \%$.

99 El poder sindical se redujo de forma ostensible, mediante la represión, la coerción y la regulación jurídica. Se suprimió el derecho a huelga, y se suspendieron los convenios colectivos de trabajo. Se fijaron topes máximos a los salarios menores a la inflación, la caída del salario real cae entonces de la siguiente manera: 1976 29,8\%, 1977 13,3\%, 1978 5,2\%.

100 Se promueve un grupo de ramas, de la actividad industrial, intensivas en recursos naturales con baja utilización de mano de obra capacitada, con tecnología de proceso continuo importada, con una alta relación capital trabajador. Privilegiando además por fuera del sector productivo, la renta financiera.

${ }^{101}$ En el sector industrial, los datos obtenidos de los censos 1974 y 1985, permiten evidenciar la desaparición de más de quince mil establecimientos industriales y la eliminación de casi doscientos mil puestos de trabajo.

102 Dueño de la principal fábrica de cosechadoras del país.
} 
del sector... me contesta que yo tengo la solución, ya que puedo importar directamente de mi planta de Brasil, y dejar de fabricar en mi planta de Argentina. Ante esa propuesta, le pregunto con asombro: ¿Usted me pide que yo le haga esto a mi país? ¿Y las divisas? ¿Y las fuentes de trabajo? Yo -me contestó- le doy las pautas de lo que conviene a la Argentina de hoy".

Por dichas razones, las medidas de desregulación y quita del estímulo estatal al sector provocaron, sobre los cuatro fabricantes de tractores del país (de origen extranjero), una caída de producción récord, de 22.000 unidades producidas en 1977 a sólo 3.000 unidades en 1981. En cuanto a la producción de cosechadoras, la misma disminuyó de 2.332 unidades fabricadas en 1977 a 312 unidades en 1981 (Huici, 1988). La quita del subsidio a las tasas financieras para la compra de equipos agrícola contrajo la demanda, sumado a ello, las medidas de apertura comercial externa desplazaron la oferta local. El gobierno militar bajó los aranceles a la importación de maquinaria agrícola, partes y componentes y flexibilizó en parte "el régimen de la industria del tractor", que impedía la importación de este tipo de maquinas y sus componentes casi en su totalidad.

La República Argentina, durante el período denominado ISI, no importó cosechadoras y en el corto lapso 4 años (1977-1980) compró en el exterior la tercera parte de lo demandado internamente. Estas importaciones evidenciaron cierto retraso tecnológico en la oferta de cosechadoras nacionales. Las firmas de capital nacional intentaron rápidamente, mediante rediseños, cerrar la brecha tecnológica con las máquinas importadas (García, 1999). Los decretos 3318/79 y 105/81 ampliaron, a su vez, los porcentajes para la importación de piezas de tractores, que incluyó motores completos (Lajer et al., 2006). De igual manera, se importaron tractores con características tecnológicas que las empresas instaladas en el país no ofrecían, con transmisión en las cuatro ruedas y mayor potencia (Huici op. cit.). Entre 1979 y 1982 el $23 \%$ de los tractores vendidos en el país eran importados, contra porcentajes mínimos de importación observados en los años inmediatamente anteriores.

El sector demandante de maquinaria agrícola, retrasaba la incorporación de equipos, debido, parcialmente, a la desaparición en los créditos a tasa negativa, con el agravante de que los precios de los granos tenían una fuerte caída desde la campaña 1976/77 ${ }^{103}$. El descenso en la demanda interna de equipos provocó la acumulación de

103 Los precios de los granos generados internacionalmente, establecen un efecto de elasticidad de ingresos cruzada con la maquinaria agrícola. Esto significa que ante un aumento de los precios internacionales de los granos aumenta la de manda de maquinaria agrícola y ante una caída de los precios internacionales de los granos sucede el proceso inverso con la demanda de maquinaria agrícola. 
stocks que generó incentivos para la exportación de tractores. Entre 1978 y 1981, se exportaron el $35 \%$ de la producción local (Lajer et al. op cit). Esto no era la consecuencia de una política de las empresas del sector de maquinaria agrícola, el tipo de cambio era desfavorable y no existía incentivo estatal que favoreciera este hecho, con lo cual se considera que fue una evidente respuesta a la acumulación de existencias y a la necesidad de liquidarlas por parte de las firmas.

A comienzos del año 1981, la situación económica del país instó al gobierno militar, a aumentar los aranceles de importación, que habían sido reducidos desde 1977, y a devaluar la moneda para recomponer el déficit del sector externo. Hacia 1983 el país se encontraba a la salida del gobierno de facto con serios inconvenientes de tipo político-económicos. El peso de la deuda externa ${ }^{104}$, la inflación, y el déficit fiscal ${ }^{105}$ serían algunas de las causas de la severa crisis de los ` 80 , década que se denominó la "década perdida".

El nuevo gobierno democrático heredó una deuda externa excesiva para la capacidad de pago del país. A su vez sucesivos ajustes no logró, a excepción de un breve período, controlar la inflación. Paralelamente se produjo una salida constante de divisas en concepto de servicios de la deuda. No obstante, el plan económico denominado por el gobierno "Plan Austral" generó, entre 1985 y 1987, un corto período de estabilidad: control de la inflación, aumento de salario real y control del déficit fiscal. Aunque, a finales de 1986 la balanza comercial se descompensó como consecuencia de una brutal caída de los precios de los granos y de un aumento de la actividad industrial, sector demandante de bienes de capital e insumos importados. Con la necesidad de restablecer el equilibrio en las cuentas externas, el gobierno devaluó la moneda. A partir de 1987 se aceleró la inflación y en consecuencia cayeron los salarios. Argentina encontró un nuevo período de "stop"106, ya no sólo por la restricción externa provocada por la estructura del aparato productivo, sino con el agravante de tener cumplir con los servicios de la deuda externa.

Mientras tanto, en el sector agropecuario, hacia mediados de la década de 1980, se producían avances y mejoras en semillas híbridas, y los productores se volcaban

De todas formas este proceso fue controlado (parcialmente) por el funcionamiento de la Junta Reguladora de Granos.

${ }^{104}$ La deuda externa alcanza en 1973-1976 los 8890 millones de dólares, en 1976-1983 45087 millones de dólares y en 1983-1989_ 65256 millones de dólares.

105 Existía en contrapartida superávit comercial, generado a partir de subas arancelarias a la importación y una devaluación del $420 \%$ en 1981.

106 Para comprender el concepto de "stop and go" al que aquí se hace referencia ver Schvarzer y Tavonaska (2008). 
hacia producciones de grano grueso (soja ${ }^{107}$ y girasol) de precios más altos. Los avances en las semillas implicaron una interdependencia mayor con agroinsumos y maquinaria más especializada (Barsky, 1988). Se produjo, entonces, un cambio cultural casi decisivo en los productores, que paulatinamente incorporaron un modo de producción más intensivo. Esto supone, a su vez, una constante capitalización de las explotaciones agropecuarias.

La industria de maquinaria agrícola en 1982 verificó una suba en las ventas, que Huici (op. cit.) explica a través del impulso generado por los grandes contratistas y productores en la reposición de equipos, demandando máquinas de gran porte ${ }^{108}$ (tractores con mayor potencia, por encima de los $100 \mathrm{cv}$ y cosechadoras con cabezales más anchos). Una vez que se satisfizo la reposición de la maquinaria que había quedado obsoleta, la demanda cayó nuevamente, acompañada además, por un descenso en los precios de los principales granos, con lo cual su caída se hizo más pronunciada (ver cuadro $\mathrm{N}^{0} 1$ ).

El sector agrícola tuvo, en la primer mitad de la década de 1980, un período de aumento de producción con subas moderadas en los precios internacionales de los cereales y se llegó al récord de producción de 44 millones de toneladas de granos en la campaña 1984/85. Esto fue consecuencia de cambios tecnológicos importantes en las formas de producción. Los principales cambios tecnológicos se observaron en las mejoras de la calidad de las semillas y también, en la intensificación del uso de maquinaria agrícola a través de contratistas (Obstchako, 1988; Pereira, 1988). Los contratistas son difusores de los cambios tecnológicos, con un mayor conocimiento aplicado a los cultivos ${ }^{109}$ y son, además, demandantes sofisticados de maquinaria. En este sentido, hubo un aumento en las dimensiones de las explotaciones agropecuarias (eaps.), esto es efecto del aumento de la cantidad de prestadores de servicios agropecuarios que trabajan tierra ajena (Lódola, et al. op cit.) y a su vez, aumentan las necesidades de mayor potencia y dimensiones de labor en los tractores y cosechadoras.

\footnotetext{
107 En Argentina las primeras plantaciones de soja se hicieron en 1862, pero no encontraron eco en el campo argentino. En 1909 se comenzó a ensayar en distintas áreas agrícolas argentinas el cultivo de la soja, pero recién para 1965 se intensificaron los trabajos de investigación sobre el tema. Si bien los resultados fueron buenos, el cultivo no logro obtener difusión entre los productores hasta entrado los años 1970 y comienzos de los 1980 (Reca, 2006). Se convierte en una producción relevante en la década de 1990.

${ }^{108}$ Esta modificación hacia equipos más grandes los marcan Huici (1988) y Giberti (1988) como patrón de cambio.

109 Es un ejemplo el cultivo de la soja de segunda, que necesita una serie de manejos, de inoculantes y herbicidas que los productores no poseen, se delega entonces en los contratistas el cultivo de verano reservándose el de invierno los dueños de la tierra (Lódola et al. op cit.).
} 
Como dato saliente del período a comienzos de la década (1981), se incorporó al mercado la empresa Zanello de capitales nacionales, ingresó en el segmento de tractores, produjo equipos grandes de más de $100 \mathrm{cv}$ y tracción en las cuatro ruedas $^{110}$ (Huici, 1988). Rápidamente esta empresa se posicionó como líder del mercado, desplazando a las filiales de las empresas transnacionales. Esto se puede explicar a partir de la captura de mercado que hace la empresa de la demanda insatisfecha, en tractores de alta potencia y con tracción en las cuatro ruedas, que queda luego de cerrarse la importación de tractores (suba de aranceles y devaluación de la moneda). La empresa Zanello produjo equipos poseedores de estas características, que hasta entonces no se habían producido en el país (ni siquiera por las filiales extranjeras). La firma fue creada en 1951 como empresa metalúrgica, pero al momento de comenzar a producir tractores ya había recorrido la senda evolutiva de aprendizaje como empresa productora de maquinaria vial, siéndole relativamente sencillo producir tractores e innovar en el sector ${ }^{111}$. Hacia 1985, Zanello integró la producción de sus propios motores, transmisiones, bombas de inyección de combustible y bombas de agua. En relación al mercado internacional, además de la venta de unidades a países limítrofes, Zanello firmó un acuerdo de producción y transferencia de tecnología de sus productos con la firma americana Steiger (actualmente Case), con el fin de exportar tractores hacia Estados Unidos y Canadá. Al ser uno de los pocos tractores articulados de potencia media y alta, Steiger (empresa estadounidense) demandó 600 unidades a Zanello, siendo comercializados bajo el modelo PUMA (Rancanello, 2011).

En términos generales, la dinámica tecnológica de la fabricación de tractores resulta de la interacción de los avances técnicos con el sistema agronómico en el cual se utilizan, proceso que se traduce en la acumulación de experiencia en los procesos de adopción y adaptación de la tecnología. Esto explica que durante el período sustitutivo de importaciones se consolide en Argentina una trayectoria tecnológica específica a un sistema de explotación caracterizado por la fuerte heterogeneidad de

\footnotetext{
110 Zanello, una empresa metalmecánica de Las Varillas Córdoba, se posiciona primero en la venta de tractores en el mercado interno. Este tipo de tractores se importaba durante el breve período de apertura entre 1978 y 1981. Zanello se incorpora como una empresa líder en el oligopolio mantenido por las empresas trasnacionales. Se suman también dos empresas más que tendrán una producción muy poco relevante.

111 Aquí hacemos referencia a la idea sobre las barreras a la entrada de Caves y Porter (1977). Esta manifiesta que frente a la incertidumbre que supone ingresar a un segmento de mercado (con características oligopólicas) que le es ajeno a la firma, la estrategia es la entrada gradual. Esto permite realizar aprendizajes sobre las condiciones internas y externas de la competencia, generar sus propias ventajas y reducir los costos irreversibles. Debemos aclarar que la firma entrante tiene "cercanía" productiva con el mercado donde quiere entrar.
} 
establecimientos y el predominio de las producciones agropecuarias extensivas. En respuesta a las características y tamaños de las explotaciones agrícolas de la pampa húmeda, las unidades producidas presentaron una menor complejidad técnica que las de los países desarrollados y una potencia superior a media a la de los países subdesarrollados, que se tradujo en una alta potencia a bajo costo (Lavarello, Gutman y Langard, 2009). ${ }^{112}$ Este es un rasgo de especificidad local que favorece los desarrollos tecnológicos endógenos a un sistema nacional.

Ahora bien, a partir de la campaña agrícola 85/86 cayeron los precios internacionales de los granos, que generaron, pese al cambio tecnológico en la producción agrícola, una crisis en el sector agropecuario de proporciones; según un trabajo de CEPAL citado por Giberti (1988) los comodities (cereales, metales y petróleo) tuvieron, en este período, los precios más bajo desde 1890. Es en entonces, que como consecuencia de la crisis de bajos precios se produjo: por un lado, caída en la producción agrícola con disminución en las superficies sembradas y por otro lado, un aumento de la implementación de soluciones tecnológicas como estrategia para mitigar la disminución en las ganancias, con un consecuente aumento de productividad (Obschatko, 1988; 1992; Pereira, 1988). Si bien, hubo un mayor uso de insumos como fertilizantes y agroquímicos (Reca y Parellada, 2001), no hubo un aumento en la demanda de maquinaria agrícola, muy por el contrario tendió a descender. Como se observa en el cuadro $\mathrm{N}^{\circ} 3$ y N 4 a partir de 1984, luego de picos de demanda, cayó, la venta de cosechadoras $75 \%$ y la de tractores un $50 \%$.

Cuadro №3 Producción, ventas al mercado interno y externo de tractores, expresado en unidades. Durante la década de 1980

\begin{tabular}{|c|c|c|c|c|}
\hline Año & Producción & Venta & Exportaciones & Importaciones \\
\hline 1980 & 3658 & 5212 & 818 & 1502 \\
\hline 1981 & 1359 & 3227 & 273 & 1547 \\
\hline 1982 & 3826 & 4407 & 647 & 780 \\
\hline 1983 & 8286 & 8145 & 5 & 598 \\
\hline 1984 & 12322 & 12920 & 41 & 185 \\
\hline
\end{tabular}

112 Esto originó una línea de tractores con características locales: tracción simple, con pocas aptitudes hidráulicas, toma de potencia no independiente, tractores de mas de $120 \mathrm{CV}$ con TDP de 540 r.p.m. (característica única en el mundo), marchas no sincronizadas, cabinas no originales, etc., lo que posibilita una alta potencia de bajo costo (Bragachini, et al, 2002) 


\begin{tabular}{|c|c|c|c|c|}
\hline 1985 & 6377 & 5683 & 247 & 172 \\
\hline 1986 & 8056 & 6661 & 923 & 155 \\
\hline 1987 & 3114 & 2551 & 635 & 187 \\
\hline 1988 & 5075 & 5116 & 126 & 591 \\
\hline 1989 & 4295 & 4786 & 215 & 600 \\
\hline Promedio & $\mathbf{5 6 3 6 , 8}$ & $\mathbf{5 8 7 0 , 8}$ & $\mathbf{3 9 3}$ & $\mathbf{6 3 1 , 7}$ \\
\hline
\end{tabular}

Fuente: elaboración propia en base a Romero Wimer (2010)

El cuadro $\mathrm{N}^{0} 3$ exhibe algunas características de mercado y producción de la industria del tractor, durante la década de 1980, con muy pronunciadas variaciones de producción y ventas de año a año. Por otro parte, nos permite observar el nivel de capacidad ociosa y la baja proporción de exportaciones, que trabajaba el sector durante los años en que disminuían las ventas. Era posible, entonces, que el oligopolio transnacional en una estrategia de market seeking (ver Dunning, 1993), extrajera ganancias en forma rentísticas, a partir del dominio del mercado interno protegido. Situación, que era avalada por un Estado laxo, que no exigía mayores esfuerzos de exportación, que mejorase los déficits del comercio externo y que permitiera aumentar la eficiencia de sus plantas industriales. Las exportaciones tuvieron un rasgo particular que quedó expresado muy claramente a partir del año 1983, y es que figura como liquidación de los remanentes de producción. No fue un proceso estable, ni en aumento, con ello se quiere expresar que existió, en esta década, una estrategia o vocación exportadora. Es por ello que se deduce que las 4 empresas transnacionales que operaban en el mercado argentino, obtenían rentas oligopólicas, que les permitían sostener notables deseconomías de escala.

Cuadro No4 Producción, ventas al mercado interno y externo e importaciones de cosechadoras en unidades. Durante la década de 1980.

\begin{tabular}{|c|c|c|c|c|}
\hline Año & Producción & Venta & Exportaciones & Importaciones \\
\hline 1980 & 490 & 670 & 90 & 245 \\
\hline 1981 & 356 & 400 & 16 & 8 \\
\hline 1982 & 1457 & 1480 & 6 & 77 \\
\hline
\end{tabular}




\begin{tabular}{|c|c|c|c|c|}
\hline 1983 & 1976 & s/d & 4 & 9 \\
\hline 1984 & 1806 & 1700 & 3 & 1 \\
\hline 1985 & 875 & 920 & 0 & 0 \\
\hline 1986 & 700 & $s / d$ & 4 & 0 \\
\hline 1987 & s/d & s/d & 3 & 3 \\
\hline 1988 & s/d & s/d & 52 & 199 \\
\hline 1989 & s/d & s/d & 11 & 247 \\
\hline Promedio anual & 1094 & 1034 & 19 & 79 \\
\hline
\end{tabular}

Fuente: elaboración propia en base a Romero Wimer (2010)

El subsector de cosechadoras tuvo, hasta este período, diferencias notables con el segmento de producción de tractores. En primer término, el mercado interno argentino fue abastecido por empresas de capital nacional, este es un dato no menor si pensamos que es el equipo tecnológicamente más complejo ${ }^{113}$. En este sentido, es llamativo la falta de análisis existente en la literatura especializada al respecto. Por otra parte, durante los períodos de apertura del gobierno de facto se hicieron explícitos algunos retrasos tecnológicos pero, que fueron, a su vez, rápidamente resueltos por la industria local. La alta propensión a abastecer únicamente el mercado interno, que tuvo el segmento de cosechadoras, con una baja capacidad exportadora expresa cierta debilidad de competitividad. Esto puede ser explicado en parte por la baja escala de planta, que poseían estas empresas, se debe considerar que para un promedio de 1000 equipos por año existían 14 firmas. En este sentido vemos que, en esta década (1980), continuó la concentración de la producción, proceso que comenzó en la década de 1960, y se profundizó en la década de 1990.

Salvo ciertas excepciones, la cosechadora fabricada en el país fue diseñada en respuesta al sistema agronómico local ${ }^{114}$. El segmento tuvo un fuerte impulso desde el

\footnotetext{
113 Las cosechadoras autopropulsadas son equipos complejos debido a la cantidad de componentes que debe armonizar en una tarea que no sólo es el corte del cultivo. Sistema motriz: generalmente sistema hidrostático con caja de cambios manual, el sistema se encarga de desplazar la cosechadora. Mecanismo de corte: dependiendo del cultivo a recolectar se utiliza uno u otro cabezal, es el encargado de cortar el cultivo y transportarlo hasta el siguiente mecanismo. Mecanismo de trillado: se encarga de desmenuzar la espiga para separar de ella el grano a base de revoluciones. Mecanismo de limpia: usa un ventilador de aire se encargan de separar los granos de partes menos pesadas y de polvo, el sistema de cribas separa el grano de partes más gruesas. Sistema de transporte y almacenaje: mecanismos encargados de transportar el grano limpio hasta la tolva normalmente por sinfines al depósito de grano, donde permanecerá hasta que sea descargado a un remolque para transportarlo.

114 Las cosechadoras nacionales fueron construidas con un concepto de eficiencia en la trilla, separación y fundamentalmente en la limpieza del grano, sin demasiado énfasis en la capacidad de recolección,
} 
Estado, durante la etapa ISI ${ }^{115}$, con varios objetivos: mecanizar la producción agrícola y aumentar su productividad; subsanar la escasez de mano de obra en el agro, principalmente en el cultivo de maíz y desarrollar la industria de bienes de capital. El volumen de producción de cosechadoras estuvo, de esta forma, asociado a la demanda del mercado interno, alcanzando un máximo de producción, a principios de los '60, de 2500 unidades anuales, para disminuir a 1600 unidades anuales en la década del '70 (García, 1998) y llegó a 1000 en 1980.

En el cuadro $\mathrm{N}^{\circ} 5$, se observa que el número de establecimientos aumenta entre 1976 y 1984, y se exhibe, a su vez, una disminución en el número de empleados. Una explicación posible, deducida del cuadro, es que para el año 1984, sólo aumenta la cantidad de establecimientos de implementos agrícolas, que son en su mayoría PyMEs familiares, de pequeñas dimensiones. Podemos inferir, también, en un contexto general de la industria, que existieron modificaciones estructurales en los procesos de producción que permitieron a las firmas prescindir de mucha mano de obra.

Cuadro $N^{\circ} 5$. Estructura de la industria de maquinaria agrícola argentina (1976 -1990)

\begin{tabular}{|c|c|c|c|c|c|}
\hline Año & $\begin{array}{c}\text { Cant. de } \\
\text { empl. }\end{array}$ & $\begin{array}{c}\text { Estab. que } \\
\text { producen } \\
\text { tractores }\end{array}$ & $\begin{array}{c}\text { Estab. que } \\
\text { producen } \\
\text { cosechadoras }\end{array}$ & $\begin{array}{c}\text { Total de estab. } \\
\text { de maquinaria } \\
\text { agrícola }\end{array}$ & $\begin{array}{c}\text { Cant. promedio } \\
\text { de empleados } \\
\text { por establ. }\end{array}$ \\
\hline 1976 & 54.000 & 5 & 13 & 370 & 146 \\
\hline 1984 & 12.943 & 7 & 13 & 424 & 30 \\
\hline 1990 & 9.611 & 7 & 10 & 235 & 41 \\
\hline
\end{tabular}

Fuente: Elaboración propia a partir de Huici (1988), CAFMA, CIDETER, y García (1999).

Gran parte de la bibliografía especializada coincide en que la década de 1980 se caracterizó por la presencia de un elevado grado de incertidumbre; relacionado con desajustes a nivel macroeconómico nacional, que afectaron, principalmente, el

\footnotetext{
capacidad de tolva y equipamiento. Dentro de las ventajas de las cosechadoras nacionales se destacó el bajo mantenimiento y la sencillez de adaptación a condiciones extremas de trabajo. Dentro de las desventajas, en las cosechadoras anteriores a los 90 , se puede mencionar la baja capacidad de trabajo, la ausencia de variador de cilindro, el inadecuado diseño de tolvas con baja capacidad, la baja ergonomía del puesto de conducción, el inadecuado diseño de los cabezales flexibles para la recolección de soja, el poco desarrollo de elementos de regulación para disminuir pérdidas (Bragachini, et al, 2002)

115 La etapa ISI que transcurrió durante 40 años, aproximadamente, tuvo cierto comportamiento homogéneo con algunas diferencias marcadas en el cuerpo del texto.
} 
financiamiento del sector. Sumado a ello, fue un período de bajos precios internacionales de los granos, con la excepción de unos pocos años en toda la década (Baruj, et al. op. cit.; Chudnovsky y Castaño op. cit.; García, op. cit.).

En los datos del cuadro $N^{0} 5$ se observa que efectivamente la década de 1980 fue un período desfavorable para toda la industria de maquinaria agrícola, en el que se tendió a reducir la cantidad de empleos y el número de establecimientos (muchos de los que sobrevivieron a la década de 1980 desaparecieron en la década posterior). La cantidad total de establecimientos en 1990 es apenas un poco más de la mitad de los de 1984. Se produce un proceso de concentración de la oferta de maquinaria agrícola, con crecimiento de empleo por empresa. Este proceso de concentración se produce, también, en el segmento de cosechadoras con el retiro del mercado de tres empresas. Queremos destacar el caso de Senor, una de las tres empresas que cierra, por ser emblemática en el país por su larga trayectoria en la producción de cosechadoras y ser pionera en varios desarrollos.

Por otro lado, la década de 1980 fue el comienzo del cambio tecnológico en la forma de producción agrícola. Los productores agrícolas, concentrados en su mayoría en cinco cultivos: soja, trigo, girasol, maíz, sorgo; adoptaron reformas productivas en la búsqueda de aumentar las certidumbres, que evitaran la alta vulnerabilidad frente a los ciclos de alzas y bajas en los precios internacionales de los granos (Obstchako, 1988; 1999; Pereira 1988). Los cambios tecnológicos más importantes, del período fueron: el uso de semillas mejoradas (híbridos), proceso que comienza a partir de mediados de 1970, la lenta adopción de la labranza "cero" del suelo (siembra directa) a fines de 1980, a finales de 1980 y comienzos de la década del 1990, aumentaron el uso de agroquímicos y ya mediados de la década de 1990, se introdujo el uso de semillas genéticamente modificada (Bisang, 2004; Reca y Parellada, 2001).

Todos estos cambios, si bien estuvieron asociados casi exclusivamente a una articulación fuerte entre la industria química (bioquímica) y los productores agrarios, necesitaron, también, un correlato directo en la industria de maquinaria agrícola. En este sentido, se comenzó, a finales de la década de 1980, la fabricación de las primeras sembradoras de siembra directa y como corolario aumentó la demanda de las pulverizadoras de arrastre. A su vez, las fábricas de tractores adaptaron paulatinamente los equipos, a la necesidad de una mayor potencia de arrastre, como consecuencia de sembradoras más grandes y al aumento en el uso de pulverizadoras con tanques y botalones también más grandes. 
Definitivamente estas modificaciones tecnológicas ayudaron a mejorar los ingresos de los productores agrícolas, como ejemplo de ello se puede mencionar la incorporación del doble cultivo trigo - soja, la soja como cultivo de verano y el trigo de invierno, es posible de estos cambios, ahora, obtener dos cosecha por año (con modificación en el tipo de semillas de trigo utilizadas de ciclo más corto). El cultivo de soja se incorporó en la matriz agrícola productiva argentina de manera paulatina, y tiene como característica que, respecto del trigo, encierra mayores riesgos en cuanto a la posibilidad de obtener un buen rendimiento; y necesita, a su vez, de una superior dotación de maquinaria (Lódola y Fossati, 2003, y Lódola et al., op cit.) o por lo menos de distintas características.

Uno de los cambios tecnológico de uso y de manejo del suelo más importante que comienza en la década de 1980, fue el pasaje del sistema agronómico convencional al de siembra directa. La forma de producción bajo siembra directa tiene como principal ventaja aparente dar solución al desgaste de nutrientes del suelo. Pero más allá de ello, el cultivo fue gradualmente incorporado por los productores por su bajo costo operativo ${ }^{116}$. A partir de estos cambios comienzan a tener mayor relevancia dos tipos de maquinaria, la sembradora y la pulverizadora, que en la bibliografía están generalmente considerados de manera agregada en el segmento de implementos agrícolas.

En resumen, la década de 1980 signada por la inestabilidad macroeconómica mostró como resultado el deterioro de las capacidades financieras de las empresas y como corolario comenzaron profundos cambios en la matriz tecnológica de producción agraria. Fue, también, una novedad importante de este período la incorporación al mercado de maquinaria agrícola de una empresa nacional de tractores de importancia. La nueva década tendrá como novedad las transformaciones en los modos de regulación económica, la profundización del sistema agronómico de siembra directa, y las modificaciones estratégicas de las empresas transnacionales.

\subsubsection{Profundización de la desestructuración productiva}

A fines de la década de 1980 se produce un cambio de gobierno y con él, una serie de cambios de regulación de tipo económica e institucional. La moneda local se fijó en paridad cambiaria al dólar estadounidense (\$1 = U\$S 1), se bajaron los

\footnotetext{
116 Más adelante se profundizará sobre el estudio del sistema de siembra directa y su incidencia en la maquinaria agrícola.
} 
aranceles a la importación, se privatizaron los servicios públicos ${ }^{117}$ y a mediados de la década se conformó el MERCOSUR. Las tasas de interés fueron superiores al nivel internacional durante toda la década, propiciando la valorización financiera vis a vis la inversión productiva.

Estas medidas generaron el control definitivo de la inflación, y como consecuencia en la primer mitad de la década, también, suba de salarios reales. La suba nominal de salarios se condicionó luego por ley a aumentos de productividad. Los sindicatos pierden fuerza de negociación frente al nuevo escenario regulatorio, y entonces los salarios reales tienden a caer a lo largo de la década (Reca y Parellada, 2001).

En el sector agropecuario se implementaron medidas dirigidas a desregular los mercados, medidas largamente proclamadas por parte del sector. En la primer mitad de la década la situación del sector agropecuario mejoró con respecto a la década pasada, pese a que el promedio de precios agrícolas es un $20 \%$ más bajos. Hacia la segunda mitad de la década, los precios internacionales de los granos subieron, para luego de la campaña 96/97 tener una abrupta caída (Reca y Parellada, 2001). La desregulación de los mercados agropecuarios implicó la desaparición de las juntas reguladoras (con la consecuente supresión de los impuestos sobre la producción agropecuaria para financiar dichos entes ${ }^{118}$ ), se eliminaron las retenciones a la exportación, y los aranceles a la importación de insumos y equipos. Estas medidas de desregulación que beneficiaron mucho al sector agropecuario en ciclos de precios en alza, lo perjudicaron gravemente en el declive de los mismos (Reca y Parellada op cit.).

Los cambios tecnológicos, ya mencionados, en los sistemas de producción agrícola se profundizaron durante esta década. La siembra directa, se complementó a partir de 1995 con semillas transgénicas asociadas a biocidas, esto marcará las pautas de la nueva forma de producir granos en Argentina.

El sector productor de maquinaria agrícola comenzó la década con una cantidad de empresas muy inferior a los establecimientos que existían a mediados de la década de 1980 (ver cuadro № 5). Las empresas que no cerraron en la década de 1980, quedaron, muchas de ellas, en una situación financiera delicada (Rougier, op cit.).

117 Los servicios públicos privatizados poseen ventajas sobre otros sectores, tienen la posibilidad de ajustar tarifas por la inflación estadounidense, mientras que la industria tiene la imposibilidad de trasladar aumentos de costos (dichos servicios) a precios, debido a que compite con productos extranjeros (con una moneda local sobrevaluada).

118 También se modificó la fuente de financiamiento del INTA, ya no era financiado a partir de las exportaciones de productos agropecuarios, sino que pasaba a depender del Tesoro Nacional. 
Nuevamente los establecimientos que variaron, en un número importante, fue el de implementos agrícolas (ver cuadro $\mathrm{N}^{0} 5$ ). La situación fue parecida para la industria de cosechadoras, en 1990 existían 10 firmas y hacia 1993 sólo quedaban 3 establecimientos. Hubo dos fenómenos que derivaron en el cierre de 7 de las 10 fábricas de cosechadoras durante este período. El primero de ellos fue el rezago tecnológico de la maquinaria y la incapacidad de las firmas nacionales para adaptar rápidamente sus productos. La demanda de equipos se volcó hacia máquinas con cabezales más anchos, potencia superior a $260 \mathrm{cv}$. y mayor capacidad de tolva características que poseían los equipos importados y los nacionales no (Bragachini, et al. 2002). El segundo factor que contribuyó a la desaparición de muchos fabricantes nacionales de cosechadoras, pero que afecto a toda la industria en general, fue el nuevo régimen de regulación macroeconómica. La apertura unilateral con la baja de aranceles a la importación de bienes de capital a nivel cero ${ }^{119}$ (Chudnovsky y Rever, 1999), junto con el régimen de tipo de cambio fijo $^{120}$, y la privatización de los servicios $^{121}$, provocaron serios desajustes en el sector. El gráfico № 1 explicita la transformación del mercado de equipos en Argentina, en el cual se sustituyó maquinaria nacional por importada, que como se observa comenzó en la década de 1990 y se profundizó en la de 2000.

Indudablemente, la década de 1990 significó para el segmento de cosechadoras un cambio de época. La apertura comercial ("en desventaja") frente al oligopolio internacional de empresas, que posee fuertes economías de escala y mejoras tecnológicas sustanciales, fueron determinantes para el subsector.

\footnotetext{
119 Se baja el arancel a cero con un reintegro del 15\% para el descuento en la venta de los bienes de capital producidos en el país, reintegro que tardó en instrumentarse, y en 1996 se elimina el reintegro manteniendo el arancel cero (Chudnovsky y Rever, 1999).

120 Durante el período de 1991 a 2001 el peso argentino se apreció considerablemente con respecto a sus dos principales socios comerciales: Brasil y EE.UU. Tomando como referencia el Índice de Tipo de Cambio Efectivo Real (ITCER), que considera la inflación de cada país y el valor de la moneda de cada país (Reca y Parellada, 2001).

121 Los servicios privatizados ajustaban sus tarifas en relación a la inflación de Estados Unidos, los productores de bienes en argentina competían con productos de todo el mundo con menores precio (muchas veces de dumping). Esto implicaba que a la industria le aumentaba los costos sin poder trasladarlos a sus productos.
} 
Gráfico No1. Evolución del mercado nacional de cosechadoras. Ventas de cosechadoras en unidades. Período 1990 - 2011

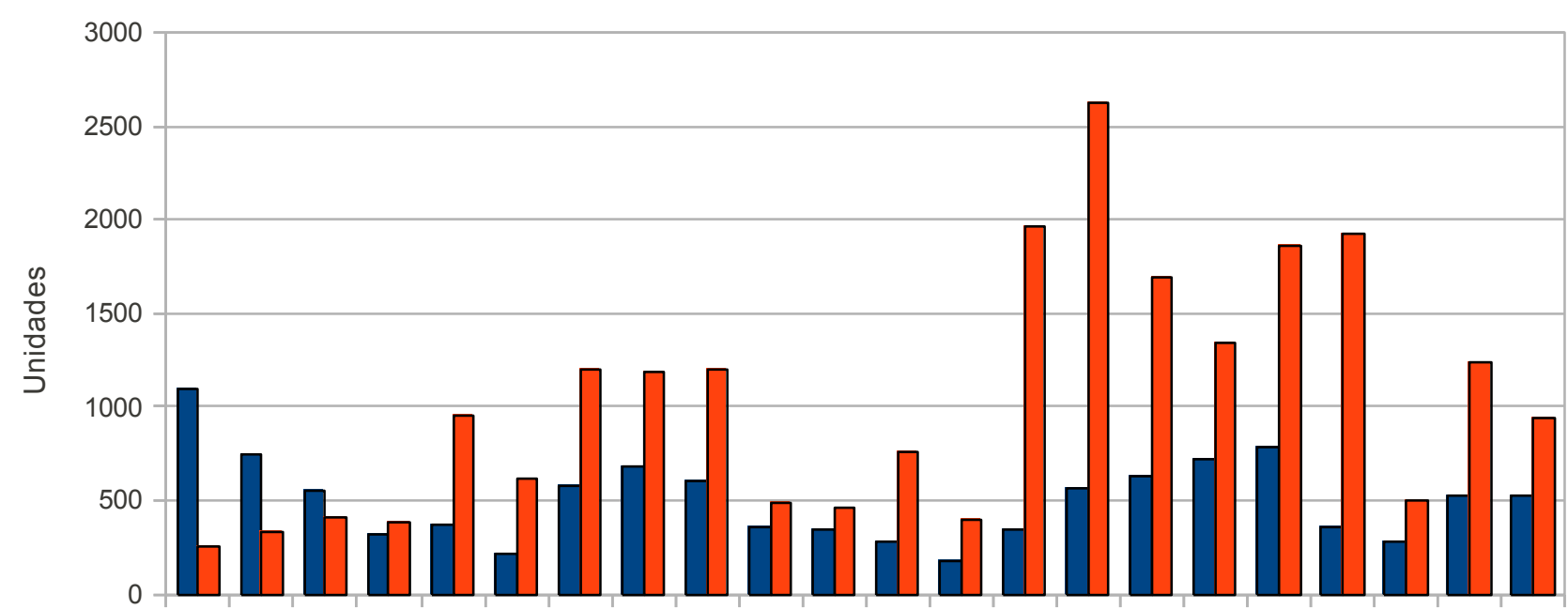

1990199119921993199419951996199719981999200020012002200320042005200620072008200920102011

Años

Cosechadoras nacionales $\square$ Cosechadoras importadas

Fuente: INDEC (2012) y Romero Wimer (2010)

De forma similar, en el cuadro $n^{\circ} 4$, se observa la evolución de la producción local de tractores y de las importaciones de tractores, como así también las ventas en el mercado interno y las exportaciones.

Cuadro $N^{\circ}$ 6. Producción, venta, exportación e importación de tractores en el país, en unidades. Período 1990 - 1999

\begin{tabular}{|c|c|c|c|c|}
\hline Año & Producción & Venta & Exportaciones & Importaciones \\
\hline 1990 & 6135 & 4615 & 22 & 600 \\
\hline 1991 & 3739 & 3250 & 46 & 289 \\
\hline 1992 & 4298 & 4051 & 71 & 543 \\
\hline 1993 & 3830 & 4411 & 42 & 550 \\
\hline 1994 & 4642 & 5637 & 101 & 1733 \\
\hline 1995 & 3490 & 3800 & 73 & 1187 \\
\hline 1996 & 5681 & 7380 & 81 & 2858 \\
\hline 1997 & 4631 & 7559 & 30 & 3514 \\
\hline
\end{tabular}




\begin{tabular}{|c|c|c|c|c|}
\hline 1998 & 3513 & 5826 & 208 & 3676 \\
\hline 1999 & 1673 & 2770 & 465 & 1059 \\
\hline Promedio anual & $\mathbf{4 1 6 3}$ & $\mathbf{4 5 3 3}$ & $\mathbf{1 1 4}$ & $\mathbf{1 6 0 1}$ \\
\hline
\end{tabular}

Fuente: elaboración propia en base a datos de: AFAT, CAFMA, INDEC y Romero Wimer (2010).

La producción de tractores, en la década de 1990, tuvo una tendencia declinante en relación a la década anterior. Este proceso se agudizó hacia el final del decenio y no se detuvo hasta el año 2002. Dicha tendencia tuvo sus razones en la reestructuración productiva de las firmas trasnacionales establecidas en el país, desde la década de 1950 (Baruj et al., 2006; García, 1999; Heybel, 2005). Todas las empresas transnacionales ${ }^{122}$ que hasta 1997 produjeron tractores en el país ya no lo hacen en el año 2000, sólo quedó produciendo Zanello, empresa de capitales nacionales, en Las Varillas, Córdoba. John Deere y Deutz ${ }^{123}$ mantuvieron en el país la producción de motores e importaban los tractores completos, mayoritariamente desde sus plantas en Brasil. Como se observa en el cuadro $N^{\circ} 6$, aumentaron las importaciones a partir del año 1994 que reemplazó poco a poco la producción nacional. Hacia el año 1998, el porcentaje de tractores importados en relación a las ventas totales era del $63 \%$. El mercado de tractores, al igual que el de cosechadoras, se encontró, en un lapso corto de tiempo, abastecido por compañías transnacionales con importaciones desde Brasil ${ }^{124}$. Por otro lado, se produjo, desde Argentina, un aumento de las exportaciones, en los dos últimos años de la década de 1990 como reacción a la caída en las ventas del mercado interno, pero no política de las compañías sino como estrategia coyuntural de realización de existencias.

Nos permitimos aquí introducir el gráfico $\mathrm{N}^{\circ} 2$, en el que se observa con claridad la transformación del segmento de tractores durante la década de 1990 y la de 2000.

\footnotetext{
122 John Deere, Deutz, Massey Ferguson, Agritec.

${ }^{123}$ Deutz es parte del grupo Agco dueño de las marcas Agco, Massey Ferguson, Valtra entre otros, en el año 2006 se vuelve a instalar como empresa fabricante integral de tractores en Rosario.

124 El $50 \%$ de las importaciones de tractores y cosechadoras provinieron de Brasil. (Balance económico de la Bolsa de Comercio de Córdoba, 2011).
} 
Gráfico № 2. Producción nacional e importación de tractores, en unidades. Período 1990 $-2008$

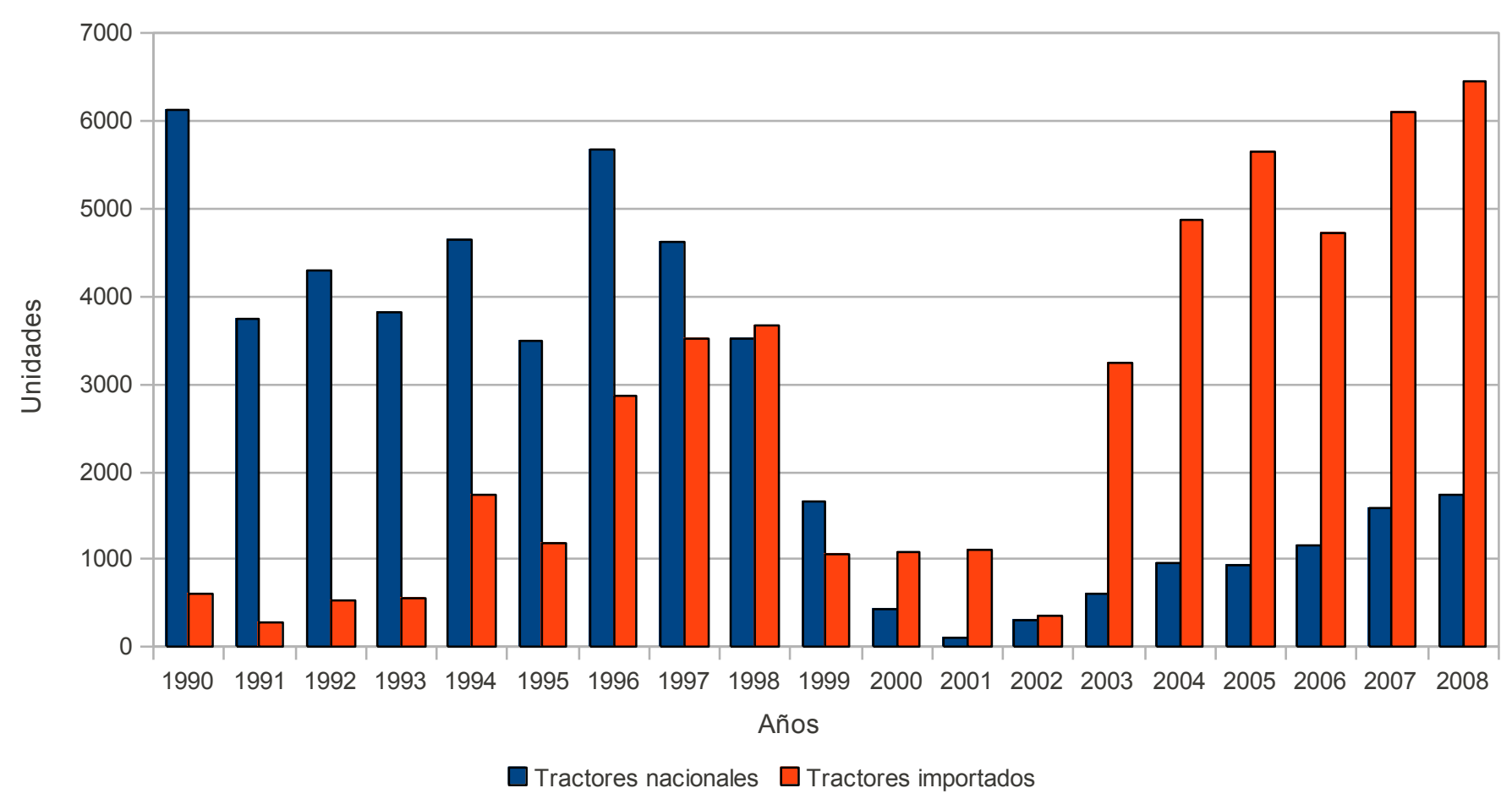

Fuente: INDEC (2012) y Romero Wimer (2010)

La crisis en la que se ve sumida la producción de maquinaria agrícola, en la década de 1990, afectó de manera diferente los distintos segmentos de producción. Si bien todos los rubros disminuyeron su producción hacia finales de la década de 1990, algunos se vieron más afectados que otros. La producción de tractores y cosechadoras tendió a desaparecer en el país, con el cierre de la totalidad de los establecimientos.

La situación del segmento de cosechadoras y tractores expresó claramente la estrategia del capital transnacional sobre el territorio nacional y regional. En los años de la década de 1980, las empresas transnacionales de maquinaria agrícola, al igual que en el resto de las actividades, inician, a nivel global, un pasaje de estrategias mercado internistas a estrategias de racionalización en el marco de la reconfiguración de la mundialización del capital (Lavarello, 2004) reduciendo su capacidad productiva local. En la década del '90, las empresas transnacionales organizaron la producción y la comercialización a partir de la conformación de un mercado interno ampliado (MERCOSUR), esto se produjo en el marco de una creciente 'globalización' del mercado mundial de maquinaria agrícola. El aumento de la utilización de piezas y partes importadas y la reducción de la utilización de la capacidad instalada en las plantas locales, llevó a una desarticulación de la red de contratistas locales 
conformada durante las décadas de 1960 y 1970, con la consiguiente reducción de los niveles de ocupación en la industria (ver cuadro № 5) (Lavarello, Gutman y Langard, 2009).

En el caso del segmento de implementos agrícolas, algunos de ellos como sembradoras y pulverizadoras, mantuvieron niveles estables de producción en los años más difíciles de la crisis (ver gráfico $\mathrm{N}^{\circ} 5$ ) y comenzaron a separarse del comportamiento generalizado del sector. Veamos a continuación gráficamente el comportamiento de la industria de maquinaria agrícola, durante la década de 1990.

El gráfico $\mathrm{N}^{0} 3$ nos permite observar la evolución de parte importante de la industria de maquinaria agrícola durante la década de 1990. Por un lado, el sostenido aumento de la producción de pulverizadoras y sembradoras y por otro lado, la disminución de la producción nacional de tractores y cosechadoras. El año 1990 mostró una estructura productiva que podríamos llamar "tradicional", donde el segmento del tractor dominaba el mercado, en segundo lugar se ubicaban las cosechadoras y, luego, el resto de los implementos un escalón por debajo. La década de 1990 es el punto de inflexión, en el que la estructura productiva se modifica pasando a ocupar un lugar predominante sembradoras y pulverizadoras (de arrastre y autopropulsadas).

Grafico $N^{\circ} 3$. Producción de maquinaria agrícola en la década de 1990, en unidades. Desagregada por segmento

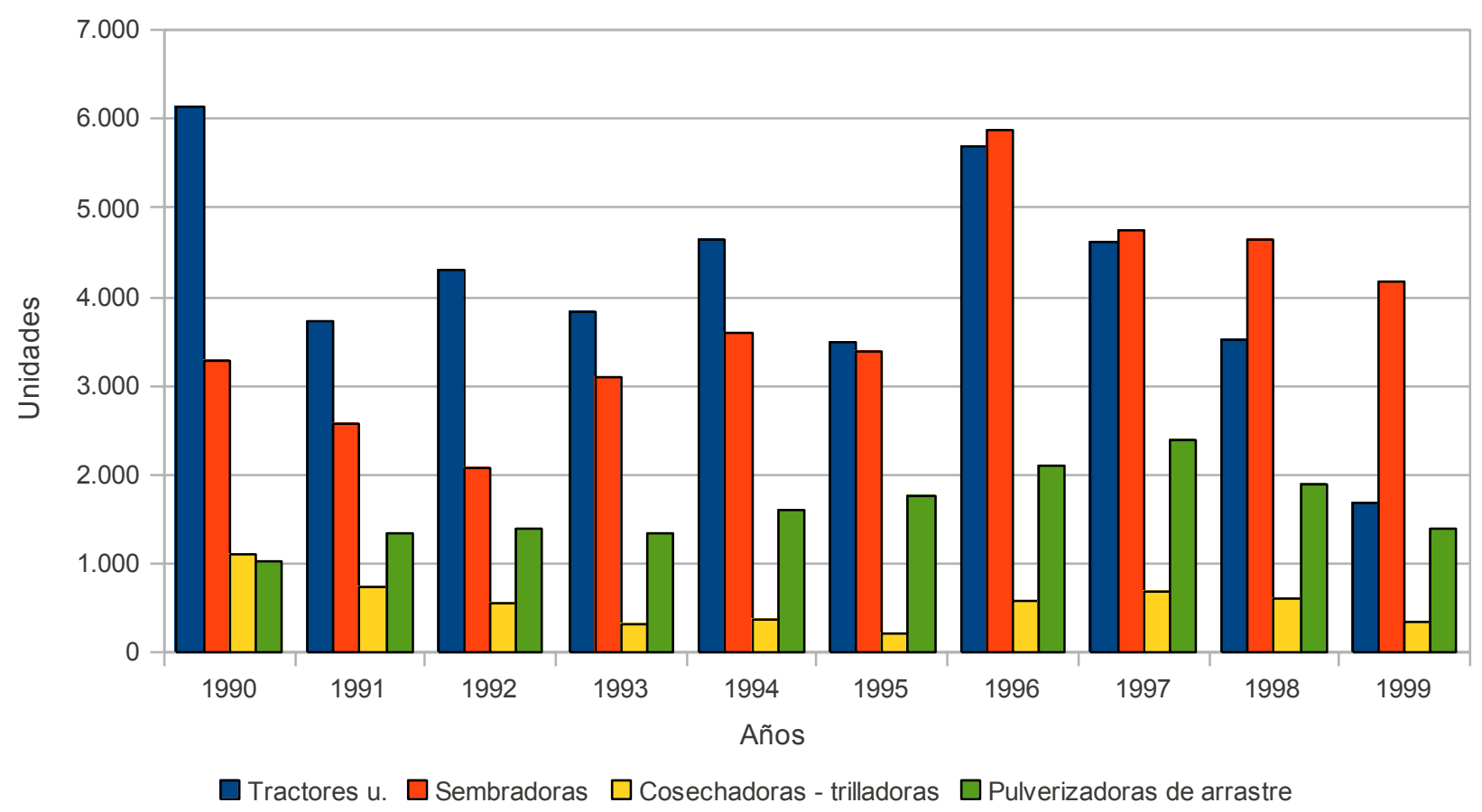


Fuente: elaboración propia en base a INDEC (2012).

Las empresas de cosechadoras, como ya dijimos, comenzaron una crisis de producción antes de 1997, el cierre de 7 de las 10 plantas existentes en 1990 fue el punto de partida de la crisis de estas fábricas. A partir del año 1993, la proporción de máquinas cosechadoras importadas supera a las de producción nacional, acentuándose el déficit en los períodos de expansión de la demanda. Finalmente en el año 2000 sólo continuaba produciendo Vassalli SA, en Firmat, Santa Fe. Las empresas de tractores, en su mayoría transnacionales, deslocalizan su producción de Argentina y abastecen el mercado interno desde sus plantas de Brasil, Estados Unidos y Europa. Para el año 2000 sólo continuaba produciendo tractores, Zanello la firma de capitales nacionales de Las Varillas, Córdoba.

Hacia el final de la década (año 1998), el país se encontraba en una recesión económica que afectaba a todos los sectores sin distinción, sumado a ello caían los precios internacionales de los principales granos de exportación de Argentina. La crisis perjudicó al conjunto de la industria de la maquinaria agrícola, pero cada segmento de mercado acorde a los distintos tipos de productos ya mencionados tuvo diferentes conductas. Las compañías de tractores, en su mayoría filiales de empresas transnacionales, se vieron afectadas por una reestructuración-racionalización, que sus casas matrices implementaron a nivel global. Sembradoras y pulverizadoras, no disminuyeron su producción de manera tan severa.

En el gráfico $\mathrm{N}^{0} 4$ se muestra la relación de la venta de algunos equipos con los precios de dos de los cultivos más importantes del país. De esta forma se intenta establecer los lineamientos para la explicación del funcionamiento heterogéneo del mercado de equipos agrícolas.

Gráfico $\mathrm{N}^{\circ} 4$. Venta de tractores, de cosechadoras, y sembradoras vinculadas al precio internacional en pesos (llevados a valores del 2008) del trigo y la soja. 


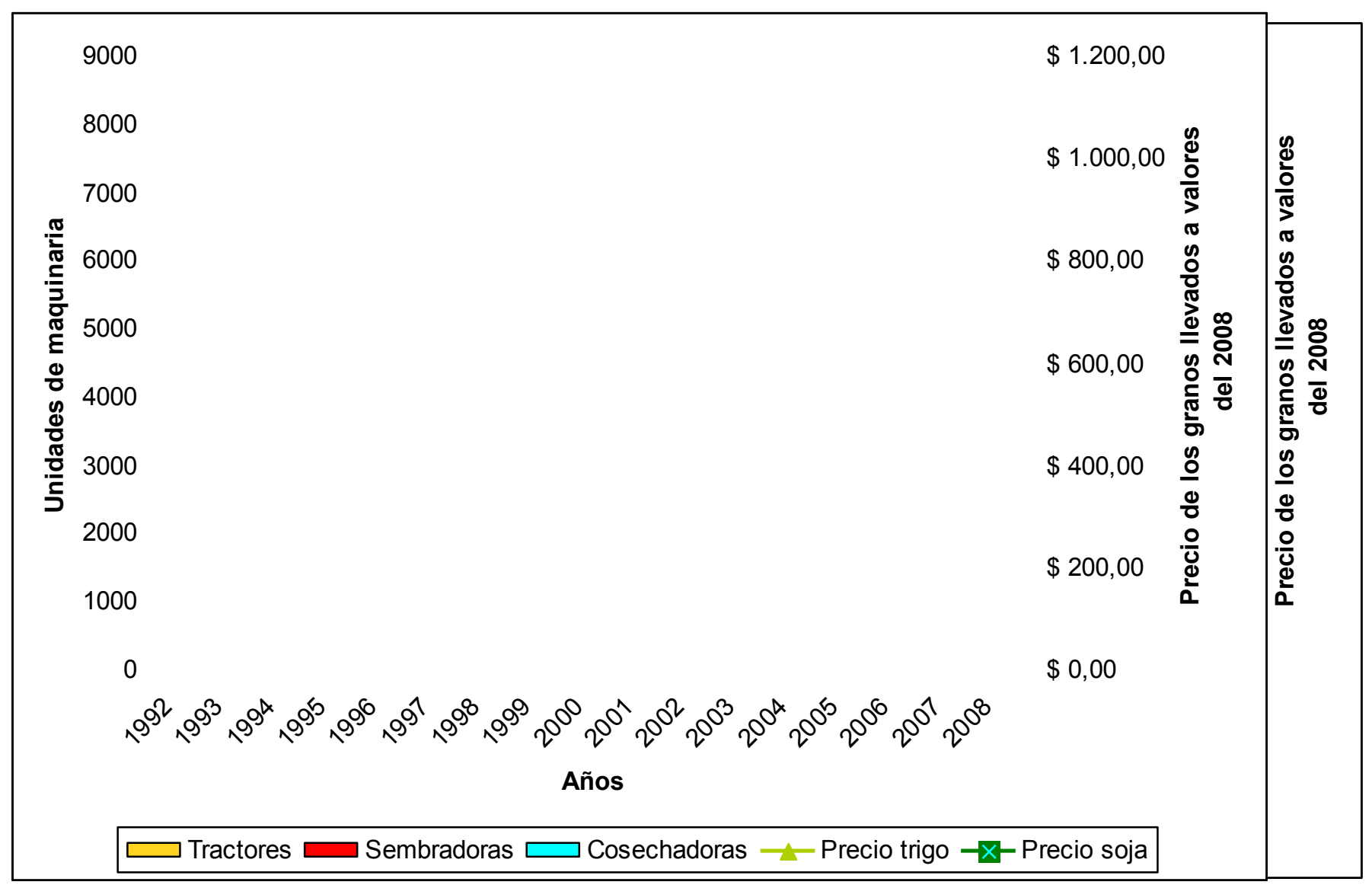

Fuente: INDEC (2012) y Ministerio de Agricultura, Ganadería y Pesca (2012).

En el gráfico $\mathrm{N}^{0} 4$ se puede observar un proceso de elasticidad cruzada de precios $^{125}$ de granos y maquinaria agrícola con ciertas particularidades. Una de ellas es que el mercado de sembradoras se aisló del ciclo de precios internacionales de granos y de la recesión de los años 1998 - 2002, a partir de la profundización del sistema de siembra directa (conjuntamente con el paquete tecnológico semilla transgénica y biocidas). Los equipos de sembradoras en los períodos de fuertes caídas de precios mantuvieron su producción, situación que quedó especialmente explicitada entre los años 1997 y 1998 y entre los años 2002 al 2005. Esto nos habla de una profundización de la inversión en tecnología de siembra directa por parte de los productores agrícolas, que se vieron favorecidos por los menores costos de producción (operativos), esto les permitió aumentar los márgenes de ganancia.

En síntesis, como resultado de las transformaciones que afectaron a la industria de maquinaria agrícola cambió la estructura productiva, ya no se producen tractores en las filiales de empresas transnacionales en el país, las empresas nacionales de

${ }^{125}$ Cuando el precio de los granos sube la cantidad de equipos agrícolas vendidos también lo hace y cuando los primeros bajan de la misma forma actúa la demanda de equipos agrícola. 
cosechadoras no acaparan el mercado local con su producción (sólo sobrevive una) y los implementos agrícolas, como sembradoras y pulverizadoras, adquirieron un peso mayor en la estructura de ventas y producción del sector. Esto último motivado por el cambio en el método agronómico de siembra. A partir de comienzos de la década del 2000 , se produce una nueva modificación del marco regulatorio. El próximo segmento ilustra los cambios de regulación referidos y su impacto sectorial en la industria de maquinaria agrícola.

\subsection{Nuevo proceso de sustitución de importaciones}

La situación general de la macroeconomía comienza a cambiar a comienzos de 2002. En ese año se dio por terminado con el plan de convertibilidad, se devaluó fuertemente la moneda ${ }^{126}$ nacional y se cesó el pago de la deuda externa. La economía argentina, luego de cuatro años de recesión (1998 - 2002), cobró nuevo impulso. Creció la inversión en capital fijo, el empelo y el PBI, desde el segundo semestre de 2002 hasta 2010 inclusive ${ }^{127}$ (CEP, 2012). El salario128 real disminuyó como consecuencia inmediata de la devaluación, para tener luego una gradual recuperación. Tanto el sector externo como el sector público tuvieron superávit en sus cuentas y la inflación se mantuvo dentro de márgenes aceptables (Kosakoff y Ramos, 2005). En cuanto a políticas focalizadas, que afectaron a la industria de maquinaria agrícola, se debe mencionar que en el año 2001 se volvió a instrumentar, por parte del Estado, la devolución del 15\% del valor por máquina vendida para todos los bienes de capital (medida que aún no se ha derogado, 2014).

La salida de la convertibilidad, que se produjo a principios del año 2002, generó un nuevo escenario. Una de las medidas que más favoreció a los industriales fue el freno a las importaciones que significó la modificación del tipo de cambio (de $\$ 1=$ U\$S 1 a U\$S 1 = \$3). Otra medida importante en el plano económico fue la pesificación "asimétrica": las deudas se "licuaron", es decir por cada 1 dólar prestado se devuelve 1 peso129 más un coeficiente de ajuste que nunca superaba en total los 2,5 pesos.

\footnotetext{
${ }^{126}$ El Estado también retiene los ahorros bancarios de la población convirtiéndolos en bonos a 10 años.

127 Con excepción del año 2009

${ }^{128} \mathrm{Al}$ respecto, debe tenerse presente que el incremento registrado en el tipo de cambio trajo aparejados múltiples resultados. En primer lugar, y fundamentalmente, determinó una brusca y directa contracción en los ingresos de los trabajadores en dólares y como producto de ello, una importante disminución en los costos salariales, consecuentemente, un incremento de los márgenes brutos de rentabilidad empresarial.

129 Siendo que los exportadores del sector agropecuario reciben por cada dólar, tres pesos, restándosele en promedio, un $20 \%$, por retenciones a las exportaciones.
} 
Esto generó en los productores agropecuarios un sustancial alivio sobre sus deudas. La capacidad de capitalización, de los productores agropecuarios aumentó sin dudas con estas medidas, viéndose reflejada en la demanda de maquinaria ${ }^{130}$ sobre todo hasta el año 2008, cuando se registró un importante período de crecimiento.

En el período comprendido entre los años 2002 y 2010 se produjo un aumento sostenido de los precios de los granos, llegando en el año 2008 al récord histórico de U\$S 600 la tonelada de soja. La industria de maquinaria agrícola crece como se ha dicho, pero en un nuevo escenario, el aumento de los precios de los granos, la devaluación de la moneda nacional y la obsolescencia de los equipos son causas simultáneas que permitieron dar impulso renovado a la demanda de maquinaria agrícola.

Por su parte, la recuperación de la demanda en tractores y cosechadoras se abasteció con importación (ver gráficos $n^{\circ} 3$ y $n^{\circ} 4$ ), de empresas transnacionales mayoritariamente instaladas en Brasil. Los equipos de sembradoras y pulverizadoras vendidos en el país fueron en su mayoría de origen local, producidos en las provincias de Santa Fe y Córdoba (INDEC, 2010).

La demanda de equipos continuó en aumento durante toda la década de 2000 con excepción del año 2009. Por otro lado, hay una profundización del modelo agrotecnólogico que necesita de insumos como fertilizantes, herbicidas, semillas transgénicas y también de equipos especiales de maquinaria agrícola, que permiten mejorar las tasas de ganancia.

Cuadro $N^{\circ} 7$. Estructura de la industria de maquinaria agrícola argentina (1993 -2008)

\begin{tabular}{|c|c|c|c|c|c|}
\hline Año & $\begin{array}{c}\text { Cant. de } \\
\text { empl. }\end{array}$ & $\begin{array}{c}\text { Estab. que } \\
\text { producen } \\
\text { tractores }\end{array}$ & $\begin{array}{c}\text { Estab. que } \\
\text { producen } \\
\text { cosechadoras }\end{array}$ & $\begin{array}{c}\text { Total de estab. } \\
\text { de maquinaria } \\
\text { agrícola }\end{array}$ & $\begin{array}{c}\text { Cant. promedio } \\
\text { de empleados } \\
\text { por establ. }\end{array}$ \\
\hline 1993 & 6197 & 7 & 3 & 229 & 27 \\
\hline 1997 & 6200 & 6 & 2 & 220 & 28 \\
\hline 2008 & 26000 & 7 & 4 & $436^{*}$ & 60 \\
\hline
\end{tabular}

${ }^{130} \mathrm{El}$ productor en relación a su moneda, que es el cereal con plan canje, puede comprar en el 2003 un $40 \%$ más de máquinas con referencia a la época de la convertibilidad. Otra aclaración que puede explicar el incremento de la inversión en maquinaria es la alta capacidad de endeudamiento de productores y contratistas por la licuación de pasivos, realizada por la salida de la convertibilidad (Bragachini et al. 2003), tampoco se debe desconocer el retraso y obsolescencia que se verificaba por la imposibilidad de invertir de los productores agropecuarios. 
* El número total de establecimiento no incluye los agropartistas, si lo hiciese el número llegaría a 837 firmas.

Fuente: elaboración propia en base a: CAFMA, CIDETER, García (1999), Albornoz et al. (2010).

A partir del cuadro $N^{0} 7$, podemos decir que el sector retoma un sendero de crecimiento que lo acerca al mejor año, 1974 (ver cuadro № 5). El Consejo Federal de Inversiones (CFI), en el año 2004, contabilizaba alrededor de 650 empresas en esta industria (incluyendo agropartistas), hacia el año 2008 se considera que existen 436 firmas, y 837 empresas si se incluyen las fábricas agropartistas (CAFMA; CIDETER, 2008). Si se compara 1997, con 220 compañías contabilizadas, año previo a la crisis (recesión económica 1998-2002), con el año 2008, observamos que hacia este último año hubo un crecimiento importante de empresas y empleo, con algunas características que nos parece importante mencionar.

A partir del año 2002, empresas como Metalfor, Pla, Marani-Agrinar, Pauny $\mathrm{SA}^{131}$, Abati-Titanium, San Vicente Agrícola (Bernardín), Apache comenzaron a producir una gama amplia de equipos. Todas estas empresas pertenecen a pequeñas localidades del interior de las provincias de Córdoba, Santa Fe y Buenos Aires a excepción de Marani - Agrinar que tiene ubicación en Rosario y Córdoba Capital.

En el cuadro $\mathrm{N}^{\circ} 8$, se intenta mostrar que existió una rápida respuesta de las empresas de maquinaria agrícola en cuanto las condiciones de mercado se modifican. Esto es posible gracias al capital humano de la región que conserva capacidades tecnológicas creadas en más de 80 años de producción y desarrollo. Esta respuesta se puede asociar, también, al carácter pequeño y mediano de las firmas, que supone una mayor flexibilidad de adaptación a los distintos escenarios. Por otro lado, vemos en el cuadro $\mathrm{N}^{\circ} 8$ que estas empresas tienen, como parte de su estrategia productiva, el desarrollo de economías de alcance o de variedad.

${ }^{131}$ Pauny SA y Marani- Agrinar producen maquinaria vial y Pauny además produjo mini buses. 
Cuadro $\mathrm{N}^{\circ}$ 8. Detalle de la diversificación de productos de algunas empresas argentinas

\begin{tabular}{|c|c|c|c|c|c|}
\hline Empresas & Tractores & Sembradoras & Pulverizadoras & Cosechadoras & Otros \\
\hline Pauny SA & $\mathrm{X}$ & & $X$ & & $X$ \\
\hline Metalfor & $x$ & & $x$ & $x$ & \\
\hline Pla SA & & $\mathrm{X}$ & $X$ & & \\
\hline Apache & $X$ & $\mathrm{X}$ & $X$ & & \\
\hline $\begin{array}{l}\text { Agrícola San } \\
\text { Vicente (Bernardín) }\end{array}$ & $x$ & & & $x$ & $X$ \\
\hline Abatti - Titanium & $x$ & $\mathrm{X}$ & & & \\
\hline Marani-Agrinar & $x$ & & & $x$ & $x$ \\
\hline
\end{tabular}

Fuente: Elaboración propia en base a las páginas de Internet de las empresas e información periodística.

Se intuye que dicho esfuerzo, lo hacen las firmas nacionales para resolver las deseconomías de escala bajo las que trabajan, en parte, por ello diversificaron su producción. Esta diversificación les permite transitoriamente mantener su parte del mercado pero al costo de mayores deseconomías de escala en desarrollos de proceso, producto y tiempos unitarios. Se genera así un círculo vicioso que ante la pérdida de mercado resultante de los mayores costos vis a vis las importaciones, las empresas diversifican y aumentan los costos unitarios. La sustentabilidad de la producción local depende en gran medida de la evolución del tipo de cambio y de la explotación de aquellos segmentos en los cuales la especificidad de la demanda justifica la compra de equipos locales.

Estos limitantes de escala serán gradualmente superados en la medida que se desarrollen economías de alcance (scope) que posibiliten ofrecer una gama variada sin aumentar los costos unitarios. Dichos cambios requieren un avance en la modularidad, esto es la realización de diseños con el concepto de familias de máquinas donde entre un modelo y otro compartan la mayor cantidad de componentes y subconjuntos posibles. Estas economías de alcance internas pueden generalizarse, en la medida que se extiendan entre fabricantes de un mismo rubro nacional y regional a partir del desarrollo de normas de productos. Algunas empresas locales se 
encuentran avanzando en esta dirección, aumentando la exportación de componentes, partes y subconjuntos (Gutman, Lavarello y Langard, 2009).

En este sentido la empresa Pauny SA desarrolla una estrategia de diversificación (no es la única) a partir de generar muchos modelos de tractores de diferentes potencias (de $120 \mathrm{hp}$ a $310 \mathrm{hp}$ ), pero con la misma transmisión, evitando así, tener que producir tantos tipos de trasmisiones ${ }^{132}$ como modelos de tractores; algunos modelos de esta firma tienen la transmisión sobredimensionada otros la tiene adecuada y otros la tienen "justa". Por otro lado, en una estrategia de mercado Raúl Giai Levra, presidente de Pauny SA, declara con respecto a uno de los productos más importantes de la empresa, el tractor articulado que:

"Si bien es un nicho pequeño dentro del mercado nacional de tractores, el (tractor) articulado fabricado es muy competitivo. Sucede que las multinacionales no fabrican sus modelos articulados en Brasil y lo tienen que traer de Estados Unidos, lo que lo convierte en extrazona y lo encarece" (La Voz de las Varillas 06/05/11).

Son estrategias que tienen un alto componente local de explotación y que deberán ser utilizadas de cierta forma que permita superar la competencia.

Ahora bien, si tomamos el caso del segmento de cosechadoras, existe un mercado interno restringido para las cuatro empresas que fabrican estos productos. Compiten con las máquinas extranjeras a partir de precio en nichos de mercado por prestaciones y/o calidad. Los equipos de producción nacional son clase 4, 5, 6 y 7 con potencias que van de 180 a 214 hp, de 215 a $267 \mathrm{hp}, 268$ a $322 \mathrm{hp}$ y de 323 a $374 \mathrm{hp}$, respectivamente y tres de las cuatro empresas tienen la opción de cilindros de trilla de tipo axial (INTA, 2009). En los últimos 10 años (2002-2011), hubo un promedio de ventas de 1808 equipos por año, de las que 432 fueron nacionales, a un precio promedio por unidad de equipos nacionales de 394.000 pesos contra 776.000 pesos de los equipos importados (INDEC, 2012). Dentro de las 4 empresas nacionales existe una, Vassalli Fabril S.A. que ha ampliado su capacidad de producción recientemente a 800 máquinas por año, mientras que las otras no superan la producción de 100 cosechadoras por año. Es decir que si se cerrara la importación no sería factible cubrir el mercado interno. La empresa con mayor capacidad también es la única dedicada únicamente a la producción de cosechadoras.

132 El tractor es una máquina con un tiro central de energia hidraúlica, que para poder arrastrar ciertos implementos es necesario que la caja de marchas y diferencial resistan. Es por esto que la transmisión es importante, ya que es una parte central del tractor y de su funcionamiento. 
Por su parte las empresas transnacionales ofrecen máquinas clase $6,7,8$ y 9 , desde Brasil, aunque las clase 8 y 9 son importadas muchas veces desde Estados Unidos y Alemania desde la casa central directamente. Existen diferencias de escala y de productividad entre las firmas nacionales y las extranjeras, que son barreras en la expansión y en la acumulación de capital de las firmas locales. Pese a ello, la empresa Vassalli Fabril SA vendió ${ }^{133}$ el desarrollo tecnológico de su modelo de cosechadora axial $A X 7.500$ a la quinta firma transnacional en ventas, la italiana Same Deutz Fahr, a la cual le transferirá el "know how"134. Esto muestra una capacidad de la firma no acorde a las condiciones de una empresa en un país periférico.

El presente análisis pone en evidencia que la industria nacional tiene fuertes potencialidades para el desarrollo de la actividad. No obstante, el desenvolvimiento del sector debe ser acompañado de una política, que garantice el mercado interno a las compañías nacionales y estimule la internacionalización de estas firmas, a partir de un fuerte incentivo a los desarrollos locales.

En este sentido, el uso de la siembra directa, más las semillas transgénicas y los biocidas dan una nueva especificidad local a la maquinaria, en relación a ello a continuación profundizamos sobre los cambios agronómicos de producción y la repercusión que esto produjo en el mercado de equipos agrícolas.

\subsection{Cambios en el manejo agronómico de la siembra y su incidencia en el mercado de maquinaria agrícola}

Durante largos períodos, los tractores representaron el $45 \%$ del valor en las ventas de maquinaria agrícola, las cosechadoras un $15 \%$ e implementos el otro $40 \%$ (Huici, 1988). Actualmente los datos de 2011, nos muestra que los tractores representan el $23,4 \%$ del valor vendido en maquinaria agrícola, las cosechadoras el $24 \%$, e implementos el $52,6 \%$ restante, de este último porcentaje las sembradoras son el $24,5 \%$, casi la mitad (INDEC, 2012).

Este cambio y diferenciación en los distintos segmentos de la industria de maquinaria agrícola se pueden explicar a partir de los cambios en el manejo agronómico de la siembra, cambios en las características de los productores agropecuarios, y cambios en el tamaño de las explotaciones (Baruj et al, op cit.;

133 A su vez, Vassalli tendrá la exclusividad en América y Africa. Díaz explicó a Clarín Rural que, en principio, el aprovisionamiento para Europa y Asia representaría la exportación de una decena de máquinas durante 2009.

134 En: http://www.clarin.com/suplementos/rural/2008/11/08/r-01798285.htm 
Heybel,op cit., Lódola et al. op cit.). Todas las modificaciones están relacionadas en mayor o menor medida, como vimos, por el nuevo método agronómico de siembra.

El menor uso del tractor en la siembra directa se expresa en la nueva estructura del mercado. El tractor disminuyó la cantidad de horas de uso entre un $30 \%$ y un $50 \%$, en función del menor laboreo de la tierra (Bragachini, 2003; Ambroggio 2004), pero necesariamente aumentó su potencia para traccionar las nuevas sembradoras y pulverizadoras mucho más grandes y pesadas.

La siembra directa se realiza con sembradoras especiales, las cuales depositan la semilla en el suelo sin labrarlo. Estas sembradoras surgen como un segmento independiente del de implementos agrícolas, adquieren una importancia creciente en el sistema agrícola nacional y tienden hacia una mayor complejidad tecnológica (Heybel, op cit; Bragachni et al. 2006), ello se refleja en su precio que ya en el año 2005 supera en promedio al precio de los tractores (INDEC, 2012).

Las pulverizadoras de arrastre y autopropulsadas (al igual que las sembradoras), tienen un uso mucho más intensivo en el cultivo por siembra directa, este tipo de siembra, actualmente, es constantemente asistido con fertilizantes y herbicidas.

El gráfico $N^{0} 5$ muestra la penetración que tuvo la siembra directa en Argentina destacándose bajo este sistema el cultivo de soja, que a partir de mediados de 1990 incorporó a la siembra directa el desarrollo tecnológico de la soja transgénica, tolerante al herbicida glifosato. Esto produce un aumento de productividad por hectárea muy grande, en momentos en que el precio de la soja es creciente y por lo tanto la cantidad de hectáreas dedicadas a este cultivo también se amplía. La producción de este cultivo, en la campaña 1993/94 fue de 11,4 millones de toneladas, en la campaña 2004/05 fue de 38,3 millones de toneladas y en la campaña 2009/10 fue de 52,7 millones de toneladas (INDEC, 2012). La producción de soja se multiplicó casi por 5 entre 1993 y 2010, estimulada por los precios internacionales de este producto, no obstante, fue posible su crecimiento por el aumento de la productividad debido a los avances tecnológicos $\mathrm{y}$, a su vez, al desplazamiento de otras producciones, como así también al avance en la frontera agrícola. 
Grafico $N^{\circ} 5$ : Difusión de la siembra directa en cantidad de hectáreas (1990-2008)

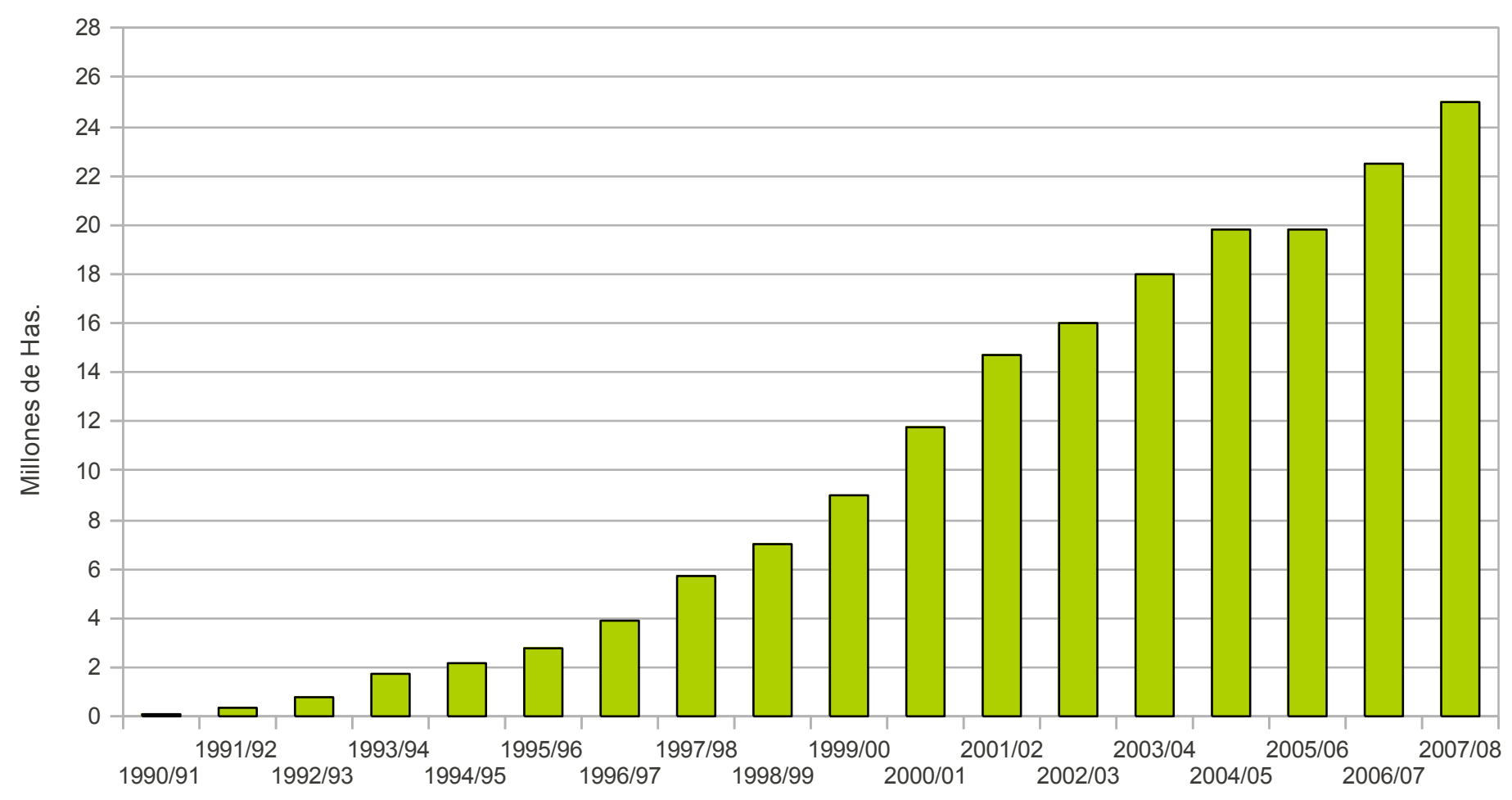

Campañas

Fuente: APRESID 2012

El nuevo sistema agronómico de siembra directa más semillas transgénicas tolerantes a herbicidas necesita un nuevo sistema de maquinaria agrícola (Heybel, op cit.). Este nuevo tipo de mecanización del agro se apoya en sembradoras, pulverizadoras, cosechadoras que distribuyen correctamente el residuo y tractores más potentes. Los cambios técnicos derivaron en menores costos por unidad de tonelada producida, pero costos mayores por hectárea, con predominio de aumentos de gastos fijos ${ }^{135}$. El costo operativo es más bajo que el del sistema convencional, pero tiene un costo inicial muy grande que no todos los productores pueden afrontar; intensificándose el uso de los servicios agropecuarios (Lódola et al., 2005), este

\footnotetext{
135 Por otra parte y por efecto de los precios relativos, la soja y el doble cultivo trigo-soja se expandieron, con aplicación masiva de agroquímicos, maquinaria de mucha mayor precisión, siembra directa y transgénicos, provocando profundos cambios en las formas de producción y en la mayor dependencia del capital y la cobertura de riesgos. Por otro lado aumenta el uso de los "contratistas" por parte de los productores dueños de la tierra o directamente se la alquilan a ellos, los contratistas son el $65 \%$ de la demanda de MA del país.
} 
proceso disminuye la cantidad de explotaciones ${ }^{136}$, con lo cual se genera un aumento de la concentración de la producción agropecuaria (Giberti, 2003).

"Al considerar el movimiento en conjunto de los precios y la producción primaria (además de los otros factores que operaron en la misma dirección) se desprende que en forma heterogénea, aún el sector agrícola ha sido beneficiado con un aumento en sus ingresos, fenómeno que motivó fuertes inversiones en el sector" (Lódola et al, 2005:34)

Cuando en el año 1997 los precios internacionales caen bruscamente, el sector agropecuario, altamente endeudado, ya había inmovilizado capital en nuevos equipos y en la adopción del nuevo paquete tecnológico. Como consecuencia, el cambio en los precios relativos (disminución en los precios de los granos) se tradujo en un reforzamiento de las trayectorias tecnológicas previas. Esto explica que la superficie implantada con siembra directa se triplique entre el año 1997 y el 2002 (ver gráfico Nº 5) aún en un contexto desfavorable para el sector ${ }^{137}$.

Las sembradoras son un componente esencial en la profundización del modelo productivo de siembra directa. El nivel de venta de sembradoras se mantuvo entre 1994 y 2010 dentro de las 3500 unidades, en contraposición la venta de tractores cayó de casi 8000 unidades en 1996, a 600 unidades en 2002. Las empresas de sembradoras en un número superior a 35 , fabrican y venden equipos durante todo el período a un ritmo estable y en el peor año de la crisis, 2002, venden 3423 unidades. En el año 2002, cuando el sector agropecuario supera la crisis138 con aumento en los precios de los granos y cambio en los precios relativos, el volumen de ventas de sembradoras llega casi a las 5000 unidades, con aumento en el número de empresas que producen en el país (el número llega a 43). Por otra parte, existe en este proceso de expansión, una importante concentración, donde dos firmas de sembradoras acaparan el $45 \%$ de la demanda.

No podemos dejar de hacer referencia al comportamiento de la producción agrícola que crece de forma constante como respuesta a la profundización de las inversiones en tecnología, mejorando los márgenes de rentabilidad, a partir de la baja

\footnotetext{
${ }^{136}$ Algunos resultados provisionales del último Censo Nacional Agropecuario, son ilustrativos de algunas de estas situaciones al dar cuenta que, entre los años 1988 y 2002, desaparecieron 103.405 explotaciones y que la superficie promedio de las unidades productivas pasó de 421 a 538 hectáreas. (Indec:2003)

137 Antonelli (1999) presenta una discusión analítica sobre el efecto de las irreversibilidades internas y externas en la profundización de los procesos de aprendizaje ante cambios de precios relativos.

${ }^{138}$ Se refinancia automáticamente la mayor parte de las deudas contraídas en dólares de forma pesificada.
} 
de costos de producción que permite el nuevo sistema de siembra directa y semillas transgénicas.

Por su parte, el segmento de producción de pulverizadoras139 tiene un comportamiento similar al de sembradoras. La fabricación de pulverizadoras mantuvo niveles constantes durante la década de 1990, recién en el año 2000 cayó su producción. No obstante, hacia el año 2002 los equipos de pulverizadoras de arrastre tuvieron una rápida recuperación, que permitió superar los niveles previos a la crisis, impulsados en parte, por el aumento de los precios en la soja y los granos en general. Los equipos autopropulsados son relativamente nuevos en el mercado y tuvieron un crecimiento de producción del 124\% entre 1997 y 2007 (Bragachini, 2008) igualando en este último año a los equipos de arrastre. Esto nos habla también de la propensión del productor agrícola a sofisticar la demanda.

A las tradicionales empresas productoras de pulverizadoras autopropulsadas Metalfor y Pla se suman por lo menos 10 empresas más, entre las que se cuentan: Praba, Golondrin, Caiman, Favot, Ombú, Castelli, Releyco SRL, Apache, Talleres Metalúrgicos Estefoni, Cinal - For, Hidraulica Tedeschi, todas ubicadas en pequeñas localidades de Santa Fe y Córdoba. Aunque, las dos empresas que producen pulverizadoras autopropulsadas con más ventas concentran el $80 \%$ del mercado. Por otro lado, queremos destacar el crecimiento de las ventas de equipos de pulverización, que va acompañado de un cambio gradual hacia maquinas autopropulsadas. Algunas de las causas de este cambio es el aumento de la superficie con siembra directa y el aumento de los lotes por productor que hace más accesible este tipo de máquina medido en costos por hectárea (INTA, 2008).

En relación a la modificación de un tipo de equipo a otro dejamos planteado un tema de suma importancia que se produce en el sector agrícola argentino, y es la sofisticación de un consumo, ya sofisticado, en maquinaria. Un dato a tener en cuenta es la incorporación de herramientas de agricultura de precisión (microelectrónica), elementos de alta complejidad que mejoran la productividad. Argentina se ubica segunda detrás de Estados Unidos en el número de monitores de rendimiento utilizados y es quinto en el mundo en el uso de estos monitores por cantidad de hectáreas sembradas: $1^{\circ}$ EE.UU., $2^{\circ}$ Dinamarca, $3^{\circ}$ Suecia, $4^{\circ}$ Gran Bretaña, $5^{\circ}$ Argentina, $6^{\circ}$ Australia, $7^{\circ}$ Holanda. En el país existen más de 10 PyME que desarrollan, diseñan y fabrican estos agro componentes de alta complejidad que permiten mejorar el automatismo y la precisión de la maquinaria.

\footnotetext{
${ }^{139}$ Las pulverizadoras autopropulsadas son más complejas tecnológicamente que las de arrastre.
} 
En resumen del apartado, diremos que la importancia de los procesos de aprendizaje proveedor-usuario y de cambio tecnológico localizado son de alta relevancia para las industrias de maquinaria agrícola. Estudios pioneros sobre la trayectoria tecnológica del tractor en Estados Unidos han mostrado que, si bien el ritmo y la magnitud del cambio tecnológico es el resultado de la experiencia acumulada por la industria proveedora de equipos, la dirección del cambio tecnológico en estas industrias es influenciada por los cambios en los parámetros clave del sistema agronómico (escala y especialización), al menos en mayor medida que lo que el sistema agronómico es influenciado por las primeras (Sahal, 1981). Con lo que la siembra directa -semillas transgénicas produce una revitalización de la industria de maquinaria con desarrollos locales de variada intensidad.

\subsection{Consideraciones finales}

El sector de maquinaria agrícola tuvo un proceso de creación artesanal relacionado con las necesidades de mecanización del agro, con un desarrollo altamente innovativo, adaptando, mejorando y generando nuevas máquinas, unido al desenvolvimiento local de la agricultura. Esto no alcanzó para generar un proceso de acumulación ampliada que desarrollara una industria proveedora de equipos a nivel local, nacional y mucho menos exportadora. Es recién en el período denominado de sustitución de importaciones, que las empresas comenzaron a producir industrialmente, y a cubrir las necesidades completas de maquinaria de la producción rural argentina, teniendo al Estado como productor y regulador. A su vez, el Estado sostuvo y fomentó la demanda, además de proteger a la industria de la competencia externa.

La industria de maquinaria agrícola, conformada en su mayor parte por PyME familiares, de origen artesanal, se reestructura a mediados de 1950 con la instalación de filiales de empresas transnacionales especializadas en la producción de tractores, las que invirtieron en el país para aprovechar los mercados protegidos. Así se consolidó una trayectoria tecnológica en respuesta a las características y tamaños de las explotaciones agrícolas de la pampa húmeda.

Las unidades de tractores producidas, en el país, presentaron una menor complejidad técnica que las de los países desarrollados y una potencia superior a media de los países subdesarrollados, lo que se tradujo en una alta potencia a bajo costo. Esta especificidad de la industria local se combinaba con importantes deseconomías de escala y bajos grados de interoperabilidad entre implementos de 
distintos modelos. A pesar de ello, esta dinámica permitió importantes procesos de aprendizaje y de acumulación de experiencia que se traduciría en una elevada capacidad de adaptación a los cambios regulatorios y macroeconómicos de las décadas siguientes.

El sector llegó, en la década de 1970, a su madurez tecnológica a nivel mundial, Argentina operaba con algunos retrasos a nivel de producto y de procesos productivos. Si bien, las empresas locales de maquinaria agrícola logran durante este período exportar hacia otros mercados, proceso que muestra cierto nivel de competitividad, no consiguió mantenerlo a largo plazo.

Entre 1976 y 2002, se produce una fase de ajuste regresivo del sector, caracterizada por el cierre de numerosas líneas de producción de las filiales de empresas transnacionales de tractores y la entrada de nuevas empresas de capital nacional, el cese de funcionamiento, la racionalización y diversificación de las fábricas de cosechadoras, y la desaparición de casi doscientas empresas de implementos agrícolas. En estos años se registraron caídas en la productividad y reducción del empleo y a su vez, se produjo un cambio en los sistemas agronómicos de producción. Esto generó un renovado proceso de aprendizaje proveedor-usuario y de cambio tecnológico localizado de alta relevancia.

En la década de 1980 se comenzaron a producir cambios en los modos de organizar la agricultura pampeana; aumento del uso de servicios agropecuarios (contratistas), introducción de la siembra directa y utilización de agroquímicos en proporciones crecientes (biocidas-fertilizantes). Paralelamente a este nuevo desarrollo, se van introduciendo en el segmento productor de sembradoras las modificaciones (generadas y adaptadas localmente140) necesarias para acoplarse al nuevo esquema de producción agrícola, el segmento ganó así participación en el mercado de maquinaria agrícola. Por su parte aumentó la potencia requerida de tractores y en las cosechadoras se mejoró la distribución de desechos.

A mediados de la década de 1990 se incorporó al nuevo sistema de siembra directa, las semillas de soja modificadas genéticamente para resistir al herbicida glifosato, se conjuga un avance en tecnología mecánica con innovación de la biotecnología. Este conjunto incluye necesariamente a las pulverizadoras, otro de los equipos de maquinaria agrícola que más creció en producción desde principios de la década de 1990, junto con el de sembradoras.

140 Se importan durante el breve período que va de 1978 a 1981 algunos equipos desde Brasil. 
A partir de la caída del plan de convertibilidad en el año 2002, y a partir de otro tipo de regulación de mercado, se generaron nuevas condiciones para el sector de maquinaria agrícola. Al cambio en los precios relativos se sumó un sostenido aumento en los precios de los granos. Es entonces, que aumentaron las ventas internas de tractores y cosechadoras, pero aproximadamente el $80 \%$ de las mismas eran máquinas importadas.

Las empresas de cosechadoras, con cuatro fábricas en funcionamiento141, avanzaron sobre el mercado interno disputándoselo a las empresas transnacionales, con ciertas debilidades estructurales y heterogeneidades muy fuertes al interior del grupo de firmas. La empresa más importante de capitales nacionales de cosechadoras tiene una capacidad 8 veces superior al de las otras tres y es, a su vez, tres veces más chica que la empresa más chica de Brasil. En el caso particular de sembradoras y pulverizadoras existen más de 50 empresas distribuidas por Santa Fe, Córdoba y Buenos Aires, que tienen un campo de acción mucho menos explorado, donde son ellas las que pueden marcar el rumbo a nivel mundial en cuanto a tecnología. En tanto, las firmas que producen tractores tienen un esquema de producción particular que asociamos a las cadenas globales de valor. Mayoritariamente producen componentes (motores) en Argentina, lo exportan Brasil e importan, del mismo país, el tractor terminado. No obstante, existen compañías nacionales de tractores que producen el tractor en el país, pero dependen de los motores de empresas transnacionales, localizadas en Argentina o el exterior.

Pese a la importante reactivación del sector a partir del 2002, la reestructuración de la producción sectorial de los años '90 no es rápidamente revertida después del cambio de precios relativos. Las decisiones de abrir o no una planta van más allá del tipo de cambio. El desarrollo de importantes economías de especialización en el marco de las estrategias de las empresas multinacionales es favorable a la localización en Brasil. La sustitución de importaciones sólo tuvo efectos positivos, en aquellas producciones en las cuales las empresas "resistieron" la apertura comercial externa unilateral con apreciación cambiaria. Estas firmas profundizaron sus capacidades tecnológicas e hicieron de las especificidades locales un rasgo distintivo (sembradoras, con un $97 \%$ de producción nacional; pulverizadoras autopropulsadas, con un $85 \%$; cabezales maiceros y girasoleros, $97 \%$ ).

141 Todas comenzaron a producir a partir de 2002 y todas son empresas con marcas fundadas en la década de 1950, Vassalli y Don Roque, Araus (producida por Metalfor), Marani, y Bernardín. 
Todo el sector ha sido influido por la variabilidad macroeconómica y los distintos marcos institucionales de regulación estatal. Observamos a grandes rasgos dos conductas, una relacionado con las empresas transnacionales, que reestructuraron su producción en función de estrategias de escala global y otra relacionado con empresas nacionales muy asociada a un cambio local de producción agrícola y de articulación con el contexto nacional de regulación económica.

Las vinculaciones con las empresas transnacionales son la expresión más notoria de procesos centro - periferia que operan ordenando el mercado de acuerdo a sus estrategias globales con mayores niveles de libertad gracias a los cambios de regulación de tipo internacional (progresiva apertura de mercados - "globalización"). En este sentido es menester comprender de qué manera la estructura internacional desestructura la organización económico nacional y regional de los países periféricos.

Las empresas nacionales se dividen a su vez en dos tipos: las productoras de tractores y cosechadoras (características de equipos más estandarizados) que tienen una relación de disputa del mercado interno, con los grandes oligopolios internacionales; y la de sembradoras y pulverizadoras que tienen un mercado interno cautivo con aparentes barreras al ingreso de la competencia extranjera, relacionadas con las necesidades locales de producción agrícola. Por otro lado, debemos mencionar que existe un alto grado de heterogeneidad al interior de cada segmento de producción con altos niveles de concentración de la oferta en las empresas más grandes, y un alto nivel de dispersión en un número relativamente amplio de PyME.

La industria argentina de maquinaria agrícola depende para su expansión del aumento de sus exportaciones y de sus avances en la internacionalización, objetivos estratégicos de las empresas que han capitalizado un conocimiento localmente creado. Dado el dinamismo de la demanda mundial de esta maquinaria, el sector puede aumentar sus ventas en el exterior, donde algunos de sus productos tienen buen desempeño competitivo. Será fundamental el comportamiento de la demanda interna, que depende en gran medida de la capacidad de compra del sector agrícola argentino. Para ampliar su internacionalización, el sector de maquinaria deberá superar algunas limitaciones, sobre todo tecnológicas, y de proceso productivo. Le será de importancia para ello contar con el apoyo de programas gubernamentales y la asistencia de organizaciones empresariales e instituciones científicas y tecnológicas (públicas y privadas).

En conclusión el capítulo muestra la configuración y conformación histórico espacial de la aglomeración de firmas de maquinaria agrícola en Argentina. El estadío 
tecnológico del sector donde en años cercanos presenta fuertes heterogeneidades en cuanto a producto y a procesos. Encontramos que se encuentran más retrasados los desarrollos de procesos productivos que la innovación de productos, asociados estos últimos a la relación proveedor-usuario y al desenvolvimiento local de la siembra directa. Por otro lado, no podemos dejar de desconocer que parte del crecimiento del sector está asociado a altos niveles de dependencia tecnológica de los países centrales y sus empresas.

En el próximo capítulo profundizamos sobre las capacidades y estrategias del oligopolio internacional de empresas transnacionales en Argentina y la respuesta de la industria nacional frente al desafío de seguir creciendo internacionalizándose. 
CAPÍTULO 3 


\section{Estructura del comercio mundial de maquinaria agrícola}

\subsection{Introducción}

Como exhibe el capítulo 2, la industria de maquinaria agrícola posee una larga trayectoria en el país, vinculada desde sus inicios al desarrollo de la agricultura pampeana y con una fuerte articulación regional. La producción de maquinaria agrícola atravesó a lo largo de los años sucesivas etapas de crecimiento y contracción, asociadas estas a las dinámicas macroeconómicas y sectoriales. Durante el período más reciente, esta industria experimentó diversas reestructuraciones enmarcadas en, por una parte, los cambios en los contextos macroeconómicos e institucionales; y por otra parte, en cambios específicos asociados a la dinámica de los complejos agropecuarios. El objetivo central de este capítulo es analizar: la importancia del mercado interno para el desarrollo del sector de maquinaria agrícola nacional, la trascendencia de las empresas transnacionales, en el mercado interno y en el externo y las formas de vinculación de las firmas locales con el mercado externo (exportación e internacionalización), como modo de independizar el destino de esta industria del mercado nacional.

A partir de la década de 1990 se decide en el país, la apertura comercial unilateral $^{142}$, se revalúa la moneda y se pone en funcionamiento el MERCOSUR. El sector de maquinaria agrícola se reestructura, entonces, en relación al nuevo escenario. Cada segmento que compone el agregado de maquinaria agrícola, tuvo diferentes comportamientos.

Las empresas transnacionales dedicadas a la fabricación completa de tractores, a través de filiales "réplica", trasladan, en la década de 1990, su producción a Brasil, aunque algunos componentes continúan siendo producidos en el país (motores). Las firmas de cosechadoras todas de capital nacional ${ }^{143}$, tienen serias dificultades para continuar produciendo frente a la nueva situación de competencia internacional, cerrando todas hacia finales de la década de 1990 y principios de 2000. Con el nuevo escenario posconvertibilidad, abren o reabren 4 firmas productoras de cosechadoras de capital nacional. Las empresas de sembradoras, con una vinculación mayor a las

142 La fijación de un arancel cero para la importación de bienes de capital en un país que produce dichos bienes es un caso inusual de política comercial (Chudnovsky y Erber, 1999). En relación al arancel 0 que se implementa en la década de 1990.

143 Se puede decir como excepción que Same Deutz-Fahr fabrica algunos equipos luego de adquirir, en 1996, la fábrica Araus en Córdoba. Esta firma cierra en 1999, con muy pocas máquinas ensambladas en el país. 
nuevas necesidades del productor argentino, en relación a un nuevo sistema agronómico de siembra, se posicionan como líderes en el mercado interno. El caso de las pulverizadoras autopropulsadas tiene cierta similitud con el segmento de sembradoras, es un segmento que se articuló con el nuevo paquete tecnológico de siembra ${ }^{144}$, al punto de conseguir una dinámica expansiva para el segmento, que permitió crear varias empresas fabricantes de este equipo en el país.

A nivel mundial, un grupo de empresas, no mayor a 12 , dominan el mercado internacional; estos grandes grupos económicos han ido concentrando la oferta de equipos a partir de fusiones y compras. Tres de esas firmas son empresas globales y manejan el $60 \%$ del comercio mundial. Estas compañías multiproducto tienen presencia en Argentina y junto a otras dos firmas, también transnacionales pero especializadas en un solo producto, poseen el 75\% (es un promedio de los años 20022008 (INDEC, 2009) del mercado de cosechadoras y tractores local.

La descripción de la situación nacional del sector en vinculación con la internacional, plantea, por un lado, la necesidad de comprender la fuerza del proceso global y, por otro lado, observar la importancia de la singularidad local. Se debe aclarar que en el presente capítulo se utilizará metodológicamente cuatro tipos distintos de maquinaria para su estudio: tractores, cosechadoras, sembradoras y pulverizadoras.

El capítulo presenta cuatro partes. La primera sección tiene dos apartados en los que se exhibe, por un lado, el carácter estructural del comercio internacional de maquinaria agrícola, representado en la relativa rigidez del dominio temporal de países y empresas líderes del mercado. Por otro lado, se muestra la posibilidad cierta de distender dichas estructuras que no son por cierto monolíticas.

En el segundo apartado se hace una descripción estilizada de ciertos caminos recorridos por las empresas transnacionales para obtener mayores porciones y mejores posiciones de mercado en el proceso competitivo. Por su parte, en la misma sección (en dos sub-secciones separadas) se profundiza el estudio de las estrategias de las firmas transnacionales en el país y de las nuevas reestructuraciones de estas empresas, a la luz de recientes modificaciones políticas en el comercio internacional de Argentina.

\footnotetext{
144 La siembra directa se define en este trabajo como la operación de siembra de los cultivos en suelos no preparados mecánicamente, en los que se abre un surco que solamente tiene el ancho y la profundidad suficiente para obtener una buena cobertura de la semilla, sin ninguna otra preparación mecánica.
} 
La tercer sección hace una revisión del comportamiento de la industria y de los distintos segmentos (aquí analizados) en cuanto a su desempeño exportador, en los últimos años, dando muestras de una notable mejora en cuanto a volumen de exportaciones, en relación a la larga trayectoria del sector en el país. Se exhibe, también, una incipiente internacionalización de las empresas de capital nacional, a través de inversión directa en otros países.

Por último a modo de síntesis se presentan las principales reflexiones que se desprenden del capítulo.

\subsection{Configuración mundial del comercio de maquinaria agrícola}

El mercado mundial de maquinaria agrícola se concentra en un reducido núcleo de grandes empresas transnacionales, cuyas estrategias y estructuras de organización están diseñadas a escala global. Hecho que se refleja en que 12 empresas de 7 países representen más del $60 \%$ del mercado mundial (Lavarello, Silva y Langard 2010).

La concentración de la oferta de maquinaria agrícola (excluidos los tractores) a nivel planetario, es pronunciada: los 10 primeros países, del ranking de UNCOMTRADE ${ }^{145}$ exporta el $75 \%$ del total, datos de 2008 . En tanto que en tractores, los 10 países que más exportan, controlan el $84 \%$ de las ventas externas a nivel mundial (UNCOMTRADE, 2008). Esta situación se vincula en forma directa con las estrategias de mercado de las compañías transnacionales. En el próximo punto se exhiben algunos datos al respecto.

\subsubsection{Empresas que dominan el mercado internacional de maquinaria agrícola}

En cierto sentido la oferta de maquinaria agrícola se encuentra fuertemente dispersa a nivel internacional, más de 50 países cuentan con capacidades de producción de equipos agrícolas. Sin embargo, la importancia de barreras a la entrada asociadas a la investigación y desarrollo, las preferencias por las marcas existentes y las extensas redes de distribución y de financiamiento, explica que, como ya se dijo, 12 empresas transnacionales concentren más de $60 \%$ del mercado global. Si bien, en los últimos años se evidencia un importante aumento en el grado de concentración, la estructura de la industria mundial de maquinaria agrícola constituye un oligopolio

145 Oficina de comercio de Naciones Unidas 
competitivo, en el cual coexisten diversos grupos estratégicos: empresas transnacionales con varias líneas de productos, empresas globales pero especializadas, competidores regionales y empresas locales de países periféricos con estrategias de bajo costo y precio (Lavarello, Goldstein y Hecker, 2008).

Cuadro $\mathrm{N}^{\circ}$ 9. Primeras 12 empresas de facturación mundial de maquinaria agrícola. En millones de dólares y en porcentaje respecto al mercado mundial.

\begin{tabular}{|c|c|c|c|c|c|c|}
\hline Compañía y país de origen & Facturación & $\%$ & Facturación & $\%$ & Facturación & $\%$ \\
\hline & \multicolumn{2}{|c|}{2005} & \multicolumn{2}{|l|}{2007} & \multicolumn{2}{|l|}{2010} \\
\hline Deere \& Company (EE.UU) & 10.100 & $14,4 \%$ & 12.121 & $15,7 \%$ & 19.818 & $22 \%$ \\
\hline CNH (Italia) & 7.600 & $10,8 \%$ & 9.948 & $12,9 \%$ & 11.528 & $13 \%$ \\
\hline AGCO (EE.UU) & 5.200 & $7,4 \%$ & 6.828 & $8,9 \%$ & $6.896,6$ & $8 \%$ \\
\hline Kubota (Japón) & 3.200 & $4,6 \%$ & 5.458 & $7,1 \%$ & 8.137 & $9 \%$ \\
\hline Claas (Alemania) & 2.500 & $3,6 \%$ & 3.380 & $4,4 \%$ & 3.515 & $4 \%$ \\
\hline Yanmar Agr. Eqp. (Japón) & 2.900 & $4,1 \%$ & 2.821 & $3,7 \%$ & 1.528 & $2 \%$ \\
\hline Same Deutz - Fahr (Italia) & 1.150 & $1,6 \%$ & 1.262 & $1,6 \%$ & 1.401 & $2 \%$ \\
\hline Iseki \& Co. (Japón) & 1.400 & $2,0 \%$ & 1.138 & $1,5 \%$ & 1.196 & $1,3 \%$ \\
\hline Mahindra \& Mahindra (India) & 700 & $1,0 \%$ & 1.031 & $1,5 \%$ & 3.080 & $3,5 \%$ \\
\hline Caterpillar (EE.UU) & 850 & $1,2 \%$ & 899 & $1,2 \%$ & 1.120 & $1,2 \%$ \\
\hline Bucher Industries (Suiza) & 625 & $0,9 \%$ & 744 & $1 \%$ & 850 & $1 \%$ \\
\hline Kverland (Noruega) & 600 & $0,9 \%$ & 733 & $1,0 \%$ & 509,5 & $0.5 \%$ \\
\hline SUBTOTAL & 36.825 & $52,5 \%$ & 46.393 & $60,3 \%$ & 59.579 & $67,0 \%$ \\
\hline TOTAL ESTIMADO & 70.200 & & 77.000 & & 88.800 & \\
\hline PRIMERAS 5 & 29000 & $41 \%$ & 33775 & $49 \%$ & 49894,6 & $56 \%$ \\
\hline
\end{tabular}

Fuente: elaboración propia en base a Lavarello, Goldstein y Hecker (2008), Albornoz (2010) y reportes anuales de las empresas.

El primer grupo de firmas comprende a las tres grandes transnacionales con una gama completa de equipos (full liners): John Deere \& Company, CNH Global y AGCO. El siguiente grupo (empresas globales pero especializadas), está compuesto por compañías que, partiendo de una base regional, ya disputan los mercados globales: Kubota, CLAAS y Yanmar. En el grupo restante es posible identificar diversas empresas especializadas y/o de alcance regional como Same Deutz-Fahr, Mahindra y Mahindra, Caterpillar, Iseki, Bucher Industries y Kverneland. 
En el tercer grupo de firmas aparecen empresas transnacionales de India que compiten con las grandes empresas dominantes en el sector. De hecho, la empresa india Mahindra y Mahindra ha incrementado su participación en el mercado, sustentada en una importante expansión de sus ventas locales, que la colocan en una situación de fuerte competencia frente a las empresas líderes de la industria global. Según fuentes de la compañía, actualmente lideran la producción de tractores, a nivel mundial, con 200 mil unidades anuales (Reporte Anual de Mahindra y Mahindra, 2012).

Las empresas productoras de los países centrales cuentan con las ventajas propias de sus sistemas nacionales de innovación, en particular, la existencia de amplios y diversificados mercados internos, que se suma a sus ventajas organizacionales basadas en la experiencia acumulada en términos de tecnología, gestión y comercialización.

Como muestra el cuadro $\mathrm{N}^{0} 1$, el comercio internacional se ha ido concentrando en el período expuesto, este proceso se hace más pronunciado en las cinco primeras compañías. La estructura oligopólica se refuerza a través de la consolidación de diferentes barreras a la entrada (Lavarello y Gutman, 2008; y Lavarello, Goldstein y Hecker, 2008). Las barreras a la entrada que destacan Lavarello, Goldstein y Hecker (2008:14) como más importantes son:

- la "construcción" de la marca de la empresa con el objetivo de captar la lealtad del consumidor de los equipos. Los clientes de estas industrias no adquieren maquinas frecuentemente, sino que la compra está limitada por distintas razones: la vida útil del equipo existente, el ritmo de acumulación de capital de las empresas agropecuarias, los precios de los granos y el ganado, etc. El soporte y servicio al cliente es crítico en esta industria en la construcción de la marca, en la cual los gastos de los clientes son espaciados. Una empresa que busca entrar al mercado debe demostrar que su producto es sustancialmente mejor que el de su competidor. Este es un objetivo difícil de cumplir, especialmente en la agricultura, en la cual los clientes exigen confiabilidad, estabilidad y confían en productos adquiridos previamente. En este sentido la fuerza de ventas y de distribución a nivel global constituye sin lugar a dudas una de las principales barreras a la entrada de esta industria. Desde mediados de los '90 las empresas reforzaron sus servicios al clientes, extendiendo la cobertura de sus garantías y seguros de venta con el resultante requerimiento de mayores controles de calidad. La proximidad geográfica a los clientes es crítica para mantener ventas y asegurar servicios post-venta. 
- Por otro lado, la creciente complejidad en los productos con la incorporación de controles electrónicos y sensores crean nuevas barreras a la entrada de empresas que no cuentan con los medios ni el tiempo para diversificar competencias hacia estas nuevas tecnologías. Las empresas líderes gastan de 2 a $5 \%$ de sus ventas en investigación y desarrollo.

- Las empresas preexistentes cuentan, además, con capacidades de producción tales, que una firma que decida entrar en la industria deberá afrontar los menores precios asociados a un exceso de capacidad. Estas economías de escala se ven reforzadas por la capacidad ociosa en activos intangibles en I\&D y marcas, dando lugar a economías de alcance basadas en complementariedades entre distintas líneas de productos.

- La fabricación de equipos integrados requiere una gran inversión en capital, dado que son producciones capital intensivas. Los costos de puesta en marcha y de inventario para entrar en esta industria son muy elevados. La innovación de procesos ha buscado relajar este alto requerimiento de capital, con énfasis por un lado en líneas de ensamblado inteligentes y, por el otro a través de una gestión "liviana" de la cadena de valor ${ }^{146}$.

- Finalmente, la capacidad de financiamiento de los clientes constituye una ventaja crítica de las empresas líderes, en un contexto de fuerte desregulación financiera y de volatilidad de los precios agrícolas. Varias de las empresas cuentan con subsidiarias de financiamiento propias (las dos empresas más grandes cuentan con una división de servicios financieros).

Si bien esta configuración de la industria deja poco margen para el ingreso de nuevas empresas, los autores Lavarello, Goldstein y Hecker (2008), también, consideran que las condiciones de entrada pueden ser relajadas por empresas de países en desarrollo, a partir de una estrategia de entrada secuencial de los segmentos de productos más simples a los más complejos. A ello se puede agregar que, la gradualidad hacia la internacionalización y la obtención de economías crecientes de escala se genera explotando primero el mercado interno e inmediatamente el regional más próximo. Sobre este tema se pondrá especial atención

146 Entre las primeras, podemos destacar la adopción de técnicas CAD/CAM (diseño y manufactura ayudadas por computadoras), centros de mecanizado computarizados, inspección ultrasónica de partes. Respecto a la gestión de la cadena de valor, las empresas terminales han buscado disminuir la alta inmovilización de capital, importante en esta industria en la que el costo de los alcanza la mitad del precio de venta mayorista. Para ello desarrollan redes de subcontratistas de productos, componentes y partes que cumplan requisitos de calidad, ajustados períodos de entrega y bajos costos. Sin embargo, racionalizar la producción y compartir tecnología propietaria, disminuyendo costos, no es una tarea simple (Lavarello, Gutman, 2008). 
más adelante.

El mercado mundial de maquinaria agrícola se caracteriza por la presencia de una multiplicidad de segmentos entre los cuales se destacan los de tractores y cosechadoras ocupando cerca del $36 \%$ de la facturación. Sin embargo, segmentos secundarios como el de sembradoras y pulverizadoras son los que muestran una perspectiva de mayor crecimiento en caso de continuar la tendencia de los últimos años de expansión de los cultivos agrícolas. La especificidad de la demanda de estos equipos, abre importantes oportunidades para empresas medianas de países en desarrollo, que pueden servir de plataforma para una entrada en los mercados de los equipos de mayor complejidad (Lavarello, Goldstein y Hecker, 2008:2). En este sentido, cuanto más específico es el equipo mayores son los vínculos territoriales que lo definen, entonces la cercanía geográfica se hace preponderante.

En al siguiente sección se analiza la estructura del comercio exterior por países y se establece la importancia de los mercados regionales en la estrategia de internacionalización de las empresas, y la mayor importancia de estos mercados para los equipos más específicos en contra posición a los más estandarizados.

\subsubsection{Países que dominan el mercado mundial de maquinaria agrícola}

La oferta global de maquinaria agrícola exhibe una elevada concentración en los denominados países centrales. Esta concentración es explicada, a su vez, por la estructura oligopólica de las empresas que manejan el mercado de maquinaria agrícola, en especial en los segmentos de mayor complejidad tecnológica, como los de tractores y cosechadoras, que determinan la dinámica del sector en su conjunto.

En este sentido, podemos decir que existe una variedad muy amplia de productos clasificados como maquinaria agrícola pero, como ya se dijo, en cantidad de dinero el comercio internacional tiene como principales productos los tractores y las cosechadoras, productos en los que se destacan las empresas transnacionales. La estructura de la industria mundial de maquinaria agrícola constituye un oligopolio competitivo, en el cual coexisten diversos grupos con estrategias y formas de organización específicas. Son los países denominados centrales los que poseen el mayor volumen de comercio, y donde se asientan también las casas matrices de las empresas transnacionales más importantes. La fortaleza de estos países en estos segmentos es el resultado en primera instancia, del desarrollo y la explotación de grandes mercados internos (Langard, 2011). En segundo término, son los principales proveedores de innovación tecnológica metalmecánica con uso agropecuario a nivel mundial, manejan el "corazón" innovador de esta industria. 
Gráfico $N^{\circ} 6$. Volumen, en dólares, de tractores exportados por país y cantidad de hectáreas cultivadas por país. Año 2010

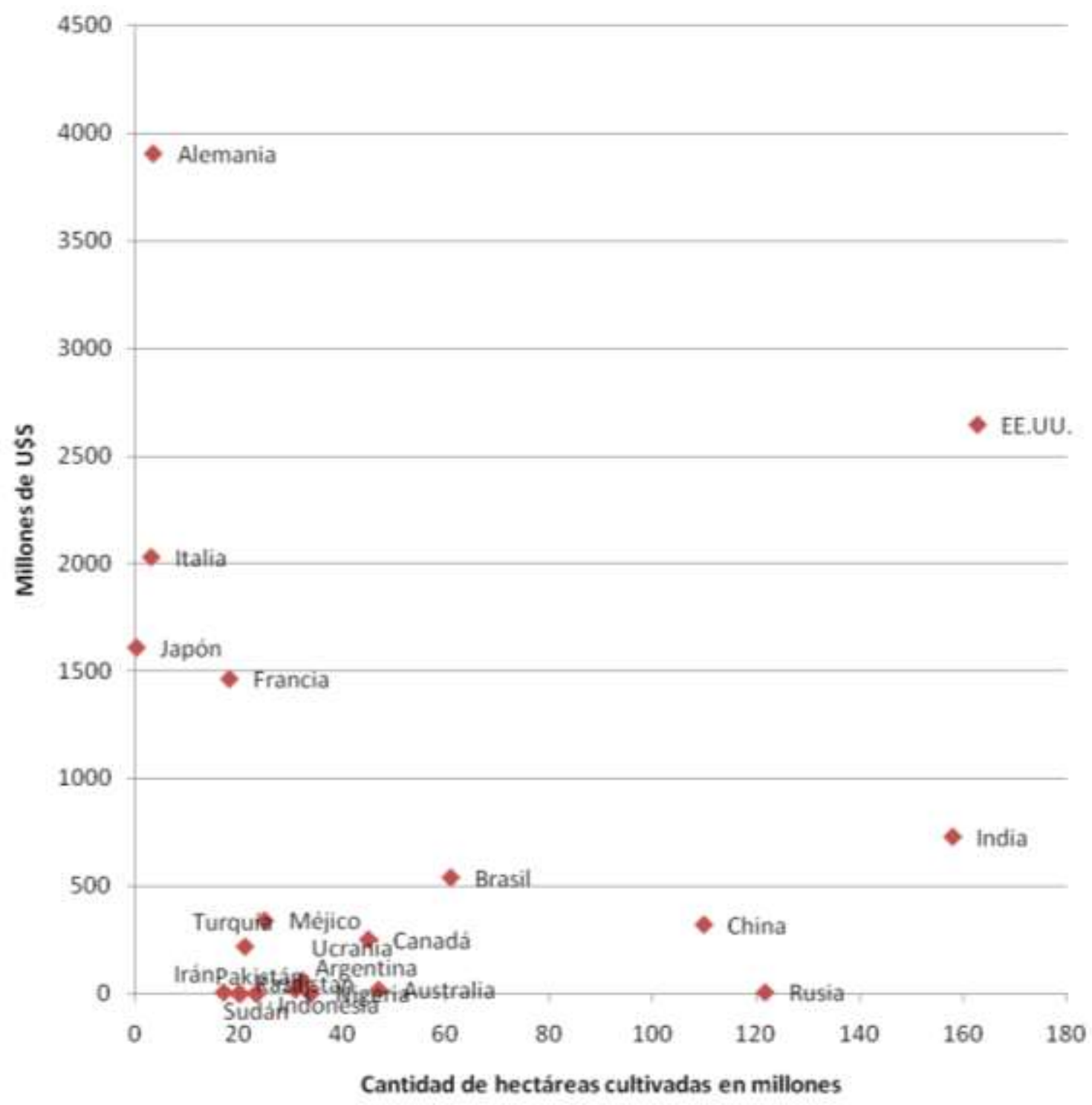

Fuente: elaboración propia con datos de FAOSTAT y COMTRADE.

El gráfico $N^{\circ} 6$ exhibe los 20 países con más área cultivada del planeta y el correspondiente volumen de exportaciones de tractores en millones de dólares estadounidenses. Se agregan, además, los países con mayor volumen de exportación de tractores y escasas hectáreas cultivadas. Se debe destacar y recordar que el tractor, como equipamiento de mecanización agraria, es el más universal de los equipos, debido a su carácter menos específico, esto le brinda mayor penetración en 
los distintos mercados. Es por eso considerado aquí apropiado para la comparación entre distintos países y continentes.

En definitiva el gráfico $\mathrm{N}^{\circ} 6$ compara a groso modo el volumen de exportación de tractores con el posible mercado interno por país. A partir de este gráfico $\left(\mathrm{N}^{\circ} 6\right)$ se pueden establecer cuatro grupos de países:

1. Aquellos con un alto volumen de exportaciones y poca cantidad de hectáreas cultivadas (Alemania, Italia y Japón).

2. En segundo término países con importantes extensiones de tierra cultivada y niveles medios - altos de exportación de tractores (Brasil, Turquía, Canadá, Ucrania, Méjico, India, China).

3. Un tercer grupo conformado por países como Argentina, Irán, Pakistán, Sudán, Australia, Nigeria, Indonesia, Kazajstán, Rusia; que tienen grandes cantidades de hectáreas cultivadas con una muy baja participación en la exportación de tractores (algunos de estos países ni siquiera producen estos equipos).

4. Un cuarto y último conjunto de países que poseen altas cantidades en ambos atributos (EE.UU.).

Esta clasificación es una primera aproximación a la estructura del comercio internacional de equipos agrícolas. El hecho de comparar hectáreas cultivadas con la exportación de tractores permite ver por un lado el dominio de los países centrales en el mercado (primer y último grupo), tengan o no importantes mercados internos (tema que se desarrollará más adelante). Por otro lado, se pueden observar países periféricos con amplios mercados internos y una creciente inserción internacional en el mercado de tractores, algunos de ellos como resultado de las estrategias de inversión regional de las empresas transnacionales y otros a partir de la expansión internacional de grupos locales (grupo 2). Por su parte, existe un grupo de países muy heterogéneo en cuanto a su desarrollo productivo pero, con ciertas características que los agrupa: poseen grandes extensiones cultivadas (amplio o potencialmente amplio mercado internos) y no tienen peso en el mercado internacional de tractores. Con la excepción de Irán, en este último grupo, todos tienen fuertes déficits comerciales externos en tractores. Por último, el caso de Estados Unidos es el país que se destaca porque, a partir, de un amplio mercado interno desarrolla su potencial industrial.

Si centramos el análisis en el tercer grupo de países, se evidencia, que es necesario algo más que poseer un amplio mercado interno para desarrollar la industria 
proveedora de equipos. ${ }^{147}$ Por otra parte, consideramos que poseer un amplio mercado interno es necesario, como ya se dijo, pero no suficiente. Veamos con detenimiento que países dominan el mercado internacional de equipos.

En el mapa $\mathrm{N}^{0} 1$ se muestra qué naciones concentran el mayor volumen de exportaciones de maquinaria agrícola ${ }^{148}$.

Mapa №2 Diez países con mayor volumen de exportación de maquinaria agrícola en 2008

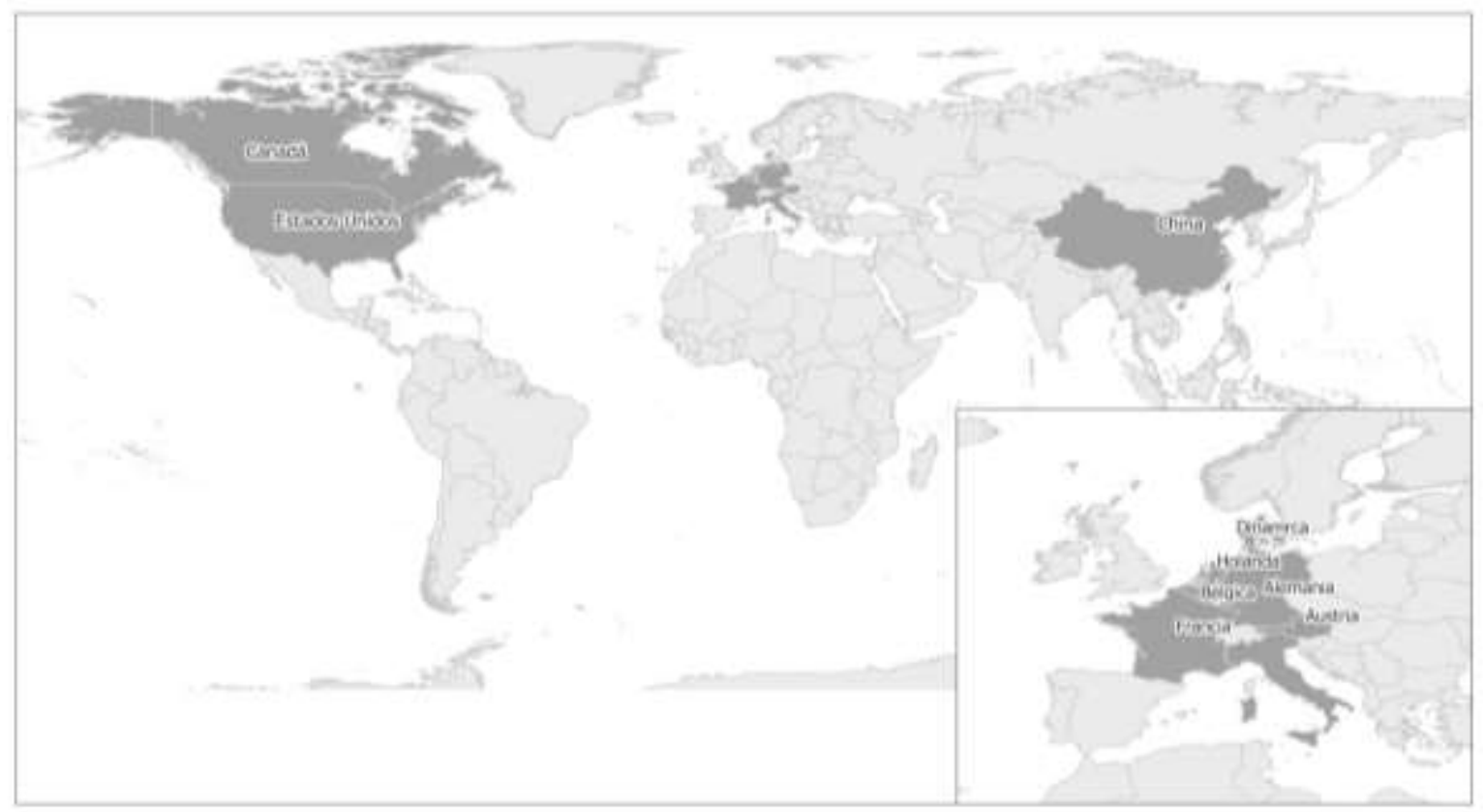

Fuente: elaboración propia en base a datos de COMTRADE.

Este grupo de 10 países, que muestra el mapa $N^{0} 1$, exporta el $75 \%$ de la maquinaria agrícola comercializada a nivel mundial (registro de 133 países de COMTRADE para el año 2008). Los 10 países, que más exportan se mantienen en una estructura medianamente estable, ya que en los últimos 10 años sólo ingresó China "al grupo de los 10", cediendo Suecia su lugar. El grueso de la producción, la investigación y el desarrollo se genera en estos países. Son también los países que

147 Para el caso de Estados Unidos se puede consultar los trabajos de Chang (2002) y de Reinert (2007), en los que se dan algunas pautas concretas de cómo logra industrializarse este país.

148 Hablar de maquinara agrícola significa englobar una cantidad de equipos muy amplia. Se toma en consideración la partida [SITC.4-721] Agricultural machinery (excluding tractors) and parts thereof, sumada a la partida de tractores, 870190 (Tractors n.e.s. in 87.01 (excl. of 87.09)). En http://comtrade.un.org/. Metodológicamente más adelante se ha decidido tomar los segmentos de tractores, cosechadoras y sembradoras. 
más importan maquinaria agrícola, generando un gran flujo de comercio intraindustrial y sin duda intrafirma. Podemos afirmar que este núcleo de países centrales domina la matriz tecnológica metalmecánica con la que se produce a nivel mundial la materia prima agropecuaria.

El mapa $N^{\circ} 3$ expone cuál es el primer destino de las ventas externas de maquinaria agrícola de los 5 primeros ${ }^{149}$ países.

Mapa $N^{\circ} 3$. Exportaciones de maquinaria agrícola (sin tractores) de los cinco primeros países en volumen de exportación. Indicando el destino principal por volumen de ventas en millones de dólares, año 2008

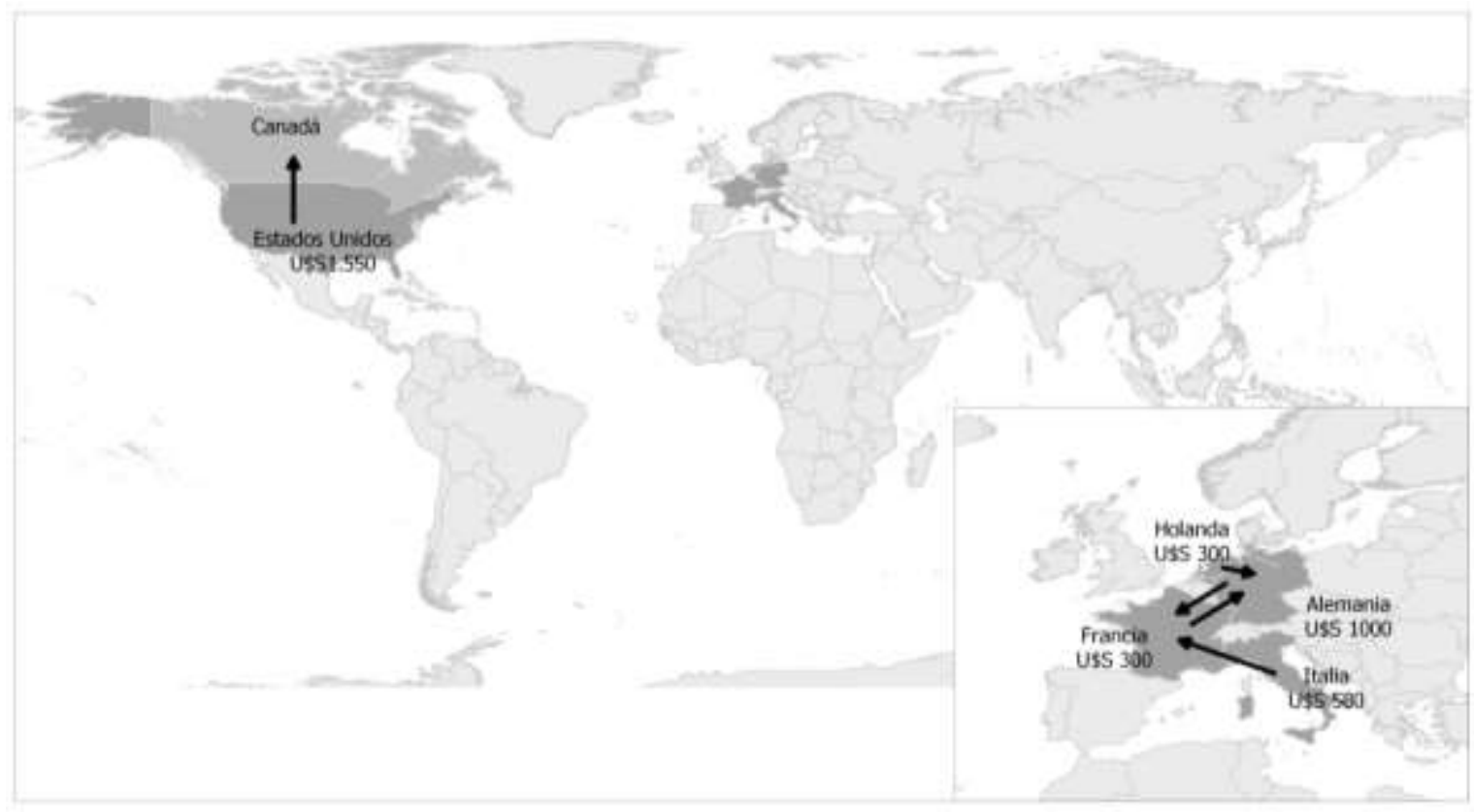

Fuente: elaboración propia en base a datos de COMTRADE.

Los países de Europa concentran su mercado en los países de la comunidad europea (CEE), mostrando claramente la potencia que tiene el mercado ampliado en la estrategia para construir el entramado industrial del sector. Es interesante destacar que Estados Unidos, si bien posee un muy amplio mercado interno y una amplia variedad de mercados de exportación, es Canadá el primer y más importante destino de sus ventas externas. Las vinculaciones comerciales están asociadas a tipos de regulación en materia de liberalización comercial entre países limítrofes, llámese

149 No se amplía a los 10 principales países por cuestiones gráficas, que hacen engorrosa su visualización. 
NAFTA o CEE. Es de suponerse, también, que existe una afinidad entre países limítrofes como consecuencia de las características similares en suelos y en sistemas de producción. Por otro lado, se destaca la superioridad productiva de Estados Unidos y Alemania, generando relaciones ampliamente asimétricas a su favor.

Ahora bien, metodológicamente se establece en el capítulo una subdivisión del mercado de maquinaria agrícola en dos grandes segmentos de equipos. En el primero de ellos, confluyen los tractores, que son las máquinas de uso más estandarizado y con características comparables a otros sectores con grandes economías de escala como la automotriz, junto con las cosechadoras que son equipos con menor volumen de comercio y no tan estandarizada en su uso. El otro segmento tiene similitudes con sectores de maquinaria con variantes tecnológicas, verificándose una especialización vinculada a las características edafológicas y agronómicas de los distintos lugares, en este grupo ubicamos las sembradoras.

Mapa $N^{\circ} 4$. Diez mayores exportadores de tractores, el principal país de destino por volumen de exportaciones en millones de dólares, año 2008

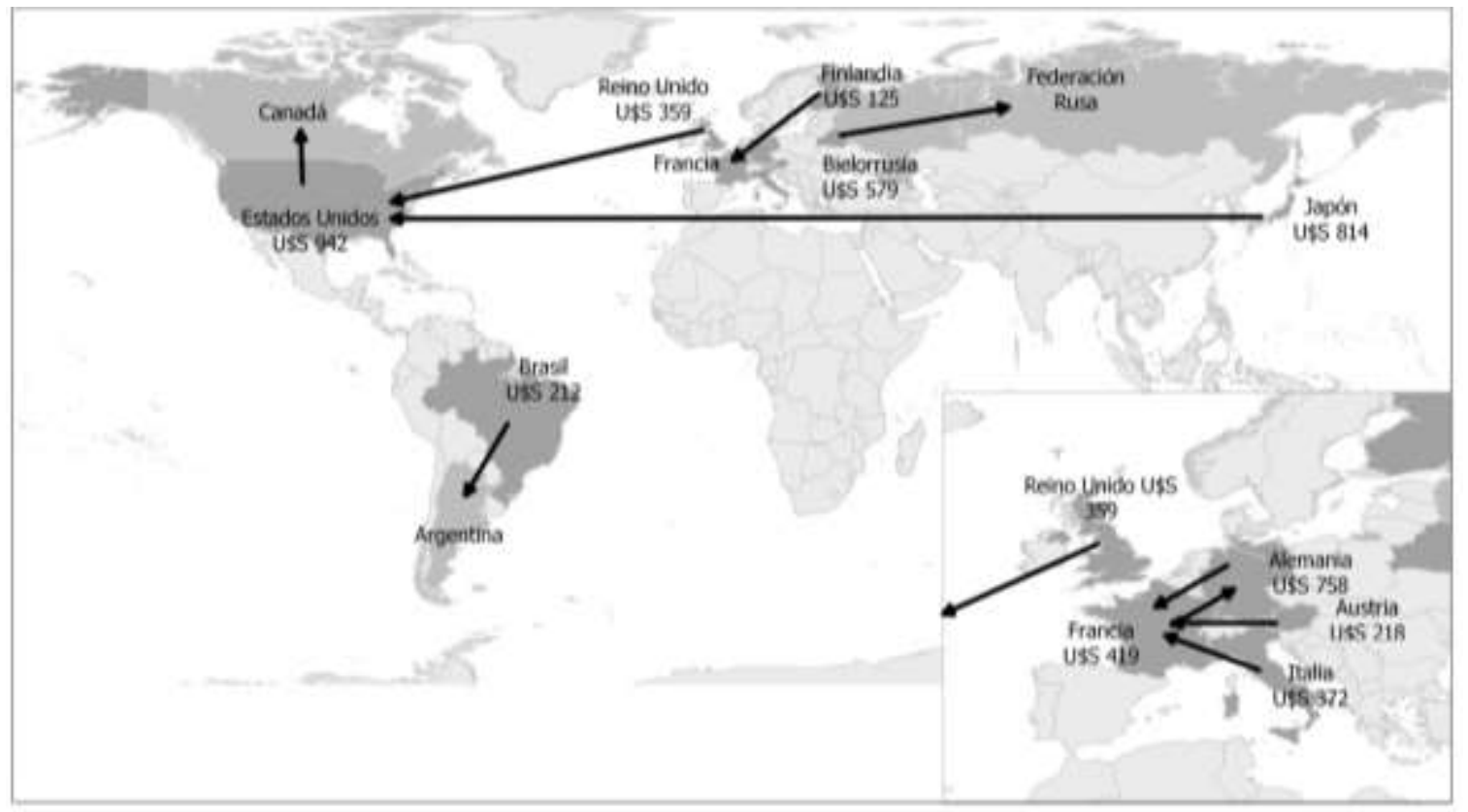

Fuente: elaboración propia en base a datos de COMTRADE.

Los mapas $\mathrm{N}^{\circ} 3, \quad N^{\circ} 4$ y $\mathrm{N}^{\circ} 5$ muestran el proceso particular en el que los mercados regionales son el salto internacional más importante, y aseguran una 
demanda que resulta fundamental, en el proceso competitivo, para el desarrollo de escalas de plantas y trayectorias tecnológicas. El mapa exhibe los 10 principales exportadores y sus respectivos mercados más importantes de exportación.

En el caso del segmento de tractores, encontramos que países como Francia y Canadá absorben una gran proporción de exportaciones de sus países vecinos, siendo el principal destino de las exportaciones regionales, con fuertes déficits sectoriales.

El subsector de tractores es, dentro del grupo más amplio de maquinaria agrícola, el equipo más estandarizado, razón por lo cual tiene menores necesidades de adaptación a condiciones locales. Por ello, es factible encontrar que Japón exporte a Estados Unidos más de 800 millones de dólares en tractores de baja potencia (menos de $80 \mathrm{hp}$ ) e igual comportamiento tenga Inglaterra, más vinculados a históricos acuerdos comerciales, que a vínculos de cercanías.

Algo relevante de este mapa, el $N^{\circ} 4$, es la aparición de Brasil dentro de los 10 países que más tractores exportan, y es Argentina en este año (2008), uno de los 10 países que más tractores importó. En los años 2007 y 2008, Argentina y Brasil, importador - exportador respectivamente, aparecen en el ranking de los 10 países que, más exportan y más importan tractores respectivamente, en consonancia con la dinámica MERCOSUR.

El mapa $\mathrm{N}^{\circ} 5$, exhibe el comercio internacional de cosechadoras, muestra una menor dispersión de mercados con respecto al mapa $N^{\circ} 4$. La cercanía física de las relaciones comerciales es una constante, en parte podemos deducir una mayor necesidad de adecuación del producto, cuestión que es más sencillo de resolver en mercados cercanos donde las similitudes entre usuarios y proveedor son mayores. Por otra parte, el mayor peso del equipo puede ser un limitante para su traslado.

Nuevamente, aparece Brasil en los 10 países que más exportan (cosechadoras), y es Argentina uno de los que más importa, de hecho Argentina se sitúa en el $3^{\circ}$ lugar dentro de los 10 países que más cosechadoras importaron en 2007 y 2008.

Este modo casi "natural" de expandir el mercado doméstico a las naciones más cercanas en distancia física, tiene como corolario una relación bidireccional de los flujos de equipos. Así como Canadá es el principal destino de las exportaciones de Estados Unidos, Canadá exporta mayoritariamente bienes similares a Estados Unidos, pero en relación deficitaria. Aunque, Canadá tiene una relación superavitaria en agropartes, dando indicios de cierto tipo de organización territorial de la producción. De todas formas, no deja de mostrar un vínculo asimétrico. 
Mapa $N^{\circ} 5$. Diez mayores exportadores de cosechadoras y el principal país de destino por volumen de exportaciones en millones de dólares, año 2008

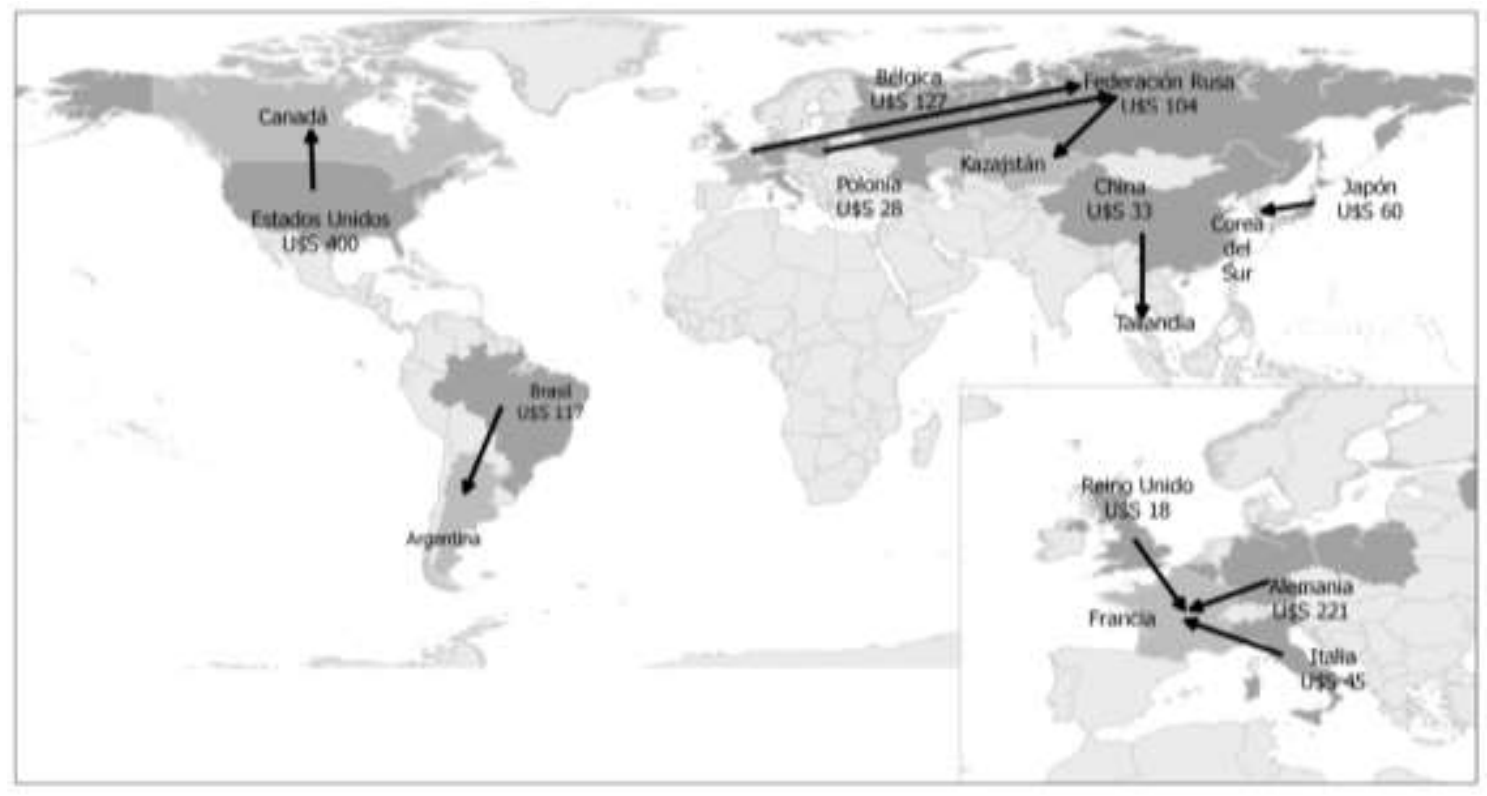

Fuente: elaboración propia en base a datos de COMTRADE.

Si vemos con más detalle la relación Alemania - Francia, ocurre una situación similar, donde pese a que Francia exporta grandes volúmenes a Alemania, no tiene incidencia en el gran déficit en la balanza comercial sectorial francesa con este país. Por su parte, Italia, el tercer país con mejor desempeño exportador mundial de equipos agrícolas, tiene como socio principal también a Francia y genera un fuerte superávit a su favor. Francia, también, exporta a Italia en relación deficitaria.

En este sentido, Argentina no exporta a Brasil grandes cantidades, ni es su primer destino en sus ventas de maquinaria agrícola. Advirtiéndose una baja integración entre ambos socios.

Ahora bien, esta configuración comercial mundial es seguramente una consecuencia de los tratados de libre comercio y unión aduanera, que han permitido a estos países, la ampliación de sus mercados. Podemos afirmar, entonces, que sigue vigente la hipótesis del mercado interno (ver Mistral 1979), como motor del desarrollo de ciertos sectores. Los mercados de los países limítrofes son parte integrante del mercado interno ampliado a partir de negociaciones políticas comerciales, donde prevalece el país con mayor capacidad productiva. 
Por otro lado, y sólo como detalle, vemos como Canadá, pese a ser un importante exportador agropecuario, no es consecuente con la tesis que plantea la tracción "aguas arriba" de los sectores proveedores (ver Faberger, 1992) en este caso de maquinaria agrícola. Su mercado interno tiene una fuerte presencia de productos estadounidenses y su desempeño exportador de maquinaria agrícola es muy bajo en relación a su socio principal (esto se verifica en parte en el gráfico $\mathrm{N}^{\circ} 6$ ).

Al respecto, Albornoz (2010: 76) expresa:

"podemos ver que mientras que en América Latina el modelo de desarrollo de la industria de maquinaria agrícola ha estado ligado al crecimiento del agro, otros países del mundo han desarrollado su industria a pesar de no contar con mercados agrícolas importantes en su interior",

El autor se refiere a Italia, Alemania y Japón ${ }^{150}$. Estamos de acuerdo con la afirmación sobre América Latina pero consideramos de igual forma el desarrollo de la industria para los países europeos y asiático. En todo caso, actualmente la industria italiana, alemana y japonesa se valen del mercado ampliado (Asia y Europa) para seguir creciendo en base a mayor productividad y mejoras tecnológicas, de la misma manera que lo hace Estados Unidos con su amplio mercado interno y el aún más amplio mercado canadiense. Como resultado de lo dicho hasta aquí, consideramos que poseer un amplio mercado interno es condición necesaria, pero no suficiente para el desarrollo de la industria de maquinaria agrícola.

Hasta aquí, se hizo mayor hincapié en los sectores de tractores y cosechadoras, que acumulan, relativamente, el mayor volumen del comercio mundial de maquinaria. Si indagamos sobre la exportación de sembradoras a nivel mundial, en volumen es tan sólo el 6,6\% del valor de lo exportado en tractores para el año 2008 (COMTRADE, 2008). La magnitud de comercio es menor, no obstante "las estructuras siguen estables"; los mismos países continúan en las primeras posiciones, y los destinos principales siguen siendo sus "vecinos" más cercanos, en este caso con más razón debido al tipo de equipo, con mayores necesidades de adaptación al suelo y al sistema de siembra. Esto nos da muestra que si bien en forma relativa el negocio de sembradoras es más reducido, no por ello es descuidado por las potencias centrales.

Al observar el mapa $\mathrm{N}^{\circ} 6$, encontramos dentro de los 10 principales exportadores de sembradoras a Brasil y Argentina. Nuestro país, por primera vez, se encuentra en

150 Italia, con un área sembrada total de 3,2 millones de hectáreas; Alemania, un total de 3,6 millones de hectáreas, y Japón, con un área sembrada total de apenas 340 mil hectáreas. 
el ranking de países que más exportan, posición número 9, alterando en parte la sólida estructura de países exportadores de equipos agrícola.

Mapa №6. Diez principales países exportadores de sembradoras en 2008

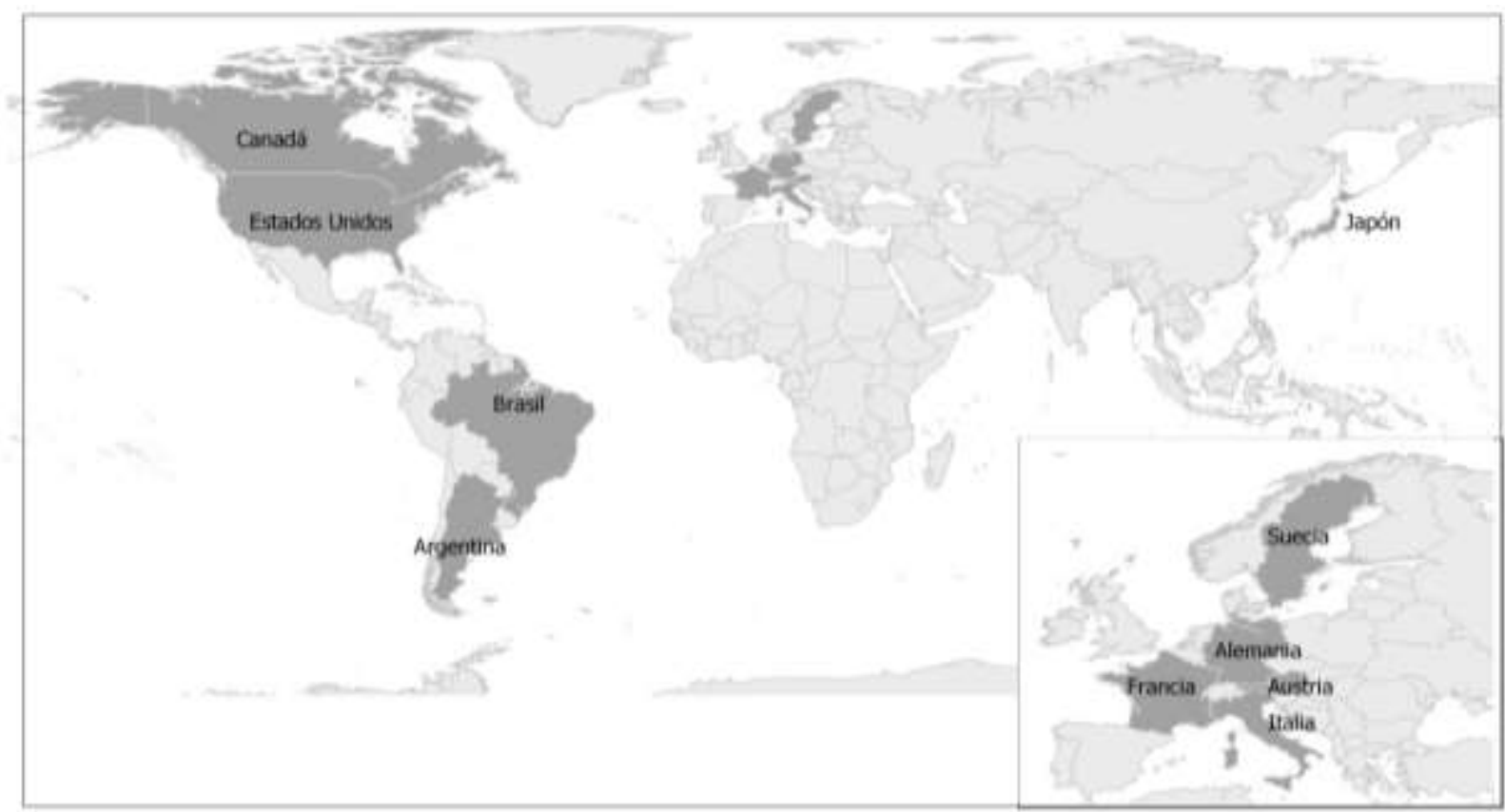

Fuente: elaboración propia en base a datos de COMTRADE.

El principal socio argentino en 2008 fue Uruguay y en segundo término Bolivia, cuestión que se comprende por la cercanía como elemento de peso en la estructura del comercio exterior. En tercer, cuarto y quinto lugar, encontramos a Federación Rusa, Kazajstán y Alemania respectivamente. Esta situación se explica, en gran parte, por la persistente tarea del INTA (INTA 2010, 2011) en países del este europeo, introduciendo el sistema de labranza cero. En paralelo a la tarea del INTA, las firmas nacionales adaptaron las máquinas a las características de los suelos extranjeros, lo que permitió dar un salto exportador de importancia.

En resumen, el comercio internacional de equipos agrícolas representa el $38 \%$ de la producción mundial (Lavarello y Goldstein, 2011), la heterogeneidad de los productos y las diferencias en las trayectorias tecno-productivas nacionales se traducen en diferentes patrones comerciales. En el escenario del comercio 
internacional, coexisten países agrícolas, que integran su propia industria de maquinaria agrícola, países exportadores netos de maquinaría agrícola y países que si bien cuentan con sectores agrícolas extensos exhiben déficits estructurales.

Este análisis, nos es útil a modo general y sirve para dar un panorama sobre dónde se concentra el grueso de la producción y el comercio de maquinaria agrícola. Se exhibe, a partir de ello, una estructura persistente de relación centro - periferia y resulta ilustrativo que los intercambios tengan un fuerte componente de cercanía.

\subsection{La concentración del capital y la estrategia competitiva de las empresas transnacionales}

El comercio mundial ha crecido frente a acuerdos de disminución arancelaria, acordada en organismos multilaterales de comercio (GATT). Como correlato de estos acuerdos, en la década de 1990 la participación de las empresas transnacionales en el comercio mundial se elevó sustancialmente.

En este sentido, las compañías transnacionales tienen, además, como tendencia a localizar filiales fuera de sus lugares de origen, ante la necesidad de reproducir condiciones de acumulación de capital disminuidas en los países de donde son oriundas, por diversas razones (Michalet, 1985). En línea con los aportes de la bibliografía sobre empresas transnacionales, Harvey (2004) considera como fundamento principal del desplazamiento del capital, la hiper - acumulación ${ }^{151}$ en los países centrales, de donde son originarias la mayoría de las empresas transnacionales. El movimiento del capital es el resultado esperable de la necesidad de expandir fronteras afuera la acumulación ampliada de capital. Cuando la expansión es hacia países periféricos, la relación de capital-trabajo, encuentra mejores condiciones para el capital por sobre fuerzas laborales con salarios más bajos y menor grado de organización sindical (Diken, 2001; Walker y Storper, 1981). Si bien, este es un incentivo de alta potencia no es el único como mostrara Dunning (1993) para quien la búsqueda de mercados y la consecuente realización de la mercancía es un motor tan importante como los bajos costos laborales. La concentración del capital, a partir de la compra de la capacidad productiva de firmas competidoras es una forma dentro del capitalismo de suprimir competencia, al mismo tiempo, actúa como forma de expansión geográfica de la valorización del capital.

151 Los indicadores de esta condición de hipertrofía del sistema son: exceso de capital, capacidad de producción ociosa, alto desempleo, inventarios grandes y sin salida, saturación de mercancías. 
Como hemos visto, las compañías transnacionales han capturado el $60 \%$ del comercio mundial de maquinaria agrícola ${ }^{152}$ y han avanzado en relevantes procesos de concentración corporativa. Son líderes en los principales segmentos del mercado, tanto por costos como por tecnología de productos.

A su vez, son los países centrales los que poseen el mayor volumen de comercio, es donde se asientan, también, las casas matrices de las empresas transnacionales más importantes de maquinaria agrícola. La expansión mundial de estas grandes corporaciones es una de las estrategias territoriales que permite el crecimiento y la continua acumulación de capital como condición sine qua non para su sobrevivencia en el marco de la competencia capitalista. En este sentido las empresas transnacionales tienen diferentes alcances geográficos y estrategias de localización.

Las tres firmas transnacionales de maquinaria agrícola más grandes son, John Deere \&Co. estadounidense (ventas totales 2010: 26.000 millones de dólares), Case New Holland, italiana (del Grupo Fiat con ventas totales 2010: 14.474 millones de dólares), y Agco, estadounidense (con ventas totales en 2010 de: 6900 millones de dólares). Estas empresas priorizan su estrategia de producción en los segmentos de mayor facturación; el ensamble de cosechadoras y tractores, más allá de producir todos los equipos que intervienen en el desarrollo de la actividad agraria cerealera, oleaginosa, pecuaria; como así también maquinaria de construcción y vial. Existen a demás, dos empresas de importancia con menor grado de facturación, pero con fuerte presencia en Argentina. Una de ellas es Claas, de origen alemán con una facturación global, en 2010 , de 3.658 millones de dólares, especializada en la producción de cosechadoras y picadoras de forraje. La otra firma es Same Deutz-Fahr, italiana especializada en la producción de tractores, cuya facturación en 2010 fue de 1153 millones de dólares. Todas estas firmas crecen a partir de un alto grado de estandarización de producto, integración y/o modularización de los distintos conjuntos y subconjuntos, establecen así unidades productivas regionales y de allí abastecen a los países cercanos. Estas empresas son también el resultado de un continuo proceso de concentración.

La empresa AGCO es uno de los ejemplos más claros de este proceso, en la página web de la historia de la empresa (2011) se pueden leer cerca de 20 compras y asociaciones realizadas desde 1990 a 2008, dando como resultado un aumento de 34.5 veces en la facturación. AGCO produce y comercializa los productos Valtra,

152 Es importante aclarar que el proceso de concentración del capital es inherente al desarrollo de la competencia capitalista en general y no privativo del mercado de maquinaria agrícola. 
Challenger, Fendt, Gleaner, Hesston, Massey Ferguson, New Idea, Rogatro, Spra Coupe, Sunflower, Terragator, White Planters, entre otros.

En el caso de John Deere, la empresa más importante a nivel mundial, ha ido absorbiendo firmas a nivel nacional (Estados Unidos) y global, como Lanz y Mashinenfabrik Kemper ambas de origen alemán, Douven holandesa, y SchneiderLogemann brasilera, también mantiene acuerdos con Goldoni y Carraro de Italia, y Zetor de República Checa.

CNH surge de la fusión entre Ford New Holand y Fiat Geotech, luego con la adquisición de Case Corporation en 1999, queda conformado el grupo Case New Holland (Heybel, 2006).

A su vez, la empresa alemana Claas, especializada en cosechadoras de granos y en picadoras de forrajes ha hecho su última adquisición importante en el año 2003, con la compra de la división agricultura de Renault en Francia, de esta forma, incorporó la producción de tractores en el esquema regional de la firma. A partir, de su fuerza a nivel regional, Claas, se ha lanzado como un jugador global con fábricas en Estados Unidos, India y Rusia.

Por su parte, la empresa Same, una firma de fuerte arraigo regional europeo, de origen italiano adquiere la empresa Hürlimann de Suiza, Deutz-Fahr de Alemania y Lamborghini de la misma Italia, conformándose el grupo Same Deutz - Fahr. Éste grupo, al igual que el resto de las compañías en su estrategia de concentración, adquiere empresas en Croacia (Đuro Đaković) y Finlandia (Sampo Roosenlew), pero también en India (Greaves Company) dando muestras de una estratégica expansión planetaria.

Estas cinco firmas son las empresas transnacionales que tienen una fuerte presencia en el mercado argentino de maquinaria agrícola, todas importan equipos y producen en el país (a excepción de Same Deutz - Fahr que sólo importa).

Argentina es un mercado importante para las compañías transnacionales. Para tener un parámetro, Argentina es el tercer mercado de cosechadoras de John Deere en volumen de ventas detrás de Estados Unidos y Brasil. Esto marca por un lado la importancia relativa del mercado nacional de cosechadoras y por otro la sofisticación de la demanda local de maquinaria, que utiliza el equipo más complejo y caro del mercado. En el próximo apartado, se profundiza el análisis de las estrategias de las firmas transnacionales en Argentina y América Latina. 


\subsubsection{Las estrategias de las empresas transnacionales, en Argentina y América del Sur}

Es de relevancia fundamental, la consideración de la inversión extranjera como un fenómeno complementario o alternativo al comercio internacional. Son las empresas transnacionales quienes invierten fuera de sus países de origen buscando reproducir los mecanismos que aseguren la acumulación ampliada de su capital, expandiéndose geográficamente. En esa expansión geográfica, actúan, de forma relativa, como difusoras de tecnología y creadoras de una nueva modalidad de comercio, denominado intrafirma ${ }^{153}$, dominando a través de él el comercio internacional.

Las empresas transnacionales de maquinaria agrícola en Argentina, operaron históricamente de manera tradicional instalando filiales designadas "filiales réplica", destinadas a elaborar domésticamente las líneas de producción de la casa matriz y de otras filiales adaptando los procesos de producción originales en escalas menores (downscaling). Este proceso fue característico de un período relacionado con la etapa de sustitución de importaciones (ver capítulo 2). En el marco de su estrategia, las empresas transnacionales, centralizan las actividades de investigación y desarrollo en la casa matriz (esto es, sus ventajas de propiedad) limitando al espacio de los países periféricos las actividades tecnológicas de adaptación de proceso y producto. John Deere, Deutz, Fiat, Fahr, Hanomag y Massey Ferguson son las empresas transnacionales que se emplazan en Argentina ajustándose a esta modalidad de "filial replica" entre 1952 y 1963.

En sucesivas etapas, la filial réplica es reemplazada por la "filial racionalizada o especializada", que como proceso, emerge a fines de los años '60 cuando las compañías transnacionales comienzan a establecer formas organizacionales más sistemáticas en sus operaciones internacionales. La liberalización de los mercados permite a las firmas transnacionales reestructurar o cerrar las filiales réplica que resultan en deseconomías de escala a nivel internacional, puede entonces, especializarse en una etapa específica de la cadena de valor (especialización de proceso) o en la producción de un reducido número de líneas de producto (especialización por línea de producto), son las alternativas de racionalización frecuentemente llevadas adelante (Lavarello, 2004). Esta nueva etapa, encuentra a las

153 El comercio intrafirma tiene lugar cuando se intercambian productos (diferentes o similares, dependiendo de las estrategias empresariales) entre filiales ubicadas en países distintos de una misma multinacional o bien entre cualquiera de éstas y la empresa matriz. 
empresas, insertas en el proceso de rivalidad del oligopolio mundial y no en la rivalidad del espacio nacional.

Las firmas de tractores antes mencionadas, atraviesan un proceso de compras y fusiones internacionales, entre las décadas del 1960 y 2000, que concentra la oferta mundial. Esto es parte de la reestructuración en la organización las empresas transnacionales. Es, también, como consecuencia de la restructuración de estas firmas, que las filiales réplica de los países periféricos se cierran y la producción se fija sobre la base de instalaciones internacionalmente interdependientes. Si bien a nivel mundial, como señalábamos, la racionalización y especialización productiva comenzó en los '60, este proceso se hizo fuerte en Argentina en la década del '90.

En el país las empresas transnacionales mostraron la siguiente reorganización: John Deere racionalizó en la década del '90 su planta de Rosario, especializándose en la sola producción de motores, actualmente integra una cadena de valor global, provee de motores a las plantas de Méjico y de Brasil (actualmente también a China), e importa los tractores y las cosechadoras de Brasil.

Deutz instalada en el país desde el año 1961 dejó de producir tractores en Morón en 1999, y especializó su fábrica en la producción de motores, también ese año, cierra la fábrica de cosechadoras en Noetinger que había adquirido a Araus. A su vez Deutz Argentina había sido comprada por AGCO en 1996.

Massey Ferguson pasó a formar parte de AGCO en 1994. Cierra su planta en Rosario en 1999, y concentró toda su fabricación regional en Brasil.

Fiat cerró su filial de producción de tractores con el nombre Agritech en Argentina en el año 1993. La empresa global de Fiat para maquinaria agrícola Case- New Holland conformada en 1994, se instala en Brasil en 1996 para operar regionalmente.

La taxonomía de Dunning (1993) nos permite clasificar a las empresas transnacionales, que se instalan en Argentina, a partir de sus objetivos. La primer etapa, durante el período de sustitución de importaciones, la estrategia fue market seeking, y ante la apertura de los mercados y condiciones favorables, reestructuran su estrategia hacia una efficiency seeking. Articulando la producción de equipos autopropulsados con Brasil, acumulando capital en "la seguridad"154 que brinda el

\footnotetext{
154 Ante posibles inconvenientes que surgieran entre los países del MERCOSUR, las empresas transnacionales se aseguran el mercado de Brasil, que posee una demanda 10 veces más grande en tractores y 3 veces más grande en cosechadoras que Argentina.
} 
mercado más amplio brasileño, en una nueva estrategia de market seeking, con cierta integración productiva con Argentina.

Argentina ha participado en la desinversión y deslocalización de las empresas transnacionales en los últimos 15 años y en paralelo Brasil se ha convertido en el centro de producción y distribución para América del Sur de las tres compañías transnacionales más importantes. Desde Brasil se abastece el $75 \%$ del mercado de tractores y cosechadoras de Argentina. Por otro lado la dependencia de las empresas transnacionales y de Brasil del mercado argentino es alto, el $80 \%$ de las exportaciones brasileras de tractores y cosechadoras, tienen como destino nuestro país.

Como se ha mostrado las compañías transnacionales del sector de maquinaria agrícola han experimentado un proceso de reestructuración mundial en respuesta a ciertas condiciones globales del capital. Este proceso se inicia en la década de 1960 pero toma fuerza, aproximadamente, a partir de la década de 1980. Las empresas del sector se reorganizan por completo para producir tamaños y modelos de maquinaria orientados a aquellas regiones con los mayores índices de volumen de utilización de cada tipo de maquinaria, y al mismo tiempo en menos lugares, ganan de esta forma en escala de producción. La nueva configuración del capital conforma las bases en la generación del armado de las cadenas de valor a escala planetaria, consecuencia directa de las etapas secuenciales del capital.

Las cadenas globales de valor tienen como uno de los aspecto más destacables para su análisis: el qué, el dónde, y el cómo se produce, y quién se apropia de los resultados. Además, de poner bajo estudio la naturaleza de las transacciones entre subsidiarias de compañías transnacionales, que representa gran parte del comercio global que se efectúa de este modo (Humprhey y Schmit, 2002). En la próxima sección, se verá de forma sintética el comportamiento estratégico reciente de las compañías transnacionales frente a nuevos escenarios en la República Argentina.

\subsubsection{Los cambios en la política industrial en el período posdevaluación en el país y las estrategias sectoriales}

Argentina tiene un lugar significativo en el mercado internacional, principalmente, como importador de equipos, y posee importancia en las estrategias de las firmas transnacionales. En el caso de John Deere, pese a que la empresa relocalizó gran parte de su producción local en Brasil desde fines de los '90, Argentina representa el $2,8 \%$ de las ventas totales del grupo y el $8,7 \%$ de sus ventas en el extranjero. Por su parte, el país representa para AGCO el 2,2\% de las ventas globales de la firma y el $2,8 \%$ de sus ventas fuera de su país de origen. El caso relevante es el de Claas, de 
reciente instalación en el país, que si bien el mercado local no supera el $2 \%$ de su facturación total, Argentina representa el $14,1 \%$ de sus ventas en el extranjero. Esta empresa, es la única que lleva adelante en el país actividades de innovación, con una inversión en el año 2007 de 1,6 millones de pesos cerca de 1\% de las ventas locales (Lavarello, Goldstein y Hecker, 2010).

La República Argentina representa para las empresas transnacionales estas firmas un importante destino de sus ventas. A su vez, el país posee algunos eslabones de la cadena de valor de maquinaria agrícola en las filiales de estas empresas, que permanecieron en territorio nacional luego de la década de 1990. Ahora bien, en los últimos años a través de la aplicación de restricciones ${ }^{155}$, desde el Estado, a la importación de maquinas a cambio de acceder a un mercado altamente dinámico, el país ha conseguido, una mayor integración de la cadena de valor.

Con una inversión de más de US\$100 millones, el Grupo Fiat, controlante de las firma $\mathrm{CNH}$, la segunda empresa más importante a nivel mundial (medido en términos de facturación), comenzará a fabricar cosechadoras, tractores y motores en Córdoba. Esta inversión está asociada a ventajas de escala y alcance, a partir de la vinculación con la fábrica de camiones IVECO que posee FIAT en el mismo predio a instalarse. Muchas partes y componentes como los motores son compartidos entre cosechadoras, tractores y camiones.

Por su parte John Deere con una inversión de US\$130 millones, entre el 2012 y 2015, tiene planeado producir en Gran Rosario 4 modelos de cosechadoras y 7 de tractores, además de ampliar la capacidad instalada en su planta de motores diesel que le permitirá fabricar 30.000 unidades al año, y comenzar a producir una nueva línea de motores de 3 cilindros, que no se producen localmente.

La empresa AGCO (asociada a Deutz) tiene proyectado una inversión por US\$ 140 millones en el plazo de cinco años, para la producción de tractores destinados al mercado nacional y a la exportación. Si bien AGCO ya produce tractores en el país los niveles de exportación son muy bajos, debido quizás al tipo de tractor producido localmente de alta cilindrada y no respetan las normas ambientales internacionales ${ }^{156}$.

En el caso de Claas, con una inversión total de U\$S 60 millones, tiene por objetivo llegar a 2015 a una producción local de 800 cosechadoras, de las cuales 200 se destinarán al mercado interno, 400 a Brasil y el resto a otros países de la región y

\footnotetext{
155 Licencias no automáticas, 1 U\$S importado - 1 U\$S exportado, y restricción en la venta de la moneda estadounidense.

156 Esto los hace más ineficientes
} 
de África. De esta manera, el complejo Oncativo Córdoba se convertirá en uno de los pilares de la plataforma para los negocios de comercio exterior de Claas en la región. Se destinarán U\$S 20 millones en la planta ubicada en Florentino Ameghino (Buenos Aires) y Sunchales (Santa Fe). En el establecimiento bonaerense, Claas aumentará su producción de cabezales girasoleros para la exportación y desarrollará piezas nacionales para sus cosechadoras. Mientras que en Sunchales, incrementará el armado de sus picadoras de forraje autopropulsadas, a las que también les sumará, aunque en menor cantidad, partes de fabricación nacional.

Todos estos proyectos, anunciados luego del año 2009, tienen como objetivo llegar a un $55 \%$ en promedio de integración nacional en cada producto. En este sentido gran parte del dinero invertido se destinará al desarrollo de proveedores locales. Este proceso de acumulación de capital productivo está en consonancia con el intento del Estado de desarrollar un fuerte proceso de sustitución de importaciones.

El país ha mostrado, además, un ascenso exportador desde el año 2002, en adelante, con crecimiento ininterrumpido (a excepción del año 2009, vinculado a la crisis financiera internacional) hasta el año 2010.

\subsection{Inserción de Argentina en el mercado internacional}

La fabricación de maquinaria agrícola en Argentina, con su larga tradición, atravesó los años 1980 y 1990 por sucesivas etapas de reestructuración regresivas asociadas a las dinámicas macroeconómicas y sectoriales. García (2008) considera que el sector se vio afectado negativamente por razones relacionadas al tamaño reducido del mercado, las fluctuaciones cíclicas de la demanda y a la baja productividad de las empresas nacionales. Para esta autora el período 1990-2001 fue un período propicio para la industria. Es interesante ver este enfoque que no considera las medidas de economía política que afectaron seriamente al conjunto de la industria durante ese período, y a la industria de bienes de capital en particular ${ }^{157}$, manifestándose la competitividad como una cuestión exclusivamente microeconómica.

\footnotetext{
157 Junto al Plan de Convertibilidad se hace una simultánea reforma arancelaria, se fija para los Bienes de Capital producidos en el país un arancel del $22 \%$ más una tasa de estadística de $3 \%$, los no producidos en el país pagaban sólo la tasa estadística (3\%), en 1992 se redujo el arancel al $15 \%$ y se aumenta la tasa de estadística 10\%. En 1993 el arancel se fija en $0 \%$ para todos los bienes de capital, incluyendo la MA, y como compensación se decidió reintegrarles a los fabricantes nacionales un $15 \%$ por máquina vendida, para que realicen este descuento en sus ventas3. En marzo de 1995 el reintegro fue del sólo $10 \%$ y en 1996 fue eliminado por el Ministerio de Economía. Por otro lado en 1995 el gobierno argentino fija un arancel de 10\% para los Bienes de Capital extra-MERCOSUR, en acuerdo con Brasil, para llegar entre 2001 y 2006, de forma paulatina a un Arancel Externo Común (AEC) del 14\%. (Chudnovsky y Erber, 1999). Argentina se adelanta y fija el $14 \%$ en agosto de 1996 . Pero a principios del año siguiente el arancel extra MERCOSUR vuelve a cero por un acuerdo entre Brasil y Argentina hasta el 31 de
} 
Más allá de ello, y de acuerdo con García (2008), las empresas nacionales necesitan expandir sus mercados a nivel internacional, como mecanismo para conseguir mayores economías de escala e independizar a la industria de ciertos ciclos del mercado interno.

En los últimos 8 años (2002 - 2008), la industria de maquinaria agrícola ha sido protagonista de un proceso de crecimiento importante, tras la casi desaparición del país de la producción de algunos segmentos de equipos como tractores y cosechadoras, máquinas, que volvieron a ser producidos en el país, pero que sólo abastecen un $30 \%$ en tractores y un $20 \%$ de cosechadoras de la demanda local (INDEC; 2010). Esto genera escalas de producción medias o bajas, que a su vez, las firmas, combinan con una producción diversificada como estrategia, que les permita disminuir los riesgos derivados de la alta incertidumbre en la demanda, consiguiendo así escalas de alcance o diversificación (scope). Otro fenómeno, muy mencionado en la literatura sobre la industria de maquinaria agrícola argentino, que ciertamente contribuyen a la baja escala, es la falta de estandarización de componentes. Este aspecto se considera un limitante de productividad mayormente en los subsectores de tractores y cosechadoras (Chudnovsky y Castaño, 2003).

En el caso de sembradoras existe una alta cantidad de fabricantes, esta cantidad parecería, en principio, ser una restricción para el desarrollo de economías de escala. Pero no es la escala su fortaleza o debilidad, pues han atravesado los períodos más difíciles sin grandes dificultades, en parte por ser proveedores especializados ${ }^{158}$ de series cortas de equipos, y por otra lado, muy probablemente posean y aprovechen economías externas por el modo de organizar la producción en aglomerados geográficos de firmas. Un caso similar se observa para las fábricas de pulverizadoras autopropulsadas, que son un número importante de empresas de escala media, al igual que sembradoras. Estos dos segmentos han dado, en los últimos 8 años, un salto exportador importante.

El alto coeficiente importador de maquinaria agrícola en Argentina da cuenta de la existencia de un mercado potencial importante para las firmas locales, que es ocupado por importación de compañías transnacionales. El país tiene un consumo estimado de 1000 millones de dólares en equipos agrícolas según INDEC, datos para

diciembre de 2005. Para compensar a los productores de la protección negativa, se establece un reintegro, por parte del Estado, del $10 \%$ con un Bono Fiscal a los fabricantes de Bienes de Capital, en el año 2001 (Decreto 379/01) y en el mismo año se aumenta el valor al 14\% Decreto Nacional (502/01).

${ }^{158}$ La introducción temprana (1980) en el país de la siembra directa condujo al desarrollo pionero de este tipo especial equipos, y a su adecuación a los suelos locales. 
el año 2010, con una representación de $48 \%$ de equipos nacionales y $52 \%$ importados. La importación de cosechadoras y tractores para el año 2010 fue de 466 millones de dólares, el $87,3 \%$ del total importado en maquinaria agrícola.

El país se encuentra hace unos 15 años en un esquema de relación con Brasil semejante al de Canadá - Estados Unidos y Francia- (Alemania - Italia), en el sentido de ser receptor de la mayoría de sus exportaciones, con la salvedad de no exportarle en la proporción que Canadá vende a Estados Unidos o Francia a Alemania.

La industria argentina de maquinaria agrícola se reestructura en la década de 1990, a partir de la racionalización y especialización a nivel regional (Argentina y Brasil) de las empresas transnacionales, con la articulación de las políticas industriales y exteriores de ambos países. Gracias a los incentivos del régimen macroeconómico de "la convertibilidad" y la consolidación del Mercosur, el comercio intrafirma entre Argentina y Brasil fue aumentando, aportando nuestro país cada vez menos valor agregado.

Argentina posee, entonces, un déficit externo estructural en equipos agrícolas, en gran parte explicado por las estrategias empresariales de las grandes corporaciones, pero sin duda las políticas nacionales son causa fundamental del tipo de impacto que las condiciones de las compañías transnacionales han tenido sobre el territorio. Por otra parte, al interior de la industria de maquinaria agrícola se evidencian dinámicas muy heterogéneas desde el punto de vista de su inserción internacional.

Cuadro $N^{\circ} 10$. Saldos comerciales del país, en miles de dólares por segmento de producto, en el período 2003-2010.

\begin{tabular}{|r|r|r|r|r|r|}
\hline \multirow{2}{*}{ Años } & \multicolumn{5}{|c|}{ Saldo Comercial } \\
\cline { 2 - 6 } & \multirow{2}{*}{ Cosechadoras } & Tractores & Sembradoras & Agropartes & Pulverizadoras \\
& & & & & \\
\hline $\mathbf{2 0 0 3}$ & $-136,817$ & $-97,022$ & 2,133 & $-4,083$ & $-12,593$ \\
\hline $\mathbf{2 0 0 4}$ & $-214,525$ & $-144,550$ & 2,238 & $-7,509$ & $-25,079$ \\
\hline $\mathbf{2 0 0 5}$ & $-129,231$ & $-166,741$ & 3,301 & $-8,496$ & $-21,406$ \\
\hline $\mathbf{2 0 0 6}$ & $-125,034$ & $-143,841$ & 10,936 & $-9,108$ & $-20,718$ \\
\hline $\mathbf{2 0 0 7}$ & $-212,981$ & $-202,192$ & 19,225 & $-14,133$ & $-28,635$ \\
\hline $\mathbf{2 0 0 8}$ & $-258,441$ & $-265,868$ & 32,569 & $-21,705$ & $-28,759$ \\
\hline $\mathbf{2 0 0 9}$ & $-22,942$ & $-63,041$ & 15,658 & $-9,807$ & $-12,272$ \\
\hline $\mathbf{2 0 1 0}$ & $-112,562$ & $-170,437$ & 13,815 & $-13,857$ & $-36,956$ \\
\hline
\end{tabular}

Fuente: Lavarello, Silva y Langard (2010). 
En el cuadro $\mathrm{N}^{\circ} 10$ observamos el carácter estructural del déficit en la mayoría de los subsectores analizados.

Los déficits de los subsectores de tractores y de cosechadoras son el resultado, entre otros factores, de la pérdida de capacidad instalada de producción en el país. Es necesario reiterar que, las firmas transnacionales de tractores entre mediados de la década de 1990 y comienzos del 2000 trasladaron la producción nacional a Brasil. Por otro lado, en esos mismos años cerraron las últimas empresas productoras de cosechadoras de capital nacional y una de capitales extranjeros. A partir del 2002 reabren algunas firmas y se crean otras nuevas, luego de los cambios macroeconómicos ${ }^{159}$ del 2001-2002.

Pese a la tradición Argentina en la producción de cosechadoras; desde el año 1996 el país adopta un papel preponderantemente importador de estos equipos. En el año 2004 llegó a ser el segundo importador mundial de esta maquinaria de gran porte y hasta 2008 se mantuvo en los primeros cinco lugares como importador mundial. Los principales proveedores fueron en orden de importancia Brasil con el $70 \%$ de las ventas, Estados Unidos con $18 \%$ y Alemania con $9 \%$ (estos porcentajes son promedio del período 2003- 2008). A partir del año 2009, la importación de cosechadoras baja de forma abrupta, de 278 millones de dólares en 2008 a 45 millones de dólares, esto se debió en parte a la implementación de licencias no automáticas por parte del gobierno (Lavarello y Goldstein, 2011), pero también a la incidencia en la caída momentánea de los precios de los granos. Para el año 2010 y 2011 la importación de cosechadoras se recupera a 147 millones de dólares en promedio, pero lejos de los 250 millones de dólares de importación que en promedio tuvo el lustro 2004 - 2008.

Por su parte, las firmas de sembradoras que tuvieron la posibilidad de acompañar desde sus inicios el sistema agronómico de siembra directa. Estas empresas desarrollaron la tecnología apropiada para tal método y la combinaron con las características de los suelos locales, lo que les permitió captar el mercado argentino. En tanto las pulverizadoras consiguen revertir un déficit ${ }^{160}$, mucho mayor al de la década del '90 y exportan en 2010 a más de 12 países. Este éxito relativo está asociado también al cambio agronómico de siembra directa y semillas transgénicas.

${ }^{159}$ Devaluación de la moneda y a nivel internacional aumento de los precios de los granos.

160 Según Lavarello y Goldstein desde 2007, con datos de aduana, existe superávit comercial de este producto. 
Gráfico $\mathbf{N}^{\circ} 7$. Exportaciones Argentinas de maquinaria agrícola. En millones de dólares corrientes. Período 2003 - 2010

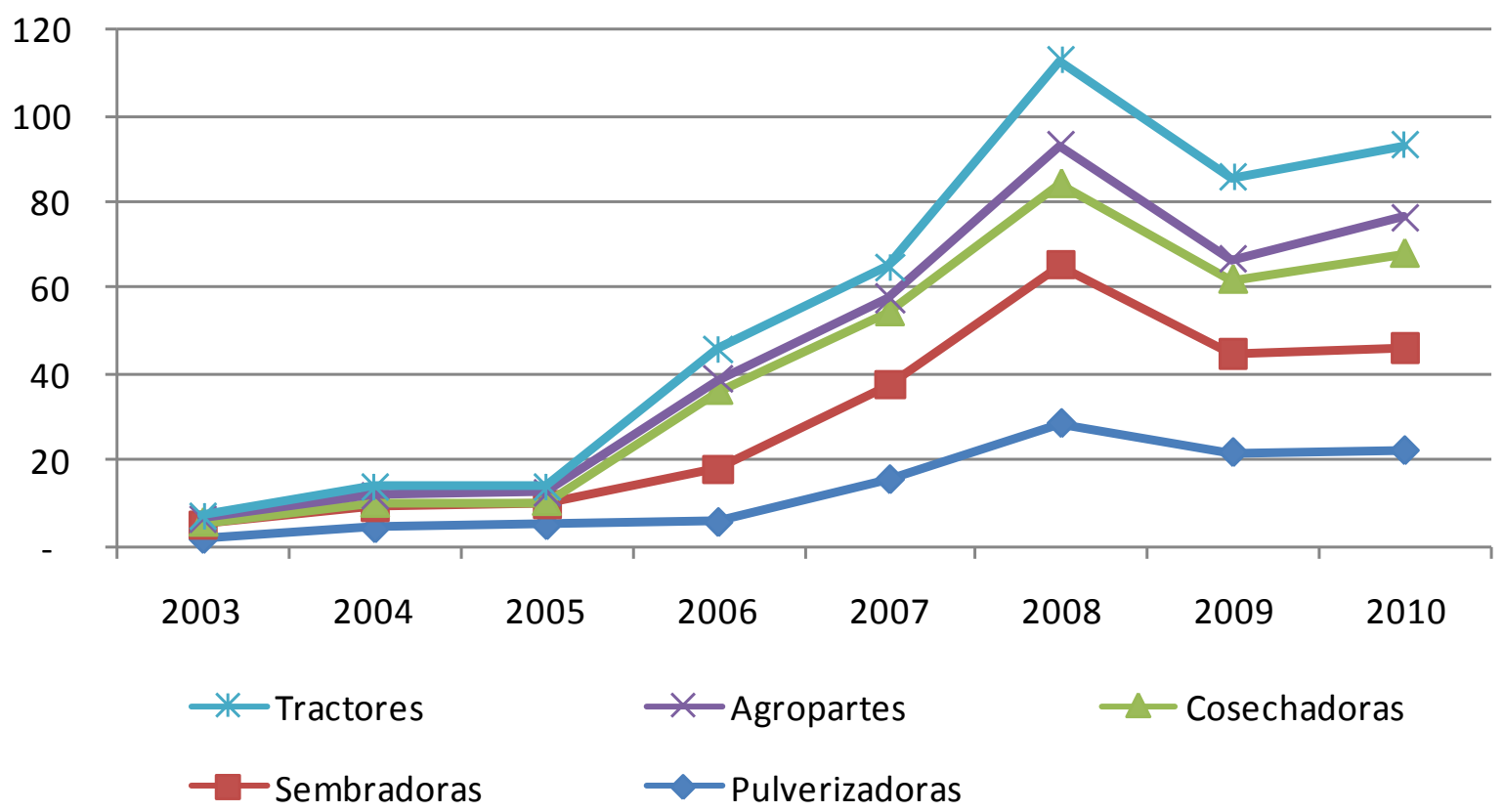

Fuente: Lavarello, Silva y Langard (2010).

En el gráfico $\mathrm{N}^{\circ} 7$, vemos el desempeño exportador de los segmentos trabajados. En él encontramos que pese a los déficits en 4 de los 5 segmentos, sus exportaciones han aumentado y lo han hecho en una situación de crecimiento del mercado interno, por lo tanto no se puede hablar de una liquidación de las existencias como sucedía en épocas pasadas. Dicho gráfico muestra una tendencia de aumento de exportación de equipos en todos los rubros aquí tratados. En los segmentos de tractores y cosechadoras, el crecimiento responde a los acuerdos con la República Bolivariana de Venezuela en 2006, constituyéndose en el principal destino de estos productos. En tanto que el resto de los segmentos tienen caminos muy variados, siendo de mucha importancia el de América Latina, pero también resaltan países no tradicionales como Alemania, Rusia, Ucrania.

En simultáneo con el "despegue" exportador, algunas empresas nacionales de las más grandes en su segmento, se han ido internacionalizando, han instalado plantas de producción fuera del país. La empresa de sembradoras Agrometal compró más de la mitad de la firma Frankhauser de Brasil, las empresas Pla SA y Metalfor, líderes en el mercado de pulverizadoras argentino, poseen plantas propias en el país vecino. La firma Pauny ensambla tractores y la compañía Ombú produce implementos agrícolas, en la República Bolivariana de Venezuela. 


\subsection{Consecuencias de la estructura mundial del comercio de maquinaria agrícola en Argentina}

Argentina posee, como ya se dijo, una industria de maquinaria agrícola de larga trayectoria, que se desarrolló a la luz de políticas industriales y proteccionistas durante el período denominado de sustitución de importaciones. Ahora bien desde el inicio de la industria de maquinaria agrícola en Argentina estuvieron presente las empresas transnacionales, las cuales complementaron el desarrollo de la industria del tractor en el país, pero también, en tiempos recientes, estos mismos actores han desarticulado los entramados industriales locales, a partir de estrategias vinculadas con un tipo de regulación económica liberal.

A partir de la configuración espacial de los grandes "jugadores" (países y empresas transnacionales), en el comercio internacional de maquinaria agrícola nos acercamos a la posición que posee Argentina en la estructura de negocios de las empresas y de los países dominantes. La organización de la producción se hace fundamentalmente en vistas al mercado regional como base central del mercado interno ampliado.

Por otra parte, la intención es poner en duda la idea que supone que, teniendo un sector competitivo a nivel mundial, éste traccionará por sí solo a otros sectores proveedores, para que también alcancen altos niveles de competitividad. Debemos considerar que esto último será factible si, (y sólo si) se acompaña con políticas industriales adecuadas y de protección del mercado interno.

El rol desempeñado por las compañías transnacionales instaladas en el país desde la década de 1950 en Argentina se fue modificando, de filiales réplica de baja escala (con deseconomías de escala), a la especialización en componentes e importadores de equipos completos. La construcción del mercado regional argentinobrasileño, se visualiza como una suerte de espejo con las regiones centrales. Las potencias Alemania, EE.UU., Japón e Italia dominan como primer paso sus "hinterlands", para luego extender su llegada geográfica mundial, desde la exportación y la inversión directa.

Argentina ha recorrido un camino más largo que Brasil en cuanto a producción y desarrollo de maquinaria agrícola, pero ante la asimetría de políticas industriales, la apertura de los mercados y el establecimiento en Brasil de las empresas transnacionales, el país se encuentra en una relación asimétrica y en desventaja para el desarrollo industrial propio. 
Cierto es que el país vislumbra la posibilidad de superar esta situación ante los importantes cambios en política comercial que se han ido sucediendo en los últimos años (2009 en adelante). 
CAPÍTULO 4 


\section{Configuración territorial y organización empresarial}

\subsection{Introducción}

El presente capítulo aborda el estudio de la industria de maquinaria agrícola en Argentina a partir del modo en que se organiza la producción. Nuestro país se encuentra entre aquellos que han mostrado un alto dinamismo y sofisticación de la demanda de maquinaria agrícola. Junto a Canadá y la Federación Rusa, se ha constituido, en la última década, en uno de los países más importantes como importadores de equipos de relativa complejidad tecnológica como es el caso de las cosechadoras $^{161}$. Este comportamiento tiene como corolario un persistente déficit en la balanza comercial del sector, a pesar de que se han registrado exportaciones de algunos productos que se revelan competitivos a nivel global (como se ha presentado en el capítulo 3). Dos rasgos caracterizan a la industria de equipos agrícolas del país: se trata de un sector estructuralmente deficitario y muestra una marcada heterogeneidad productiva.

Existen dinámicas globales y locales que reproducen dicha heterogeneidad, como se discutió en el capítulo 1, las que se expresan en las estrategias de las empresas transnacionales y en la actividad de las firmas locales territorialmente aglomeradas. Las primeras tienden a desarticular la producción local, proceso vinculado a una mayor capacidad de movilidad geográfica del capital, mientras que las firmas locales tienden a desarrollar vínculos regionales.

Existen distintos modos de articulación de la industria en el territorio según la configuración específica de cada segmento de producción, lo que se expresa en diferencias en la generación y difusión de conocimiento tecnológico (Lavarello, Silva y Langard, 2009; capítulos 2 y 3 de esta tesis)

Durante las últimas tres décadas, como se describió en el capítulo 2, estas industrias experimentaron sucesivas reestructuraciones, enmarcadas, en primer lugar, en los cambios en los contextos macroeconómico e institucionales de la época (liberalización financiera, apertura comercial, apreciación cambiaría y la posterior devaluación); en segundo lugar, en cambios específicos asociados a la dinámica de

161 Según datos de COMTRADE (2013), en

http://comtrade.un.org/db/ce/ceDefault.aspx?Page=1\&Phrase=harvester, Argentina tuvo el siguiente posicionamiento en los ranking mundiales de países importadores de cosechadoras $2003\left(3^{\circ}\right), 2004\left(2^{\circ}\right)$, $2005\left(5^{\circ}\right), 2006\left(5^{\circ}\right), 2007\left(3^{\circ}\right), 2008\left(4^{\circ}\right), 2009\left(21^{\circ}\right), 2010\left(3^{\circ}\right), 2011\left(7^{\circ}\right), 2012\left(16^{\circ}\right)$. 
los complejos agropecuarios, entre otros, el aumento y mayor variabilidad de los precios internacionales de los productos agrícolas; y en tercer término en nuevas tecnologías genéricas que modelan los procesos agronómicos e impulsan la difusión de modernos paquetes tecnológicos en los principales cultivos de granos y oleaginosas.

Estas reestructuraciones produjeron tensiones entre las dinámicas de las empresas transnacionales fabricantes de tractores y cosechadoras y las dinámicas de las empresas PYME nacionales, de fuerte arraigo regional y de articulación local con los sistemas de innovación. Esto es particularmente importante en el contexto tecnoeconómico posfordista, como vimos en el capítulo 1, con la difusión de métodos de producción flexible y formas de organización territorial de la producción, susceptibles de generar nuevas oportunidades de innovación. En la industria de maquinaria agrícola, estas oportunidades están asociadas a la experiencia acumulada de las empresas localmente concentradas y a los desarrollos en los sistemas agronómicos y biotecnológicos.

Teniendo en cuenta estos elementos de contexto, el presente capítulo se estructura de la siguiente forma. En la segunda sección, se discute la organización espacial de la industria partiendo de una revisión del concepto de clusters, en aspectos funcionales relevantes para el estudio de la industria de maquinaria agrícola argentina, retomando temas presentados en el capítulo 1. En la tercera sección, se delimita espacialmente el aglomerado territorial de industrias de maquinaria agrícola y se presenta de forma precisa la región ${ }^{162}$ de estudio.

En las secciones subsiguientes se analiza la estructura de la industria de maquinaria agrícola del país a partir de dos fuentes de información empírica: las encuestas del proyecto "Redes de Conocimiento en tramas productivas: Generación, circulación y apropiación del conocimiento y creación de ventajas competitivas en seis tramas de la Argentina. Componente Maquinaria Agrícola" PEC A-26 FLACSO-IDRC; y las entrevistas realizadas a dos filiales de compañías transnacionales líderes a nivel mundial en el contexto del estudio llevado a cabo por Lavarello y Hecker (2009) para el Ministerio de Economía de la Nación. Estas dos compañías también formaron parte de la muestra encuestada en el PEC A-26.

162 El concepto de región es entendido como instrumento teórico, analítico, construido sobre la base de criterios definidos por el investigador (Haesbert, 2009). 
La cuarta sección presenta las características estructurales productivas, de mercado y de desempeño de las firmas de los distintos segmentos ${ }^{163}$ de firmas de la industria de maquinaria agrícola. Las características estructurales al interior de la industria muestran una marcada heterogeneidad de productividad de la que se intentará dar explicación a lo largo del capítulo. De este análisis surge que uno de los segmentos con más alta productividad es el que está más asociado a la organización de la producción en cadenas de valor global, con alta desintegración vertical y fuertes economías de escala. No obstante existe un segundo segmento de producción con alta productividad, que no exhibe las características propias de los sectores de producción escala intensivos. Este contraste genera uno de los interrogantes que guían el presente capítulo ¿cómo obtiene altas productividades este segundo segmento?

A partir de la sección quinta, se busca dar respuesta a esta cuestión y se analizan todos los segmentos de la producción de maquinaria agrícola, detallando las tramas de proveedores de los mismos, distinguiendo entre empresas transnacionales y locales-nacionales. La siguiente sección examina la importancia de las vinculaciones no mercantiles para el desarrollo del aglomerado productivo, analizando la receptividad técnica de cada subsector. El análisis se profundiza en la sección siete al examinar las capacidades organizacionales endógenas de las firmas, las que están relacionadas con las posibilidades de captar las externalidades que se generan con el entorno.

En la octava sección se analizan las estrategias de localización y organización de la producción de las dos empresas transnacionales seleccionadas, a partir de las entrevistas abiertas, ya mencionadas. De esta manera se puede contrastar el desenvolvimiento de estas firmas vis a vis las empresas de capital nacional, identificando el rol de estas compañías en la desestructuración territorial y en la profundización de la heterogeneidad estructural en los términos desarrollados en el capítulo 1.

Finalmente, la sección novena, presenta una síntesis de los resultados obtenidos a partir del análisis de la heterogeneidad interna del aglomerado productivo y del rol de cada segmento en su reproducción y aumento en el debilitamiento de los factores que la generan.

\footnotetext{
${ }^{163}$ La clasificación de las distintas firmas se establece por segmento de producto, a partir de una tipología utilizada la tesis, desarrollada previamente (ver Lavarello, Silva, Langard, 2009).
} 


\subsection{Organización espacial de la industria de maquinaria agrícola}

El propósito de esta sección es plantear algunos interrogantes acerca del tipo de configuración y organización espacial que tiene la industria de maquinaria agrícola argentina tomando como punto de partida la discusión conceptual planteada en el capítulo 1 sección 5 respecto de las lógicas espaciales de la producción industrial.

Se retoma la visión crítica al concepto de cluster propuesto en ese capítulo y se discute la primer limitación o "falla" del enfoque de cluster presentada por Fernandez et al. (2008), en referencia a la ambigüedad de las delimitaciones espaciales y los aspectos constitutivos funcionales que en este marco se toman como referencia.

Para ello, se definen en el territorio las características heterogéneas de los distintos subsectores de la industria de maquinaria agrícola, relacionadas con los vínculos que se generan entre el conjunto de empresas y agentes espacialmente colocalizados a través de relaciones verticales del tipo de nexos proveedor/usuario y de relaciones horizontales, entendidas estas últimas como vínculos entre firmas ubicadas en una misma etapa productiva, que pueden ser de cooperación o de competencia.

El gráfico $N^{\circ} 8$ presenta una visión global de la cadena de valor, sin considerar las especificidades de cada segmento productivo, tema éste que se retoma en las secciones subsiguientes. Las cadenas de valor de los distintos segmentos productivos dependerán del grado de la división del trabajo, de la integración vertical y de la forma de articulación con proveedores locales o extranjeros ${ }^{164}$.

La primera etapa de la cadena comprende la materia prima, la que es provista por las empresas de siderurgia; se trata de fundiciones que se producen bajo plano, proveedores de conjuntos y proveedores de subconjuntos estandarizados. En ciertos casos estos eslabones son procesos que están integrados por las empresas terminales. Esta etapa comprende la construcción del cuerpo estructural del equipo, transformando el acero laminado plano, planchuelas, perfiles y caños. Sumado a ello, existen proveedores de conjuntos y subconjuntos, que resultan del ensamble de distintas piezas y partes, que cumplen funciones centrales en las máquinas

\footnotetext{
${ }^{164}$ En este sentido se debe tener en cuenta que en las producciones metalmecánicas, la profundidad o densidad de la cadena de producción puede estar técnicamente condicionada por la complejidad del producto. En este sentido la densidad puede ser potencialmente mayor en el caso de una cosechadora que tiene alrededor de 10.000 piezas mientras que en el caso de un arado moderno, entre 7 y 20 (INTA, 2011). Esta relación está reforzada por el grado de complejidad de dichas piezas, partes y conjuntos. No obstante, como se discutirá empíricamente en el resto del capítulo la complejidad no determina mecánicamente el grado de integración de una cadena y su densidad sino que otros factores de carácter económico y estratégico.
} 
producidas. Las terminales toman las partes, piezas, conjuntos y subconjuntos producidos en la primera etapa y los ensambla o sueldan junto con otros componentes para configurar la estructura central de cada maquinaria de acuerdo al diseño. Se incorporan luego los insumos estándar tales como neumáticos, llantas, correas, cilindros hidráulicos, etc., los que son provistos por partistas generales y agropartistas específicos.

\section{Gráfico № 8. Cadena de valor de la maquinaria agrícola}

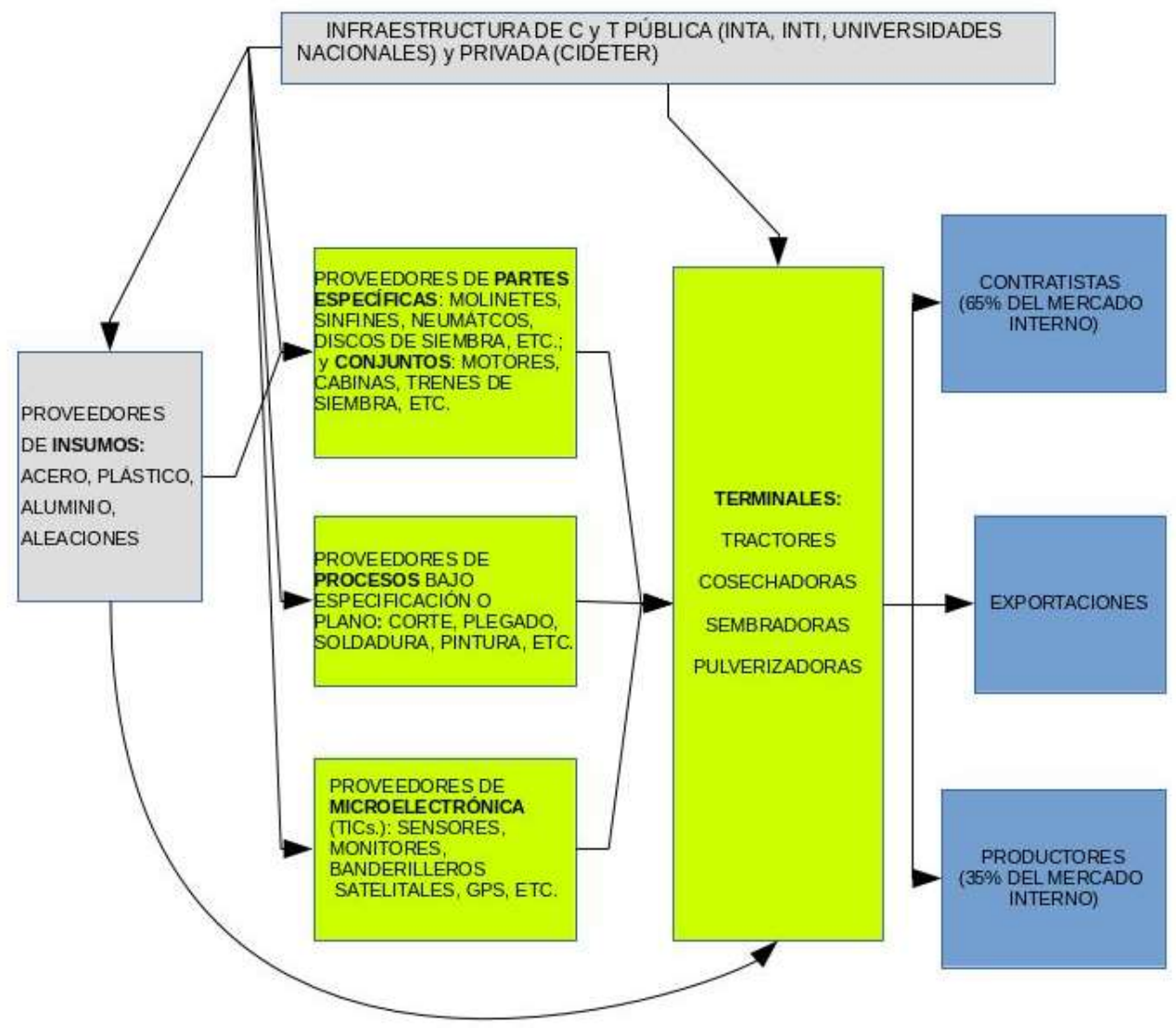

Fuente: Elaboración propia en base a Heybel (2006).

Es de destacar que una aglomeración territorial no engloba, necesariamente, a todas las empresas, etapas productivas y comerciales que definen a una cadena de valor. Por el contrario, la mayoría de las veces, sólo están localizadas en el espacio en cuestión algunas de las etapas de la cadena. Los análisis de clusters incluyen las empresas de producción especializadas; las empresas proveedoras; firmas prestadoras de servicios, instituciones de investigación e instituciones públicas y 
privadas de soporte básico localizadas en el territorio en cuestión (estos tres últimos actores, se los considera dentro del conjunto de relaciones horizontales).

La visión de la literatura sobre clusters se focaliza en el estudio de la generación de ventajas competitivas de aglomeración y de economías externas o externalidades del sector para la región (externas a la empresa e internas al conjunto de firmas), que impulsan las dinámicas competitivas de las firmas. En este sentido, un aspecto central, para el desarrollo sustentable económico y social de un cluster, es la creación de capacidades productivas especializadas y espacialmente localizadas. El funcionamiento de vinculaciones entre productores y usuarios-clientes es una de las condiciones centrales para que se generen ventajas competitivas dinámicas. La conformación de un cluster es a la vez el resultado de la concentración de firmas e industrias en un espacio territorial delimitado, de manera "espontánea", que junto a instancias políticas desarrollan las necesarias instituciones públicas y privadas y la infraestructura de soporte.

Nuestra visión, a la vez, que propone una diferenciación entre aglomeración industrial territorial y cluster, como caso particular, este último, de mayor desarrollo, como se planteara en el capítulo 1, también, confiere cierta importancia a la delimitación territorial de la aglomeración de industrias. Cuestión que veremos a continuación con respecto a la industria de maquinaria agrícola en Argentina.

\subsection{Delimitación territorial del área de estudio ${ }^{165}$}

La industria de maquinaria agrícola argentina se ha desplegado territorialmente bajo el impulso de la inserción de la región pampeana en la economía mundial como exportadora de granos, configurándose un núcleo central conformado por 12 departamentos de las provincias de Santa Fe y Córdoba, donde se concentra la mayor cantidad de empresas de equipos agrícolas del país. Esta región engloba departamentos de larga trayectoria histórica en la producción de maquinaria agrícola y a la vez refleja el proceso de expansión espacial que tuvo lugar en un período de más reciente desarrollo (etapa ISI, ver capítulo 2). ${ }^{166}$

\footnotetext{
${ }^{165}$ Esta sección se elaboró en base a información brindada por las cámaras empresarias (AFAMAC , CAFMA y CIDETER), a partir del conocimiento que estas tienen sobre el sector y de los requerimientos de la investigación.

166 Estos 12 departamentos de Santa Fe y Córdoba concentran el 62,5\% de las empresas productoras de maquinaria agrícola y agropartes, sobre un total del I $68 \%$ en el territorio de ambas provincias. La provincia de Buenos Aires (la de mayor desarrollo industrial del país) y la Entre Ríos (la cuarta provincia con mayor cantidad de firmas de maquinaria agrícola) concentran el $24,3 \%$ de las empresas sobre un
} 
A partir de los padrones de empresas aportados por las cámaras sectoriales (CAFMA y CIDETER) se pudo constatar el tamaño y diversificación productiva de la industria, así como la amplia extensión territorial del sector. En el mapa $\mathrm{N}^{0} 1$ se muestra la región de estudio donde se ubican las firmas que participaron de la encuesta por departamentos y por localidades.

\section{Mapa № 7. Región de estudio}
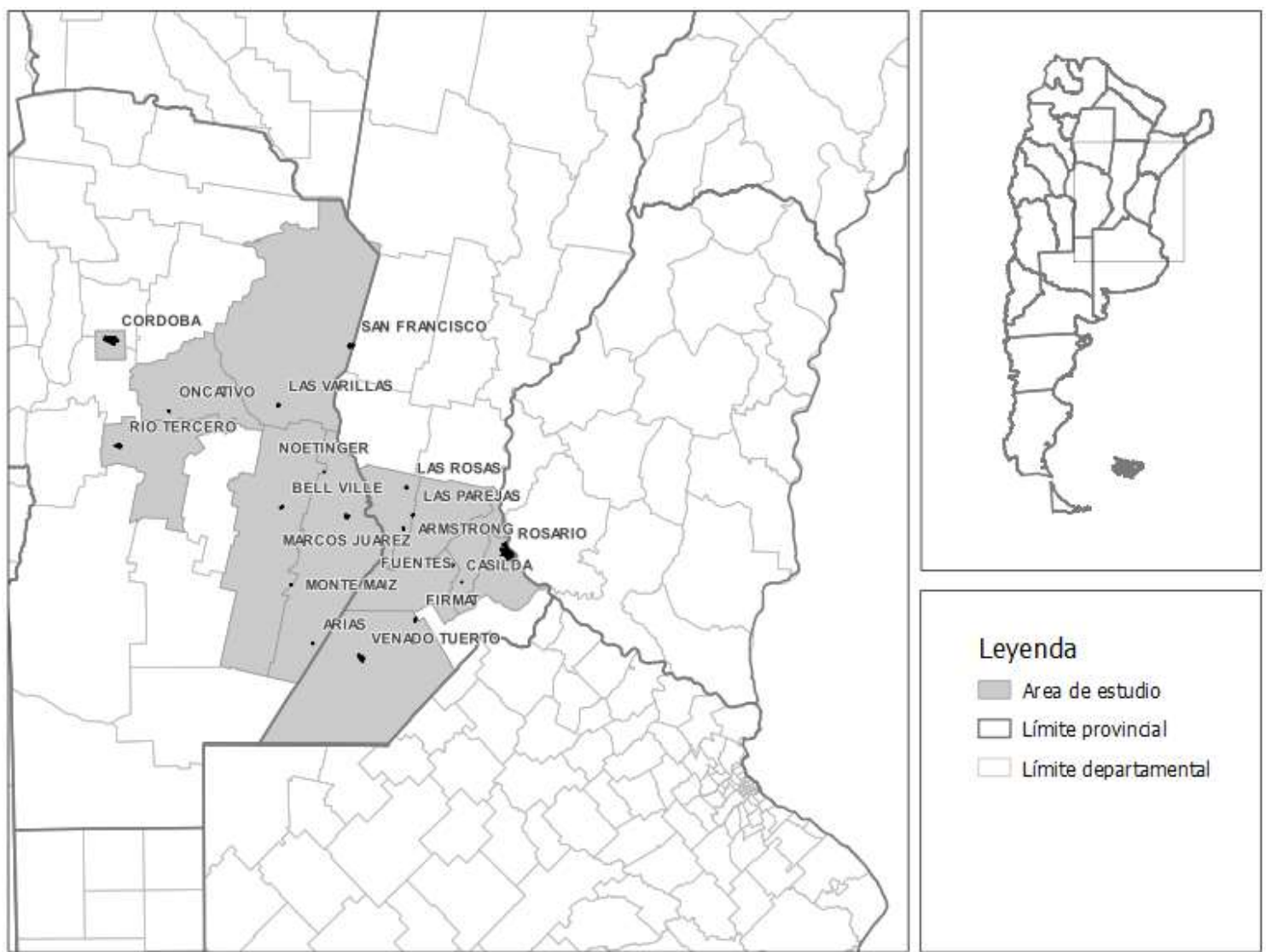

Leyenda

Area de estudio

Límite provincial

Límite departamental

Fuente: elaboración propia

Siguiendo con la estructura de análisis a partir de los límites que pueden encontrarse a la teoría de cluster según Fernandez et al. (2008) ${ }^{167}$, se considera que los clusters engloban una serie de actividades y actores que poseen cierta

total de 838. Por otra parte, la característica más relevante de los departamentos santafesinos y cordobeses es su grado de contigüidad física, en contraste con otras provincias, como Buenos Aires, en las que la dispersión de las empresas es alta (ver Moltoni y Gorestein, 2009).

167 Ver capítulo 1. 
heterogeneidad, factores que es necesario analizar para comprender la dinámica de cluster. Para ello, a continuación se analizarán algunas de las características estructurales del sector para, en las subsiguientes secciones, abordar el estudio de los procesos de un cluster que son generadores de mayor innovación, economías externas y alta productividad ${ }^{168}$.

\subsection{Estructura de los distintos segmentos de la industria en la región de estudio}

La respuesta del sector a nuevas configuraciones macroeconómicas y tecnológicas ha sido distinta según los diferentes segmentos de productos de la industria. Las eventuales formas organizacionales adoptadas por los distintos subsectores para enfrentar la competencia en innovación se diferencian según las firmas tengan un vínculo mayor o menor con la región. Este vínculo estará determinado, en primer lugar, por grado de asociación directa del producto a las especificaciones agronómicas locales de la producción y, en segundo término, por la importancia de las economías de escala.

Cuadro $N^{\circ}$ 11. Tamaño de empresas ${ }^{169}$. En porcentajes por cantidad de firmas.

\begin{tabular}{|l|c|c|c|c|c|}
\hline & Agropartistas & $\begin{array}{c}\text { Cosechadoras } \\
y \text { tractores }\end{array}$ & $\begin{array}{c}\text { Implementos } \\
\text { agrícolas }\end{array}$ & $\begin{array}{c}\text { Pulveriza- } \\
\text { doras }\end{array}$ & $\begin{array}{c}\text { Sembra- } \\
\text { doras }\end{array}$ \\
\hline Micro & 4,3 & 0 & 7,1 & 0 & 0 \\
\hline Pequeña & 52,2 & 0 & 21,4 & 11,1 & 15,4 \\
\hline Mediana & 34,8 & 40 & 57,2 & 66,7 & 61,5 \\
\hline Grande & 8,7 & 60 & 14,3 & 22,2 & 23,1 \\
\hline
\end{tabular}

Fuente: elaboración propia en base a datos del Proyecto "Redes de Conocimiento en tramas productivas: Generación, circulación y apropiación del conocimiento y creación de ventajas competitivas en seis tramas de la Argentina. Componente Maquinaria Agrícola" PEC A-26 FLACSO-IDRC. Fuente: Datos recogidos en el año 2008.

\footnotetext{
168 La muestra de empresas con la que se trabajo es un número de 64 firmas. Compuestas por 5 compañías de tractores y cosechadoras; 13 de sembradoras; 9 de pulverizadoras; 23 de agropartes; 14 de implementos agrícolas. La misma es representativa de la industria de maquinaria agrícola en Argentina. El trabajo de campo se realizó en el marco del a datos del Proyecto "Redes de Conocimiento en tramas productivas: Generación, circulación y apropiación del conocimiento y creación de ventajas competitivas en seis tramas de la Argentina. Componente Maquinaria Agrícola" PEC A-26 FLACSOIDRC.

${ }^{169}$ El tamaño se midió según el número de empleados. De 1 a 5 empleados se considera microempresa, de 6 a 25 pequeña, de 26 a 250 mediana y de 251 en adelante grande.
} 
En el cuadro $\mathrm{N}^{\circ} 11$, es posible apreciar que el tamaño de las firmas difiere según los distintos segmentos. Las firmas productoras de cosechadoras y tractores son las más grandes. En el otro extremo las firmas agropartistas son mayoritariamente micro, pequeñas y medianas empresas. Entre ambos segmentos se encuentra el universo de empresas de sembradoras y pulverizadoras, mayormente firmas medianas. Los tamaños de las firmas de implementos agrícolas son los más variados aunque se concentran en un amplio porcentaje en empresas medianas. Las empresas agropartistas por su parte tienen una representación fuerte de empresas pequeñas.

En el cuadro $\mathrm{N}^{\circ} 12$ se presentan los valores promedio de los principales indicadores de estructura y desempeño, con el propósito de establecer las diferencias entre los distintos segmentos. Como puede apreciarse, las empresas de los distintos subsectores se diferencian en los niveles de productividad aparente (ventas sobre empleados), en los coeficientes de importaciones, en el grado de asimetría en la relación con sus proveedores y en los niveles de integración vertical.

Como puede observarse, las firmas productoras de tractores y cosechadoras son más grandes, tienen una alta provisión de insumos importados, gran parte de su producción es exportada a filiales de la misma firma y poseen una muy baja integración vertical. Este sector se asemeja a una industria de ensamble escala intensiva inserta en una cadena de valor global, lo que se aprecia en el alto nivel de tercerización de procesos productivos y de servicios y una muy alta concentración en sus proveedores, en su mayoría extranjeros.

En contraste, los otros cuatro segmentos de la industria se abastecen de insumos, partes y componentes en mayor medida de forma local o nacional. Del total de compras de insumos, estas empresas (su mayoría PYME) importan menos del $20 \%$ en bienes intermedios y el peso de las exportaciones intrafirma es limitado, mostrando una débil inserción en cadenas globales de valor.

Las firmas que producen sembradoras tienen niveles medios-altos de integración vertical. Este segmento de producción también posee la más alta diversificación de proveedores y una alta productividad aparente.

En el caso de las firmas de pulverizadoras poseen una diversificación media-alta de proveedores y una baja integración vertical, con un coeficiente importador superior 
al subsector de sembradoras. Inferimos que este coeficiente está determinado por la importación de motores, transmisiones y bombas (conjunto motriz y de dispersión de líquidos).

Cuadro № 12: Maquinaria Agrícola. Indicadores estructurales de la trama ${ }^{170}$ 2006-2007.

\begin{tabular}{|c|c|c|c|c|c|c|}
\hline & $\begin{array}{l}\text { Agropar- } \\
\text { tistas }\end{array}$ & $\begin{array}{l}\text { Cosechadoras } \\
\text { y tractores }\end{array}$ & $\begin{array}{l}\text { Implemen- } \\
\text { tos agrícolas }\end{array}$ & $\begin{array}{l}\text { Pulveriza- } \\
\text { doras }\end{array}$ & $\begin{array}{l}\text { Sembra- } \\
\text { doras }\end{array}$ & $\begin{array}{l}\text { Prueba } \\
\text { medias } \\
\text { (Anova) }\end{array}$ \\
\hline Ocupados & 28 & 222 & 50 & 94 & 92 & 0 \\
\hline $\begin{array}{c}\text { Ventas sobre } \\
\text { ocupados (\$ de 2003) }\end{array}$ & 76,4 & 274,8 & 108,9 & 165,3 & 212,2 & 0 \\
\hline $\begin{array}{l}\text { Coeficiente de } \\
\text { exportaciones }^{171}\end{array}$ & 15 & 8,6 & 10 & 8,4 & 11,3 & 0,92 \\
\hline $\begin{array}{l}\text { Coeficientes de } \\
\text { exportaciones } \\
\text { intrafirma }\end{array}$ & 18,3 & 50 & 5 & 5,2 & 10 & 0,04 \\
\hline $\begin{array}{l}\text { Coeficiente de } \\
\text { importaciones }\end{array}$ & 20,3 & 55 & 7,9 & 14,1 & 9 & 0 \\
\hline $\begin{array}{c}\text { Porcentajes de } \\
\text { compras a los } 5 \\
\text { principales } \\
\text { proveedores }\end{array}$ & 86,8 & 60,3 & 60,7 & 57,9 & 41,3 & 0 \\
\hline Número de empresas & 23 & 5 & 14 & 9 & 13 & \\
\hline \multicolumn{6}{|c|}{ Integración vertical en porcentajes de empresas ${ }^{173}$} & $\begin{array}{l}\text { Prueba de } \\
\text { Chi } \\
\text { Cuadrado }\end{array}$ \\
\hline ALTO & 30,4 & 0 & 7,7 & 25 & 53,8 & \multirow{3}{*}{0} \\
\hline MEDIO & 26,1 & 40 & 61,5 & 25 & 38,5 & \\
\hline BAJO & 43,5 & 60 & 30,8 & 50 & 7,7 & \\
\hline
\end{tabular}

Fuente: elaboración propia en base a Lavarello, Silva y Langard (2009)

Por su parte, las empresas agropartistas, constituido por firmas de reducido tamaño, muestran cierto grado de inserción en cadenas globales de valor con

\footnotetext{
170 Los datos son las medias estadísticas de la muestra

171 Exportaciones sobre el nivel de ventas totales

${ }^{172}$ Importaciones sobre el nivel de las compras totales

173 El indicador se construyó a partir de la información proporcionada por las empresas de la forma (interna o externa) en que desarrollan un conjunto de actividades productivas (Cortado y plegado, soldadura, mecanizado, ensambles, pintado y sus sub-procesos, automatización y control de calidad). Se estimó un índice de grado de integración cuyos valores alto o bajo dependerá del número de actividades realizadas internamente.
} 
moderados niveles de exportación e importación. Los valores de integración vertical son bajos, con una muy alta concentración de proveedores. Este segmento ostenta los niveles más bajos de productividad aparente.

Por último el segmento de implementos agrícolas, tiene una baja productividad relativa, alta concentración de proveedores, son empresas en promedio más grandes que las agropartistas, pero de todas formas son chicas y los niveles de integración vertical son medios.

Luego, es posible sostener que la industria de producción de maquinaria agrícola muestra tres estructuras altamente diferenciadas según los segmentos productivos. Por un lado, segmentos conformados por empresas de gran tamaño, insertos en cadenas globales de valor con elevada productividad y altos grados de externalización, pero con un bajo coeficiente de exportaciones, como es el caso de los fabricantes de cosechadoras y tractores. Por otro lado, segmentos como los de sembradoras e implementos en los cuales predominan empresas nacionales relativamente integradas y con menores coeficientes de importaciones, que se caracterizan, a su vez, por una incipiente competitividad en mercados externos. Entre estos dos extremos, se evidencian situaciones intermedias en la fabricación de pulverizadoras y de agropartes. Como es de esperar las firmas más grandes son las de más alta productividad aparente y las más pequeñas, por el contrario, las de más baja productividad aparente.

Respecto al grado de integración vertical de las empresas (ver cuadro $N^{\circ} 12$ ), que determina en parte la cantidad de productos y de proceso que se realizan fuera de la planta, se puede establecer un mayor o menor número de relaciones mercantiles y no mercantiles entre proveedores y usuarios. Los subsectores que se destacan son el de sembradoras por su alto grado de integración y el de cosechadoras y tractores por su bajo nivel de integración vertical. El resto de los segmentos tienen, en forma relativa, un grado intermedio de integración vertical.

Del análisis realizado, surge el siguiente interrogante ¿cómo logran las firmas productoras de sembradoras alcanzar niveles de productividad cercanos a los de las empresas de tractores y cosechadoras, no teniendo las características clásicas de empresas de alta productividad? ${ }^{174}$

Esta cuestión es de interés para el análisis que se realiza en las siguientes secciones sobre las diferentes estrategias de organización, en el territorio e

${ }^{174}$ Con características clásicas se hace referencia a empresas grandes, de gran escala de producción, desintegradas verticalmente. 
internamente, de los distintos subsectores. Estas estrategias están relacionadas con la mayor o menor vinculación que tengan las empresas con agentes locales, lo que se traduce en grados diferentes de generación de valor a partir de conocimientos producidos y aplicados localmente, incidiendo a su vez en diferentes formas de desarrollo territorial.

\subsection{Configuración de relaciones proveedor - usuario}

Durante los últimos 10 años, con la difusión de nuevas tecnologías, se han multiplicado las competencias requeridas para el diseño y desarrollo de equipos agrícolas. Los procesos productivos se han hecho más complejos y la industria ha debido aumentar sus capacidades tecnológicas incluyendo una variedad de disciplinas que trasciende al diseño mecánico estructural (principal competencia de las empresas locales) e incluyen tecnologías hidráulicas, neumáticas, electrónicas, software y tecnologías de la información y comunicación en un sentido amplio (Lengyel y Bottino, 2010; Lavarello y Goldstein, 2011).

La importancia de la experiencia acumulada en la industria de maquinaria agrícola en Argentina, durante la industrialización sustitutiva, permite inferir que los distintos subsectores de esta industria responden a dinámicas diferentes, fuertemente influenciadas por las distintas capacidades de las firmas de absorción y formas diferentes de vinculación con proveedores, clientes y la infraestructura de ciencia y técnica. Las articulaciones proveedor-usuario pueden ser fuentes de externalidades positivas para el desarrollo productivo de una aglomeración, como se desprende de varios trabajos realizados a partir de la experiencia de los países escandinavos y de trabajos locales para el caso de las agroindustrias. Las articulaciones proveedorusuario son fuentes de generación de innovaciones en el espacio nacional y local (Lundvall, 1999; Edquist y Lundvall, 1993; Lavarello y Goldstein, 2011).

No obstante, los procesos de transnacionalización plantean límites a las posibilidades de desarrollo de estos aprendizajes (Chesnais, 1992; Lavarello, 2004; Gutman y Lavarello, 2003). Por ello, es de relevancia analizar la estructura de abastecimiento de insumos y componentes de los distintos subsectores según el origen de los insumos distinguiendo entre dos tipos diferentes de articulación:

En el segmento de tractores y cosechadoras, se genera una fuerte articulación comercial con proveedores extranjeros, debido a que algunos de los componentes más importantes de estas maquinarias no son fabricados en el país (o lo son de 
manera insuficiente) y son componentes que tienen un elevado peso en el armado final de la máquina, como es el caso, por ejemplo, de los motores importados completamente o ensamblados localmente con gran cantidad de piezas y componentes extranjeros, al igual que las bombas hidráulicas, electrónica y las transmisiones.

Los otros cuatro subsectores, con niveles bajos y medios de desintegración vertical, se proveen de materia prima e insumos de producción nacional. La mayor parte de los insumos son adquiridos dentro de la región a productores o distribuidores locales. Cabe interrogarse en qué medida el grado de asimetría entre las partes de la vinculación afecta a las posibilidades de aprendizaje. En este sentido debemos destacar que el acero, insumo clave y de gran peso en estos productos, es comprado, mayoritariamente en distribuidoras de los grandes grupos siderúrgicos de posición oligopólica ${ }^{175}$.

Ahora bien, con el fin de visualizar gráficamente las distintas articulaciones comerciales, según segmento de producto, en los gráficos a continuación se presenta la red de aprovisionamiento, elaborada con datos surgidos de la encuesta, a partir de las respuesta de las empresas terminales con respecto a cuáles son los principales proveedores, cruzada con la respuesta de los partistas respecto a cuáles son los principales clientes.

A partir de estos gráficos se puede establecer, entre otros parámetros, la densidad de la trama y la centralidad de algunas firmas en ella. La densidad de la trama se remite de forma relativa a la cantidad de firmas dentro de la muestra y al número de relaciones generadas entre ellas. Por otra parte, el hecho que la trama esté o no cerrada es relevante en su relación sistémica. A su vez, aquellas empresas que tienen una mayor cantidad de vinculaciones como proveedoras, poseen una posición central y se las denomina "nodos".

El gráfico № 9 identifica a las empresas terminales de tractores y cosechadoras en color amarillo, a proveedores locales en color verde, los proveedores nacionales en color azul (firmas de capital nacional y extranjero instalados con producción en el país) y los extranjeros en color rojo. Si bien la muestra de empresas encuestadas contiene cinco empresas de cosechadoras y tractores, en esta gráfica aparecen seis, debido a que se agregó una empresa terminal multiproducto productora de pulverizadoras que

\footnotetext{
175 Es un dato importante el hecho que las empresas del sector no hayan logrado unirse para realizar compras conjuntas de acero que les permita negociar con las acerías directamente, para conseguir mejores condiciones en las compras. De hecho, las empresas productoras de acero son mencionadas en las entrevistas como agentes limitantes al mejoramiento del sector por su poder de mercado.
} 
diversificó su producción hacia cosechadoras.

\section{Gráfico $N^{\circ}$ 9. Trama de proveedores del subsector de tractores y cosechadoras.}

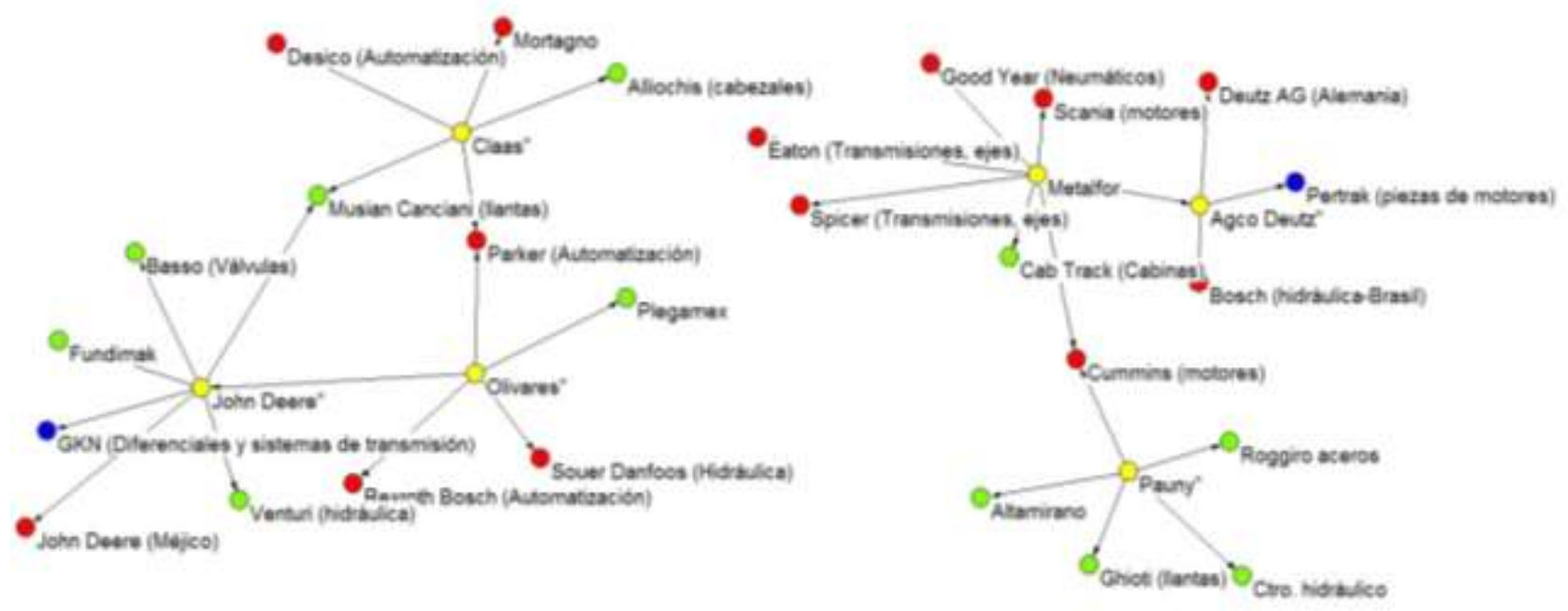

Fuente: elaboración propia en base a datos del Proyecto "Redes de Conocimiento en tramas productivas: Generación, circulación y apropiación del conocimiento y creación de ventajas competitivas en seis tramas de la Argentina. Componente Maquinaria Agrícola" PEC A-26 FLACSO-IDRC. Fuente: Datos recogidos en el año 2008.

Un aspecto central a destacar de esta trama, es que los proveedores extranjeros superan a los nacionales, teniendo los primeros mayor presencia en la cadena de valor. Dicha situación desarticula en el territorio el entramado productivo local y nacional. Por otra parte, en dos casos una empresa terminal (de capital extranjero) de tractores se convierte en proveedora de motores de una firma de cosechadoras.

Veamos, entonces, como se presenta la trama de proveedores. En primer lugar a simple vista se presentan dos subsistemas desconectados, cada uno de ellos con tres firmas terminales de tractores y/o cosechadoras. La trama de la izquierda, integrada por John Deere, Olivares, y Claas (empresas terminales), se encuentra unida por el proveedor Parker ${ }^{176}$, empresa transnacional de electromecánica, y Musian Canciani y Cía. firma local de llantas, mientras que John Deere vende motores a Olivares.

En el caso de la segunda trama (a la derecha), las terminales participantes son: Agco - Deutz, Pauny y Metalfor. La trama no está cerrada y están unidos Metalfor a Pauny por Cummins, fabricante extranjero de motores y por otro lado Metalfor,

176 http://www.parker.com 
también compra motores a Deutz, firma extranjera que produce en el territorio nacional.

Ambos segmentos tienen proveedores de conjuntos y sistemas de cierta complejidad, que son en su mayoría empresas extranjeras transnacionales. Las firmas GKN $^{177}$, Parker, Sauer Danfoss ${ }^{178}$, Spicer ${ }^{179}$, Eaton ${ }^{180}$, Bosch, Scania ${ }^{181}$ son proveedoras globales de bombas hidráulicas, motores, transmisiones, automatización y otros conjuntos para maquinaria pesada, agrícola y autotransporte.

El segmento tiene como uno de sus nodos articuladores al conjunto propulsor de la máquina, ya que el motor es uno de los componentes centrales del tractor y de la cosechadora. Se debe destacar que gran parte de las mejoras tecnológicas de estas máquinas están asociadas a la evolución y desarrollo de este componente. Ejemplo de ello es el incremento de la eficiencia y potencia, a partir de la introducción de la electrónica en su funcionamiento y del avance en los materiales con los que se confeccionan. El motor y gran parte de sus componentes es provisto por firmas transnacionales que en algunos casos tiene producciones en el país, aunque la mayor parte es importada.

\section{Gráfico $\mathbf{N}^{\circ} 10$. Trama de proveedores del subsector pulverizadoras}

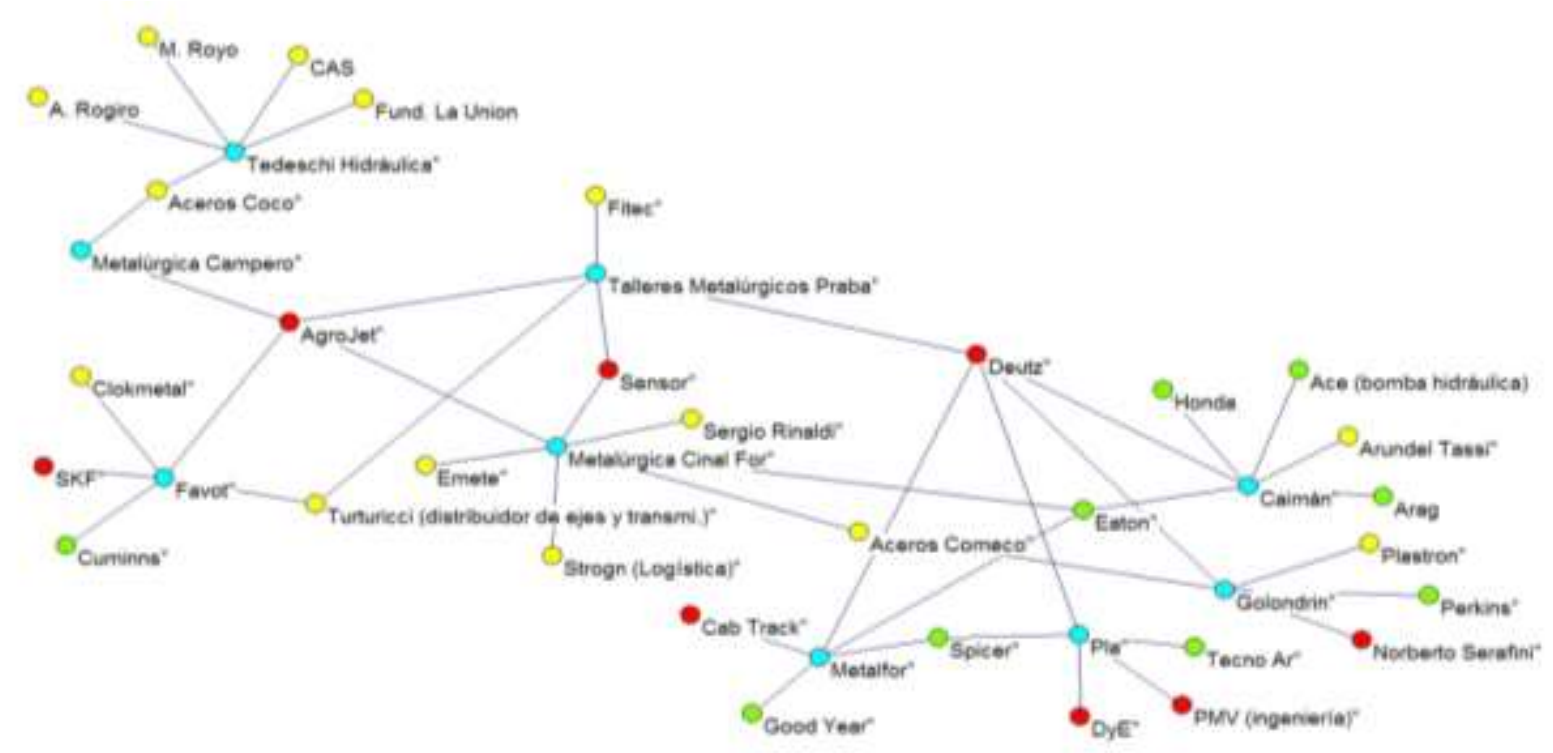

\footnotetext{
177 http://www.gkn.com , esta empresa tiene una planta en Argentina, en Chivilcoy.

178 http://www.sauer-danfoss.com

179 http://spicerparts.com/

180 http://www.eaton.com

181 http://www.scania.com.ar
} 
Fuente: elaboración propia en base a datos del Proyecto "Redes de Conocimiento en tramas productivas: Generación, circulación y apropiación del conocimiento y creación de ventajas competitivas en seis tramas de la Argentina. Componente Maquinaria Agrícola" PEC A-26 FLACSO-IDRC. Fuente: Datos recogidos en el año 2008.

El gráfico № 10 presenta a las empresas terminales de pulverizadoras en color celeste, a los proveedores nacionales de partes en color amarillo, a los proveedores nacionales de conjuntos en color rojo (también incluye a los fabricantes nacionales de capital transnacional caso Deutz) y a los extranjeros en verde. En este caso los proveedores nacionales doblan en número a los extranjeros. Con respecto al gráfico $N^{\circ} 9$, vemos que además de aumentar el número de relaciones (número de líneas), no queda ninguna terminal (de pulverizadoras) aislada con su grupo de proveedores. Este punto es de importancia en el registro que se hace de la fortaleza del entramado productivo, en un aspecto esencial que son las vinculaciones sistémicas proveedorusuario.

En cuanto a cuáles son los componentes de mayor peso por cantidad y complejidad tecnológica, se puede decir que no existe un desequilibrio pronunciado como en el subsector de tractores y cosechadoras en lo referente a la planta motriz. No obstante, motores, transmisión y sus componentes tienen importancia. En este sentido Deutz y Eaton son centrales, al igual que los proveedores de acero y plásticos rotomoldeados. Por otro lado, se encuentran cuatro empresas de microelectrónica (DyE, Sensor, Agrojet, y Arag italiana) que producen los instrumentos de agricultura de precisión. Tres de estas firmas son nacionales y poseen cierta centralidad en la trama.

El gráfico № 11 exhibe la trama de proveedores que sustenta la producción de implementos agrícolas. En este gráfico, las empresas de implementos agrícolas se representan en color amarillo, las proveedoras de acero en color verde, las partistas locales en color rojo y las firmas extranjeras de color rosa, quedando dos azules que son clientes y no proveedores. Se evidencia el peso de las acerías en la trama y, en una segunda instancia, se observa una baja incidencia de componentes importados. Las acerías prevalecen en número entre los proveedores y constituyen los puntos de unión en la trama. En este segmento se generan mayoritariamente el tipo de vinculaciones proveedor-usuario que limita los aprendizajes interactivos. 


\section{Gráfico $\mathbf{N}^{\circ}$ 11. Trama de proveedores del subsector implementos agrícolas}

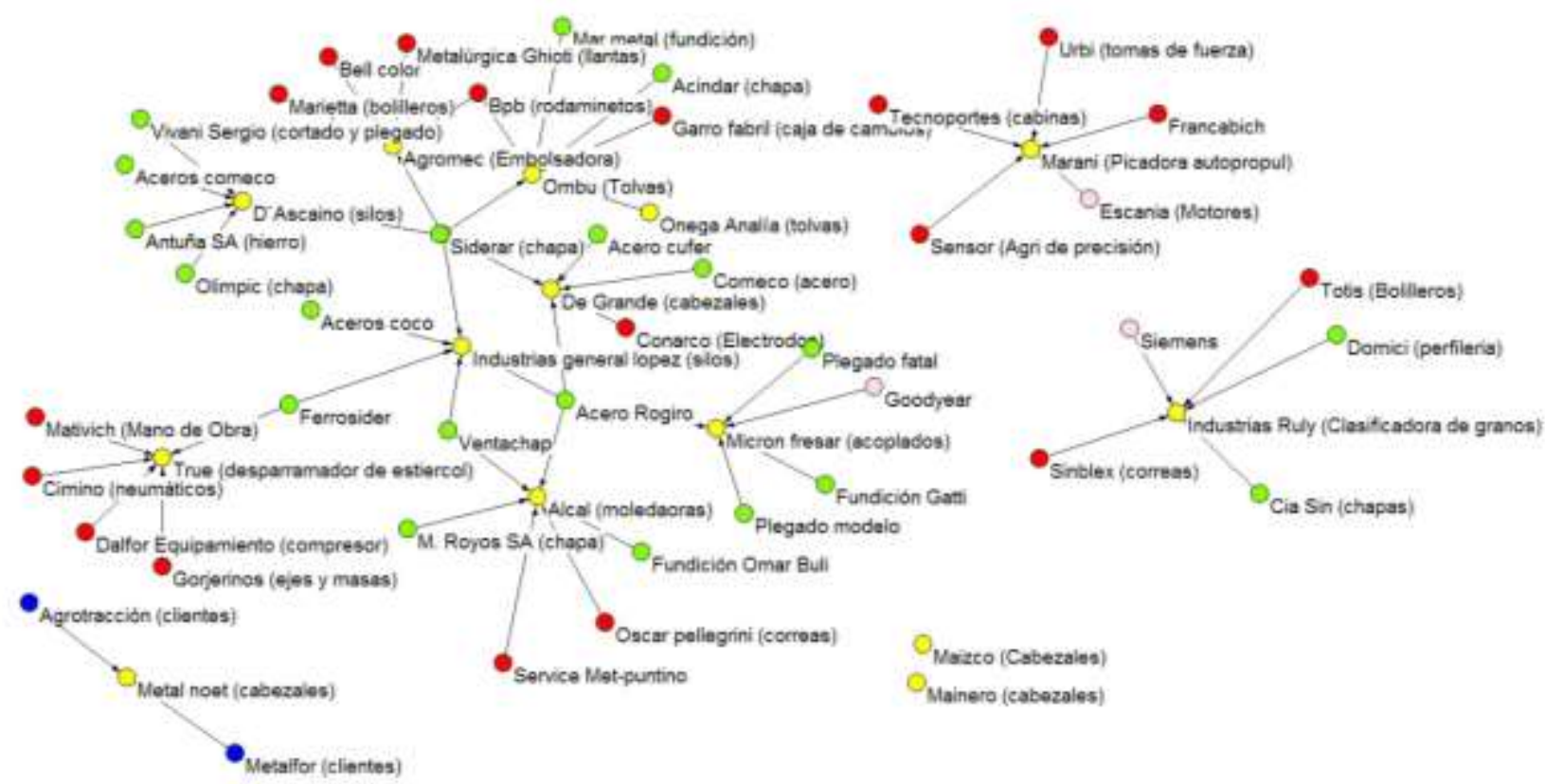

Fuente: elaboración propia en base a datos del Proyecto "Redes de Conocimiento en tramas productivas: Generación, circulación y apropiación del conocimiento y creación de ventajas competitivas en seis tramas de la Argentina. Componente Maquinaria Agrícola" PEC A-26 FLACSO-IDRC. Fuente: Datos recogidos en el año 2008.

Por otra parte, si bien la cantidad de empresas de implementos encuestadas (16) es superior a las de cosechadoras y tractores (5) y pulverizadoras (9), la densidad de relaciones es relativamente menor. Se observan dos firmas de implementos aisladas con sus respectivos proveedores. Se trata de Industrias Rully y Marani SACI, empresas que tienen características tecnológicas diferentes a la mayoría de firmas de implementos, y en las que prevalecen los proveedores de electrónica, sensores, y sistemas hidráulicos de cierta sofisticación.

El gráfico № 12 gráfico muestra el entramado de proveedores del subsector de sembradoras, el que, a diferencia de los casos previos, muestra una mayor complejidad.

Las firmas de sembradoras se representan en color celeste, las partistas específicas en color verde, las partistas genéricas en color rojo y las proveedoras de acero y fundición en amarillo. 
Encontramos que el conglomerado de proveedores del segmento de sembradoras es el más "denso": 1) la cantidad de vinculaciones es muy grande, 2) no quedan "islas" dentro del conjunto, 3) son todos proveedores locales - nacionales a excepción de las acerías Acindar, Siderca y Siderar, que son nacionales y 4) no se registran proveedores de componentes importados, o bien éstos no se encuentran dentro de los considerados como principales por las firmas. La cantidad de acerías no parece sobredimensionada como en el caso de los implementos agrícolas, pero estas empresas tienen cierta importancia que no se debe subestimar. Por otro lado, resalta la posición destacada de ciertas partistas que actúan como nodos centrales en la red. Estos nodos son empresas proveedoras especializadas de discos de siembra, dosificadores, cajas de mando y trenes de siembra. Las empresas que fabrican estos productos son relativamente pocas en la región (DEMS, Geronzi, Garro Fabril, IMEC, Ingersoll, Establecimiento Metalúrgico Oncativo) y concentran la oferta. Dado el tamaño reducido de estas empresas no es de esperar una posición oligopólica ni manejo de mercado a su favor, en claro contraste con los grandes productores de acero, quienes a partir de su carácter concentrado, pueden afectar las condiciones de entrega y los costos de los productos, que perjudican a las PyME nacionales e inclusive a las empresas transnacionales de maquinaria agrícola que producen en Argentina.

\section{Gráfico $\mathbf{N}^{\circ}$ 12. Trama de proveedores del subsector sembradoras}

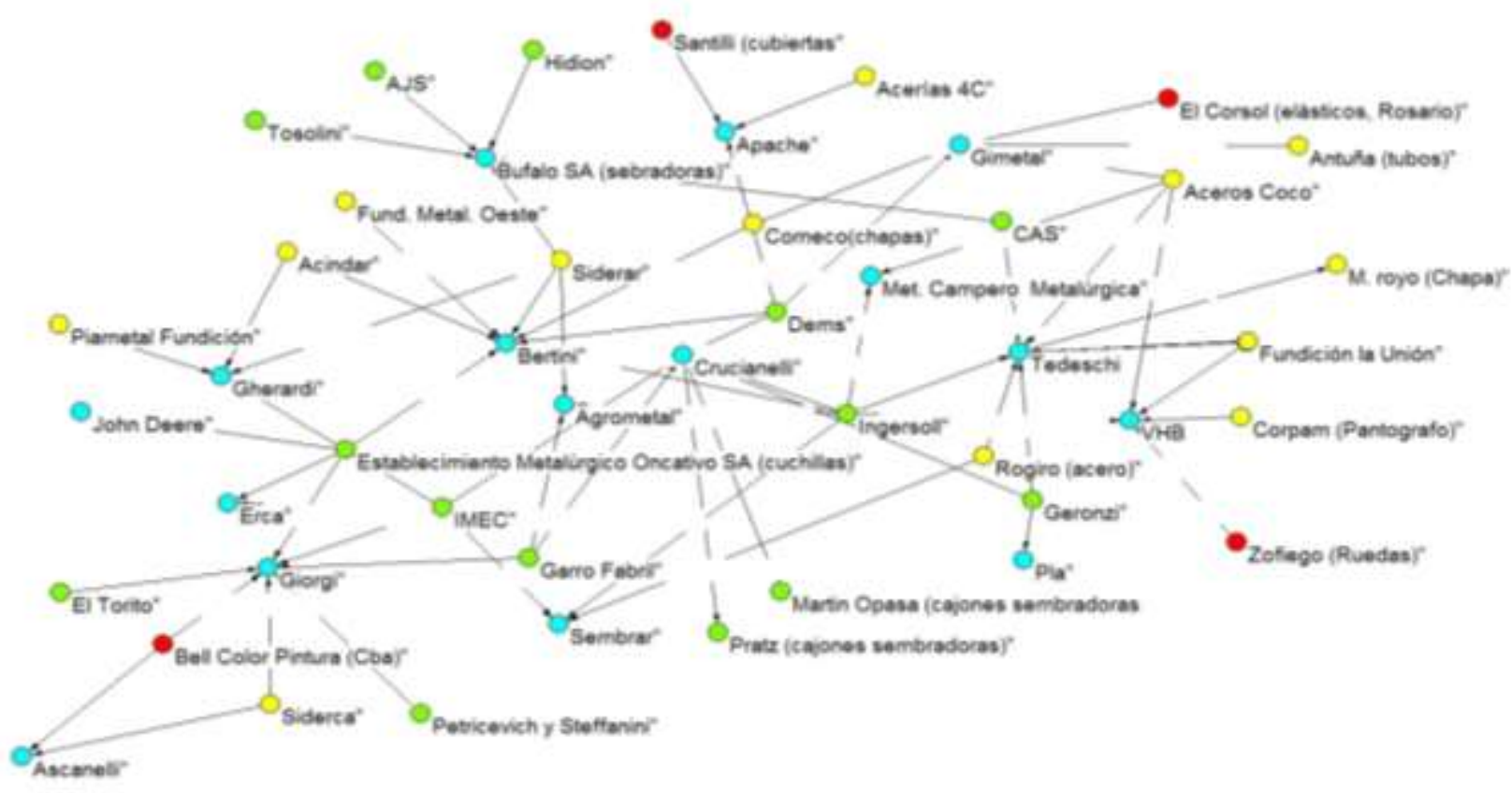


Fuente: elaboración propia en base a datos del Proyecto "Redes de Conocimiento en tramas productivas: Generación, circulación y apropiación del conocimiento y creación de ventajas competitivas en seis tramas de la Argentina. Componente Maquinaria Agrícola" PEC A-26 FLACSO-IDRC. Fuente: Datos recogidos en el año 2008.

En síntesis, los entramados analizados permiten observar que las empresas de tractores y cosechadoras (de manera consistente con lo expuesto en la cuadro $\mathrm{N}^{\circ} 2$ ), se proveen mayoritariamente de partes y conjuntos producidos en el exterior, siendo "islas" sólo articuladas por proveedores de motores. En cambio, en los otros cuatro segmentos de producción se establecen vínculos locales y nacionales, aspecto que evidencia la presencia de un entramado comercial diferenciado.

También, se observa que del gráfico № 9 al №12 las relaciones y la densidad comercial va en aumento. Los posibles espacios de aprendizaje e interacción que son fuentes de economías externas se hacen más compactos en las tramas de los gráficos $\mathrm{N}^{\circ} 10$ y $\mathrm{N}^{\circ} 12$. No hay aquí agentes aislados, lo cual permite suponer una mayor generación de aprendizajes y transferencia de conocimientos a lo largo de toda la cadena de valor (relaciones de proveedor-usuario).

En la sección siguiente se avanza en el análisis de otras articulaciones distintas a las relaciones comerciales.

\subsection{Aprendizajes sistémicos en la industria de maquinaria agrícola argentina}

En esta sección se profundiza el análisis de las relaciones al interior del aglomerado productivo prestando atención a la calidad de las vinculaciones más allá de los vínculos meramente comerciales.

En esta línea, y como se analiza en el capítulo 1, se considera que la posibilidad de generar aprendizajes entre productores y usuarios es una importante fuente de innovaciones incrementales territorialmente localizadas (Lundvall, 1992; Yoguel y Boscherini, 1996; Freeman, 2003).

El concepto de aglomerado territorial de industrias que se presenta en esta tesis está vinculado al concepto de cluster, considerado éste como una situación más dinámica. Reconociendo diferentes estadíos o etapas entre el simple aglomerado territorial de industrias y el cluster. Estas etapas están vinculadas a la organización y configuración del espacio. Las relaciones, derivadas tanto de las transacciones de compra - venta, de los flujos de información, de experiencias y de conocimientos, que 
circulan por los canales formales e informales constituidos entre los distintos actores, establecen el tipo de organización espacial particular

Para captar empíricamente la existencia de procesos de aprendizajes en un aglomerado territorial de industrias, se parte de indicadores alternativos ${ }^{182}$ de tipo cualitativo y cuantitativo y de la idea que la capacidad innovativa está localmente concentrada (Boscherini y Yoguel, 2001). La innovación como proceso interactivo entre distintos actores (públicos y privados) de una misma región es uno de los procesos sociales que otorga a la configuración espacial o aglomerado productivo, el carácter de organización espacial de tipo cluster.

Cuadro $\mathrm{N}^{\circ}$ 13. Cantidad de empresas con al menos una vinculación, con el objetivo de mejorar ciertos aspectos específicos de la firma ${ }^{183}$. Expresado en porcentajes de empresas

\begin{tabular}{|l|c|c|c|c|c|}
\hline Vinculación con... & $\begin{array}{c}\text { Agropar- } \\
\text { tistas }\end{array}$ & $\begin{array}{c}\text { Cosechadoras y } \\
\text { tractores }\end{array}$ & $\begin{array}{c}\text { Implemen- } \\
\text { tos agrícolas }\end{array}$ & $\begin{array}{c}\text { Pulveriza- } \\
\text { doras }\end{array}$ & $\begin{array}{c}\text { Sembra- } \\
\text { doras }\end{array}$ \\
\hline proveedor nacional & $68 \%$ & $80 \%$ & $63 \%$ & $44 \%$ & $67 \%$ \\
\hline proveedor internacional & $14 \%$ & $80 \%$ & 0 & $33 \%$ & $8 \%$ \\
\hline cliente nacional & $82 \%$ & $40 \%$ & $50 \%$ & $33 \%$ & $50 \%$ \\
\hline competidor & $32 \%$ & $40 \%$ & $31 \%$ & $11 \%$ & $42 \%$ \\
\hline consultora & $41 \%$ & $40 \%$ & $25 \%$ & $22 \%$ & $42 \%$ \\
\hline asociación empresaria & $36 \%$ & $40 \%$ & $31 \%$ & $33 \%$ & $33 \%$ \\
\hline universidad & $18 \%$ & $60 \%$ & $13 \%$ & $33 \%$ & 0 \\
\hline $\begin{array}{l}\text { centro } \\
\text { científico }\end{array}$ & $36 \%$ & $40 \%$ & $31 \%$ & $33 \%$ & $33 \%$ \\
\hline política publica & $18 \%$ & 0 & $19 \%$ & $22 \%$ & $17 \%$ \\
\hline
\end{tabular}

Fuente: elaboración propia en base a datos del Proyecto "Redes de Conocimiento en tramas productivas: Generación, circulación y apropiación del conocimiento y creación de ventajas competitivas en seis tramas de la Argentina. Componente Maquinaria Agrícola" PEC A-26 FLACSO-IDRC. Fuente: Datos recogidos en el año 2008.

\footnotetext{
182 Se trata de indicadoresdiferentes alos más tradicionales como gasto en I+D o patentes.

${ }^{183}$ Los vínculos con objetivos de mejoras se refieren a: a. Comerciales b. Certificación de calidad c. Capacitación de Recursos Humanos d. Actividades de diseño y/o desarrollo e. Financiamiento para la innovación f. Utilizar/compartir infraestructura g. Reducir costos y riesgos de innovación h. Cambios organizacionales i. Mejoras ambientales.
} 
El cuadro $\mathrm{N}^{\circ} 13$ muestra el porcentaje de empresas de cada subsector $\mathrm{o}$ segmento de producción que declara tener al menos un vínculo, contractual o no, destinado a generar mejoras, (de proceso, organizacional, de comercialización o de producto), entendidas como forma de innovación incremental. Estos vínculos están desagregados según el actor con el cuál haya existido relación.

En primer lugar se debe destacar que todos los subsectores tienen un importante porcentaje de relaciones con proveedores locales-nacionales. Es este uno de los datos más relevante del cuadro analizado. Ahora bien, las empresas agropartistas se destacan además por su vínculo con clientes locales. Esto tiene coherencia con lo expuesto en la sección 4.5, pues muchos de sus clientes son las empresas ensambladoras de los otros cuatro subsectores.

Si hacemos una lectura por columnas del cuadro $\mathrm{N}^{0} 13$, vemos que las empresas de cosechadoras y tractores son las que diversifican más homogéneas sus vinculacione, aunque el fuerte de sus relaciones está en los proveedores locales y los internacionales. Ambos subsectores o segmentos de producto poseen, en menor medida, relaciones con parte de la oferta pública y privada de tecnología presentes en la región y ningún vínculo con las políticas públicas, como programas de apoyo financiero. Las relaciones que este subsector mantiene dentro y fuera del territorio, permite suponer una apertura de la aglomeración a prácticas tecnológicas internacionales. Son, además, el único segmento en el que la totalidad de los participantes de la muestra declaran haber innovado en producto (anexo XIII).

Al vincular estos datos con lo discutido en la sección anterior se puede observar que los productores de cosechadoras y tractores tienen como articuladores de una trama poco densa de proveedores a los fabricantes de motores ${ }^{184}$. Se trata, en todos los casos, de empresas transnacionales, algunas de ellas con filiales en territorio nacional.

Las empresas fabricantes de cosechadoras y tractores no sólo tienen vínculos fuertes con una red internacional de clientes, proveedores y sus casas matrices, sino que también recurren aL sistema local de innovación. Cabe interrogarse si etas articulaciones, como contrapartida, dan lugar a la transferencia de tecnología en entramados locales "aguas arriba" aspecto que analizaremos en la sección 4.8.

Los subsectores (sembradoras, pulverizadoras, implementos agrícolas, agropartistas) con importante presencia de empresas PyME de capitales nacionales, jerarquiza sus vínculos con firmas locales - nacionales (proveedores, clientes y

\footnotetext{
${ }^{184}$ Cummins, MWM, John Deere, Deutz, Scania, Perkins.
} 
competidores). Estas empresas utilizan, relativamente poco, a las instituciones públicas y privadas presentes en la región para el desarrollo de mejoras, a diferencia de las empresas de tractores y cosechadoras. Se destaca además el subgrupo de pulverizadoras por el alto porcentaje de firmas que tienen vínculos internacionales, representando un escalón intermedio entre las empresas de cosechadoras y tractores y el resto.

Los segmentos de sembradoras y el de pulverizadoras, asociados a las nuevas prácticas de siembra directa, están vinculados, en mayor medida, a productores agropecuarios (clientes), partistas (proveedores) y a instituciones públicas y privadas. De esta forma han desarrollado y obtenido mejoras de producto, muy adaptadas a las necesidades locales.

El segmento de producción de pulverizadoras desarrolla importantes vínculos con sus proveedores, clientes, centros tecnológicos y universidades. En relación a ello, casi el $90 \%$ de estas empresas declaran haber innovado en productos (ver anexo XIII). En este sentido, es necesario considerar dos aspectos, lo relativamente nuevo del producto "pulverizadora autopropulsada" y su vínculo con el paquete tecnológico agricultura de precisión - semillas transgénicas - herbicidas. Esto supone una fuerte y fluida relación, por un lado, con los proveedores de partes y conjuntos, y por otro con los clientes. Con estos últimos probablemente a partir de los servicios de asistencia técnica, de post - venta y de garantía. A su vez, la relación directa con el nuevo paquete tecnológico, estimula las vinculaciones con los centros de investigación especializada; en particular INTA, CIDETER y la Asociación Argentina de Productores en Siembra Directa (Aapresid).

En la sección anterior, se pudo observar que la trama de proveedores del subsector de pulverizadoras es diversa, y con cierta complejidad tecnológica. Esto nos permite inferir que existen aprendizajes sistémicos proveedor-usuario de importancia, si bien presentan cierta dependencia de tecnología extranjera que se incorpora en el equipo.

Por su parte, las empresas de sembradoras basan en una parte importante de su actividad innovativa (92\% de las firmas declara haber innovado en producto) en sus relaciones con los proveedores y clientes nacionales. Con estos últimos el subsector ha desarrollado las máquinas de siembra directa, y sobre todo, las ha perfeccionado. En relación a los proveedores nacionales, como se discutió en la sección anterior de este capítulo, las fábricas de sembradoras, están vinculadas y articuladas mayoritariamente a productores nacionales de conjuntos, específicamente a 
proveedores de trenes de siembra, cajas de cambio, discos y dosificadoras. Se infiere, que son estos algunos de los más importantes proveedores locales-nacionales especializados con los cuales el subsector desarrolla partes esenciales del equipo. Es importante destacar la casi inexistencia de proveedores extranjeros. Se encuentra en este sentido un muy alto nivel de aprendizaje sistémico nacional-local por parte de las firmas de sembradoras y podemos inferir que en forma "transitiva" de sus proveedores. Se puede agregar que no es despreciable el vínculo que mantienen con las universidades y centros tecnológicos (INTA, CIDETER, Aapresid, UTN, UNC y UNR) instituciones dedicadas al desarrollo de la siembra directa.

Por su parte, las empresas agropartistas generan gran parte de su innovación (82\% de las firmas declara haber innovado en producto) en relación con sus clientes, que son en su mayoría el resto de los segmentos aquí analizados. Sin ánimo de ser repetitivos se dirá que el principal vínculo de las compañías de agropartes es el que se establece, en contacto bidireccional, con las empresas terminales, o sea con los clientes. No obstante las tres cuartas partes de estas firmas generan fuertes vínculos, también, con proveedores nacionales.

Pocas empresas de implementos agrícolas se relacionan con el sistema de innovación, aunque algunas de ellas, mantienen altos niveles de vínculos con todo el espectro de actores de la trama. Muchas de estas firmas son productoras de cabezales para cosechadoras, roto-enfardadoras y la única productora de picadoras de forraje autopropulsadas, que muestran un comportamiento mucho más dinámico que las empresas que producen rastras, roturadores, silos o acoplados, cuyo ciclo innovador de producto está en declive.

El segmento de implementos agrícolas, de carácter muy heterogéneo hacia su interior, tiene vínculos principalmente con proveedores y clientes nacionales. Si vinculamos esta característica con el importante peso de las acerías en este segmento de producción, que son mayoritariamente distribuidoras locales de acero (sección 4.5), se puede inferir que el aprendizaje sistémico del segmento es débil.

Por otra parte, se debe aclarar que las estructuras formales de investigación y desarrollo $(I+D)$ no están extendidas en el conjunto de firmas de capital nacional y de tamaño reducido. En ellas predominan estructuras de I+D informales. De hecho muchos entrevistados consideraron que la pregunta, "¿Tiene Ud. un laboratorio o área definida de I+D?" no era pertinente, por su tamaño (PyME). En muchos casos, los departamentos de I+D se circunscriben a la actividad de ingenieros, técnicos o a las personas con más experiencia dentro de la planta, las que realizan trabajos de 
ingeniería reversa, adaptan y mejoran los equipos según las especificaciones de los clientes. Son los que descifran y capturan los saberes no codificados (Yoguel y Boscherini, 1996).

A pesar, de la muy baja cantidad de laboratorios de $I+D$, existe una alta proporción de empresas que realizan innovaciones incrementales de producto. La generación de la innovación sucede como resultado de aprendizajes interactivos dentro y fuera de la empresa (Lundvall, 1992; Yoguel y Boscherini, 1996; Nonaka y Takeuchi, 1995; Yoguel y Boscherini, 2000) y puede inferirse que, en parte, la región es el soporte de apoyo a las firmas para su estrategia competitiva de innovación.

Es interesante destacar que el $81 \%$ de las firmas productoras de implementos agrícolas declara haber innovado en producto. Si bien es el porcentaje más bajo de todos los segmentos de producción, es un porcentaje alto. Esto se explicaría, en gran parte, porque muchas de estas firmas producen bienes más rudimentarios en relación al resto y tienen como estrategia "migrar" poco a poco hacia productos más sofisticados y con otra dinámica de mercado, como rotoenfardadoras, tolvas, mixers y embolsadoras. En parte, esta situación estaría explicando los altos niveles de innovación de producto.

En resumen, todos los subsectores se vinculan en algún actor interno a la región para conseguir mejoras. Los segmentos de cosechadoras y tractores, que tienen un vínculo internacional fuerte, no dejan por ello de desarrollar relaciones dinámicas locales que les permiten acceder a los conocimientos generados en una de las 10 regiones del mundo con más importantes extensiones de producción agropecuaria (FAO, 2013) y con cierta sofisticación en la demanda en equipos agrícolas. Las firmas más asociadas al nuevo sistema agronómico de siembra, sembradoras y pulverizadoras, se mantienen en relación permanente con contratistas y productores agropecuarios (clientes/usuarios) y en muchos casos marcan el ritmo de innovación a las firmas proveedoras de partes. Por su parte, las empresas agropartistas dependen en gran medida de su relación con las empresas terminales para el desarrollo y diseño de nuevos productos. Sin dudas esta relación es determinante en su capacidad de innovación y desarrollo. Los productores de implementos agrícolas, que son, como ya se dijo, muy heterogéneos; muestran ciertos aprendizajes sistémicos que les permiten subsistir en el mercado interno.

Se han analizado, hasta aquí, los elementos que componen parte del desarrollo de la dinámica de cluster dentro de un sistema local y nacional de innovación, de un grupo de empresas de maquinaria agrícola geográficamente aglomeradas. Los 
procesos de generación, circulación y apropiación del conocimiento producido de forma externa a la firma o en vinculación de la empresa con otros agentes, necesitan para su procesamiento y mejor aprovechamiento del desarrollo de competencias endógenas. Esto se expresa en una organización interna del proceso productivo que potencie los procesos de aprendizaje y la integración de los conocimientos codificados y tácitos (Roitter et al. 2007). En la siguiente sección se analizará, de manera complementaria a la generación de "externalidades", el nivel de las competencias internas de las firmas.

\subsection{Desarrollo de competencias endógenas en torno a la organización de la producción}

En la presente sección se discute el grado de desarrollo de las competencias endógenas de las 64 empresas entrevistadas. Previamente se vuelven a discutir algunos elementos conceptuales o debates acerca de la forma de la organización de la producción presentados en el capítulo 1.

Una característica general de las empresas de maquinaria agrícola argentinas es que tienen una escala de producción reducida, con series cortas, no obstante ello, fabrican cierta variedad de equipos (García, 2005, Heybel, 2006; Chudnovsky y Castaño, 2003). Esto permitiría plantear el interrogante sobre la factibilidad de la existencia de un esquema de producción, semejante al descripto por Piore y Sabel (1984), denominado "especialización flexible", que surge tras la crisis de acumulación de capital fordista.

Contrariamente a lo que sostiene esta bibliografía, el modelo productivo emergente tras la crisis de la producción de productos estandarizados no eliminó los límites de escala. Como se expresa en el capítulo 1 a partir de Coriat (1990), la especialización rígida del fordismo fue reemplazada en realidad por una flexibilidad de masa. La tendencia a una mayor flexibilidad, como respuesta al aumento de la competencia, aumentó la complejidad tecnológica en lugar de volver a un predominio de la forma "artesanal" más rudimentaria. La expansión de la producción flexible a través del dinamismo tecnológico que acercó sus costos a los de producción en serie, ha permitido que ambos paradigmas de producción coexistan.

Se muestran como fundamentales dos componentes en la "especialización flexible" para que sea competitiva, por un lado la incorporación de máquinas 
herramientas mucho más versátiles (instrumentos manejados por microelectrónica a través de software) y por otro obreros u operadores calificados que puedan y sepan utilizar la máquina en la producción de series cortas.

Las máquinas convencionales necesitan ajustes físicos ante cambios en los bienes a producir, deben reajustarse los equipos, los que muchas veces deben ser reemplazados pero cuando el equipo está controlado por computadora, sólo se reprograma. En el caso de series de producción largas, no supone mayores inconvenientes el cambio total de maquinaria inclusive con costos de organización elevados puesto que genera costos unitarios bajos. Si las series son cortas, las máquinas herramientas manejadas por ordenador y de fácil adaptación (universales) resultan sensiblemente más económicas. Por su parte, este cambio en los métodos de producción se traduce en una rejerarquización del trabajador altamente especializado en tareas repetitivas. La electrónica en las máquinas necesita operarios más calificados, como veremos a continuación.

\subsubsection{Tipo de equipamiento para la producción}

Contra la visión idealizada de la especialización flexible, el grado de automatización de la producción se encuentra directamente vinculado al tamaño de la empresa. La capacidad de incorporación de máquinas herramientas (programables) de última generación, que permiten a las firmas aumentar productividad y tener un alto grado de respuesta ante cambios en la demanda, tiene como obstáculo la capacidad financiera de las firmas ${ }^{185}$. La adquisición de un torno a CNC (control numérico computarizado) supera en muchos casos los U\$S 100.000 , valores altos para una pequeña compañía argentina, que tiene dificultades para acceder al crédito bancario. De de todas formas, las pequeñas y medianas empresas compran con fondos propios máquinas herramientas modernas sin modificar totalmente el proceso productivo hacia un esquema de producción flexible. Las PyME requieren de un largo período para modernizar totalmente la planta con máquinas programables modernas, por lo que conviven máquinas herramientas de última generación con procesos y métodos más rudimentarios, lo que genera a la vez cuellos de botella y diferencias de calidad.

Como puede apreciarse en el cuadro $\mathrm{N}^{\circ} 14$, el porcentaje de firmas con equipamiento programable de la muestra es relativamente bajo, el $53 \%$ de las firmas tienen menos del $30 \%$ del parque de máquinas con control programable. Pese a ello el

${ }^{185}$ Este vínculo se hace evidente en la relación "tamaño de firma" - "Rango de porcentajes de equipo programable" (ver anexo II) de la muestra. 
$78 \%$ de las firmas considera que su equipamiento es "moderno o de punta", mientras que el $22 \%$ restante lo considera antiguo (ver anexo IV). Se puede inferir que la organización de la producción no descanse, mayoritariamente, en equipos de tecnología avanzada. Coexiste un esquema de producción dual, que combina tecnologías modernas con formas "artesanales" de producción. ${ }^{186}$

Cuadro $\mathrm{N}^{\circ}$ 14. Cantidad de empresas con máquinas herramientas programables, por rangos porcentuales, según segmento de producto (en porcentajes)

\begin{tabular}{|c|r|r|r|r|r|r|}
\hline $\begin{array}{c}\text { Equipo } \\
\text { programable (\%) }\end{array}$ & $\begin{array}{c}\text { Agropar- } \\
\text { tistas }\end{array}$ & $\begin{array}{c}\text { Cosechadoras } \\
\text { y tractores }\end{array}$ & $\begin{array}{c}\text { Implemen- } \\
\text { tos agrícolas }\end{array}$ & $\begin{array}{c}\text { Pulveriza- } \\
\text { doras }\end{array}$ & $\begin{array}{c}\text { Sembra- } \\
\text { doras }\end{array}$ & Total \\
\hline $0-15$ & 43,5 & 0,0 & 53,8 & 12,5 & 7,7 & 29,7 \\
\hline $16-30$ & 8,7 & 0,0 & 15,4 & 37,5 & 46,2 & 23,4 \\
\hline $31-45$ & 17,4 & 20,0 & 0,0 & 12,5 & 15,4 & 14,1 \\
\hline $46-60$ & 13,0 & 0,0 & 15,4 & 25,0 & 15,4 & 15,6 \\
\hline $61-75$ & 13,0 & 40,0 & 7,7 & 0,0 & 7,7 & 9,4 \\
\hline $76-100$ & 4,3 & 40,0 & 7,7 & 12,5 & 7,7 & 7,8 \\
\hline Total & 100,0 & 100,0 & 100,0 & 100,0 & 100,0 & 100,0 \\
\hline
\end{tabular}

Fuente: elaboración propia en base a datos del Proyecto "Redes de Conocimiento en tramas productivas: Generación, circulación y apropiación del conocimiento y creación de ventajas competitivas en seis tramas de la Argentina. Componente Maquinaria Agrícola" PEC A-26 FLACSO-IDRC. Fuente: Datos recogidos en el año 2008.

El cuadro $\mathrm{N}^{\circ} 14$, también, nos permite ver los rangos de maquinaria programable dentro de la firma por segmento de producto. El subsector con más "retraso" en la incorporación de este tipo de equipos es el de implementos agrícolas. Este segmento, como se viene destacando, tiene una baja complejidad de producto y un mercado poco dinámico. No está de más resaltar que muchos de estos productos como arados de distintos tipos y usos (aperos, gradas, subsoladores, cultivadores, etc.) han perdido y siguen perdiendo mercado frente a la siembra directa. Casi el $70 \%$ del conjunto de las empresas de implementos agrícolas tiene un parque de maquinarias programables menor al $30 \%$, el número más reducido de toda la muestra. Más allá de ello, sólo el

\footnotetext{
186 Por "artesanal" se designa a los procesos productivos que, por oposición a la producción en serie, se realizan ya sea por encargo o en series cortas y específicas. No se hace referencia al proceso de trabajo artesanal tradicional realizado de forma manual sin ayuda de energía electromecánica.
} 
$18 \%$ de las firmas de implementos agrícolas considera que su equipamiento es antiguo. En este sentido, muy probablemente, el proceso productivo se haga con corte de chapa, plegado de piezas y tornos todos electro-mecánicos; soldadura y pintura de forma manual. Una de las estrategias de estas firmas es la de tercerizar parte de los procesos, consiguen, de esta manera resolver, en parte, el retraso tecnológico. Este es el segmento de empresas que más subcontrata parte o gran parte de los procesos de producción.

El gráfico del "Anexo V" expresa una relación entre integración productiva y equipo programable, el que muestra que el $85 \%$ de las firmas consideradas de baja integración vertical son también las que tienen los niveles más bajos de equipos programables. La falta de incorporación de este tipo de maquinaria no puede, tampoco, atribuirse de manera determinante a dificultades financieras severas ya que la mayoría de las empresas de ese segmento son de tamaño mediano a grande, las que cuentan con mayor acceso relativo al crédito bancario (ver cuadro $N^{\circ} 11$ ). No obstante, un $30 \%$ de empresas de este segmento tiene entre $46 \%-100 \%$ de sus maquinas -herramientas programables y consideran su equipamiento de punta 0 moderno. En este segundo grupo, se registran productores de equipos asociados a dinámicas de mercado más exigentes. Parte importante de su producción (un $20 \%$ ) se exporta y esto, sin duda, necesita una mayor capacidad productiva y de respuesta ante aumentos rápidos de demanda y de variación en los tipos de producto.

En segundo lugar, se ubican tres grupos de firmas con una proporción menor en el uso de equipo programable con respecto al segmento de tractores y cosechadoras. Estas son las empresas de sembradoras, pulverizadoras y agropartes. Los tres segmentos tienen la mitad de las firmas con bajos niveles de equipamiento programable (dentro de los rangos $0-15 \%$ y $15 \%$ - $30 \%$ ).

El segmento de las sembradoras ha tenido un rol destacado en los períodos de convertibilidad y de posconvertibilidad, con aumento de la producción, y la cantidad de empresas y con desarrollos de productos. Las empresas encuestadas exhiben un alto grado (media - alta) de integración vertical, muy superior al del resto de los subsectores (ver cuadro $\mathrm{N}^{\circ} 12$ ). Las empresas más grandes e integradas, utilizan en mayor medida equipamiento con características tecnológicas de punta; las de menor tamaño utilizan herramientas más rudimentarias, o externalizan a otras empresas ciertas actividades.

De acuerdo, con los grupos de firmas por segmento productivo y en orden creciente según mayor uso de equipo programable, encontramos a las agropartistas 
donde un $52 \%$ de las firmas tiene bajos niveles de utilización de equipos programables (entre 0 a $30 \%$ de estas máquinas). Es esperable, en un sistema con un buen funcionamiento, que este grupo de empresas tenga una alta productividad, para impulsar la competitividad del resto de la industria. La industria de maquinaria agrícola en su conjunto avanza hacia mejores prácticas productivas, pero en el grupo de firmas de agropartes conviven una mezcla de técnicas y equipos de avanzada con otras de tipo precarias y muy artesanales. Esto sin dudas conspira contra el logro de altos niveles de productividad. Ello es en parte, la causa de la "alta" integración vertical de algunas de las firmas productoras de maquinaria agrícola. Sin embargo, por otra parte, las firmas agropartistas tienen altos niveles de flexibilidad y adaptabilidad en la producción de nuevos bienes.

La adopción de equipo programable, en el caso de las pulverizadoras, tampoco es uniforme; como se observa en el cuadro $\mathrm{N}^{\circ} 14$, el $50 \%$ de las empresas tiene menos de $30 \%$ de su parque con maquinas herramientas programables. La integración vertical de la producción es baja en un 50\% de las firmas y en un $25 \%$ es medio, lo que incide en los bajos niveles de automatización de sus equipos. Ante la baja integración puede suponerse que en parte importante de los procesos que se realicen en la propia planta, sean relativamente pocos los equipos programables y la flexibilidad de estas empresas descanse en la subcontratación de procesos. El 86\% de este grupo de empresas declara hacer el diseño con lo que se puede considera que manejan en su mayoría parte del corazón del negocio (ver anexo VI). Las que declararon no hacerlo (el diseño) informaron subcontratarlo en la región de la aglomeración productiva (ver anexo VI). Sin dudas, la tercerización y subcontratación funciona como estrategia competitiva de estas empresas durante el ciclo expansivo de demanda.

El último subgrupo, el de cosechadoras y tractores, es el que más ha adoptado equipo programable, no existe empresa sin equipos automáticos de producción, y a su vez poseen una baja integración productiva (ver cuadro $N^{\circ} 12$ ) y son compañías de tamaño mediano a grande (ver cuadro $N^{0} 11$ ). Esto supone una organización de la producción diferente; por un lado gran parte de lo que hacen estas empresas es ensamblaje, por importante que sea su integración (caso Pauny SA), debido a que muchos de sus componentes no se fabrican en Argentina. El proceso de ensamble está total o parcialmente automatizado.

En relación al uso de equipo programable, la industria ha mostrado respuestas diferentes. Mayoritariamente no presenta una modalidad fordista de producción en serie, pero tampoco podemos afirmar que es un esquema generalizado de especialización flexible, en todo caso, al contrario de cómo lo especifica la bibliografía, 
son las firmas más grandes las que adoptan dicho esquema. Se ha exhibido que coexiste un tipo artesanal de producción con incorporación parcial de equipos programables. A fin de avanzar en un mejor entendimiento de las características de la producción, en la sección siguiente introducimos el estudio de la organización del trabajo en las empresas.

\subsubsection{Sistemas de organización productiva del trabajo}

Los componentes principales de los modelos no seriados de producción parten de una combinación con distinta intensidad de las siguientes variables: base tecnológica, flexibilidad del uso de la mano de obra y organización industrial (Novick et al.1998). Como ya se sugirió a partir de Piore y Sabel (1984), la vinculación entre trabajo y tecnología de producción confieren buena parte del carácter flexible de las empresas y no hay un modelo único de combinación entre automatización y trabajo. Por otro lado y más allá del aspecto flexible de producir varios productos en lotes reducidos y cambiar con facilidad entre diferentes productos, la organización de los procesos de trabajo juega un papel fundamental en el desempeño competitivo de este tipo de empresas (Katz y Stumpo, 2008). La automatización genera, por un lado, el reemplazo de un gran número de operaciones anteriormente realizadas por los operarios (humanos), alejando cada vez más a las personas del proceso; por el otro, la eficiencia del sistema se garantiza en la medida en que el trabajo se ejecute de manera coordinada y cooperativa.

En este sentido Novick et al. (1998) sostienen que, detrás de la necesidad de producir con calidad, se confirma la necesidad de una estrategia diferente en la organización de los recursos humanos basada en la participación de los asalariados. Los modelos teóricos caracterizan un nuevo tipo de trabajador: polivalente, autónomo y creativo, contraponiéndolo al obrero "alienado" de la línea fordista. En definitiva se apunta a saturar los tiempos muertos y a tener en un solo obrero, varios (aumento en la intensidad del proceso de trabajo). ${ }^{187}$

La división de tareas (entre concepción y ejecución) puede variar dentro de las empresas, lo que modifica las condiciones de los trabajadores y estas cambian en relación con las nuevas exigencias y responsabilidades que se les impone. Estas exigencias devienen de la delegación en los trabajadores del control de calidad, del mantenimiento y, también, de algunas tareas de supervisión, administración, hasta de programación de la producción. Los principios rectores de la eficacia de la producción implican, como ya se dijo, en una saturación de los tiempos favorecida por la

\footnotetext{
187 Aumento de la extracción de plusvalía.
} 
polivalencia de los trabajadores.

Por otro lado, la organización del trabajo, que por sus características permite un verdadero proceso de creación y circulación de conocimientos, se caracteriza por el trabajo en células, autonomía de los trabajadores y facilidad de adquisición de experiencias ligada a los procesos de polivalencia.

En este sentido se debe considerar que, en términos generales, desde la perspectiva de la organización del trabajo, en la industria manufacturera argentina predomina un enfoque taylorista que limita el desarrollo de las competencias endógenas de las firmas y de las tramas de las que estas forman parte. Los empleados y operarios suelen ser contratados y entrenados con consignas rígidas (Roitter et al. 2007: 15).

Teniendo en cuenta estos conceptos y elementos se propone en esta sección analizar la organización del trabajo, a partir de las siguientes variables: (i) la autonomía de los trabajadores188, (ii) la forma de organizar el proceso productivo, ya sea de manera individual o en equipos de trabajo y (iii) la polivalencia y la adquisición de experiencias.

La autonomía que las firmas de maquinaria agrícola de la muestra otorgan a sus operarios es bajo - medio en el $98,4 \%$ de los casos. Al contrario de lo que se podría esperar de un sistema que tiende a ser más flexible, el nivel de autonomía de los empleados es bajo, con mayor semejanza a un sistema de producción en serie. En este sentido se destaca el subsector de firmas de sembradoras las que (casi) el $70 \%$ de sus empresas otorga baja autonomía a sus operarios; por otro lado el subsector de tractores y cosechadoras tiene un $60 \%$ de firmas con media alta autonomía de sus operarios (anexo VII).

En relación a la segunda dimensión, predomina el trabajo realizado en forma "individual", con inexistencia de equipos de trabajo en el $65 \%$ de las empresas del panel de la muestra. En este contexto, se destacan el $72,8 \%$ de las fábricas de implementos agrícolas, el $71,5 \%$ de las empresas de agropartes y el $69,2 \%$ de las empresas de sembradoras, las cuales organizan el trabajo de forma individual teniendo características de producción más estilo taylorista - fordista con una reducida

\footnotetext{
188 El indicador de autonomía fue construido a partir las respuestas a las preguntas "Competencias más importantes para operarios: Autonomía e independencia"; "Competencias más importantes para operarios: Capacidad de resolución de imprevistos"; "Frente a los problemas que aparecen frecuentemente en las actividades de producción, ¿cuál es el comportamiento típico de los operarios?"
} 
participación de las firmas que poseen equipos de trabajo "integral" ${ }^{189}$ (ver anexo VIII).

Estos resultados son claves para establecer las formas de desarrollo de la dinámica de la circulación y producción de conocimientos y su integración a los procesos de aprendizaje, debido a que el carácter individual de la realización de las tareas, predominante en las firmas analizadas, tiende a limitar esas dinámicas acotando las posibilidades de procesos interactivos entre los miembros de la organización.

Al respecto, debemos decir que el trabajo en equipo u organizado en células, requiere la existencia de ciertas condiciones para que pueda ser considerado formativo. La primera de ellas, es la organización del trabajo en grupos que tengan a cargo la realización de una parte del proceso de producción, en reemplazo del trabajo fordista realizado por medio de una línea de producción, donde cada trabajador tenía una tarea asignada. La segunda condición, es la realización de tareas que van más allá de aquellas relativas al proceso productivo. En este sentido, observamos que el $73 \%$ de las firmas de la muestra confiere a sus operarios una amplia variedad de tareas ("Operativas y de programación y de puesta a punto de las máquinas"; "Operativas y mantenimiento de primer nivel" y "Todas las anteriores"), generando un cuerpo de operarios polivalentes, pero con una baja - media independencia para tomar decisiones y resolver inconvenientes en el 95\% de los casos, sumado a ello el $65 \%$ de las empresas organizan el trabajo de forma individual (ver anexos $N^{\circ}$ VIII y $N^{\circ}$ XII).

Son excepción en este comportamiento, las empresas del segmento de cosechadoras y tractores que tienen en la versatilidad de los operarios un elemento importante, ya que todas le confían más de una tarea a sus operarios (ver anexo № XII). Este grupo de empresas es el que más utiliza la organización del trabajo en equipo ${ }^{190}$ y el único subsector que tiene una empresa que otorga un alto grado de

\footnotetext{
189 Se llama aquí trabajo integral a la realización del proceso productivo por medio de equipos que tiene características enriquecedoras cuando más allá de la mera ejecución de tareas promueve i) el intercambio de funciones dentro del grupo, ii) la posibilidad de compartir experiencias a partir de la acción misma y iii) un mayor protagonismo de los trabajadores en actividades de concepción del proceso de trabajo y en la programación de maquinarias.

190 La organización del trabajo en células o equipo alude a una forma diferente de articular la dimensión técnica y social del trabajo a partir de la constitución de unidades elementales de trabajo, bajo el principio de descentralización de la producción y la administración local de flujos. Por un lado, las máquinas son dispuestas en grupos a fin de que acompañen el flujo de las piezas, completando el ciclo entero de producción listas para el ensamble. A partir del cambio de layout se obtiene un significativo ahorro de los costos de fabricación, ya sea porque se reduce el traslado de piezas entre máquinas y los stocks intermedios, como el tiempo de preparación de máquinas durante el ciclo de fabricación de un determinado tipo de piezas al permitir optimizar el balanceo entre los tiempos hombre-máquina. Los principios fundamentales de la división de tareas (entre concepción y ejecución) pueden sufrir distintos grados de variabilidad o incluso no ser cuestionados en absoluto pero, sin embargo, las condiciones de movilización de los trabajadores cambian en relación con las nuevas exigencias y responsabilidades que
} 
autonomía a sus operarios, dando muestras de cierto comportamiento regular en cuanto a mejores prácticas productivas en la búsqueda de competitividad (ver anexos $\mathrm{N}^{0} \mathrm{VII}, \mathrm{N}^{\circ} \mathrm{VIII}$ y $\left.\mathrm{N}^{\circ} \mathrm{XII}\right)$.

En síntesis, los rasgos a través de los cuales pueden analizarse los elementos que favorecen la producción y circulación de conocimientos en las empresas en torno a la organización del trabajo muestran limitaciones, marcando a su vez un freno a los procesos de innovación con participación de los trabajadores. Si bien, se evidencian diferencias entre los distintos segmentos, donde el grupo de firmas de tractores y cosechadoras muestra una mejor performance en las dimensiones hasta aquí analizadas, está muy lejos de extenderse hacia otras firmas las mejores prácticas de la organización del trabajo. Aunque cabe destacarse al segmento de pulverizadoras en una situación intermedia entre una severa rigidez y un sistema más flexible. De esta manera, el carácter que muestran las diferentes dimensiones de la organización del trabajo limita un modelo que integra los procesos de conocimiento, aprendizaje e innovación. Por otro lado este tipo de organización rígida también conspira contra la posibilidad de aumentar productividad a partir de un esquema más flexible. En términos generales, la combinación de polivalencia de los trabajadores con bajos (o medios) niveles de autonomía, se traduce, no sólo, en menores logros de productividad en relación a los estándares esperables de la producción flexible, sino, también, en una intensificación del proceso de trabajo.

En la próxima sección, se profundiza sobre alternativas que permiten a las empresas aumentar la productividad y la calidad del producto.

\subsubsection{Cultura hacia la calidad y la mejora continua}

Como afirma Coriat (1994) las fuentes de competitividad son múltiples; en esta sección se analizan algunas de las "nuevas" herramientas de carácter interno a la firma de que se dispone en la búsqueda de una mayor competitividad. Se parte del supuesto de que, cualquiera sea el modelo productivo, debe buscase simultáneamente productividad y calidad y no solamente productividad o solamente calidad, incluyendo en calidad el concepto de variedad y de diferenciación.

Las fuentes de la competitividad han adquirido un alto grado de complejidad en

se les impone de allí en más. Estas exigencias devienen de la delegación en algunos casos además del control de calidad y el mantenimiento, también de algunas áreas de supervisión, administración y hasta de programación de la producción. Los principios rectores de la eficacia bajo el paradigma de una gestión de la producción tensa implica una saturación de los tiempos favorecida por la multifuncionalidad y polivalencia de los trabajadores (Novick et al. 1998:27). Se pasa de un control técnico/burocrático a uno de pequeños grupos o individuos que mantienen intercambios entre sí regulados por "la mano invisible informática". 
las últimas décadas. La gestión de la calidad constituye el segundo plano determinante de las competencias endógenas de la firma, luego de las laborales (Roiter et al, 2007).

Consideramos cinco variables para evaluar las competencias dentro de la muestra de firmas: (i) la existencia de normas, (ii) la importancia del control de proceso $^{191}$, (iii) la cultura hacia la calidad, (iv) el uso de herramientas para mejoras y (v) el desarrollo de procesos de innovación.

Desde la perspectiva de la existencia de normas, el $47 \%$ de las empresas afirma cumplir con una norma de proceso. Sin embargo, cuando se tiene en cuenta a aquellas que declaran tener estas normas implementadas en su totalidad, la proporción de respuestas positivas se reduce (33\% del panel). Este análisis es muy importante para confirmar la consistencia de los datos relevados, ya que un proceso modelo guiado por una norma certificable puede tomar años e incluso convertirse, sólo, en una mera declaración de intenciones.

El control de procesos, que permite reducir la variabilidad del producto final, incrementar la eficiencia, reducir el impacto ambiental y mantener el proceso dentro de los límites de seguridad que correspondan, es adoptado en alto grado por las firmas en su conjunto ( $75 \%$ del total). Todos los subsectores implementan estos controles en niveles "altos - medios". Más del $90 \%$ de las firmas intentan, a partir del control sistemático, mejores prácticas productivas, a excepción de las fábricas de sembradoras, en las que un $23 \%$ empresas tienen bajos niveles de control de los procesos (ver anexo $\mathrm{N}^{\circ} \mathrm{IX}$ )

Al analizar el comportamiento de las firmas en relación a la calidad, encontramos que si bien los niveles de adopción de la calidad como método son más bajos, que en los de controles de proceso, no dejan de tener un nivel medio - alto. Este comportamiento es homogéneo en el total de empresas, superando el $90 \%$ del total de firmas estos niveles en el uso de herramientas que aseguren y mejoren la calidad ${ }^{192}$.

\footnotetext{
191 Se estudia a partir de las respuestas a las siguientes preguntas de la encuesta: ¿Existen especificaciones de las materias primas e insumos críticos?; ¿Están identificadas las características críticas del proceso producto y/o servicio?; ¿Están documentadas las características críticas del proceso, producto y/o servicio?; ¿Están controladas las características críticas del proceso, producto y/o servicio?; ¿Existe trazabilidad?
}

\footnotetext{
192 Se estudia a partir de las respuestas a las siguientes preguntas de la encuesta: ¿Existe una política de calidad definida y comunicada a todo el personal?; ¿Están definidos y se exhiben públicamente los indicadores clave de calidad?; ¿Existen equipos para solucionar problemas o lograr mejoras en los procesos?; ¿Se realizan auditorías internas?; ¿Existe algún sistema para mantener el orden y limpieza?; ¿Existen comunicaciones periódicas con los clientes para detectar cambios en los requerimientos?; ¿Se utilizan esas comunicaciones para modificar el producto y/o servicio?; ¿Existen comunicaciones periódicas con los proveedores? ¿Se utilizan estas comunicaciones para modificar el producto y/o servicio?; ¿Hay algún sistema de reconocimiento de ideas o aportes destacados?
} 
Dentro de este conjunto se destacan las empresas agropartistas de las cuales el $78 \%$ de ellas tienen un alto grado de utilización de estos instrumentos.

Un avance hacia la mayor flexibilidad en la organización del trabajo, que posibilita un fluido intercambio de saberes orientados a analizar y resolver problemas del proceso productivo o del producto, se evidencia cuando se implementan equipos de mejora continua que satisfacen un conjunto de condiciones básicas. Esto se articula y se complementa con la implementación de métodos sistemáticos para mejora e innovación de procesos.

En cuanto a la utilización de métodos sistemáticos para mejora e innovación de procesos $^{193}$, la tendencia se invierte en relación a los datos antes presentados, lo que muestra que el 92,2\% de las firmas del panel tienen un nivel de utilización medio bajo, con un núcleo de $62,5 \%$ de empresas con un bajo grado de uso.

La utilización de herramientas orientadas a generar mejoras e innovación de procesos (diagramas de causa y efecto, diagramas de Pareto, histogramas, Análisis Modal de Fallas y Efectos, gráficos de control estadístico de procesos, entre otros) sólo es empleado por las firmas de tractores y cosechadoras. Únicamente un tercio de los restantes subsectores de producción aprovechan dichos métodos y lo hacen de forma acotada (nivel medio).

De acuerdo a Yoguel y Boscherini (1996) la mayor parte de las PyME tienen solo una visión parcial del proceso innovativo (incluyendo el proceso de mejora) y, por lo tanto, tienen dificultad para percibir la importancia del desarrollo de competencias y de procesos de aprendizaje dinámico. Esto trae, como consecuencia que se ignoren o parcialicen los esfuerzos orientados a generar mejoras en los resultados operativos y maximizar la competitividad.

El análisis de estos indicadores da cuenta de un circuito de calidad crecientemente complejo, a medida que se avanza del control de procesos hasta el uso de herramientas para la mejora y la calidad. De esta manera, la escasa utilización de un solo grupo de estas herramientas podría afectar la implementación del conjunto de sistemas de calidad.

\footnotetext{
${ }^{193}$ Este indicador engloba una serie de instrumentos que utiliza la industria para entre otras cosas mejorar la calidad, fiabilidad y seguridad de un producto o proceso, mejorar la imagen y competitividad de la organización, aumentar la satisfacción del usuario, reducir el tiempo y coste de desarrollo del sistema, recopilación de información para reducir fallos futuros y capturar conocimiento de ingeniería, reducción de problemas posibles con las garantías, identificación y eliminación temprana de problemas potenciales, poner énfasis en la prevención de problemas, minimización de los cambios a última hora y sus costes asociados, catalizador del trabajo en equipo y el intercambio de ideas entre departamentos. Los instrumentos son: Diagrama de causa y efecto, Diagrama de Pareto, Histogramas, AMFE (Análisis Modal de Fallas y Efectos), Gráficos de control estadístico de proceso.
} 
A pesar de los elevados niveles registrados en los indicadores de control de procesos y cultura hacia la calidad, sólo un número reducido de firmas puede ser caracterizado como de elevado nivel en cuanto a calidad y mejora continua, ya que sólo pocas empresas completan los cuatro indicadores. Esto es así debido a que los diversos planos que permiten en conjunto identificar la presencia de una "gestión hacia la calidad" son varios y concurrentes. En este sentido sólo se destacan aquí las firmas de tractores y cosechadoras sobre las restantes. En las firmas de sembradoras, pulverizadoras, implementos agrícolas, y agropartes predomina un nivel medio de adopción de estos métodos.

A modo de síntesis se elaboró el cuadro № 15 , que resume los datos de las competencias endógenas de las firmas.

\section{Cuadro $\mathbf{N}^{\circ}$ 15. Nivel de Competencias Endógenas por tipo de firma ${ }^{194}$. En porcentaje de firmas según segmentos de producción.}

\begin{tabular}{|l|r|r|r|r|r|r|}
\hline & $\begin{array}{c}\text { Agropar- } \\
\text { tistas }\end{array}$ & $\begin{array}{c}\text { Cosechadoras } \\
\text { y tractores }\end{array}$ & $\begin{array}{c}\text { Implemen- } \\
\text { tos agrícolas }\end{array}$ & $\begin{array}{c}\text { Pulveriza- } \\
\text { doras }\end{array}$ & $\begin{array}{c}\text { Sembra- } \\
\text { doras }\end{array}$ & Total \\
\hline Bajo & 35,4 & 20,0 & 38,7 & 32,4 & 41,0 & 35,3 \\
\hline Medio & 27,5 & 20,0 & 33,4 & 31,7 & 32,1 & 30,5 \\
\hline Alto & 37,1 & 60,0 & 27,9 & 35,9 & 26,9 & 34,3 \\
\hline Total & 100,0 & 100,0 & 100,0 & 100,0 & 100,0 & 100,0 \\
\hline
\end{tabular}

Fuente: elaboración propia en base a datos del Proyecto "Redes de Conocimiento en tramas productivas: Generación, circulación y apropiación del conocimiento y creación de ventajas competitivas en seis tramas de la Argentina. Componente Maquinaria Agrícola" PEC A-26 FLACSO-IDRC. Fuente: Datos recogidos en el año 2008.

Es posible extraer algunas conclusiones generales a partir de los resultados de este cuadro. El segmento de agropartistas presenta un alto porcentaje de firmas con bajas competencias endógenas y un gran porcentaje con altas competencias, mientras que el $27 \%$ de las firmas del segmento presenta competencias medias, lo que se traduce en un limitante dado el alto grado de modularización que requiere la industria para que los esquemas de producción flexible no se limiten a las terminales. En este

${ }^{194}$ Este indicador es el resultado del promedio simple de las dimensiones analizadas, lo que equivale a decir que todas ellas fueron igualmente ponderadas. 
caso los tamaños de los lotes de producción se miden en cientos, y aun en decenas, y las máquinas utilizadas son mayoritariamente de tipo no programables, esto es, son más polivalentes y flexibles pero de menor productividad (más rudimentarias). En líneas generales, sería posible afirmar que la competitividad del sector de maquinaria agrícola no reposa en los proveedores de agropartes, si bien existe un porcentaje de firmas del subsector que se ha modernizado y ha alcanzado altos niveles de competencias.

El segmento de cosechadoras y tractores presenta niveles de competencias endógenas superiores al promedio del sector. En tanto se trata del segmento que produce la maquinaria más compleja, sería posible establecer una relación entre la complejidad de la producción y los niveles de absorción de conocimientos necesarios para el desarrollo de la misma. Dicho en otros términos, el segmento tecnológicamente más desarrollado del sector es, también, el que estaría en mejores condiciones de aprovechar las oportunidades tecnológicas del entorno y transformar dichas oportunidades en nuevos diseños, mejoras de productos y/o procesos. Es el segmento mejor equipado y con mejores prácticas laborales. En este sentido se debe destacar que los tamaños de lote que producen estas empresas se miden en miles y permiten el uso de equipos "específicos", es decir, que sólo hacen un único producto, aumentando la productividad vis a vis la flexibilidad. Muy probablemente parte de la flexibilidad necesaria se obtenga mediante los altos niveles de subcontratación de procesos y partes, muchas de ellas importadas.

Cerca del $39 \%$ de las firmas del segmento de implementos agrícolas tiene bajas competencias, un $33 \%$ "medias" y $28 \%$ "altas" En tal sentido, existe un nivel de competencias promedio medio-bajo, con un grupo reducido de firmas en condiciones de realizar diseños y desarrollos complejos, situación coherente con las características tecno-productivas del segmento. Este subsector se encuentra dominado por empresas cuya organización se caracteriza por la asignación individual de tareas, una baja incorporación de maquinaria de avanzada y una baja rotación de los puestos de trabajo.

El subsector de pulverizadoras invita a pensar en la necesidad de mejorar ciertas dimensiones de la organización productiva de estas firmas, como medio necesario para la consolidación de un segmento de la industria que se ha destacada por su dinamismo. En dicho sentido, cabe destacar que aunque cuenta con un porcentaje considerable de firmas con altas competencias endógenas, se encuentra muy alejado del grado de modernización de los esquemas organizacionales de las empresas de cosechadoras y tractores 
El segmento de sembradoras presenta el mayor porcentaje de firmas con bajas competencias endógenas, se trata de un $41 \%$, lejos de su comportamiento en cuanto a dinamismo, productividad y competitividad. Hay una relación directa de estos niveles con el bajo desempeño en cuanto a la organización laboral del proceso productivo. Sin embargo, el $27 \%$ del segmento presenta elevadas competencias.

Las sembradoras y pulverizadoras tienen un mix heterogéneo de equipos programables que suponemos "universal" (mayoritariamente tornos y fresadoras a cnc) y equipos no programables manuales (a veces muy precarios) que entregan bajos niveles de productividad. El segmento ha ido evolucionando hacia la incorporación de maquinarias con automatización. Estos dos segmentos de productos están en un "escalón" intermedio.

En resumen, los datos analizados muestran que son las filiales de empresas transnacionales presentes en la región de estudio las que presentan los mayores niveles de competencias endógenas. En la próxima sección se analizarán las estrategias y las características productivas de dos de estas empresas transnacionales, que figuran entre las más importantes a nivel mundial. Ello permitirá, por un parte, realizar un análisis comparativo entre las formas de organización de las empresas transnacionales y las firmas nacionales, y por la otra, analizar la incidencia de la estructuración de cadenas de valor global en el territorio local.

\subsection{Estrategias de las empresas transnacionales de maquinaria agrícola en Argentina}

A fin de analizar con mayor profundidad la organización productiva de las empresas de maquinaria agrícola, en esta sección, se estudiará el caso de dos empresas transnacionales que producen en Argentina, en base a las entrevistas realizadas en el estudio Lavarello y Hecker (2009) para el Ministerio de Economía de la Nación en el año 2008. Estas empresas (que denominamos A y B para conservar el secreto estadístico) producen y/o ensamblan los equipos más complejos (tractores y cosechadoras) con los niveles más altos de productividad sectorial relativa (ver cuadro $\left.N^{0} 12\right)$.

Existe cierto consenso en considerar que las empresas transnacionales tienen la capacidad de ser portadoras de progreso tecnológico, y de tener una fuerte inserción en el comercio internacional. Sin embargo, poseen estrategias altamente selectivas (Lavarello, 2004), los laboratorios de I+D de estas firmas están localizados, en su mayoría en los países industrializados: Estados Unidos, Europa, o Japón. Desde cierta 
perspectiva, los efectos de transferencia tecnológica más importantes que pueden esperarse de estas empresas se centran en las articulaciones de las mismas con los proveedores locales La capacidad de absorción de las firmas y las características de la matriz productiva de la economía receptora son determinantes en el resultado de la acumulación tecnológica y de ello también depende el tipo de "arribo" que haga la empresa transnacional. Por otro lado, para que la transferencia tecnológica tenga sentido, se debe transferir al receptor, no sólo la capacidad técnica para producir un producto, si no la capacidad de dominar conceptualmente, desarrollar y producir de manera autónoma la tecnología que subyace al producto (Lavarello, 2004).

El análisis de las empresas transnacionales se centra en los siguientes aspectos:i) estrategia global y local de las firmas, ii) esquema de producción organización de la empresa, iii) el grado de profundización del entramado productivo local, y iv) las características que presentan estas empresas en cuanto a la innovación y desarrollo y el nivel de articulación y vinculaciones con el SNI.

La empresa $A$ es un joint venture entre una empresa alemana y una estadounidense y la empresa $B$ es una firma estadounidense. Ambas compañías han ubicado parte de su producción en la ciudad de Rosario, se instalaron en el período de sustitución de importaciones, y las dos tienen más de 50 años produciendo en el país.

En 1959, con la fusión de las empresas Cantábrica S.A. y una compañía de Alemania Federal (empresa A), se constituye una empresa de capital mixto con el objeto de producir en nuestro país, motores, camiones y ómnibus. Poco tiempo después, a fines de ese año, se inicia en los talleres de la empresa la producción de tractores y motores. Las inversiones continúan y en 1962 se inaugura la segunda planta en la localidad de Haedo, vecina a la primera.

La empresa B, al inicio de sus actividades locales en el año 1961, en el marco de una estrategia multidoméstica, fabricó tractores, implementos y equipos para la construcción. La planta, hasta 1980, tenía un alto grado de integración, e incluía la fabricación de los motores en series cortas. En esos años, dada la fuerte caída del mercado local, se exportaron equipos a toda Latinoamérica e incluso en algunos años a España. La empresa acondicionaba los productos importados, resultando en importantes esfuerzos de adaptación de productos y procesos.

\subsubsection{Articulación de la estrategia local de las compañías y la estrategia global}

La compañía A inicia en los años '90 a nivel internacional un proceso de racionalización y de concentración de sus competencias centrales (motores) 
desprendiéndose de la fabricación de maquinara agrícola, segmento de producto que vende a la principal empresa italiana del rubro. Sus ventajas organizacionales radican a partir de entonces en sus competencias en I+D y en fabricación de nuevas generaciones de motores "tailor made" hechos a medida; adaptados a la necesidad de potencia, al sistema, a las revoluciones por minuto y a las normas ambientales.

Esta empresa tiene plantas de producción situadas en Alemania, en donde funciona la casa matriz, España y China. La filial española funciona como fabricante de motores, y como proveedora de partes a la planta alemana. A partir de la crisis internacional del año 2008 pasó a cumplir exclusivamente la segunda función. La filial China se inauguró recientemente y tiene las tecnologías más modernas de producción.

La estrategia de la empresa a nivel global se basa en el control de la tecnología y en la operación internacional mediante licencias y alianzas con sus principales clientes como es el caso de la principal empresa sueca de maquinaria vial, de construcción y camiones, una firma ítalo - germánica de maquinaria agrícola, y empresas de menor tamaño de Turquía, y China. La alianza con la firma sueca involucra desarrollos conjuntos y una participación de la empresa nórdica en el capital de la empresa A. Con la compañía ítalo - germánica existen lazos de cooperación en $I+D$, con un liderazgo tecnológico de la firma $A$ en las nuevas series de productos. $A$ nivel global la firma A centra su negocio en la producción de motores para "maquinaria móvil" (este tipo de equipos es muy variado, e incluye desde equipos de perforación de minas hasta maquinaria de construcción urbana como las perforadoras, elevadoras, apisonadoras, trituradoras). Con una facturación global de 1.237 millones de euros en el año 2012, la maquinaria agrícola sólo significó el 15\% de ese total a nivel mundial (Annual Report A, 2012).

Actualmente la filial Argentina produce dos series de motores de las 42 series que fabrica la empresa a escala global. La serie 913, con refrigeración por aire e inyección mecánica y la serie la 1013 para buses con refrigeración por agua, inyección electrónica y componentes más modernos. Cada serie cuenta con 4 o 5 modelos tailor made. La primera está destinada a máquinas agrícolas, grupos electrógenos, usinas y equipos de riego y la segunda a colectivos. El componente nacional de la primera serie es del $80 \%$ y de la segunda no supera el $10 \%$.

En cuanto a las normas y controles de calidad y ambientales, en el MERCOSUR no existen restricciones para las emisiones de (CO2) de los motores de máquinas agrícolas. Los motores agrícolas producidos localmente no entran dentro de la 
reglamentación TIER $1^{195}$, mientras que en la casa central en Alemania y en la filial China se está produciendo bajo la norma TIER 2 y TIER 3, que tienen restricciones mayores en cuanto a la emisión de elementos contaminantes. Es por ello que sigue en producción la serie 913 de motores pese a no alinearse con la reglamentación europea sobre contaminación ambiental. Está de más decir que esto significa un limitante para su exportación fuera de América Latina.

EI pasaje a normas TIER 3 (que lo cumple la serie 1013) implicaría reemplazar las líneas de producción para cambiar casi la totalidad de las piezas. La filial española venía fabricando motores de la serie 914 , que son más eficientes que los producidos en nuestro país (cumple TIER 1 y 2), aunque el sistema tiene características de funcionamiento similares (inyección mecánica). En la planta local, se completó la incorporación de esta tecnología en el 2012. Cabe aclarar que la tecnología de la serie 913 dejó de usarse en Alemania hace tiempo.

El motor de la línea 1013 cumple con todos los requisitos establecidos por la Comunidad Europea y por otros países, pero no tiene salida para el mercado agrícola en nuestro país ni en la región, por sus elevados costos. Sus componentes son en un 90\% importado, principalmente de Alemania, y se arman localmente. La intención de la empresa es sustituir, en el futuro cercano, varias partes importadas por producción local, exceptuando las electrónicas. En la actualidad, como el volumen de ventas de este modelo es reducido, esta sustitución de partes se dificulta. Durante 2008 se comercializaron 300 motores de esta línea. La inyección electrónica es muy compleja y no hay capacidad para producirla localmente. Este componente explica el $20 \%$ del precio de costo del motor. Otro componente de alta complejidad es el turbo, que tampoco se podría producir localmente, según se desprende de las entrevistas realizadas.

En cuanto a la empresa $B$ su desarrollo geográfico es mucho más extendido, ya que posee plantas de producción en Estados Unidos de América, Argentina, Brasil, China, Francia, Alemania, Rusia, India, Méjico, Canadá, Holanda e Inglaterra. Si bien, han instalado un centro de investigaciones y desarrollos en India, las actividades centrales de I+D de la empresa está centralizadas en los Estados Unidos de América, donde invierte, en ello, alrededor de mil millones de dólares anuales (Anual Report, 2012). La empresa es la segunda productora de motores para maquinaria pesada del mundo, detrás de Caterpillar. Anualmente fabrica a nivel mundial 350.000 motores que se usan para los equipos que comercializa y se venden, además, a otras empresas de

\footnotetext{
${ }^{195}$ Reglamentación ambiental estadounidense.
} 
maquinaria agrícola, como Claas y Lamborghini.

Localmente se producen dos series de motores de las cinco que fabrica la empresa en el mundo. Estas incluyen motores que van de los 75 HP a los $350 \mathrm{HP}$ y son destinados, en general, a equipos de tamaño mediano a grande (aunque los motores de mayor tamaño se fabrican sólo en Estados Unidos).

Los motores fabricados a nivel local se utilizan en tractores, cosechadoras, grupos generadores y grupos de riego del MERCOSUR ${ }^{196}$. La empresa estima que el $81 \%$ de la producción se exporta a Brasil, un $10 \%$ a México y un $3 \%$ a China, para su utilización en tractores y cosechadoras producidos por la firma. A nivel internacional, la empresa se especializa en equipos estándar como es el caso de tractores y en menor medida cosechadoras; su expansión en el país se explica por su adaptación a las exigencias locales, en particular en relación al cabezal y el sistema de trilla de la cosechadora, lo que requirió desarrollos ingenieriles específicos.

La planta de motores se localiza en un área especial de la empresa, y la filial ha ido acrecentando su importancia paulatinamente, a partir de su buena performance desde 1996. Ha sido clave en este proceso la decisión de la empresa, en agosto de 2008, de especializar cinco fábricas de motores en el mundo, racionalizando las líneas de producción en otras localizaciones. El cambio organizacional le permitió a la filial local una mayor penetración internacional, ya que dejó de depender de las decisiones de la división agrícola de Brasil y pasó a formar parte de una estrategia global de la firma en la producción de motores. Previamente, en las primeras etapas del MERCOSUR, la empresa cambió su estrategia productiva y se relocalizó en Brasil, ensamblando allí las cosechadoras con los motores fabricados en Argentina. ${ }^{197}$ En 1995 se relocaliza la producción de tractores en Brasil, quedando en Argentina la fabricación de los motores y algunas piezas (mandos finales y ejes para su exportación a las filiales de Brasil. Luego, en el 2008, como se señaló la filial local se independiza de la filial brasilera. En la actualidad vende motores a China para la exportación de equipos de este país a Rusia, Tailandia y Singapur (los equipos vendidos en China son de tamaño pequeño y utilizan motores fabricados en ese país con menor sofisticación). Adicionalmente, exporta motores a México y algunos componentes a la filial de Francia, que también produce motores.

La filial local tiene cierta independencia ya que realiza planes quinquenales con

\footnotetext{
196 Para su expansión en el segmento de riego, la empresa acaba de adquirir una empresa con sede en Israel, y una planta localizada en San Juan.

197 Pasa de un esquema de "filial réplica" a "filial racionalizada" y a "filial especializada".
} 
revisión semestral, aunque los cambios en la estrategia se deciden en el marco de la estrategia global de la empresa, con escasa influencia de los cambios coyunturales locales.

La filial local, además, acondiciona los equipos finales recibidos de otros países. En relación a ello su actividad se focaliza en la comercialización, realizando solo el alistamiento de equipos importados (tractores y cosechadoras) con un semiensamblado, y tareas administrativas, de atención de una extensa red de comercialización (que incluye 54 concesionarias agrícolas y 6 de jardinería y golf), y de prestación de servicios de postventa y de financiamiento.

La empresa tiene el propósito de captar parte del mercado local de sembradoras como parte de su estrategia de aumentar las ventas que se afectaron por la reducción del negocio de las cosechadoras. ${ }^{198}$ Al respecto, entre 1999 y 2001 se fabricó en la filial un equipo desarrollado y patentado en el país, para grano fino y grueso, con el que llegó a participar en el 10\% del mercado local; luego deslocalizó la producción en Méjico.

\subsubsection{Esquema de producción. Organización del proceso de trabajo}

La capacidad máxima de fabricación de la empresa $\mathbf{A}$, operando con dobles turnos, es de 5000 motores por año ${ }^{199}$. La empresa contaba en el 2009 con 140 empleados, cuales $70 \%$ de los cuales estaba dedicado a las tareas productivas y un $8 \%$ a las actividades de ingeniería. ${ }^{200}$ La firma está realizando inversiones para desarrollar componentes para la nacionalización de la línea 1013, aunque encuentran límites para la producción de los componentes electrónicos.

La organización del trabajo en la planta se realiza a partir de un "lay out" en línea con trabajadores en puestos fijos. Si bien la organización no es en células se tiende a buscar una mayor rotación de tareas dentro de la misma categoría a fin de posibilitar reemplazos de personal y ajustarse al ciclo. De esta manera un operario puede pasar de apretar cabezas de cilindro a instalar el cigüeñal. Existe bajo grado de autonomía de los operarios, los que si bien llevan adelante tareas adicionales a las

\footnotetext{
198 Dentro de los productos de maquinaria agrícola, el tractor es el más estandarizado, la cosechadora presenta un componente de mayor diferenciación (en la trilla y el cabezal) y la sembradora es el producto de mayor diferenciación.

${ }^{199}$ Este nivel de producción - sin lanzamiento de nuevos productos- podría ser alcanzado con inversiones menores en el banco de pruebas (lugar donde se prueban los motores, con máquinas como dinamómetros y flujómetros).

200 Aquí sólo se considera la planta de motores y transmisiones de Haedo. La filial tiene en Rosario un número similar de empleados para el ensamble del tractor.
} 
operativas (mantenimiento, puesta en marcha de maquinaria), no pueden resolver problemas que puedan surgir en la línea, los que se derivan al supervisor. Se desarrollan métodos sistemáticos de control de procesos y cuentan con un alto grado de documentación de los mismos. Lo que les posibilita cumplir con las normas de calidad propias y de certificación ISO. En consonancia con esto se exige, a los proveedores más importantes que tengan certificación ISO.

En el caso de la empresa B, la relocalización de la producción en Brasil significó un importante cambio organizacional buscando una mayor especialización y racionalización de la planta. De esta forma, se pasa de la fabricación de 700 tractores y 1000 motores a 5000 motores en una primera etapa, llegando hasta 17000 en el pico máximo de producción en el año 2008. Esto incluyó importantes cambios en la filial, en cuanto a la adquisición de nueva tecnología, cambio del lay out, la adopción de una organización de la producción similar a la japonesa y la contratación de mayor personal que paso de 200 a 470 trabajadores en el año 2008 de los cuales 205 se dedican a la producción, 75 están ocupados con tareas de ingeniería, y el resto se trabaja en las áreas de servicio, de calidad y de administración y comercialización.

Los principales componentes de los motores - el block, tapa de cilindro, cigüeñales- son mecanizados internamente en la empresa por razones estratégicas. En la fabricación de partes y de motores, la filial trabaja en las mejores prácticas tecnológicas internacionales.

El lay out se organiza por líneas de ensamble de distintos subconjuntos a partir de una organización de flujo de demanda ${ }^{201}$. En ese marco los operarios "se acomodan" atendiendo a dos o tres líneas simultáneamente agregando horas extras. Esto les permite disminuir su requerimiento de mano de obra y, además, poder bajar la cadencia de las líneas sin reducir la cantidad de personal ante caídas en la producción. Este es un aspecto clave ante los importantes limitantes de personal capacitado (se requieren dos años de formación a partir de una formación general para alcanzar la capacitación necesaria).

Más allá de las normas de calidad ISO, la empresa cuenta con un sistema interno de calidad de proceso, denominado DPS, similar al de Toyota pero adecuado a los requerimientos específicos de proceso de la firma. Éste homogeneíza los procesos que se realizan en las distintas filiales del mundo. Por otra parte, posee otro sistema de calidad para los productos, que va desde el proceso de fabricación a la atención al

201 El flujo de demanda de Tecnología utiliza métodos matemáticos aplicados para vincular materias primas y materiales en proceso con unidades de tiempo y recursos de producción a fin de crear un flujo continuo en la fábrica. 
cliente y los servicios. Estas innovaciones organizacionales se apoyan en el uso de TICS, a partir de software tales como monitores en la línea y herramientas inteligentes (la maquina avisa si operó bien o mal). Y sin delegar en el operario la responsabilidad de estas tareas,

Es importante resaltar que los costos fijos son muy bajos, incluyendo la amortización de equipo y los gastos administrativos, que se diluyen en la producción en flujos altos. Esta es una de las principales fuentes de competitividad de la empresa, y solo es posible obtenerla con niveles altos de uso de la capacidad instalada. En caso de reducir el uso de la capacidad a menos del $50 \%$, estos costos aumentarían un $40 \%$, lo que afectaría la rentabilidad de la planta y de la división regional.

La operación en flujo de demanda en forma flexible le permite a la firma B mantener la eficiencia de la planta. Las principales limitaciones de esta estrategia provienen de los proveedores que no cuentan con esta organización en flujo de demanda propio de la especialización flexible

Por otro lado, a diferencia de lo que ocurre en las empresas PyMEs, la caída en la demanda no afecta seriamente la sustentabilidad de la planta. En estos casos, se utiliza el tiempo sobrante para capacitar a los operarios en otras tareas, de forma de aumentar su polivalencia, y se eliminan las horas extras. En el siguiente punto se describe las características que adquiere la articulación de estas dos compañías con los proveedores de escala nacional.

\subsubsection{Impactos sobre el entramado productivo loca}

La empresa A, como se señaló, fabrica la serie 913 de motores, y se abastece de sus componentes en un $80 \%$ con proveedores nacionales, manteniendo con buena parte de ellos (la mitad) contratos de exclusividad y a los que en muchos casos otorga máquinas en comodato. Los proveedores más importantes tienen certificación ISO. Entre ellos se encuentran Pertrak (con 35\% del costo de materias primas), y la Fundición Martinez, ambas empresas de capitales nacionales. La compañía A, además, utiliza fundición importada de la firma Susir Francosanti de Brasil y nacional de Paraná Metal. El 15\% de sus compras de partes y componentes de ambas series de motores provienen de la casa matriz (Alemania) y de la firma BOSCH (Alemania/Brasil).

La empresa Pertrak con capacidades en mecanizado tiene un contrato con la firma A para la provisión de partes, entre las que se incluyen algunas significativas como cigüeñales y blocks. Como parte del contrato, la empresa $\mathbf{A}$ entregó máquinas 
herramientas a Pertrak, y le solicitó que se abstuviera de vender motores agrícolas en el país. Sin embargo, Pertrak vende un pequeño número de equipos a compradores puntuales, y aumenta su oferta en los períodos de expansión de la demanda. Ello es debido a las dificultades que enfrenta la empresa $A$, al igual que todas las empresas centradas en el mercado interno, para hacer frente a las mayores demandas programando la producción sobre una base anual, (como lo realizan las empresas a nivel internacional).

La empresa considera que los proveedores nacionales son competitivos en precio (por el tipo de cambio) y en calidad, en componentes mecanizados y en fundición. No es el caso de los componentes electrónicos, los que son requeridos para los motores a inyección; la empresa importan los cigüeñales de Brasil (no incluyendo la forja) y los componentes electrónicos de Alemania. Por su parte, los contratos que la empresa realiza con los proveedores nacionales e internacionales, no involucran las actividades centrales de la misma: investigación, diseño y desarrollo, calidad, capacitación del personal.

La empresa B considera de central importancia el desarrollo de proveedores debido a la escasa presencia en el país de proveedores especializados, en particular proveedores de inyección, de turbos, y de fundiciones pesadas. La falta de escala del mercado local lleva a que la empresa importe algunas partes centrales para la fabricación de los motores. Los equipos de inyección y los turbos provienen de otras plantas de la firma, mientras que los cigüeñales se importan de México.

A pesar de las importaciones, un $60 \%$ de los costos directos de fabricación de esta empresa (incluyendo partes más mano de obra) son de origen nacional. Ello se asienta, en buena medida, en el desarrollo de proveedores locales, los más importantes de los cuales son Basso, Fundimac, Venturi, Muncian Cansani y GKN esta última empresa es una filial de una compañía transnacional. Algunos de estos proveedores exportan a otras plantas de la empresa, y también venden a Brasil para la fabricación de tractores, como es el caso de Venturi y Muncian Cansani.

Los dos principales "cuellos de botella" que enfrenta la empresa están asociados, por un lado, a los mayores costos derivados de prácticas monopólicas de empresas proveedoras, y por otros a de capacidad de respuesta de la cadena de valor a las variaciones en la demanda, asociada a la falta de inversión de los proveedores.

En los años 2008 y 2009 se deterioró la relación costo-beneficio de la filial, transformándola en pasando de ser la filial más eficiente de la empresa, a la filial 
menos eficiente. Ello fue consecuencia de la rigidez a la baja en los precios de las materias primas, característica de los mercados oligopólicos de los grandes proveedores de aluminio, acero, y de plásticos. Por su parte, la falta de inversión en tecnología de los proveedores de partes limita la oferta en la fase de expansión de la industria, como sucedió en el año 2008, si bien algunos proveedores no tuvieron dificultades en su oferta.

\subsubsection{Innovación y desarrollo. Vinculaciones con el SNI}

En relación a las actividades de $I+D$, la filial de la empresa $\mathbf{A}$ no cuenta con un departamento formal porque estas actividades están centralizadas en la casa matriz y en otras filiales como la localizada en la India. Existe un departamento de ingeniería que, además de realizar ingeniera de proceso y adaptación a normas, se ocupa de desarrollos de partes y componentes periféricos para proveedores, y de las adaptaciones exigidas por el cliente. El diseño y desarrollo de los motores se realiza en Alemania y localmente se hacen desarrollos menores de piezas y componentes. Los acuerdos de mejora de producto con clientes, se limitan a ciertos ajustes menores al sistema, no existiendo en ningún caso contrato de exclusividad.

Las relaciones contractuales de la empresa están acotadas a las vinculaciones con proveedores y clientes. La empresa no realiza relaciones formales con cámaras, universidades o centros tecnológicos, no recibe apoyo de la política de innovación nacional o provincial. Su estrategia tecnológica local se limita a la capacitación de proveedores y clientes.

La empresa B para el año 2009, se concentró en la producción de motores que incluyó la calibración, el desarrollo del sistema de combustible y el proceso de manufactura para los componentes, además del desarrollo de proveedores. Como se señaló, en los años 1999 y 2001 la filial local de la empresa había desarrollado una sembradora de grano fino y grueso, que participó con el $10 \%$ del mercado local, obteniendo una patente nacional.

En resumen, estas compañías logran insertarse en el mercado nacional de maquinaria agrícola en una estrategia de market seeking, (ver capítulos 2 y 3 ). No tienen una amplia política de desarrollo de proveedores, y cuando lo hacen, éstos tienen bajos niveles de sofisticación tecnológica de producto. Las actividades de investigación y el desarrollo no se localizan en nuestro país. De todo ellos se desprende que estas empresas persiguen una estrategia orientad a capturar cierto know how local, a la vez que invierten en el desarrollo de ciertos equipos (sembradoras) que son particularmente innovadores para la región. 


\subsection{Conclusión}

A partir del análisis realizado, pueden observarse distintas formas de organizar la producción de las empresas en el territorio. Algunas de ellas conforman una aglomeración regional y sectorialmente especializada, con fuertes vínculos con otros actores que les permiten alcanzar altos niveles de innovación. Estos vínculos están más asociados a relaciones proveedor/usuario que al soporte institucional público o privado de tecnología. Por otro lado, cada subsector o segmento tiene particularidades asociadas a las características de los distintos segmentos productivos, como puede apreciarse en el cuadro $N^{\circ} 16$.

Cuadro $\mathrm{N}^{\circ}$ 16. Productividad relativa aparente, capacidades endógenas y externalidades de las firmas de maquinaria agrícola según segmentos productivos

\begin{tabular}{|l|c|c|c|c|c|}
\hline & $\begin{array}{c}\text { Agropar- } \\
\text { tistas }\end{array}$ & $\begin{array}{c}\text { Cosechadoras y } \\
\text { tractores }\end{array}$ & $\begin{array}{c}\text { Implemen- } \\
\text { tos agrícolas }\end{array}$ & $\begin{array}{c}\text { Pulveriza- } \\
\text { doras }\end{array}$ & $\begin{array}{c}\text { Sembra- } \\
\text { doras }\end{array}$ \\
\hline $\begin{array}{l}\text { Productividades } \\
\text { (aparentes) }\end{array}$ & BAJA & MUY ALTA & BAJA & MEDIA & ALTA \\
\hline $\begin{array}{l}\text { Incidencia positiva de } \\
\text { factores externos }\end{array}$ & MEDIA & ALTA & MEDIA & ALTA & MUY ALTO \\
\hline $\begin{array}{l}\text { Incidencia positiva de } \\
\text { factores endógenos }\end{array}$ & MEDIA & MUY ALTA & MEDIA & MEDIA & BAJA \\
\hline
\end{tabular}

Fuente: elaboración propia

El segmento de cosechadoras y tractores, mayoritariamente de empresas transnacionales, opera en todas las escalas y sus fuentes de conocimiento y aprendizaje innovador son tanto internacionales, de la región, como internas a la empresa. Si bien, tienen menos proveedores locales que el promedio de los otros subsectores, no dejan por ello de tener un vínculo estrecho con la región, capturan conocimientos generados localmente. Tienen prácticas productivas que están en la frontera tecnológica internacional, aunque algunas compañías conservan configuraciones "híbridas" entre formas fordistas y flexibles de organización de la producción. Las firmas transnacionales conservan su activo específico de diseño y desarrollo en las casas matrices, no haciendo transferencias directas de tecnología. Tampoco han desarrollado proveedores de bienes tecnológicamente avanzados, y 
cubren la demanda local con equipos agrícolas importados.

Estas empresas se encuentran asociadas directamente a cadenas de valor globales integradas. Al mismo, que ponen en tensión el desarrollo de la capacidad local de producción, se articulan al SNI y asimilan capacidades locales.

Por otro lado, las empresas PyME nacionales, de fuerte arraigo regional, también encuentran alagunas oportunidades de desarrollo a partir de sus articulaciones locales con los SNI. Esto es particularmente importante, para algunos segmentos de maquinaria, en el contexto de la difusión de los nuevos paradigmas tecnológicos de producción agrícola (TICs. y biotecnología) para los cuales la adaptación a los sistemas agronómicos locales exige esfuerzos de diseño y articulación con clientes. En este entorno se han generado oportunidades de innovación, asociadas a la experiencia acumulada por las firmas locales y a los desarrollos alcanzados en la infraestructura de ciencia y técnica nacionales, como es el caso de las innovaciones relacionadas con los equipos de sembradoras y pulverizadoras.

Las empresas productoras de sembradoras y pulverizadoras han logrado alcanzar altos niveles de competitividad gracias a las innovaciones desarrolladas en articulación con en el sistema agronómico local. Estas empresas adaptaron tempranamente tecnologías importadas a los requerimientos específicos de la siembra directa y luego al desarrollo de la siembra con semillas transgénicas y herbicidas. A tal, fin utilizaron parte importante del soporte regional del SNI, instituciones, proveedores y clientes. Desde esta perspectiva, estos segmentos son los que jugaron el rol propio de las industrias de bienes de capital en los aprendizajes proveedorusuario y la difusión de las innovaciones sistémicas señalados en el capitulo1.

En el caso de las firmas productoras de sembradoras, el grupo de proveedores que las abastecen es exclusivamente local, con quienes tiene fuertes lazos de aprendizaje y desarrollo. El soporte institucional del INTA y de CIDETER ha sido clave en el progreso de la competitividad de estas firmas. Estas empresas se encuentran en una situación intermedia entre los esquemas flexible y fordistas de producción: el grupo de empresas que concentran mayor porción de mercado conservan formas rígidas fordistas de producción, mientras que el resto de las firmas combina esquemas fordistas - tayloristas, con maquinas herramientas más rudimentarias y mayor diversificación de la producción.

Las empresas productoras de pulverizadoras autopropulsadas se articulan a una red de proveedores locales importantes, a excepción de los componentes motrices, como motores y transmisiones. Estos son nodos de articulación con el 
"núcleo transnacionalizado" de la trama, que comparten ese rol con las firmas proveedoras de los equipos de agricultura de precisión, mayoritariamente nacionales. Este subsector posee un mercado muy concentrado, dos empresas capturan el $80 \%$ de la producción y otras 10 empresas se distribuyen el $20 \%$ restante. Las dos firmas más grandes se diversificaron en productos de igual o mayor complejidad (tractores, sembradoras y cosechadoras) y las firmas más chicas se encuentran diversificadas en implementos más "rudimentarios", porque en algunos casos esa era su producción original. En cuanto a la forma de organizar la producción puertas adentro de la fábrica tienen un esquema más flexible que el de sembradoras, pero no por ello deja de ser un tipo híbrido en el que se combina fordismo - flexibilidad y atraso.

Muchas de las empresas de sembradoras y pulverizadoras, con una menor participación en el mercado, en momentos de crisis y caída de demanda se "repliegan" hacia la producción de los productos más simples y se convierten en talleres de reparación para ocupar su capacidad ociosa.

El segmento productor de implementos agrícolas es mucho menos dinámico que los anteriores. Es un subsector que tiene pocos proveedores específicos y las acerías que están fuera de la región son las articuladoras de la trama con distribuidoras dentro del territorio. El subsector produce equipos poco sofisticados cuyas mejoras son reducidas y no utilizan la vinculación con el resto de los agentes como plataforma de innovación y mejora. Aunque se debe destacar que dentro del agregado hay empresas que tienen un comportamiento dinámico y elevan los promedios de innovación del mismo. Existe también un proceso importante de diversificación hacia equipos más sofisticados. Este segmento posee los niveles de heterogeneidad más grandes.

El subsector de agropartes es fundamental en la elaboración de piezas y partes, conjuntamente con las empresas terminales. Necesariamente deben localizarse cerca unas de otras para lograr un entendimiento de las necesidades de las empresas ensambladoras (relaciones proveedor/usuario). Sus proveedoras, se encuentran en la región, aunque sus vínculos son mayormente mercantiles. Por otro lado, este segmento de producción que es flexible en cuanto a la capacidad para seguir a la demanda, es también muy rudimentario en sus capacidades productivas.

En el gráfico $\mathrm{N}^{0} 13$, se exhibe el tipo de organización territorial que presenta la industria de maquinaria agrícola. El gráfico nos permite sintetizar algunas características de cada subsector y de esta forma se hace una acercamiento al grado de aproximación que tienen los distintos subsectores a una dinámica de cluster. 


\section{Gráfico Nº 13. Dinámicas de cluster}
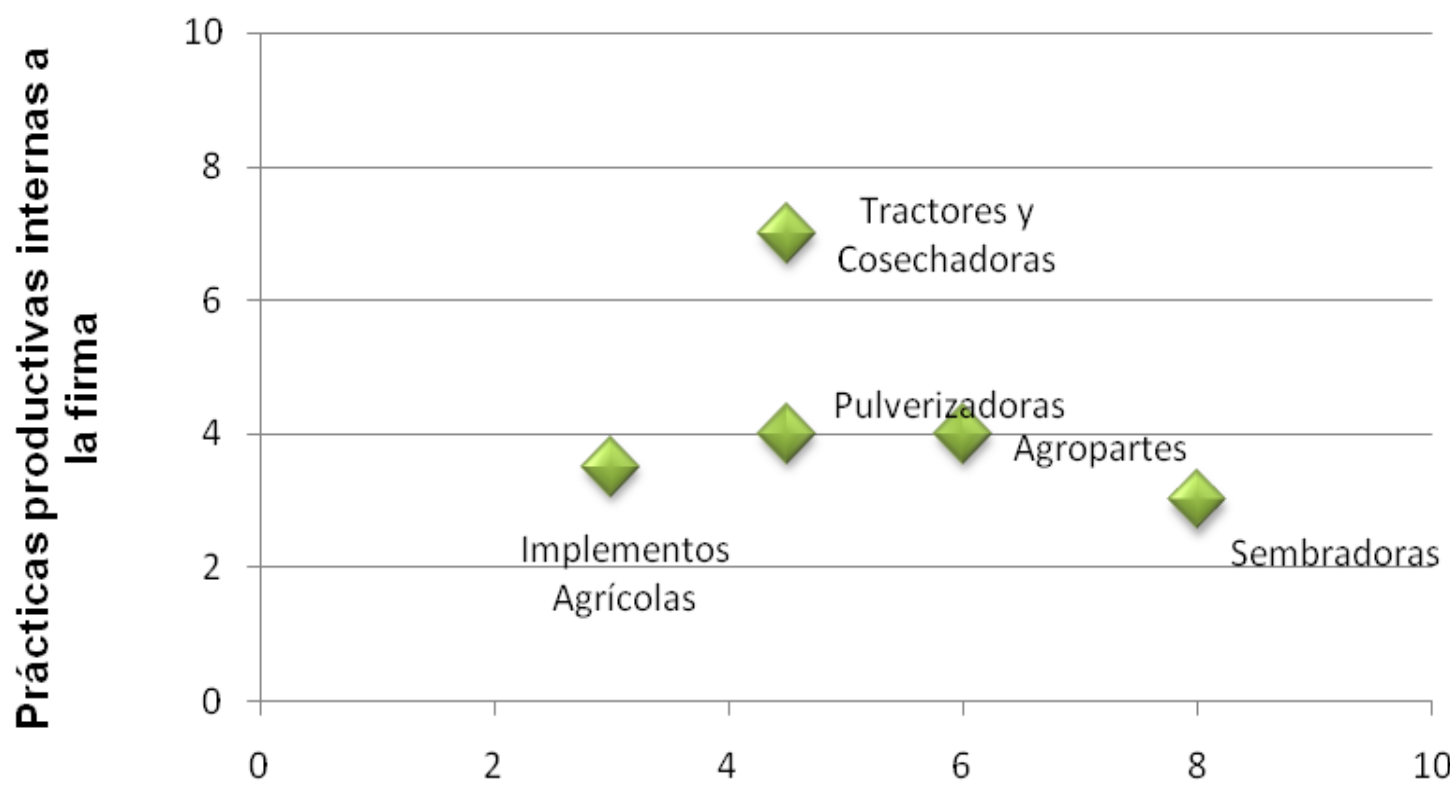

\section{Grado de vinculación}

Fuente: Elaboración propia

En el gráfico $\mathrm{N}^{\circ} 13$ se presentan las prácticas productivas externas e internas a las empresas, ponderadas por la trama de proveedores que posee cada subsector $^{202}$ (no se consideró la productividad aparente).Si bien, ninguno de los subsectores tiene una dinámica que pueda asimilarse totalmente a un cluster, (como lo describe la literatura al respecto), se puede hacer un ejercicio de aproximación a este tipo "ideal" de organización espacial de producción, en oposición a una configuración territorial estática.

En este sentido, se considera que la organización espacial de la producción de sembradoras tiene las características más cercanas a una organización tipo cluster en relación al resto de los segmentos de producción, pese a ser uno de los subsectores que posee una más alta integración vertical y en el que la organización de la producción interna de las firmas presenta ciertas debilidades. Un escalón por debajo (hacia la izquierda del gráfico) se encuentran las compañías de agropartes que tienen un fuerte arraigo regional, por las características de sus producto y el origen del capital, aunque a diferencia del segmento de sembradoras presentan bajos niveles de productividad aparente. Más rezagadas en cuanto a su integración en el territorio se encuentran las compañías de pulverizadoras, con mayor cantidad de componentes

202 El gráfico se construyó a partir del cuadro № 10 que condensa la información sobre las competencias internas de los distintos subsectores, volcadas en el eje "y"; y de la cantidad de vinculaciones, expresadas en el eje " $x$ " (cuadro $N^{\circ} 13$ ) junto con la ponderación de las distintas tramas de proveedores. 
importados. Las empresas de cosechadoras y tractores tienen altos niveles de vinculación e innovación, pero son a su vez muy dependientes de componentes extranjeros, articulándose casi exclusivamente con empresas transnacionales. Ostentan, también, los mejores niveles en las prácticas productivas internas. Por otra parte, el subsector de implementos agrícolas no participa de manera importante en lo que denominamos dinámicas de cluster.

Es importante destacar, que el conjunto de firmas regionales de maquinaria agrícola no presenta en forma pura un estilo fordista seriado de producción y tampoco un esquema de especialización flexible al estilo del norte italiano como el que describieran Piore y Sabel (1984).

En definitiva el análisis realizado permite comprobar la heterogeneidad estructural sectorial, la que es generada y reproducida por distintos motivos, todos ellos concurrentes. Los segmentos de tractores y cosechadoras, sembradoras y pulverizadoras son los de más alta productividad relativa, mientras que los agropartistas e implementos agrícolas poseen la más baja productividad. Los equipos de tractores y cosechadoras son los más sofisticados y se producen a gran escala lo que explica sus niveles de eficiencia y productividad. La producción se organiza en un esquema global de abastecimiento mayormente externo que se traduce en heterogeneidad estructural sectorial y desestructuración del territorio. La estrategia empresaria en el territorio mantiene una lógica global gobernada desde las casas matrices, concentrando los eslabones centrales de la actividad en los países de origen (dirección estratégica, investigación y desarrollo). No obstante, la empresa más importante a nivel mundial de maquinaria agrícola desarrolló una sembradora a nivel local, dando muestras de ciertas ventajas y especificidades en el desarrollo de este segmento en la región.

En este sentido el segmento de sembradoras a la vez que produce con altos niveles de eficiencia relativos, muestra un alto nivel de integración local - nacional estructurando la región y la aglomeración productiva en una aglomeración territorial de tipo cluster. Esto sumado a un ciclo de producto relativamente nuevo le permite a este segmento capturar ciertas rentas tecnológicas.

El segmento de pulverizadoras es un caso particular que obtiene ventajas de la difusión de una agricultura fuertemente demandante y dependiente de la aplicación de bioquímicos. La estructura de proveedores es en parte local y en parte extranjera con mejores prácticas productivas internas que el segmento de sembradoras pero de todas formas con un menor nivel de productividad relativa. 
En definitiva, las dinámicas internacionales y locales se expresan en organizaciones de la producción heterogéneas que permiten, no obstante, el desarrollo de subsectores como el de sembradoras y pulverizadoras, que capturan ventajas locales transitorias. Estos segmentos se enfrentan a la oportunidad de dar el "salto" hacia las mejores prácticas productivas para enfrentar un mercado cada vez más dominado por empresas transnacionales. Los próximos años se transitará, muy probablemente, hacia un intento de las empresas transnacionales por controlar los mercados de sembradoras y pulverizadoras, como ocurrió en la década de 1980 con el mercado de cosechadoras (ver capítulo 2). 
CONCLUSIONES 


\section{Conclusión}

En las páginas anteriores hemos trabajado la relación existente entre distintas formas de organizar la producción en el territorio. En esta línea, uno de los ejes que ha estructurado la investigación ha sido la identificación de los diferentes modos de configurar la producción de maquinaria agrícola, ya sea a partir de aglomeraciones productivas estilo clusters o cadenas de valor globales. A su vez, se reconoció la correlación existente entre estas dos configuraciones territoriales de producción, el origen del capital de las empresas y la especificidad del bien que las firmas producen.

En otras palabras, el trabajo puso en evidencia la capacidad de las compañías trasnacionales de desestructurar el tejido productivo local, a través de cadenas de valor globales, en contraposición a la firmas PyME de origen nacional, que estructuran el territorio en aglomeraciones productivas. Por un lado, esta última configuración territorial surge como una expresión histórica de la vinculación entre industriales y productores agropecuarios. Por otro lado, en el contexto de un país periférico, la capacidad estatal de regular la forma en la que el capital transnacional estructura la producción local, es un factor determinante en la definición de un perfil productivo nacional propio.

En este sentido, el abordaje estructuralista mantiene su vigencia ya que expresa el carácter periférico y dependiente de la economía argentina. Esta situación se explica por un proceso histórico en el que el país no pudo o no supo cambiar la matriz productiva, más allá de los diferentes modelos de acumulación con sus respectivas formas de regulación, que se han sucedido en el país. Asimismo, el contexto internacional ha condicionado el perfil económico de Argentina, a partir de la fuerza productiva y comercial de los países centrales, aspecto que resulta estructural por su persistencia en el tiempo.

En la Argentina, la producción de equipos agrícolas tuvo un surgimiento temprano, dando muestras de cierta potencialidad para el desarrollo de una industria de bienes de capital nacional. Esta situación se explica, en parte, por el fuerte vínculo con la agricultura, sector que se convirtió hacia finales del s. XIX en el más dinámico de la economía argentina. De allí que el origen de la producción de maquinaria agrícola se produjo en la región centro - sur de Santa Fe y este de Córdoba, donde se 
registró: un tipo de ocupación del suelo rural en chacras de no más de 300 ha., asociada a los inmigrantes europeos que colonizaron esas tierras, quienes poseían la capacidad y los saberes en el manejo de la metalurgia. De todas formas, esto no alcanzaría para generar un proceso de acumulación ampliada de capital que desarrollara una industria proveedora de equipos a escala nacional y habría que esperar a las activas políticas estatales del período ISI para superar la etapa "artesanal" y de prototipos.

En el período ISI, los establecimientos de reparación, copia, adaptación y mejora de equipos importados de la etapa previa (fines de s. XIX hasta 1930) comienzan a producir industrialmente y a cubrir las necesidades de maquinaria para la producción rural argentina, con excepción del segmento de tractor hasta principios de la década de 1950. En esta línea, la política estatal tuvo un rol central en el sostenimiento y fomento de la demanda, además de proteger la industria de la competencia externa. El Estado no sólo se comportó como regulador del mercado sino que, también, fue productor de tractores junto a filiales de empresas transnacionales a partir de 1953.

Hemos visto que la producción de tractores presentó, durante la ISI, una serie de particularidades: esta producción tuvo importantes deseconomías de escala y las unidades de tractores combinó bajo grado de interoperabilidad entre implementos de distintos modelos, alta potencia y una mecánica más sencilla que los tractores producidos en los países centrales. Asimismo, esta dinámica permitió importantes procesos de aprendizaje y de acumulación de experiencia, que se traduciría en una elevada capacidad de adaptación de las empresas a los cambios regulatorios y macroeconómicos de las décadas siguientes. De esta forma, se consolidó una trayectoria tecnológica en respuesta a las características de las explotaciones agrícolas de la pampa húmeda.

Hacia 1976 con la culminación del período de la ISI, la industria llegaba a su madurez tecnológica a nivel mundial y, en Argentina, ésta operaba con algunos retrasos a nivel producto y más específicamente a nivel de los procesos productivos. Las firmas transnacionales productoras de tractores trabajaban con deseconomías de escala, no obstante la protección del mercado interno permitía al oligopolio de compañías transnacionales fijar precios con "captura" de rentas. En tanto, las empresas locales de maquinaria agrícola lograban durante la primera mitad de la década de 1970 exportar hacia otros mercados y demostraban cierto nivel de competitividad, de todas maneras no consiguieron estabilizar dicho proceso. 
Entre 1976 y 2002, a instancias de un brusco cambio en la política económica, se produjo un período de 25 años de ajuste regresivo del sector. Esto generó el cierre de numerosas líneas de producción de las filiales de empresas transnacionales de tractores, la desaparición de casi doscientas empresas de implementos agrícolas, el cese del funcionamiento, la racionalización y diversificación de las fábricas de cosechadoras. A su vez, se crearon algunas nuevas empresas de capital nacional de éxito relativo. Durante este período, se registraron caídas en la productividad y en el empleo. En paralelo al proceso mencionado, se produjo un cambio en los sistemas agronómicos de producción. Aspecto que instituyó, un renovado estímulo de aprendizaje proveedor-usuario y de cambio tecnológico localizado de alta relevancia.

En el breve lapso que transcurre entre 1998 y 2002, las últimas fábricas de cosechadoras y tractores dejaron de producir. No obstante la crisis y la caída de la producción, las empresas de pulverizadoras y sembradoras sostuvieron niveles aceptables de fabricación, que les permitieron permanecer en el mercado interno como los principales proveedores.

Ahora bien, luego de la caída del plan de convertibilidad en el año 2002, se generaron nuevas condiciones para el sector de maquinaria agrícola. Al cambio en los precios relativos posdevaluación, se sumó un sostenido aumento internacional en los precios de los granos. Como resultado, aumentaron las ventas internas de maquinaria agrícola. Sin embargo, en el caso de tractores y cosechadoras se observó una profundización de la importación, aproximadamente el $80 \%$ de los equipos vendidos fueron importados.

Tras la profunda crisis que atravesó el país y devaluación de la moneda mediante, la producción de equipos agrícolas nacionales ha comenzado a recorrer un nuevo camino de expansión. Como se registró en el capítulo 2, cuatro fábricas de cosechadoras abrieron o reabrieron sus instalaciones de producción y, con debilidades estructurales y fuertes heterogeneidades, continúan intentando disputar el mercado interno a las empresas transnacionales. El caso particular de las sembradoras nos mostró que existen más de cuarenta empresas distribuidas por Santa Fe, Córdoba y Buenos Aires, cuyo campo de acción se encuentra menos explorado que el de los tractores y cosechadoras. Estas firmas son, en cierta medida, las que podrían marcar el rumbo a nivel mundial en cuanto al avance tecnológico del segmento. Además, se observó que las compañías de pulverizadoras con un número superior a diez es un segmento de producto que complementa, junto a las compañías de sembradoras, el conjunto de siembra directa - biotecnología - maquinaria específica. 
Si bien, se produjo una importante reactivación de la industria de maquinaria agrícola a partir del año 2002, en el desarrollo de esta tesis hemos visto que las consecuencias del ajuste regresivo que sufrió esta industria durante 25 años, aún no fueron totalmente revertidas. La recuperación y superación de los niveles de producción alcanzados en la década de 1990, tuvieron en el período posdevaluación mejor respuesta en aquellas segmentos de producción que transitaron mejor el período de convertibilidad. Esto fue factible, a partir de la profundización de las capacidades tecnológicas acumuladas con una sensible adaptación a las especificidades locales.

Por otro lado, la fuerte presencia de empresas transnacionales en el segmento de tractores y cosechadoras ha dificultado el abastecimiento del mercado doméstico con producción nacional. La posición dominante en el mercado nacional por parte de estas empresas productoras de tractores y cosechadoras se ha sostenido con la importación de equipos y no ha tenido mayor modificación en la década de 2000 respecto de la década de 1990. Las economías de especialización, en el marco de las estrategias de las empresas transnacionales, han favorecido su localización en Brasil y esto ha seguido funcionando así pese al cambio de escenario macroeconómico en Argentina.

El resultado del análisis de la trayectoria de la industria de maquinaria agrícola argentina dio cuenta de las características particulares de esta industria y de una historia atravesada por fuertes oscilaciones en la política económica, como así también del carácter dependiente y periférico de su desarrollo.

Quedó expuesto que esta industria ha sido influida por la variabilidad macroeconómica y los distintos marcos institucionales de regulación estatal. Asimismo, se verificó que la configuración territorial de la actividad tiene una fuerte inscripción histórica. También, observamos dos conductas: una, relacionada con las empresas transnacionales que reestructuran su producción en función de estrategias de escala global y, otra, vinculada a la conducta de empresas nacionales que han acompañado las transformaciones locales del sector agrícola.

En este sentido, hemos elaborado una clasificación que nos permitió distinguir dos grupos de las empresas nacionales. El primer grupo se encuentra asociado a las compañías de sembradoras y pulverizadoras, que tienen un mercado interno momentáneamente "cautivo", con aparentes barreras al ingreso de la competencia extranjera, relacionadas estas barreras con las necesidades locales de producción agrícola y la especificidad de los equipos. El segundo grupo se configura en torno a las 
empresas de tractores y de cosechadoras, cuyo origen del capital es nacional y tienen una relación de disputa dentro del mercado interno con los oligopolios internacionales.

Por su parte, las empresas transnacionales han sido identificadas como la expresión más notoria de procesos centro - periferia y de dependencia, que operan en el mercado argentino de acuerdo a estrategias globales propias, con mayor facilidad frente a los cambios de regulación nacional. A partir del comportamiento que han tenido estas compañías, a lo largo de la historia, se reforzó la heterogeneidad de la trama productiva y se reconfiguró la relación entre esta industria y su anclaje en el territorio nacional.

Como hemos visto las empresas transnacionales estuvieron presentes en la Argentina desde el inicio de la industria de maquinaria agrícola, primero a través de la importación y, luego, con un rol central en la producción de tractores en el país. También, observamos que en tiempos recientes, estos actores han desarticulado los entramados industriales locales, a partir de estrategias globales vinculadas a políticas liberales. El rol desempeñado por las compañías transnacionales instaladas, desde la década de 1950 en Argentina, se fue modificando de filiales réplica de baja escala (con deseconomías) a la especialización en la fabricación de componentes y/o la importación de equipos completos.

Por otra parte, consideramos que el MERCOSUR y la construcción del mercado regional argentino-brasileño, replica el esquema que hemos identificado en las regiones centrales. Los países de Alemania, Estados Unidos, Japón e Italia dominan como primer paso sus "hinterlands", para luego expandir a través de la exportación y la inversión directa su llegada geográfica mundial. En un esquema similar, Brasil se erige como proveedor de equipos agrícolas a la Argentina, con la salvedad que lo hace a través de filiales de empresas transnacionales de países centrales.

Por su parte, Argentina ha recorrido un camino más largo que Brasil en cuanto a producción y desarrollo de maquinaria agrícola, pero ante la asimetría de políticas industriales, la apertura de los mercados y el establecimiento en Brasil de las empresas transnacionales, el país se encuentra en la actualidad en una relación asimétrica y en desventaja para el desarrollo industrial propio. Complementariamente, nuestro país es un mercado importante para la estructura de negocios de las empresas y de los países dominantes, pero la organización de la producción de las 
firmas transnacionales se hace fundamentalmente en vistas al mercado regional, MERCOSUR, como base central del mercado interno ampliado.

Esta situación nos permitió ampliar la tesis de Mistral (1979) acerca de la importancia del mercado interno en el desarrollo industrial, al papel que juega el mercado interno ampliado en las nuevas configuraciones de los mercados regionales, en contraposición a quienes sostienen la posibilidad de desarrollar la industria de maquinaria agrícola independientemente de la escala del mercado interno.

A su vez, el estudio del caso Argentino nos posibilitó cuestionar la tesis de Fagerberg (1992) que supone que teniendo un sector competitivo a nivel mundial (en nuestro caso el sector agropecuario), éste traccionará por sí solo a otros sectores proveedores "aguas arriba", para que también alcancen altos niveles de competitividad. Debemos considerar que esto último es factible sólo si el Estado instrumenta políticas industriales adecuadas y de protección del mercado interno, a largo plazo.

Un párrafo aparte merece los 5 últimos años, luego que el gobierno nacional en 2009 tomara medidas restrictivas para la importación de maquinaria agrícola. A partir de ello cuatro de las compañías transnacionales más grandes del mundo $(\mathrm{CNH}$, AGCO, John Deere y Claas) han proyectado inversiones millonarias en dólares, para comenzar a producir (en un principio sólo ensamblar) equipos de cosechadoras y tractores en el país. Si bien, los efectos de estas medidas exceden los límites temporales de la definición original de nuestro objeto de estudio, consideramos que esto refuerza la importancia del mercado interno argentino de maquinaria agrícola para las empresas transnacionales y el rol que juegan las políticas estatales en el desarrollo del sector.

A partir del análisis realizado en esta tesis, pudieron observarse distintas formas de organizar territorialmente la producción de las empresas. Algunas de ellas, como es el caso de las sembradoras, conforman una aglomeración regional y sectorialmente especializada, con fuertes vínculos con otros actores que les permiten alcanzar altos niveles de innovación. Hemos detectado que estos vínculos están más asociados a relaciones proveedor/usuario que al soporte institucional público o privado de tecnología. Sin embargo, como veremos a continuación cada segmento productivo tiene sus particularidades. 
El segmento de cosechadoras y tractores es el más complejo tecnológicamente dentro de la industria de maquinaria agrícola y en el mercado nacional predominan las empresas transnacionales. Algunas de las empresas transnacionales que producen estas máquinas (o partes de ellas) en el país, desarticulan el entramado productivo local al estructurar su cadena de valor con mayor participación de proveedores extranjeros. A su vez, los escasos proveedores locales que poseen estas firmas en el país incorporan los eslabones productivos de menor sofisticación tecnológica. Por otra parte, hemos identificado que a pesar de que estas compañías tienen menos proveedores locales que el promedio de los otros segmentos, éstas no dejan de tener vínculos estrechos con la región, entre ellos la incorporación de conocimientos generados localmente. Dicho en otras palabras, por un lado no generan "derrames" positivos a la región y al país, pero incorporan desarrollos hechos de forma colectiva en la región.

En este contexto, registramos que las prácticas productivas que tienen las filiales de las compañías transnacionales de maquinaria agrícola en Argentina se hallan en la frontera tecnológica internacional. Aunque algunas empresas conservan configuraciones "híbridas" entre formas fordistas y flexibles de organización de la producción. Al respecto, nos es difícil comprobar las afirmaciones expresadas por Piore y Sabel (1984) y por Lipietz (1994) expresadas en el capítulo 1. Ideas que vinculan a la periferia con métodos, casi exclusivamente, fordistas - tayloristas de producción. Con referencia a la observación por Lipietz (1994), si se demuestra aquí, que las firmas transnacionales conservan su activo específico de diseño y desarrollo en las casas matrices, sin hacer transferencias directas de tecnología. En este sentido, verificamos que estas empresas se encuentran asociadas directamente a cadenas globales de valor integradas, pero al mismo tiempo articuladas parcialmente con el sistema nacional de innovación.

Por otro lado, las PYME nacionales, de fuerte arraigo regional, encuentran algunas oportunidades de desarrollo a partir de sus articulaciones locales con el sistema de innovación nacional. Esto es particularmente importante, para algunos segmentos de maquinaria en el contexto de la difusión de los nuevos paradigmas tecnológicos de producción agrícola (TICs. y biotecnología), para los cuales la adaptación a los sistemas agronómicos locales exige esfuerzos de diseño y articulación con clientes. En este entorno se han generado oportunidades de innovación, asociadas a la experiencia acumulada por las firmas locales y a los desarrollos alcanzados en la infraestructura de ciencia y técnica nacional (INTA + CIDETER), como es el caso de las innovaciones relacionadas con los equipos de 
sembradoras y pulverizadoras.

Al recuperar el análisis conjunto de la estructura productiva de la industria de maquinaria agrícola argentina, la organización de la producción interna a las firmas relevadas y la organización territorial de la producción, es posible realizar las siguientes afirmaciones.

Primero, las empresas productoras de sembradoras y de pulverizadoras han logrado alcanzar altos niveles de competitividad gracias a las innovaciones desarrolladas en asociación con en el sistema agronómico local. Con tal fin, utilizaron parte importante del soporte regional del SNI: instituciones, proveedores y clientes. Desde esta perspectiva, estos segmentos son los que se comportaron como industrias de bienes de capital de vanguardia con aprendizajes proveedor-usuario, desarrollo de equipos específicos y difusión de las innovaciones. En cuanto al modo de producir, se encuentran a mitad de camino entre una producción fordista y niveles obsoletos o "artesanales". En este sentido, advertimos que el segmento de sembradoras produce con procesos rudimentarios, que suponen niveles bajos de eficiencia relativos en términos de producción física (cantidad de unidades), a la vez que tienen una alta productividad relativa aparente (ventas sobre empleados) con lo que se puede inferir cierta capacidad para captar rentas tecnológicas "schumpetereanas", sobre un producto de innovación local.

Segundo, hemos notado que las empresas productoras de pulverizadoras autopropulsadas se articulan a una red de proveedores locales importantes, a excepción de los componentes motrices (motores y transmisiones). Estas empresas son nodos de articulación con el "núcleo transnacionalizado" de la trama y comparten ese rol con las firmas proveedoras de los equipos de agricultura de precisión, mayoritariamente nacionales. Este segmento tiene una oferta muy concentrada, recordemos que dos empresas representan el $80 \%$ de la oferta. En cuanto a la forma de organizar la producción "puertas adentro" de la fábrica tienen un esquema más flexible que el de sembradoras, pero no por ello deja de ser un tipo híbrido en el que se combina fordismo - flexibilidad y "atraso", con un menor nivel de productividad relativa que en ese segmento.

Tercero, una de las principales características que hemos registrado para el segmento productor de implementos agrícolas es su menor nivel de dinamismo respecto de los segmentos anteriores. Se destacan como proveedores generales las productoras de acero que están fuera de la región, las cuales a través de una estructura oligopólica articulan la trama productiva. Este subsector tiene pocos 
proveedores específicos. Las empresas que producen estos equipos no utilizan, en mayor medida, la vinculación con el resto de los agentes como plataforma de innovación y mejora. Debemos destacar que dentro del agregado, hay empresas que tienen un comportamiento dinámico y elevan los promedios de innovación del mismo.

Cuarto, distinguimos al segmento de agropartes como fundamental en la elaboración de piezas y partes en conjunto con las empresas terminales. Necesariamente deben localizarse cerca unas de otras para lograr un entendimiento de las necesidades de las empresas ensambladoras (relaciones proveedor/usuario). Sus proveedoras, se encuentran en la región, aunque sus vínculos son relativamente débiles. Es un segmento flexible, en cuanto a la capacidad para seguir a la demanda, pero es, también, muy rudimentario en sus capacidades productivas.

Quinto, hemos observado que el segmento de tractores y cosechadoras es el más avanzado en cuanto a procesos productivos. Estos equipos se producen a una escala que permite explicar, en parte, sus altos niveles relativos de eficiencia y productividad. La producción se organiza en un esquema internacional de abastecimiento y la estrategia de estas compañías mantiene una lógica global gobernada desde las casas matrices. Este segmento concentra los eslabones centrales de la actividad en los países de origen (dirección estratégica, investigación y desarrollo). No obstante, cabe recordar que la empresa más importante a nivel mundial de maquinaria agrícola (en volumen de facturación) desarrolló una sembradora a nivel local. Aspecto que pone en evidencia ciertas ventajas y especificidades regionales en el desarrollo de este segmento.

En síntesis, las dinámicas internacionales y locales se expresaron en organizaciones heterogéneas de la producción que permitieron el desarrollo de subsectores como el de sembradoras y pulverizadoras, que obtuvieron ventajas locales transitorias. Estas ventajas se basaron en desarrollos locales a partir de una fluida relación proveedor-usuario y una significativa expansión de la siembra directa en el país, que en el corto o mediano plazo pueden ser capturadas y replicadas a gran escala por el capital transnacional. Como ocurrió en la década de 1980 con el subsector de empresas nacionales de cosechadoras, el mercado interno de sembradoras y pulverizadoras enfrenta el riesgo de estar dominado por empresas transnacionales. Al mismo tiempo, este segmento transita, en este momento histórico, la oportunidad de dar el "salto" hacia mejores prácticas productivas para enfrentar un mercado cada vez más competitivo. 
Por último, nos proponemos realizar una revisión de algunas ideas o enfoques que estructuraron esta tesis. En primer lugar recuperamos el concepto cluster, luego haremos algunas consideraciones sobre los aportes del estructuralismo latinoamericano, que reúne los debates sobre centro-periferia, dependencia, heterogeneidad estructural y desarrollo endógeno. En articulación con esta última perspectiva, se retoma el enfoque del Sistema Nacional de Innovación. Finalmente, efectuaremos una observación respecto de la idea de las cadenas de valor global.

A partir del análisis realizado de la industria de maquinaria agrícola argentina, podemos afirmar que ninguno de los segmentos tiene una dinámica que pueda asimilarse totalmente a un cluster. Sin embargo, el segmento de sembradoras mostró una alta productividad y verificamos que ese rendimiento no es producto de la organización interna de la producción de las firmas. Esto nos permite inferir que, ha sido el tipo de organización espacial de la producción de sembradoras, con las características más cercanas a una organización de tipo cluster, lo que les posibilitó a estas empresas desarrollar un equipo innovador con especificidades locales y con capacidad para competir en el extranjero.

En cambio, las compañías de agropartes que tienen un fuerte arraigo regional, por las características de sus productos y el origen del capital, presentan bajos niveles de productividad aparente. Por su parte, las compañías de pulverizadoras, con una productividad aparente intermedia, tienen por un lado una especificidad de producto vinculada a la siembra directa, similar al segmento de sembradoras, pero por otro lado, poseen una mayor cantidad de componentes importados. Finalmente, las empresas de cosechadoras y tractores tienen altos niveles de vinculación e innovación, pero se distancian de la idea de cluster debido a su dependencia de componentes extranjeros.

También, es importante destacar que el conjunto de firmas relevadas de maquinaria agrícola no presenta en forma pura un estilo fordista de producción. La especialización flexible al estilo del norte italiano, como el que describieran Piore y Sabel (1984), no existe en esta industria. En relación a ello debemos decir que son las empresas más grandes y, no las más chicas, las que más adoptan algunos elementos descriptos por estos autores. De hecho, observamos que son las empresas transnacionales las que desarrollan de forma combinada formas flexibles y fordistas.

En definitiva el análisis realizado permite comprobar la heterogeneidad estructural intra-industrial sectorial, generada y reproducida por distintos motivos, 
todos ellos concurrentes. Los segmentos de tractores y cosechadoras, sembradoras y pulverizadoras son los de más alta productividad relativa, mientras que los segmentos agropartistas y de implementos agrícolas poseen la más baja productividad aparente. A su vez, el segmento de implementos agrícolas exhibe una fuerte polarización interna.

Como vimos, la teoría estructuralista puso énfasis en las restricciones propias y externas para la acumulación local de capital en ciertos sectores claves específicos. Aspecto que abrió el debate sobre las posibilidades que posee un país periférico de cambiar su especialización productiva. En este punto, nos interesa destacar la vigencia del estructuralismo latinoamericano al confrontarlo con el comportamiento y desarrollo de la industria aquí estudiada.

En primer lugar, el concepto de centro-periferia que expresa un sistema jerárquico de naciones a nivel mundial, vinculado a la matriz productiva de cada país, se sigue reproduciendo, en tanto la estructura de comercio internacional de maquinaria agrícola mantiene una dominación duradera por parte de los países centrales y/o por sus empresas transnacionales. En segundo lugar, esta estructura de relaciones entre países se encuentra fuertemente influida por la heterogeneidad estructural de los países periféricos como Argentina. Heterogeneidad estructural que es reforzada por la desestructuración generada por las mismas empresas transnacionales, a partir de su modo de vincularse con el entramado productivo local. En tercer lugar, la dependencia que nuestro país tiene de los componentes y productos más sofisticados tecnológicamente para esta industria, se agravó en el período 1976 - 2002 y no pudo ser revertida entre 2002 y 2010 , en un nuevo período de sustitución de importaciones. En cuarto lugar, la heterogeneidad estructural se exhibe con mayor fuerza en las etapas históricas en las que el país intenta industrializarse. Es en estos períodos, que a la tendencia desfavorable de los términos de intercambio, a largo plazo, se agrega la necesidad de provisión de ciertos componentes como: mano de obra especializada, maquinarias y equipos, capacidad tecnológica proveniente de los países centrales. En quinto lugar, es posible afirmar que la dependencia de la estructura productiva de los países latinoamericanos sigue existiendo, incluso se agudiza luego del intento de industrialización reciente.

Complementariamente, el enfoque del núcleo endógeno nos permitió identificar, desde un concepto intermedio asociado a los sistemas nacionales de innovación la importancia de la creación tecnológica y de la innovación local como factor de competitividad. En este sentido, la industria de maquinaria agrícola opera como un 
núcleo endógeno de desarrollo regional y es el segmento de sembradoras el que posee las características más destacables.

No obstante, persisten dificultades para que la industria de maquinaria agrícola se convierta en un núcleo endógeno de desarrollo con mayor autonomía nacional y sustentabilidad en el tiempo. Uno de los aspectos centrales es la necesidad de plantear mejoras estructurales en los procesos de producción, que permitan a los segmentos que actualmente capturan rentas tecnológicas, sostenerse en el tiempo. El segundo aspecto de relevancia, es lograr mayor integración regional - nacional de aquellos bienes que poseen altos niveles de tecnología incorporada. Ya que como hemos descripto, el no desarrollo de ciertos sectores y productos, que en muchos casos son de vanguardia en el avance tecnológico, frenan los eslabonamientos hacia atrás en la cadena de producción y cierran la posibilidad de dar el "salto" y dominar el proceso productivo completo. Un tercer aspecto que se desprende del anterior, es que el funcionamiento de esta industria de bienes de capital posee algunos de los eslabones centrales de la cadena de producción controlados por empresas transnacionales. No dominar la producción de estos bienes, como es el caso de motores, es expresión del sostenimiento de los procesos de dependencia y el reforzamiento de una estructura heterogénea de producción. Sin dudas, la no integración en la cadena de producción de estos componentes en empresas nacionales coarta la posibilidad de una completa estrategia innovadora en los segmentos autopropulsados.

En relación al enfoque de las cadenas de valor global, no se pudo constatar que se haya producido la actualización y mejora (up graiding) de empresas nacionales, a partir de su integración a las mismas. En primer lugar, porque los bienes de los que se proveen localmente, las empresas transnacionales asociadas a cadenas de valor global, son poco sofisticados. En segundo lugar, porque no existen evidencias de vinculaciones entre empresas transnacionales y proveedores locales en las que se hayan transferido tecnología o know how. 
BIBLIOGRAFIA 


\section{Referencias bibliográficas}

Abeles M., Lavarello P., Montagu H., (2011) Heterogeneidad estructural y restricción externa en la economía argentina en Infante C. "Desarrollo inclusivo en Argentina. Examen de algunas de sus dimensiones" Dcumento de proyecto CEPAL, en prensa.

Albornoz I., Anlló G., Bisang R., (2010). La cadena de valor de la maquinaria agrícolaargentina: estructura y evolución del sector a la salida de la convertibilidad. Cepal.

Santiago.En:

http://www.eclac.cl/cgibin/getProd.asp?xml=/publicaciones/xml/2/39782/P39782.xml\&x sl=/argentina/tpl/p9f.xsl

Albornoz Ignacio (2010). La inserción internacional de la industria argentina de Maquinaria Agrícola. Posicionamiento económico y estratégico en el marco de las Cadenas Globales de Valor, y perspectivas futuras. Tesis de maestría en Economía y Desarrollo Industrial. UNGS. Buenos Aires. En http://www.ungs.edu.ar/areas/pos tesis/79/la-insercion-internacional-de-la-industriaargentina-de-maquinaria-agricola-posicionamiento-economico-y-estrategico-en-elmarco-de-las-cadenas-global.html

Ambrosio M. (2004) Miembro directivo de APRESID. Fundamentos agronómicos de la siembra directa. Expo Sinaloa 2004.

Amin, Ash y Robins, Kevin (1994). "El retorno de las economías regionales. Geografía mítica de la acumulación flexible", en Benko, Georges y Lipietz, Alain; Las regiones que ganan, Alfons el Magnanim, Valencia. (Páginas 123 a 158)

Andersen E. S. (1992). Los sistemas nacionales de innovación desde el punto de vista de la estructura de producción y la vinculación. En: Lundvall Beng-Ägke (Comp.) "Sistemas nacionales de innovación. Hacia una teoría de la innovación y el aprendizaje por interacción". $1^{\circ}$ Edición en español. 2009. UNSAM. Bs. As.

Arocena Rodrigo y Sutz Judith (1999). Mirando los Sistemas Nacionales de Innovación desde el Sur. Conferencia "Sistemas Nacionales de Innovación, Dinámica Industrial y Políticas de Innovación", organizado por la Danish Research Unit on Industrial Dynamics (DRUID) en Rebild, Dinamarca, 9-12 de junio de 1999.

Arturi Diego J. (2007). Factores territoriales y desempeños de las micro y pequeñas empresas industriales. Un abordaje desde las dinámicas de la proximidad. Geograficandovol. 3. N³. (pp. 89-105). U.N.L.P. Dunken. La Plata. 
Azpiazu, D., Basualdo, E., y Nochteff, H. (1990): Los limites de las politicas industriales en periodos de reestructuraci6n regresiva: el caso de la informática en la Argentina, en Desarrollo Económico, №118, Buenos Aires.

Barletta María Florencia (2010). La trama de maquinaria agrícola en Argentina: conducta innovativa y desempeño exportador. Facultad Latinoamericana de Ciencias Sociales (FLACSO/Argentina) - Universidad de San Andrés en cooperación con la Universidad de Barcelona. Maestría en relaciones y negociaciones internacionales ciclo 2006/2007 trabajo de disertación final. Buenos Aires

Barro R. y Sala-i-Martín (1995). Economic Growth, MacGraw Hill. New York.

Barsky O., Bocco A. Y Llovet I., (1988). La economía agraria argentina. Consideraciones sobre su evolución y situación actual. XX Congreso Internacional de Economistas Agrarios. Buenos Aires. Asociación Argentina de Economistas Agrarios.

Baruj, G., Giudicatti, M.,Vismara, F. y Porta, F. (2005). Generación y uso de conocimiento científico. Situación productiva y gestión del cambio técnico en la industria argentina de maquinaria agrícola. Sistemas Nacionales y Sistemas locales de innovación, SECyT-Redes. Buenos Aires.

Becattini, G., (2004). Vicisitudes y potencialidades de un concepto: El distrito industrial. Conferencia: 25 Años del Distrito Industrial Marshalliano. Universidad Internacional Menéndez Pelayo de Barcelona Centre Ernest Lluch.

Becattini, G., ed. (1994). El distrito marshaliano: una noción socio económica. En G. Benko y A. Liepitz: Las regiones que ganan. Distritos y redes. Los nuevos paradigmas de la geografía económica. Edicions Alfons el Magnànim/Generalitat Valenciana/ Diputació provincial de Valéncia.

Bil, D. (2008). Origen y transformación de la industria de maquinaria agrícola en la argentina. La trayectoria de Schneider, Istilart y Senor. I JORNADAS INTERNACIONAES DE INVESTIGACION Y DEBATE POLITICO "PROLETARIOS DEL MUNDO, UNIOS" Buenos Aires, del 30/10 al 1/11 de 2008.

Bil, D. (2011). Acumulación de capital en la rama de maquinaria agrícola y tractores en la Argentina y los límites de su competitividad internacional (1870 - 1975). Jornadas de economía crítica. 25, 26 y 27 de Agosto de 2011. Córdoba. 
Bisang, R., (2004) Innovación y estructura productiva: la ampliación de la biotecnología en la producción agrícola argentina cap. 3 en Bárcena, A. Katz, J. Morales, C. Schaper, M. Los transgénicos en América Latina y el Caribe: un debate abierto, Libros de la CEPAL nro. 78. 2004

Borello José y Yoguel Gabriel, (Agosto - Diciembre 2002.), '¿Cuándo los economistas hablan del territorio...con quién hablan?', Curso de Posgrado Desarrollo local en áreas metropolitanas. Los Polvorines, Universidad Nacional de General Sarmiento.

Boyer R., (2007). Crisis y regímenes de crecimiento: una introducción a la teoría de la regulación. Edición en español del libro: "La théorie de la régulation I. Les fondamentaux" (2004). CEIL-PIETE CONICET. Buenos Aires.

Bragachini, M. (2003). Argentina: Sistemas productivos predominantes y su relación con la mecanización agrícola. INTA. Manfredi.

Bragachini, M., Mendez A., Scaramuzza F., Proietti F., (2006). Proyecto agricultura de precisión. Actualización técnica Nº6. INTA. Oncativo.

Bragachini, M., Von Martini, A., Méndez, A. Y Monchamp, J. (2002); Eslabonamiento Productivo del Sector Maquinaria Agrícola Argentina, Consejo Federal de Inversiones.

Buratovich T., (2010). De industriales y maquinistas pioneros criollos. Trabajos, publicaciones y notas de asesoramiento. Asociación de Museos de la Provincia de Santa Fe. Santa Fe.

Cardoso Fernando y Faletto Enzo (1969). Dependencia y desarrollo en América Latina. Siglo XXI. Buenos Aires.

Caves, R.E., y Porter, M.E. (1977). From entry barriers to mobility barriers: Conjectural decision and contrived deterrence to new competition. Quarterly Journal of Economics, Vol. 91, pp. 241-261. Oxford University Press. Oxford.

CEPAL (2005). Aglomeraciones en torno a los recursos naturales en América Latina y el Caribe: Políticas de articulación y articulación de políticas. CEPAL. GTZ. Santiago.

Cimoli Mario y Porcile Gabriel (2009). Sources of learning paths and technological capabilities: an introductory roadmap of development processes. En Economics of Innovation and New Technology. Routledge. London. 
Cimoli Mario, Porcile Gabriel, Primi Annalisa, Sebastián Vergara (2005) "Heterogeneidad estructural, asimetrías tecnológicas y crecimiento en América Latina". Proyecto El reto de acelerar el crecimiento en América Latina, CEPAL/BID, ATN/SF8260-RG. Santiago de Chile.

Coraggio José L., (1987). Territorios en transición. Crítica a la planificación regional en América Latina. CIUDAD (Ed.). Quito.

Coriat Benjamín, (1994). Globalización de la economía y dimensiones macroeconómicas de la competitividad. Seminario Intensivo de Investigación, organizado por PIETTE (Programa de Investigaciones Económicas sobre Tecnología y Empleo) del CONICET y el CREEDLA del CNRS (Centre d'EtudesetDocumentation sur l'Amérique Latine), 22-25 de marzo de 1994.

Coriat, Benjamin (2004). El taller y el robot. Ensayos sobre el fordismo y la producción en masa en la era de la electrónica. Siglo XXI. Buenos Aires.

Chang Ha-Joon (2003). Patada a la escalera: La verdadera historia del libre comercio. Facultad de Ciencias Económicas y Ciencias Políticas. Universidad de Cambridge. Trabajo presentado en la conferencia sobre "Globalisation and the Myth of Free Trade" («La mundialización y el mito del libre comercio») celebrada en la New School University de Nueva York, el 18 de abril del 2003. Traducción al castellano de José A. Tapia.

Chesnais François, (1992). Sistemas nacionales de innovación, IED y las operaciones de las empresas trasnacionales. En LundvallBengt- Ake (ed.), (1992). Sistemas nacionales de innovación. Hacia una teoría del innovación. Edición en español de 2009. UNSAM EDITA. San Martín.

Chesnais, François (1994). La mondialisation du capital. Syros, $1^{\text {a }}$ ed., París.

Chudnovsky D. y Erber F. (1999). Impacto del MERCOSUR sobre la dinámica del sector de máquinas y herramientas. Integración \& Comercio, $\mathrm{N}^{\circ} 7 / 8$, Buenos Aires, Enero-Agosto 1999.

ChudnovskyD.,y Castaño A. (2003); Sector de la Maquinaria Agrícola; Estudio 1.EG.33.6; Préstamo BID 925/OC-AR. Pre II. Coordinación del Estudio: Oficina de la CEPAL-ONU en Bs As, a solicitud de la Secretaría de Política Económica, Ministerio de Economía de la Nación. 
Chudnovsky D. y Rever F. (1999). El impacto del MERCOSUR sobre la dinámica del sector de máquinas y herramientas. En Taccone J.J. y Garay L. J. (ed.) "Impacto sectorial de la integración en el MERCOSUR". BID - INTAL, Buenos Aires

Chudnovsky, D. y Nagao M. (1987). Bienes de capital y tecnología en el tercer mundo. CEAL. Buenos Aires

Dalum, B. (1992): Export specialization, structural competitiveness and national systems of innovation, en B-A. Lundvall (comp.), National Systems of Innovation. Towards a Theory of Innovation and Interactive Learning, Londres, Pinter Publishers.

De Mattos, Carlos A. (1989). Reestructuración social, grupos económicos y desterritorialización del capital. El caso de los países del Cono Sur. Revista EURE, Santiago de Chile, num. 47, diciembre.

De Mattos, Carlos A. (2001). Movimientos del capital y expansión metropolitana en las economías emergentes latinoamericanas. Revista de Estudios Regionales № 60. Pp. 15-43. Santiago. En: http://www.revistaestudiosregionales.com/pdfs/pdf686.pdf

Dicken Peter, (1999). Global shift. Transforming the world economy. Paul chapman publishing Itd. London.

Dunning, J.H. (1993). Multinational Enterprises and the Global Economy. AddisonWesley Reading, Massachusets.

Edquist C. y Lundvall B. A., (1993). Comparando los sistemas danés y sueco de Innovación. En: Nelson R.R. (ed.), "Sistemas nacionales de innovación - Análisis compartivo." Oxford Press University. Oxford.

Fagerberg Jan (1992). Un nuevo examen de la hipótesis del mercado interno: el impacto de la interacción usuario-productor sobre la especialización exportadora. En Lundvall Beng-Ägke (Comp.) "Sistemas nacionales de investigación y el aprendizaje por interacción." $1^{\circ}$ Edición en español. 2009. UNSAM. Bs. As.

Fajnzylber F. (1983). La industrialización trunca de América Latina. Bibliotecas Universitarias, Centro editor de América Latina. Méjico.

Fajnzylber, Fernando (1992). Industrialización en América Latina. De la «caja negra» al "casillero vacío». Nueva Sociedad nro.118, marzo- abril 1992, PP. 21-28. En: http://www.unsa.edu.ar/histocat/haeconomica07/2088 1.pdf 
Fernandez V. R., Vigil J. I, Davies C. L, Dundas M. V., Güemes M. C., Villalba M. L. (2008): Clusters y desarrollo regional en América Latina. Reconsideraciones teóricas y metodológicas a partir de la experiencia argentina.Miño y Dávila. Buenos Aires.

Freeman C. y Perez C. (1992). Crisis estructurales de ajuste, ciclos económicos y comportamiento de la inversión. En François CHESNAIS y Juio César NEFFA. "Ciencia y tecnología y crecimiento económico". CEIL - PIETTE CONICET. Trabajo y Sociedad. Buenos Aires, (2003).

Freeman Christopher, (2003). La naturaleza de la innovación y la evolución de los sistemas productivos. En François Chesnais y Juio César Neffa. Ciencia y tecnología y crecimiento económico. CEIL - PIETTE CONICET. Trabajo y Sociedad. Buenos Aires.

Garofoli G. (2002). Los distritos industriales y la competitividad: comparación internacional y los escenarios evolutivos. En: Paganetto L. y Galli G.P. (eds.). "Reporte de la competitividad de Italia". Edición El sol 24. Milán

García G. (1998). Industria Argentina de Maquinaria Agrícola: del mercado protegido al mercado abierto. Terceras Jornadas Investigaciones en la Facultad de Ciencias Económicas y Estadística. Rosario.

García G. (1999). Transformaciones Macroeconómicas y Reestructuración de los Mercados Argentinos de Equipos Agrícolas: Algunas Evidencias. Rosario: Cuartas Jornadas "Investigaciones en la Facultad" de Ciencias Económicas y Estadística Instituto de Investigaciones Económicas, Escuela de Economía. Rosario.

García, G. (2000). Reestructuración y contexto global: el caso de la filial argentina de una multinacional de maquinaria agrícola. Universidad Nacional de Rosario. Instituto de Investigaciones Económicas, Escuela de Economía. Rosario.

García, G. (2001). Reestructuración y capacidad tecnológica. El caso de dos empresas argentinas de cosechadoras, Universidad Nacional de Rosario. Instituto de Investigaciones Económicas, Escuela de Economía.

García, G. (2005). Régimen de incentivos y conducta tecno-productiva: el caso de tres empresas argentinas de sembradoras, Décimas Jornadas "Investigaciones en la Facultad" de Ciencias Económicas y Estadística, Universidad Nacional de Rosario. Rosario. 
García, G. (2007). Conducta tecnológica en la industria argentina de cosechadoras: Algunas evidencias, Undécimas Jornadas "Investigaciones en la Facultad" de Ciencias Económicas y Estadística, Universidad Nacional de Rosario. Rosario.

Gereffi G., Humphrey J., Sturgeon T., (2005). The governance of global value chains. Review of International Political Economy. Taylor \& Francis Ltd.

Giberti H. (1988). La economía agraria argentina. Consideraciones sobre su evolución y situación actual. XX Congreso Internacional de Economistas Agrarios. Buenos Aires. Asociación Argentina de Economistas Agrarios.

Girbal-Blacha N, Zarrilli G., Balza J. Estado, sociedad y economía en la Argentina (1930 - 1997). UNQui, cap. 3. Quilmes.

Gómez Minujín Gala, (2005). Competitividad y complejos productivos: teoría y lecciones de política. CEPAL, Naciones Unidas. Santiago de Chile.

Gutman G. E., Iturregui Ma. E. y Filadoro A. (2004). Propuestas para la formulación de políticas para el desarrollo de tramas productivas regionales. El caso de la lechería caprina enArgentina. Serie Estudios y Perspectivas. CEPAL. Buenos Aires.

Gutman G. E. y Gorestein S., (2003). Territorios y Sistemas Agroalimentarios. Enfoques conceptuales y dinámicas recientes en la Argentina. Revista Desarrollo Económico $\mathrm{N}^{\circ}$ 138. IEDE. Buenos Aires. 3 - m

Gutman, G. E. y Lavarello P. J. (2008). La Industria de Maquinaria Agrícola en Argentina. Dinámica reciente, capacidades innovativas. Informe de pre-diagnóstico del estudio "Generación, circulación y apropiación de conocimiento tecnológico en el Sector de maquinaria agrícola en Santa Fe y Córdoba". UNGS-CEUR/CONICET. Buenos Aires.

Gutman, G. E. y Lavarello P. J. (2003): La trama de oleaginosas en Argentina, Documento B-3, Estudio 1.EG.33.7, Buenos Aires, Oficina de la CEPALen Buenos Aires.

Haesbaert R., (2009) O espaço como categoria e suaconstelação de conceitos: uma abordagem didática. (inédito). Trabajo presentado en el $X$ Encuentro Nacional de Práctica de Enseñanza en Geografía, Porto Alegre. 
Harvey David (1982). Los límites del capitalismo y la teoría marxista. Fondo de cultura económica. México.

Harvey David (2008). La condición de la posmodernidad. Investigación sobre los orígenes del cambio cultural. Amorrortu Editores. Avellaneda.

Heybel D. (2006). Cambios en el complejo productivo de maquinarias agrícolas 1992 2004. Desafíos de un sector estratégico para la recuperación de las capacidades metalmecánicas. Documentos de trabajo 3. Instituto Nacional de Tecnología Industrial. Buenos Aires

Hirschman Albert (1958): The Strategy of Economic Development, New Haven, Yale University Press.

Hirschman Albert (1980): A generalized linkage approach to development with special reference to staples, Essays on Economic Development and Cultural Change in Honor of Bert F. Hoselitz, vol. 25, suplemento, Chicago, Chicago Illinois, University of Chicago Press.

Hopkins K. Terence y Wallerstein Immanuel (1986). Commodity chains in the capitalista World-economy prior to 1800. Review, Vol. 10, Num. 1, Pages: 157-170

Huici N. (1988). La industria de maquinaria agrícola. En "Argentina. En: la agricultura pampeana. Transformaciones productivas y sociales". Fondo de Cultura Económica. Buenos Aires.

Humphrey J. y Schmitz H. (1995). Principles for promoting clusters \& networks of SMEs. Small and Medium Enterprises Branch of the United Nations Industrial Development Organization (UNIDO). Viena.

Humphrey John y Schmitz Hubert, (2002) Las empresas de los países en vías de desarrollo en la economía mundial: poder y mejora de las cadenas globales de valor. Publicado en Aportes Instituto Nacional de Tecnología Industrial (INTI). Buenos Aires

Katz J. y Stumpo G. (2001). Regimenes sectoriales, productividad y competitividad internacional. CEPAL. Santiago de Chile

Kosacoff B. y Ramos A., (2005). Comportamientos macroeconómicos en entornos de alta incertidumbre: la industria argentina. Boletín Informativo Techint 318. Buenos Aires. 
Lajer A., Odisio J. C., Y. Raccanello M, (2006) Una mirada sobre los avatares del sector productor de maquinaria agrícola. XX Jornadas de Historia Económica de la Asociación Argentina de Historia Económica. Mar del Plata.

Langard F. (2008). La producción de maquinaria agrícola en Argentina desde comienzos de siglo a nuestros días. En: V Jornadas de investigación y debate "Trabajo, propiedad y tecnología en el mundo rural argentino". UNQui. Quilmes.

Langard F. (2011). La industria de maquinaria agrícola en Argentina frente a la estructura sectorial del mercado internacional. Revista Geograficando; vol. 7, no. 7. FaHCE. UNLP. La Plata.

Lavarello P. J. (2004). "Estrategias empresariales y tecnológicas de las firmas multinacionales de las industrias agroalimentarias argentinas durante los años noventa." Desarrollo Económico No 174. Vol. 44, julio-setiembre 2004. IDES. Buenos Aires.

Lavarello P. J. y Hecker J. (2009). Asistencia Técnica para la Planificación Estratégica Sectorial. Componente Maquinaria Agricola."Programa de Fortalecimiento Institucional de la Secretaría de Política Económica".Buenos Aires.

Lavarello P.J., Gutman G. E., Langard F., (2009). La Industria de Maquinaria Agrícola en Argentina. Dinámica reciente, trayectorias innovativas. VI Jornadas Interdisciplinarias de Estudios Agrarios y Agroindustriales. FCE. UBA. Buenos Aires.

Lavarello Pablo y Gutman Graciela (2008): La Industria de Maquinaria Agrícola en Argentina. Dinámica reciente, capacidades innovativas. Documento de Trabajo/PEC A26. Disponible en http://www.continentedigital.net

Lavarello Pablo, Silva Diego, Langard Federico (2009): El desarrollo de las redes de conocimiento tecnológico: el caso de la industria de maquinaría agrícola en Argentina. Seminario Latino-Iberoamericano de Gestión Tecnológica Altec 2009. Paola Andrea Amar Sepúlveda (Compiladora). Javegraf. Bogotá.

Lavarello, Pablo; Silva Failde, Diego y Langard, Federico (2010): Transferencia de tecnología, tramas locales y cadenas globales de valor: Trayectorias heterogenias en la industria de maquinaria agrícola argentina. Revista InnovacónRICEC, vol.2 n.1 p.1-17. México. 
Lavarello, Pablo y Goldstein, Evelin (2011). Dinámicas heterogéneas en la industria de maquinaria agrícola argentina. Revista Problemas del Desarrollo, 166 (42), julioseptiembre 2011. UNAM. Méjico.

Lavarello, Pablo; Goldstein, Evelin y Hecker, Julian (2010) Lineamientos para un cambio estructural de la economía argentina. Desafíos para el bicentenario. 2do. Congreso Anual de AEDA, 20 y 21 de septiembre, 2010.

Lengyel, M. y G. Bottino, (2010). La Co-producción de la Innovación y su Diseño Institucional: Evidencia de la Industria Argentina, BID, Science and TechnologyDepartment.

Levín Pablo (1981). Diseño de subsistemas, Boletín geográfico № 8 , Depto. de Geografía, UNCo.

Lipietz Alain (1994). El posfordismo y sus espacios. Las relaciones capital - trabajo en el mundo. Documento de trabajo N²4. PIETTE del CONICET. Ciudad autónoma de Bs. As.

Lódola A. y Fosati R., (2002). Servicios agropecuarios y contratistas en la provincia de Buenos Aires Régimen de Tenencia de la Tierra, Productividad y Demanda de Servicios Agropecuarios. Universidad Nacional de La Plata y Dirección Provincial de Estadística de la Provincia de Buenos Aires.

Lódola A., Angeletti K., Fossati R. y Kebat C. (2005). Maquinaria Agrícola, Estructura Agraria y Demandante. Becas banco rio para proyectos de investigación científica para el desarrollo regional. La Plata.

Lundvall B. (1992). National Systems of Innovations. Towards a Theory of Innovation and Interactive Learning, Pinter, Sussex.

Marx Karl (1867). El Capital. Tomo I, El Proceso de Acumulación Capitalista. Edición de 2002. En http://www.ucm.es/info/bas/es/marx-eng/capital1/. Última fecha de revisión 12-12-2011.

Massey D. (1984). Spatial Division of Labor. Social structures and the Geography of Produccion. Methuen, New York.

MasseyDoreen (1984). Introducción: la geografía importa. En Albet Abel y Benach Núria (2012). Un sentido global del lugar. Icaria Espacios Críticos. Barcelona. 
Michalet, C. A., (1985): "Le capitalisme mondial", PUF, Paris (2da. edición).

Mistral Jacques,(1978). Compétitivité et formation du capital en longue période. In: Economie et statistique, $N^{\circ} 97$. Les grandes économies dans la crise: défits structurels à long terme, désordres monétaires à court terme. pp. 3-23.

Moltoni L. y Gorestein S. (2009). Territorios de la industria de maquinaria agrícola argentina: conocimiento, aprendizaje y redes locales de cooperación. XI Seminario internacional. Red Iberoamericana de Revistas. Mendoza. 26/10 al 30/10 de 2009.

Naclerio (2010), Sistemas Productivos Locales, Políticas Públicas y Desarrollo Económico, Programa Naciones Unidas Para el Desarrollo, PNUD, Buenos Aires.

Nardowsky Patricio, (2007). La escala local desde la periferia. Análisis de la industria de la maquinaria agrícola en Las Parejas (Provincia de Santa Fe, Argentina) relacionada con su contexto, dentro de la economía Argentina.Geograficando vol. 3 N³. (pp. 67-88). Dunken. La Plata.

Neffa J. C., (1996). Modos de regulación, regímenes de acumulación y sus crisis en Argentina (1880-1996). Eudeba. Buenos Aires.

Nelson R. R. (1993). National Innovation Systems. London: Oxford University Press,

Nonaka, I. y Takeuchi, H. (1995): The Knowledge-Creating Company. Oxford UniversityPress.

Novick M., Bartolomé M., Buceta M., Miravalles M., Senén González C., (1998). Nuevos puestos de trabajo y competencias laborales. Un análisis cualitativo en el sector metalmecánico argentino. OIT. Montevideo.

Obstchako E. (1988). La economía agraria argentina. Consideraciones sobre su evolución y situación actual. XX Congreso Internacional de Economistas Agrarios. Asociación Argentina de Economistas Agrarios. Buenos Aires.

Ocampo José Antonio (2004). La búsqueda de la eficiencia dinámica: dinámica estructural y crecimiento económico en los países en desarrollo. Revista de trabajo. Ministerio de trabajo de la nación argentina. Año 4. Número 5. Enero - julio 2008.

Ocampo José Antonio (2007). Raul Prebisch y la agenda del desarrollo en los albores del siglo XXI. Documento presentado en el seminario "La teoría del desarrollo en los albores del siglo XXI", organizado por la CEPAL para conmemorar el centenario de 
nacimiento de Raúl Prebisch. En Archivo: http://www.alide.org.pe/download/Memoria/Memo2007/Memoria-2007.pdf

Pavitt K., (1984). Patrones sectoriales de cambio tecnológico: hacia una taxonomía y una teoría. En François Chesnais, Julio Neffa (comp.) (2003) "Sistemas de innovación y política tecnológica". CEIL - PIETTE. CONICET. Bs. As.

Pavitt Keith y Pattel Parimal (1991). The continuing, widespread (and neglected) importance of improvements in mechanical technologies. Science Policy Research Unit, University of Sussex, Falmer, Brighton BNI 9RF, UK.

Pereira H. (1988). La economía agraria argentina. Consideraciones sobre su evolución y situación actual. XX Congreso Internacional de Economistas Agrarios. Asociación Argentina de Economistas Agrarios. Buenos Aires.

Perez C. (2001). Cambio tecnológico y oportunidades de desarrollo como blanco móvil. Revista de la CEPAL No 75. Santiago.

Perroux F (1967). ¿Quién integra? ¿En beneficio de quién se realiza la integración?Revista de la Integración $N^{\circ}$ 1, noviembre 1967. En www.iadb.org, revisada última vez el 27/02/12.

Pietrobelli C. y Rabellotti R., (2005). Mejora de la competitividad en clusters en cadenas productivas en América Latina. El papel de las políticas. Banco Interamericano de Desarrollo. Washington, D. C.

Pinto, A. (1976): Heterogeneidad estructural y modelo de desarrollo reciente de la América Latina. Inflación: raíces estructurales, Fondo de Cultura Económica, México, D.F.

Piore Michael J. y Sabel Charles F. (1984). La segunda ruptura industrial. Alianza. Edición en español (2007). Buenos Aires.

Porter, M., (1999). 'Los clusters y la competitividad. En Elgue, M. (ed.): Globalización, desarrollo local y redes asociativas. Corregidor. Buenos Aires.

Prebisch, R. (1949). El desarrollo económico de América Latina y algunos de sus principales problemas. UN E/CN.12/89, Rev. 1. Santiago: CEPAL.

Raccanello Mario (2010). Del Pampa a Pauny: el intenso medio siglo de la industria del tractor (1952-2002). Asociación argentina de historia económica. Universidad Nacional 
de Río Cuarto. XXII Jornadas de historia económica. Río Cuarto (Córdoba).21-24 de septiembre de 2010.

Ramos Joseph (1999). Complejos productivos en torno a los recursos naturales ¿una estrategia prometedora? Versión resumida del artículo: "Una estrategia de desarrollo a partir de complejos productivos en torno a los recursos naturales", Revista de la CEPAL Nº6, diciembre 1998, Santiago, CEPAL.

Reca L. (2006). Aspectos del desarrollo agropecuario argentino 1875-2000. Academia Nacional de Agronomía y Veterinaria. Bs. As.

Reca L. y Katz L. (1988). Procesos de ajuste, políticas agropecuarias y alimentarias. Instituto Interamericano de Cooperación para la Agricultura (IICA). Buenos Aires.

Reca. L. y Parellada, (2001). El sector agropecuario argentino. Aspectos de su evolución, razones de su crecimiento reciente y posibilidades futuras. Editorial Fac. de Agronomía de la UBA. Buenos Aires.

Reinert Erik S. (2007). La Globalización de la pobreza. Cómo se enriquecieron los países ricos y porqué los países pobres siguen siendo pobres. Crítica Barcelona. Barcelona.

Rofman, A. y Romero, J.L. (1974). Sistema socioeconómico y estructura regional en la Argentina. Amorrortu, Bs. As.

Roitter S., Erbes A, Yoguel G., Delfini M., y Pujol A. (2007). Conocimiento, Organización del Trabajo y Empleo en Agentes Pertenecientes a las Tramas Siderúrgica y Automotriz. LITTEC. Instituto de industria. UNGS. General Sarmiento

Romero Wimer F. (2010). Los fierros vienen marchando ¿de dónde vienen? maquinaria agrícola y capital extranjero en el agro pampeano, 1976-2008. En: Documentos del CIEA No5, Facultad de Ciencias Económicas de la Universidad de Buenos Aires. Buenos Aires.

Rosenberg Nathan, (2003) Bienes de capital, tecnología y crecimiento económico. En Chesnais François y Neffa Julio César (comp). Ciencia, tecnología y crecimiento económico. CEIL- PIETTE CONICET. Trabajo y Sociedad. Buenos Aires. 
Rougier M, (2006). Encadenamientos productivos entre el agro y la industria. La fábrica de cosechadoras Vassalli en el sur de Santa Fe, Argentina. Sesión 78.XIV International Economic History Congress, Helsinki.

Sahal, Devendra, (1981).El tractor agrícola y la naturaleza de la innovación.En: "La política de investigación: estudios de política y gestión de la ciencia, la tecnología y la innovación."Elsevier, ISSN 0048-7333. Vol.10.1981, 4, p. 368-402.Amsterdam

Santos Milton y Ma. Laura Silveira. (2001) O’ Brasil. Capítulo V. Editora Record. Rio de Janeiro-San Pablo.

Santos Milton, (2000). La naturaleza del espacio: técnica y tiempo, razón y emoción. Ariel. Barcelona.

Santos, M., (1990). Por una Geografía Nueva. Espasa Calpe. Madrid.

Schumpeter, J. (1942). Ed. (1946). Capitalismo, socialismo y democracia. Orbis. Bs. As.

Schvarzer J. 1996. La industria que supimos conseguir. Planeta, Buenos Aires.

Setterfield M. (2005) . Una Perspectiva Neokaldoriana sobre el Auge y el Declibe de la Edad de Oro, en M. Setterfiedl (ed.), La Economía del Crecimiento Dirigido por la Demanda, Ediciones Akal.

Storper R. (1997). Las economías regionales como activos relacionales, capítulo 2 de la publicación "The Regional World: Territorial Development in a Global Economy", The Guilford Press, New York-London.

Storper Richard y Walker Michel (1981). Capital and industral location. Progres in human geography. Arnold. California. pp. 473-509.

Storper, M y Harrison, B. (1994) "Flexibilidad, jerarquía y desarrollo regional: los cambios de estructura de los sistemas productivos industriales y sus nuevas formas de articulación del poder en los años '90”. En Benko, George y Lipietz, Alain, Las regiones que ganan. Valencia, Ed. Alfons el Magnánim

Sunkel Osvaldo (1970). Desarrollo, subdesarrollo, dependencia, marginación y desigualdades espaciales; hacia un enfoque totalizante. EURE [en línea]. Vol. 1, no. 1 [citado 2012-04-16], pp. 13-49. Disponible en Internet: 
http://www.eure.cl/numero/desarrollo-subdesarrollo-dependencia-marginacion-ydesigualdades-espaciales-hacia-un-enfoque-totalizante/.

Sztulwark, Sebastián (2005), El estructuralismo latinoamericano. Fundamentos y transformaciones del pensamiento económico de la periferia, Prometeo Libros, UNGS, Buenos Aires.

Taylor Peter J. y Flint Colin (2002). Geografía política. Economía mundo, estado nación y localidad. Segunda edición en español. Trama editorial S.L. Madrid.

Taylor Peter, (1994). Geografía Política. Economía Mundo, Estado - Nación y localidad. Trama. Madrid.

Vargas Sanchez G. (2006). Introducción a la teoría económica: Un enfoque latinoamericano. Prentice Hall. México.

Wolf E. y Patriarca, C. (1991). La gran inmigración. Editorial Sudamericana. Buenos Aires.

Yoguel Gabriel , Borello José, Erbes Analía, (2006). Sistemas Locales de Innovación y Sistemas Productivos Locales: ¿cómo son, cómo estudiarlos y cómo actuar sobre ellos? En: http://www.littec.ungs.edu.ar/pdfespa\%F1ol/DT\%2004-2006\%20YoguelBorello-Erbes.pdf Consultado por última vez en 09-2013.

Yoguel Gabriel y Boscherini Fabio, (1996). Algunas reflexiones sobre los procesos de innovación. En revista Redes $n^{\circ} 8$, volumen 3. Universidad Nacional de Quilmes. Buenos Aires.

Yoguel Gabriel y Boscherini Fabio, (2000).El desarrollo de las capacidades innovativas de las firmas y el rol del sistema territorial.Instituto de Industria - Littec (www.littec.com), Universidad Nacional de General Sarmiento.

Williamson Oliver E. (1989). Las instituciones económicas del capitalismo. Fondo de Cultura Económica. Méjico. 


\section{Otras fuentes}

AGCO http://agco.com.mx/default/compania/acerca de AGCO/historia.aspx

AFAT. Asociación Fabricantes Argentinos de Tractores, www.afat.com.ar

Bolsa de comercios de Córdoba, http://www.bolsacba.com.ar/

CAFMA. Cámara Argentina de Fabricantes de Maquinaria Agrícola, www.cafma.com.ar

CFI. Consejo Federal de Inversiones informe sobre maquinaria agrícola, 2004.

Disponible en: www.cifred.org.ar

FAO. Organización para la Alimentación y la Agricultura. En: www.fao.org

INDEC: Instituto Nacional de Estadística y Censos www.indec.gov.ar

INDEC: Censo Nacional Agropecuario 2003. Disponible en

http://www.indec.mecon.ar/

INDEC: Informe de coyuntura de la maquinaría agrícola, año 2004 al 2012. Disponible en http://www.indec.mecon.ar/

INTA. Instituto Nacional de Tecnología Agropecuaria. En: www.inta.gov.ar

INTA Informa. Rusia también quiere el know-how del INTA.

http://intainforma.inta.gov.ar/?tag=rusia

INTA (2009). Precop. Proyecto eficiencia de cosecha y postcosecha de granos.

Actualización Técnica Nº 38. En: www.cosechaypostcosecha.org

IPEC (2008). Análisis del crecimiento poblacional. En:

http://www.santafe.gov.ar/index.php/web/content/download/58623/285635/file/crecimie nto poblacional\%5B1\%5D.pdf

La Voz (2011) http://www.lavoz.com.ar/movil?nota=349260

MODEMAQ (2004): Movimiento para la defensa y el desarrollo de la maquinaria agrícola y sus industrias integradas. En www.modemaq.com.ar. 


\section{Índice de abreviaturas}

Aapresid: Asociación Argentina de Productores en Siembra Directa

AFAMAC: Asociación de Fabricantes de Maquinaria Agrícolas y Agro Componentes de la Provincia de Córdoba - Asociación Civil

AFAT: Asociación Fabricas Argentinas de Tractores

CAD: Computer-Aided Design

CAFMA: Cámara Argentina de Fabricantes de Maquinaria Agrícola

CAM: computer-aided manufacturing

CEE: Comunidad Económica Europea

CEP: Centro de Estudios para la Producción

CEPAL: Comisión Económica para América Latina

CFI: Consejo Federal de Inversiones

CIDETER: Centro de Investigación y Desarrollo Tecnológico Regional

EAPS: explotaciones agropecuarias

FAO: Food and Agriculture Organization

FMA: Fábrica Militar de Aviones

GATT: General Agreement on Tariffs and Trade

IAME: Industrias Argentinas Metalmecánicas del Estado

IED: inversión extranjera directa

I+D: investigación y desarrollo 
INDEC: Instituto Nacional de Estadísticas y Censos

INTA: Instituto Nacional de Tecnología Agropecuaria

INTI: Instituto Nacional de Tecnología Industrial

IPEC: Instituto Provincial de Estadística y Censos de la provincia de Santa Fe

ISI: Industria por Sustitución de Importaciones

MERCOSUR: Mercado Común del Sur

NAFTA: North American Free Trade Agreement

OCDE: Organización para la Cooperación y Desarrollo Económicos

PBI: producto bruto interno

PyME: pequeñas y medianas empresas

SNI: Sistemas Nacionales de Innovación

TICs: Tecnologías de la Información y las Comunicaciones

UNC: Universidad Nacional de Córdoba

UNR: Universidad Nacional de Rosario

UTN: Universidad Tecnológica Nacional 


\section{Índice de figuras}

Cuadro $N^{0} 1$. Diagnóstico de los déficits estructurales de Latinoamérica

Cuadro $\mathrm{N}^{\circ} 2$. Detalle de los desarrollos de maquinaria agrícola en Argentina en el período 1900 al 1945

Cuadro $N^{\circ} 3$. Producción, ventas al mercado interno y externo de tractores, expresado en unidades. Durante la década de 1980

Cuadro $\mathrm{N}^{\circ} 4$. Producción, ventas al mercado interno y externo e importaciones de cosechadoras en unidades. Durante la década de 1980

Cuadro $N^{\circ} 5$. Estructura de la industria de maquinaria agrícola, en Argentina. Años $1976-1990$

Cuadro $N^{\circ} 6$. Producción, venta, exportación e importación de tractores en el país, en unidades. Período 1990 - 1999

Cuadro $N^{\circ} 7$. Estructura del sector de maquinaria agrícola

Cuadro $N^{\circ} 8$. Detalle de la diversificación de productos de algunas empresas argentinas

Cuadro $N^{\circ}$ 9. Primeras 12 empresas en facturación. Millones de dólares y \% respecto al mercado total

Cuadro $N^{\circ} 10$. Saldos comerciales del país, en miles de dólares por segmento de producto, en el período 2003-2010.

Cuadro $N^{0}$ 11. Tamaño de empresas. En porcentajes por cantidad de firmas

Cuadro No 12: Maquinaria Agrícola. Indicadores estructurales de la trama 2006-2007.

Cuadro $N^{0}$ 13. Cantidad de empresas con al menos una vinculación, con distintos agentes, que tenga como objetivo final mejorar ciertos aspectos específicos de la firma. Expresado en porcentajes de empresas

Cuadro $\mathrm{N}^{0}$ 14. Cantidad de empresas con máquinas herramientas programables, por rangos porcentuales, según segmento de producto (en porcentajes) 
Cuadro $N^{0}$ 15. Nivel de Competencias Endógenas por tipo de firma. En porcentaje de firmas según segmentos de producción.

Cuadro $N^{\circ} 16$. Productividad relativa aparente, capacidades endógenas y externalidades de las firmas de maquinaria agrícola según segmentos productivos Gráfico $N^{0} 1$. Evolución del mercado nacional de cosechadoras. Ventas de cosechadoras en unidades. Período 1990 - 2011

Gráfico N² 2. Producción nacional e importación de tractores, en unidades. Período $1990-2008$

Grafico № 3. Producción de maquinaria agrícola en la década de 1990, en unidades. Desagregada por segmento

Gráfico $N^{\circ} 4$. Venta de tractores, de cosechadoras y sembradoras, en unidades. Vinculadas al precio internacional en pesos (llevados a valores del 2008) del trigo y la soja.

Grafico $N^{\circ} 5$. Difusión de la siembra directa en cantidad de hectáreas. Período 19902008

Gráfico $N^{\circ} 6$. Cantidad de tractores exportados por país, en dólares y cantidad de hectáreas cultivadas por país, en hectáreas. Año 2010

Gráfico $N^{\circ} 7$. Exportaciones Argentinas de maquinaria agrícola. En millones de dólares corrientes. Período 2003 - 2010

Gráfico Nº 8. Cadena de valor de la maquinaria agrícola

Gráfico $N^{\circ} 9$. Trama de proveedores del subsector de tractores y cosechadoras.

Gráfico № 10. Trama de proveedores del subsector pulverizadoras

Gráfico $N^{0}$ 11. Trama de proveedores del subsector implementos agrícolas

Gráfico N 12. Trama de proveedores del subsector sembradoras

Gráfico № 13. Dinámicas de cluster

Mapa $N^{\circ} 1$. Provincias de Córdoba y Santa Fe: localización de las primeras colonias agrícolas. Con diferenciación según los años de comienzo de la colonización. 
Mapa $\mathrm{N}^{\circ}$ 2. Los 10 países con mayor volumen de exportación de maquinaria agrícola en 2008.

Mapa $N^{\circ} 3$. Exportaciones de maquinaria agrícola (sin tractores) de los 5 primeros países en volumen de exportación. Indicando el destino principal por volumen de ventas en millones de dólares, año 2008.

Mapa $\mathrm{N}^{\circ} 4$. Los 10 mayores exportadores de tractores, el principal país destino por volumen de exportaciones. En millones de dólares. Año 2008

Mapa $N^{\circ} 5$. Los 10 mayores exportadores de cosechadoras y el principal país de destino por volumen de exportaciones. En millones de dólares. Año 2008

Mapa $N^{\circ} 6$. Los 10 principales países exportadores de sembradoras en 2008.

Mapa Nº 7. Región de estudio 
ANEXOS 


\section{Anexos}

\section{Anexo I}

Tamaño de empresas (en porcentaje) por cantidad de máquinas herramientas programables en las firmas.

\begin{tabular}{|c|c|c|c|c|c|}
\hline $\begin{array}{l}\text { Rango de } \\
\text { porcentajes de } \\
\text { equipo programable }\end{array}$ & Micro & Pequeña & Mediana & Grande & \multicolumn{2}{|l|}{ Total } \\
\hline $0-15$ & 100 & 57,9 & 15,6 & 9,1 & 29,7 \\
\hline $16-30$ & 0 & 21,1 & 25,0 & 27,3 & 23,4 \\
\hline $31-45$ & 0 & 5,3 & 12,5 & 36,4 & 14,1 \\
\hline $46-60$ & 0 & 5,3 & 25,0 & 9,1 & 15,6 \\
\hline $61-75$ & 0 & 10,5 & 12,5 & 0,0 & 9,4 \\
\hline $76-100$ & 0 & 0,0 & 9,4 & 18,2 & 7,8 \\
\hline & 100 & 100,0 & 100,0 & 100,0 & 100 \\
\hline
\end{tabular}

Anexo III

\begin{tabular}{|c|c|c|c|c|c|}
\hline & \multicolumn{4}{|c|}{ Tamaño } & \multirow[b]{2}{*}{ Total } \\
\hline & Micro & Pequeña & Mediana & Grande & \\
\hline Agropartistas & 4,5 & 54,5 & 31,8 & 9,1 & 100 \\
\hline $\begin{array}{l}\text { Cosecahdoras y } \\
\text { Tractores }\end{array}$ & 0,0 & 0,0 & 60,0 & 40,0 & 100 \\
\hline Implementos Agrícolas & 6,3 & 25,0 & 56,3 & 12,5 & 100 \\
\hline Pulverizadoras & 0,0 & 11,1 & 66,7 & 22,2 & 100 \\
\hline Sembradoras & 0,0 & 16,7 & 58,3 & 25,0 & 100 \\
\hline
\end{tabular}

Anexo IV

¿Cómo calificaría el estado de la maquinaria que interviene directamente en el proceso productivo? Clasificación desagregada. En números absolutos

\begin{tabular}{|l|c|c|c|c|c|c|}
\hline & Agropartistas & $\begin{array}{c}\text { Cosechadoras } \\
\text { y Tractores }\end{array}$ & $\begin{array}{c}\text { Implementos } \\
\text { Agrícolas }\end{array}$ & Pulverizadoras & Sembradoras & Total \\
\hline De punta & 18,2 & 0 & 18,8 & 11,1 & 8,3 & 14,1 \\
\hline Moderno & 45,5 & 100 & 50,0 & 88,9 & 83,3 & 64,1 \\
\hline Antiguo & 36,4 & 0 & 31,3 & 0,0 & 8,3 & 21,9 \\
\hline & 100 & 100 & 100 & 100 & 100 & 100 \\
\hline
\end{tabular}

\section{Anexo V}




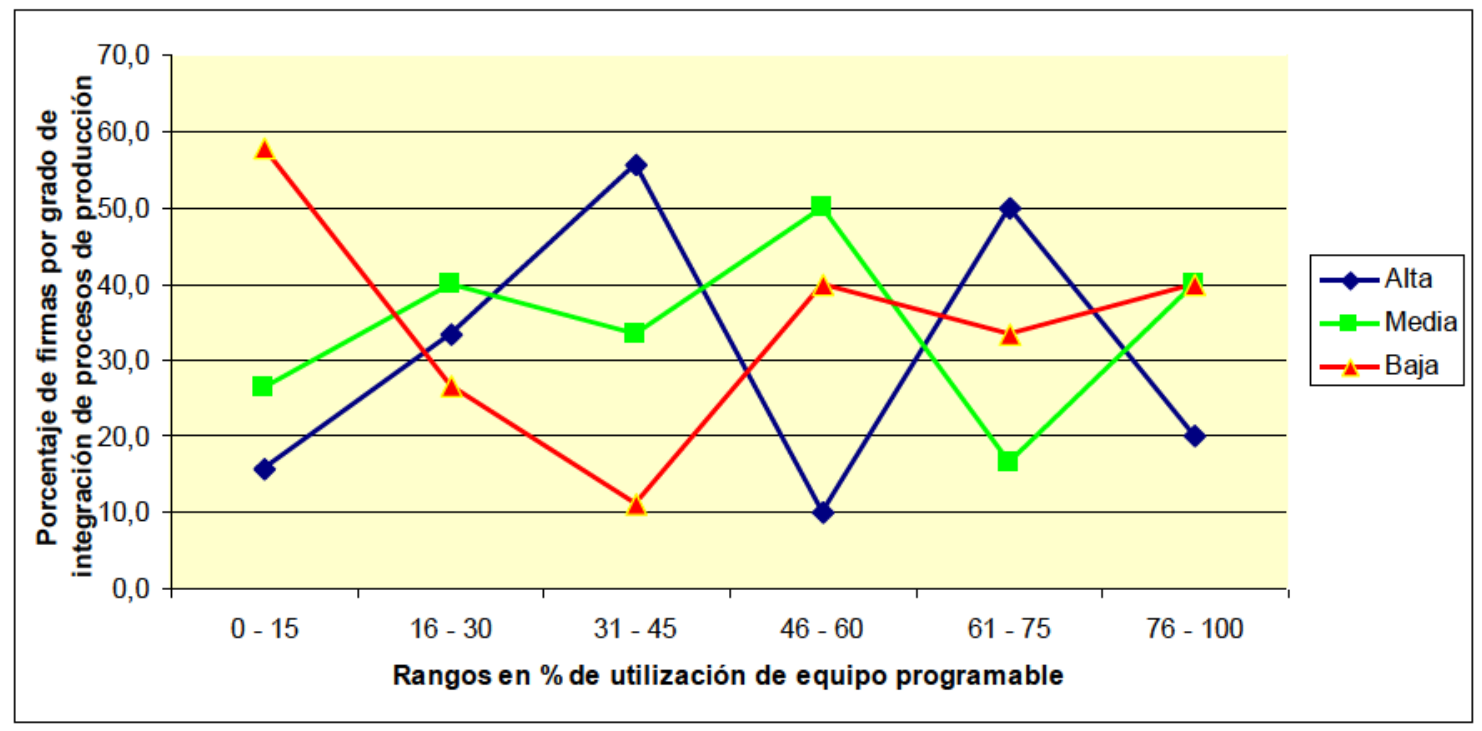

Anexo VI Porcentaje de empresas que hacen su propio diseño

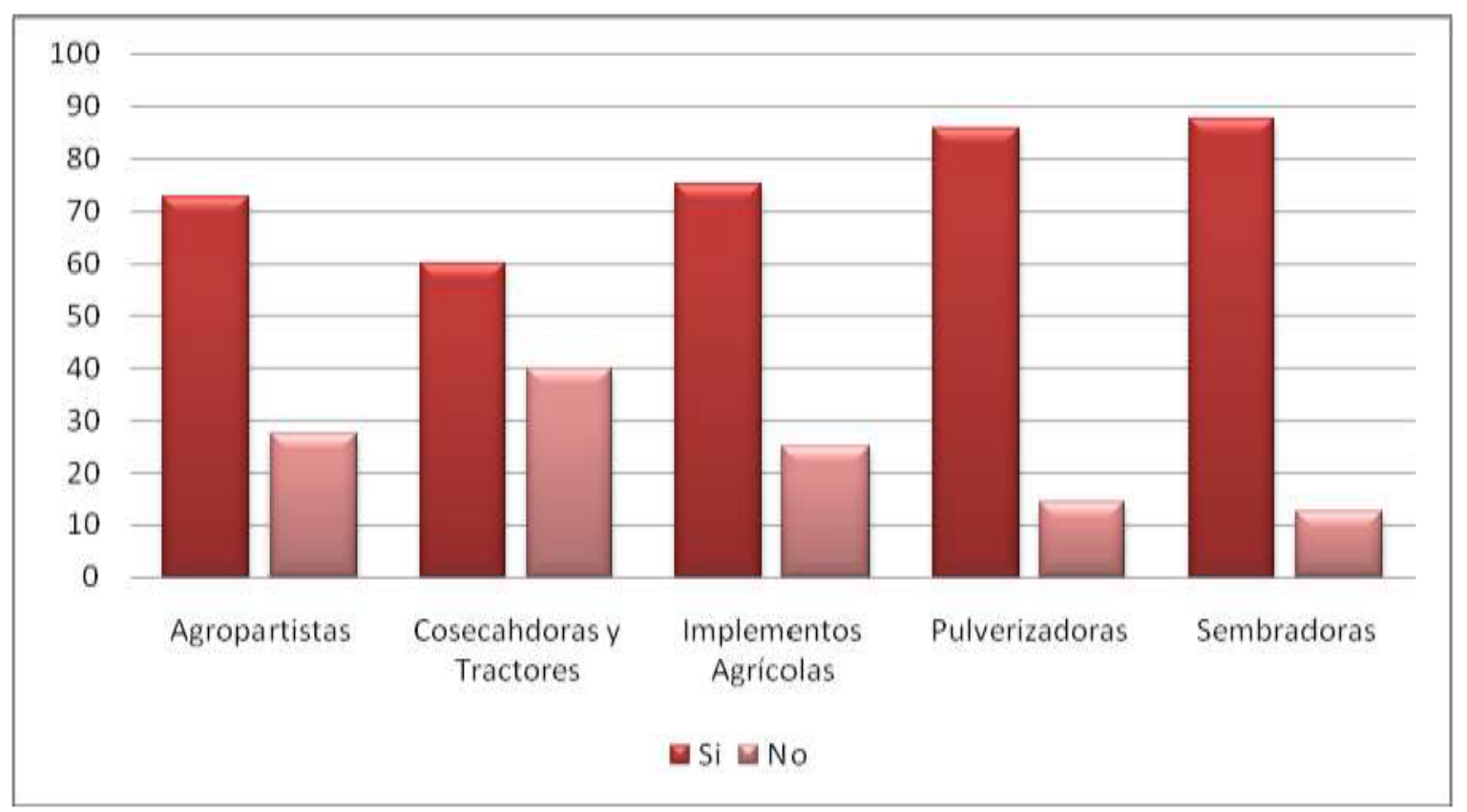

Fuente: elaboración propia en base a datos del Proyecto "Redes de Conocimiento en tramas productivas: Generación, circulación y apropiación del conocimiento y creación de ventajas competitivas en seis tramas de la Argentina. Componente Maquinaria Agrícola" PEC A-26 FLACSO-IDRC. Fuente: Datos recogidos en el año 2008.

Anexo VII. Grado de autonomía de los operarios según segmentos de producción ${ }^{203}$ (en porcentajes).

\begin{tabular}{|l|l|l|l|l|l|l|}
\hline & Agropartistas & $\begin{array}{l}\text { Cosechadoras y } \\
\text { Tractores }\end{array}$ & $\begin{array}{l}\text { Implementos } \\
\text { Agrícolas }\end{array}$ & Pulverizadoras & Sembradoras & Total \\
\hline
\end{tabular}

${ }^{203} \mathrm{El}$ indicador de autonomía fue construido a partir las respuestas a las preguntas "Competencias más importantes para operarios: Autonomía e independencia"; "Competencias más importantes para operarios: Capacidad de resolución de imprevistos"; "Frente a los problemas que aparecen frecuentemente en las actividades de producción, ¿cuál es el comportamiento típico de los operarios?" 


\begin{tabular}{|l|l|l|l|l|l|l|}
\hline Baja & 50 & 40 & 46,2 & 44,4 & 69,2 & 51,6 \\
\hline Media & 50 & 40 & 53,8 & 55,6 & 30,8 & 46,8 \\
\hline Alta & 0 & 20 & 0 & 0 & 0 & 1,6 \\
\hline Total & 100 & 100 & 100 & 100 & 100 & 100 \\
\hline
\end{tabular}

Fuente: elaboración propia en base a datos del Proyecto "Redes de Conocimiento en tramas productivas: Generación, circulación y apropiación del conocimiento y creación de ventajas competitivas en seis tramas de la Argentina. Componente Maquinaria Agrícola" PEC A-26 FLACSO-IDRC. Fuente: Datos recogidos en el año 2008.

\section{Anexo VIII. Funciones desarrolladas por el personal operativo de las empresas de maquinaria agrícola, según segmento de producción (en porcentaje del $n^{\circ}$ de empresas para cada tarea)}

\begin{tabular}{|l|c|c|c|c|c|c|}
\hline & Agropartistas & $\begin{array}{c}\text { Cosechadoras y } \\
\text { Tractores }\end{array}$ & $\begin{array}{c}\text { Implementos } \\
\text { Agrícolas }\end{array}$ & Pulverizadoras & Sembradoras & Total \\
\hline Sólo operativas & 27,3 & 0,0 & 38,5 & 33,3 & 23,1 & 27,4 \\
\hline $\begin{array}{c}\text { Operativas y de } \\
\text { Programación y } \\
\text { puesta a punto de } \\
\text { Máquinas }\end{array}$ & 36,4 & 40,0 & 38,5 & 11,2 & 61,5 & 38,7 \\
\hline $\begin{array}{l}\text { Operativas y } \\
\text { mantenimiento de } \\
\text { primer nivel }\end{array}$ & 13,6 & 0,0 & 7,6 & 11,1 & 0,0 & 8,1 \\
\hline $\begin{array}{l}\text { Todas las } \\
\text { anteriores }\end{array}$ & 22,7 & 60,0 & 15,4 & 44,4 & 15,4 & 25,8 \\
\hline Total & 100 & 100 & 100 & 100 & 100 & 100 \\
\hline
\end{tabular}

Fuente: elaboración propia en base a datos del Proyecto "Redes de Conocimiento en tramas productivas: Generación, circulación y apropiación del conocimiento y creación de ventajas competitivas en seis tramas de la Argentina. Componente Maquinaria Agrícola" PEC A-26 FLACSO-IDRC. Fuente: Datos recogidos en el año 2008.

\section{Anexo IX. Uso de instrumentos de control de procesos en firmas de maquinaria agrícola, según segmentos de producción ${ }^{204}$ (en porcentajes)}

\begin{tabular}{|l|c|c|c|c|c|c|}
\hline & Agropartistas & $\begin{array}{c}\text { Cosechadoras } \\
\text { y Tractores }\end{array}$ & $\begin{array}{c}\text { Implementos } \\
\text { Agrícolas }\end{array}$ & Pulverizadoras & Sembradoras & Total \\
\hline Bajo & 8,70 & 0,00 & 7,14 & 0,00 & 23,08 & 9,38 \\
\hline Medio & 8,70 & 0,00 & 28,57 & 22,22 & 15,38 & 15,63 \\
\hline Alto & 82,61 & 100,00 & 64,29 & 77,78 & 61,54 & 75,00 \\
\hline Total & 100 & 100 & 100 & 100 & 100 & 100 \\
\hline
\end{tabular}

Fuente: elaboración propia en base a datos del Proyecto "Redes de Conocimiento en tramas productivas: Generación, circulación y apropiación del conocimiento y creación de ventajas competitivas en seis tramas de la Argentina. Componente Maquinaria Agrícola" PEC A-26 FLACSO-IDRC. Fuente: Datos recogidos en el año 2008.

204 Se estudia a partir de las respuestas a las siguientes preguntas de la encuesta: ¿Existen especificaciones de las materias primas e insumos críticos?; ¿Están identificadas las características críticas del proceso producto y/o servicio?; ¿Están documentadas las características críticas del proceso, producto y/o servicio?; ¿Están controladas las características críticas del proceso, producto y/o servicio?; ¿Existe trazabilidad? 


\section{Anexo $X$. Adopción de métodos de calidad en firmas de maquinaria agrícola, según segmentos de producción (en porcentajes)}

\begin{tabular}{|l|c|c|c|c|c|c|}
\hline & Agropartistas & $\begin{array}{c}\text { Cosechadoras y } \\
\text { Tractores }\end{array}$ & $\begin{array}{c}\text { Implementos } \\
\text { Agrícolas }\end{array}$ & Pulverizadoras & Sembradoras & Total \\
\hline Bajo & 8,70 & 0,00 & 7,14 & 11,11 & 7,69 & 7,81 \\
\hline Medio & 13,04 & 40,00 & 42,86 & 33,33 & 38,46 & 29,69 \\
\hline Alto & 78,26 & 60,00 & 50,00 & 55,56 & 53,85 & 62,50 \\
\hline Total & 100 & 100 & 100 & 100 & 100 & 100 \\
\hline
\end{tabular}

Fuente: elaboración propia en base a datos del Proyecto "Redes de Conocimiento en tramas productivas: Generación, circulación y apropiación del conocimiento y creación de ventajas competitivas en seis tramas de la Argentina. Componente Maquinaria Agrícola" PEC A-26 FLACSO-IDRC. Fuente: Datos recogidos en el año 2008.

\section{Anexo XI. Uso de métodos sistemáticos para mejora e innovación de procesos (en porcentajes de firmas según segmentos de producción)}

\begin{tabular}{|l|c|c|c|c|c|c|}
\hline & Agropartistas & $\begin{array}{c}\text { Cosechadoras y } \\
\text { Tractores }\end{array}$ & $\begin{array}{c}\text { Implementos } \\
\text { Agrícolas }\end{array}$ & Pulverizadoras & Sembradoras & Total \\
\hline Bajo & 65,22 & 40,00 & 64,29 & 55,56 & 69,23 & 62,50 \\
\hline Medio & 26,09 & 20,00 & 28,57 & 44,44 & 30,77 & 29,69 \\
\hline Alto & 8,70 & 40,00 & 7,14 & 0,00 & 0,00 & 7,81 \\
\hline Total & 100,00 & 100,00 & 100,00 & 100,00 & 100,00 & 100,00 \\
\hline
\end{tabular}

Fuente: elaboración propia en base a datos del Proyecto "Redes de Conocimiento en tramas productivas: Generación, circulación y apropiación del conocimiento y creación de ventajas competitivas en seis tramas de la Argentina. Componente Maquinaria Agrícola" PEC A-26 FLACSO-IDRC. Fuente: Datos recogidos en el año 2008.

\section{Anexo XII. Organización del trabajo en la fábrica}

\begin{tabular}{|c|c|c|c|c|c|c|}
\hline & Agropartistas & $\begin{array}{c}\text { Cosechadoras } \\
\text { y Tractorees }\end{array}$ & $\begin{array}{c}\text { Implementos } \\
\text { Agrícolas }\end{array}$ & Pulverizadoras & Sembradoras & Total \\
\hline $\begin{array}{l}\text { Se organiza el } \\
\text { trabajo de manera } \\
\text { individual y se le } \\
\text { asigna a las } \\
\text { mismas personas } \\
\text { las mismas tareas, } \\
\text { los puestos son } \\
\text { fijos. }\end{array}$ & 36,4 & 20 & 42,9 & 33,3 & 53,8 & 39,7 \\
\hline $\begin{array}{l}\text { Se organiza el } \\
\text { trabajo de manera } \\
\text { individual y se rota } \\
\text { regularmente a las } \\
\text { personas en los } \\
\text { distintos puestos. }\end{array}$ & 36,4 & 0 & 28,6 & 22,2 & 15,4 & 25,4 \\
\hline $\begin{array}{l}\text { Se organiza el } \\
\text { trabajo en } \\
\text { células/equipos y } \\
\text { dentro de cada } \\
\text { equipo los puestos } \\
\text { son fijos. }\end{array}$ & 0 & 40 & 7,1 & 44,4 & 15,4 & 14,3 \\
\hline $\begin{array}{l}\text { Se organiza el } \\
\text { trabajo en } \\
\text { células/equipos, } \\
\text { dentro de cada } \\
\text { célula la gente rota } \\
\text { entre las tareas. } \\
\end{array}$ & 22,7 & 40 & 14,3 & 0 & 15,4 & 17,5 \\
\hline Otros & 4,5 & 0 & 7,1 & 0 & 0 & 3,2 \\
\hline Total & 100 & 100 & 100 & 100 & 100 & 100 \\
\hline
\end{tabular}

Fuente: elaboración propia en base a datos del Proyecto "Redes de Conocimiento en tramas productivas: Generación, 
circulación y apropiación del conocimiento y creación de ventajas competitivas en seis tramas de la Argentina. Componente Maquinaria Agrícola" PEC A-26 FLACSO-IDRC. Fuente: Datos recogidos en el año 2008.

Anexo XII. Porcentaje de empresas que realizan u organizan recurrentemente actividades de capacitación para sus empleados. Dividido por segmento de productos.

\begin{tabular}{|l|c|c|c|c|c|c|}
\hline & Agropartistas & $\begin{array}{c}\text { Cosechadoras } \\
\text { y Tractores }\end{array}$ & $\begin{array}{c}\text { Implementos } \\
\text { Agrícolas }\end{array}$ & Pulverizadoras & Sembradoras & Total \\
\hline Si & 60,87 & 80 & 64,29 & 44,44 & 61,54 & 60,9 \\
\hline No & 39,13 & 20 & 35,71 & 55,56 & 38,46 & 39,1 \\
\hline
\end{tabular}

Fuente: elaboración propia en base a datos del Proyecto "Redes de Conocimiento en tramas productivas: Generación, circulación y apropiación del conocimiento y creación de ventajas competitivas en seis tramas de la Argentina. Componente Maquinaria Agrícola" PEC A-26 FLACSO-IDRC. Fuente: Datos recogidos en el año 2008.

Anexo XIII. Porcentaje de empresas que expresan haber innovado en producto en el período 2004-2006.

\begin{tabular}{|c|c|c|c|c|c|}
\hline Innovación & Agropartistas & $\begin{array}{c}\text { Cosechadoras y } \\
\text { Tractores }\end{array}$ & $\begin{array}{c}\text { Implementos } \\
\text { Agrícolas }\end{array}$ & Pulverizadoras & Sembradoras \\
\hline Producto & $82 \%$ & $100 \%$ & $81 \%$ & $89 \%$ & $92 \%$ \\
\hline
\end{tabular}

Fuente: elaboración propia en base a datos del Proyecto "Redes de Conocimiento en tramas productivas: Generación, circulación y apropiación del conocimiento y creación de ventajas competitivas en seis tramas de la Argentina. Componente Maquinaria Agrícola" PEC A-26 FLACSO-IDRC. Fuente: Datos recogidos en el año 2008. 
Anexo XIV. Encuesta estructurada realizada en 2008.

PROGRAMA DE INVESTIGACION SOBRE ECONOMIA DEL CONOCIMIENTO EN AMERICA LATINA Y EL CARIBE

IDRC-CRDI

INSTITUTO DE INDUSTRIA-UNGS

MAQUINARIA AGRICOLA

\section{A - DATOS GENERALES DE LA EMPRESA}

101. ¿Podría indicar los siguientes datos generales de su empresa?

\begin{tabular}{|c|c|c|}
\hline a. Nombre de la firma o Razón Social & & \\
\hline b. CUIT de la empresa & & \\
\hline c. Dirección & & \\
\hline d. Localidad & & $\begin{array}{l}\text { e. Código } \\
\text { Postal }\end{array}$ \\
\hline f. Teléfono & & g. Fax \\
\hline h. E. Mail & & \\
\hline i. Página web & & \\
\hline j. Año de inicio de actividades de la empresa & & \\
\hline k. Año de inicio de actividades de la planta & & \\
\hline I. Año de compra / fusión & & \\
\hline & $\%$ & \\
\hline m. Participación de empresas extranjeras en el & País & \\
\hline capital de la empresa & Empresa & \\
\hline & $\mathrm{Si}$ & No \\
\hline $\begin{array}{l}\text { n. ¿La empresa forma parte de un grupo } \\
\text { empresario? (nombre) }\end{array}$ & Nombre & \\
\hline & $\mathrm{Si}$ & No \\
\hline o. Indique si opera con licencia internacional & Licencia & \\
\hline
\end{tabular}




\begin{tabular}{||l|l||}
\hline p. Indique la actividad principal de la empresa & \\
\hline q. Indique la actividad secundaria de la empresa & \\
\hline r. Principales productos o servicios que ofrece & \\
\hline s. Número de plantas & \\
\hline t. Nombre, cargo e e-mail del Entrevistado & \\
\hline
\end{tabular}

102. Indique los canales de comercialización que utiliza y el porcentaje de participación en el total de las ventas del 2006.

\begin{tabular}{|l|l|l|l||}
\hline & No & Si & \% \\
\hline a. Mercado interno & & & \\
\hline Para terminales & & & \\
\hline a.1. Concesionarios & & & \\
\hline $\begin{array}{l}\text { a.2. Venta directa (productores, } \\
\text { contratistas) }\end{array}$ & & & \\
\hline Para proveedores & & & \\
\hline a.3. Terminales & & & \\
\hline a.4. Otros agropartistas & & & \\
\hline a.5. Mercado reposición & & & \\
\hline a.6. Otros & & & \\
\hline b. Exportación & & & \\
\hline a.7. a otras filiales de la empresa & & & \\
\hline a.8. otras empresas o intermediadios & & & \\
\hline c. Total & & & 100 \\
\hline
\end{tabular}

En caso de no realizar exportaciones, pase a la pregunta 106.

103. En lo que respecta a las exportaciones directas, ¿podría mencionar los destinos de sus productos?

\begin{tabular}{|l|l|l|}
\hline \multicolumn{1}{|c|}{ Destinos } & No & Si \\
\hline a. Mercosur & & \\
\hline b. Resto de América Latina & & \\
\hline c. EEUU y Canadá & & \\
\hline d. Europa & & \\
\hline e. Asia & & \\
\hline f. Resto del Mundo & & \\
\hline
\end{tabular}

104. El ingreso al mercado externo, ¿requirió cambios en los productos ofrecidos? No Si $\square$

108. Indique en qué consistieron: 
105. Para realizar esos cambios, ¿contó con asistencia técnica y recomendaciones de sus clientes? No $\square$ Si $\square$

\section{Exclusivo para proveedores agropartista}

106. ¿Podría indicar el número de clientes principales en orden decreciente de ventas?
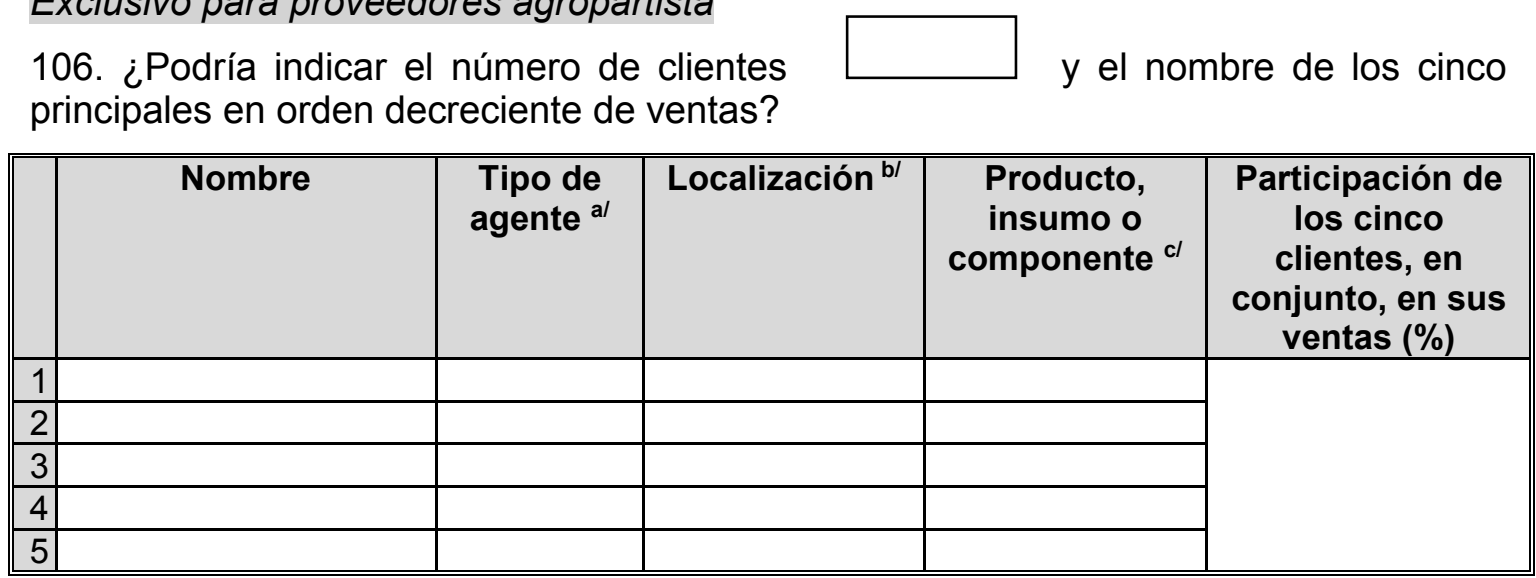

a/ 1) productor nacional o a su distribuidor 2) otras filiales de la empresa en el país; 3)distribuidor nacional de productos importados; 4) importación directa; 5) otras filiales en el extranjero; 6) Otros.

b/ 1) Capital Federal, 2) Gran Buenos Aires, 3) Mar del Plata, 4) Córdoba, 5) Resto del país, 6) MERCOSUR, 7) Resto del mundo.

107. Indique si desarrolla las siguientes actividades y, en caso positivo, si se realizan interna o externamente, o a partir de una combinación de ambas.

\begin{tabular}{|c|c|c|c|c|c|c|}
\hline Opciones & $\begin{array}{l}\mathbf{N} \\
\mathbf{0}\end{array}$ & $\overline{S i}$ & Interno & Externo & Mixto & $\begin{array}{c}\text { Localid } \\
\text { ad al }\end{array}$ \\
\hline \multicolumn{7}{|l|}{ Producción } \\
\hline \multicolumn{7}{|l|}{ a. Cortado y/o plegado } \\
\hline \multicolumn{7}{|l|}{ d. Soldadura } \\
\hline \multicolumn{7}{|l|}{ e. Mecanizado } \\
\hline \multicolumn{7}{|l|}{ g. Ensambles } \\
\hline \multicolumn{7}{|l|}{ h. Automatización } \\
\hline \multirow{2}{*}{\multicolumn{7}{|c|}{$\begin{array}{l}\text { I. Control de calidad final } \\
\text { Servicios }\end{array}$}} \\
\hline & & & & & & \\
\hline \multicolumn{7}{|l|}{ m. Distribución/Logística } \\
\hline \multicolumn{7}{|l|}{ n. Publicidad/Marketing } \\
\hline \multicolumn{7}{|l|}{ o. Seguridad industrial } \\
\hline \multicolumn{7}{|l|}{ p. Capacitación } \\
\hline \multicolumn{7}{|l|}{$\begin{array}{l}\text { q. Asesoramiento profesional } \\
\text { (legal, tributario, RRHH, etc.) }\end{array}$} \\
\hline \multicolumn{7}{|l|}{ r. Mantenimientos/ reparación equipos } \\
\hline \multicolumn{7}{|l|}{ s. Informática } \\
\hline \multicolumn{7}{|l|}{$\begin{array}{l}\text { t. Tratamiento y disposición de efluentes y } \\
\text { desechos }\end{array}$} \\
\hline \multicolumn{7}{|l|}{ u. Diseño } \\
\hline v. Otros (especifique) & & & & & & \\
\hline
\end{tabular}

a/ En el caso de la Cuidad de Buenos Aires, especificar barrio.

108. ¿Cómo ha evolucionado la participación de la subcontratación a terceros en sus costos los últimos cinco años? Aumentó $\square$ Disminuyó $\square$ Permaneció igual $\square$ 
111. ¿Podría indicar del total de compras efectuadas en 2003 y 2006 qué proporción proviene de?

\begin{tabular}{||l|c|c|}
\hline \multicolumn{1}{|c|}{ Origen de materia prima } & \multicolumn{2}{c|}{$\%$} \\
\cline { 2 - 3 } & $\mathbf{2 0 0 3}$ & $\mathbf{2 0 0 6}$ \\
\hline a. Productores nacionales & & \\
\hline b. Distribuidores nacionales de productos importados & & \\
\hline c. Importación directa & & \\
\hline d. Filiales de producción en el extranjero & & \\
\hline e. Otros & & 100 \\
\hline f. Total & 100 & \\
\hline
\end{tabular}

\section{Exclusiva para terminales}

112. ¿Podría indicar el número de proveedores

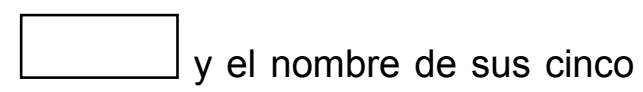
principales proveedores de insumos y/o partes, en orden decreciente de acuerdo a la importancia que tienen?

\begin{tabular}{|c|c|c|c|c|c||}
\hline \hline Nombre & $\begin{array}{c}\text { Tipo de } \\
\text { agente }^{\text {al }}\end{array}$ & $\begin{array}{c}\text { Localización } \\
\text { b/ }\end{array}$ & $\begin{array}{c}\text { Insumo o } \\
\text { componente } \\
\text { que provee }^{c /}\end{array}$ & $\begin{array}{c}\text { Participación en conjunto } \\
\text { de los cinco proveedores } \\
\text { en sus compras (\%) }\end{array}$ \\
\hline 1 & & & & & \multirow{2}{*}{} \\
\hline 2 & & & & & \\
\hline 3 & & & & & \\
\hline 4 & & & & & \\
\hline 5 & & & & & \\
\hline
\end{tabular}

a/ 1) productor nacional o a su distribuidor 2) otras filiales de la empresa en el país; 3)distribuidor nacional de productos importados; 4) importación directa; 5) otras filiales en el extranjero; 6) Otros.

b/ 1) Capital Federal, 2) Gran Buenos Aires, 3) Mar del Plata, 4) Córdoba, 5) Resto del país, 6) MERCOSUR, 7) Resto del mundo.

113. Indique con qué anticipación, en promedio, se define la programación general de aprovisionamiento de su principal proveedor (o cliente, en el caso de los proveedores).
Anual $\square$
Trimest $\square$
Mens $\square$ al
Ser $\square$ anal

114. ¿Podría decir si es frecuente que se vea afectado por una re-programación? No Si $\square$

En caso negativo, pase a la pregunta 201

115. En caso positivo ¿usted comparte con su proveedor (o cliente) los costos asociados?

Comente.

$$
\text { No } \square \mathrm{Si}
$$




\section{B. RELACIONES CON EMPRESAS CLIENTES Y OTROS AGENTES DE LA TRAMA}

\section{B.I ACTIVIDADES DE COOPERACIÓN CON OTRAS FIRMAS E INSTITUCIONES}

201. Indique si su empresa realizar actividades conjuntas de mejoras con los siguientes agentes. Por favor, indique el grado de formalización.

\begin{tabular}{|c|c|c|c|c|}
\hline \multirow[t]{2}{*}{ Agentes } & \multirow[t]{2}{*}{ No } & \multirow[t]{2}{*}{ Si } & \multicolumn{2}{|c|}{$\begin{array}{c}\text { GRADO DE } \\
\text { FORMALIZACIÓN DE LA } \\
\text { RELACIÓN }\end{array}$} \\
\hline & & & $\begin{array}{c}\text { Con } \\
\text { acuerdo } \\
\text { firmado }\end{array}$ & $\begin{array}{l}\text { Sin } \\
\text { acuerdo } \\
\text { firmado }\end{array}$ \\
\hline a. Proveedores nacionales & & & & \\
\hline b. Proveedores internacionales & & & & \\
\hline c. Clientes nacionales & & & & \\
\hline d. Clientes internacionales & & & & \\
\hline e. Otras empresas del sector & & & & \\
\hline f. Consultores & & & & \\
\hline g. Cámaras o asociaciones empresariales & & & & \\
\hline h. Universidades & & & & \\
\hline i. Centros tecnológicos (por ejemplo ITU) & & & & \\
\hline $\begin{array}{l}\text { j. Programas públicos (FONTAR, Programas de } \\
\text { Competitividad SECyT) }\end{array}$ & & & & \\
\hline
\end{tabular}

202. En relación a las vinculaciones mencionadas en la pregunta 201, por favor indique también cuáles son las áreas en las que se desarrolla esta vinculación con cada uno de los siguientes agentes:

\begin{tabular}{|c|c|c|c|}
\hline & $\begin{array}{c}\text { OTRAS } \\
\text { EMPRESAS DEL } \\
\text { SECTOR } \\
\text { (PROVEEDORES } \\
\text { Y/O CLIENTES, } \\
\text { NACIONALES, } \\
\text { EXTRANJEROS) }\end{array}$ & $\begin{array}{c}\text { CÁMARAS O } \\
\text { ASOCIACION } \\
\text { ES } \\
\text { EMPRESARIA } \\
\text { LES O } \\
\text { CONSULTOR } \\
\text { AS }\end{array}$ & $\begin{array}{c}\text { UNIVERSIDADES, } \\
\text { CENTROS } \\
\text { TECNOLÓGICOS (INT/ } \\
\text { INTI, ITU) O } \\
\text { PROGRAMAS } \\
\text { PÚBLICOS (FONTAR, } \\
\text { PROGRAMAS DE } \\
\text { COMPETITIVIDAD } \\
\text { SECYT) }\end{array}$ \\
\hline \multicolumn{4}{|l|}{ a. Objetivos comerciales } \\
\hline \multicolumn{4}{|l|}{ b. Certificación de calidad } \\
\hline \multicolumn{4}{|l|}{$\begin{array}{l}\text { c. Capacitación de Recursos } \\
\text { Humanos }\end{array}$} \\
\hline \multicolumn{4}{|l|}{$\begin{array}{l}\text { d. Actividades de diseño y/o } \\
\text { desarrollo }\end{array}$} \\
\hline \multicolumn{4}{|l|}{ e. Financiamiento para la innovación } \\
\hline \multicolumn{4}{|l|}{ f. Utilizar/compartir infraestructura } \\
\hline \multicolumn{4}{|l|}{$\begin{array}{l}\text { g. Reducir costos y riesgos de } \\
\text { innovación }\end{array}$} \\
\hline \multicolumn{4}{|l|}{ h. Cambios organizacionales } \\
\hline \multicolumn{4}{|c|}{\begin{tabular}{l|l|l|l|} 
i. Mejoras ambientales & & & \\
\end{tabular}} \\
\hline \multicolumn{4}{|c|}{$\begin{array}{l}\text { a. Contacto con nuevos proveedores y clientes, servicios complementarios, compra conjunta de materia prima, } \\
\text { exportaciones conjuntas, desarrollo de canales comerciales, obtener información del contexto de negocios. d. } \\
\text { Información tecnológica sobre productos, procesos y materiales; desarrollo y adaptación de productos, procesos e } \\
\text { insumos; diseño conjunto }\end{array}$} \\
\hline \multicolumn{4}{|c|}{ 203. Indique si las interacciones mencionadas tuvieron impacto en: } \\
\hline & $\begin{array}{c}\text { OTRAS } \\
\text { EMPRESAS DEL }\end{array}$ & $\begin{array}{l}\text { CÁMARAS O } \\
\text { ASOCIACIONES }\end{array}$ & $\begin{array}{l}\text { UNIVERSIDADES, } \\
\text { CENTROS }\end{array}$ \\
\hline
\end{tabular}




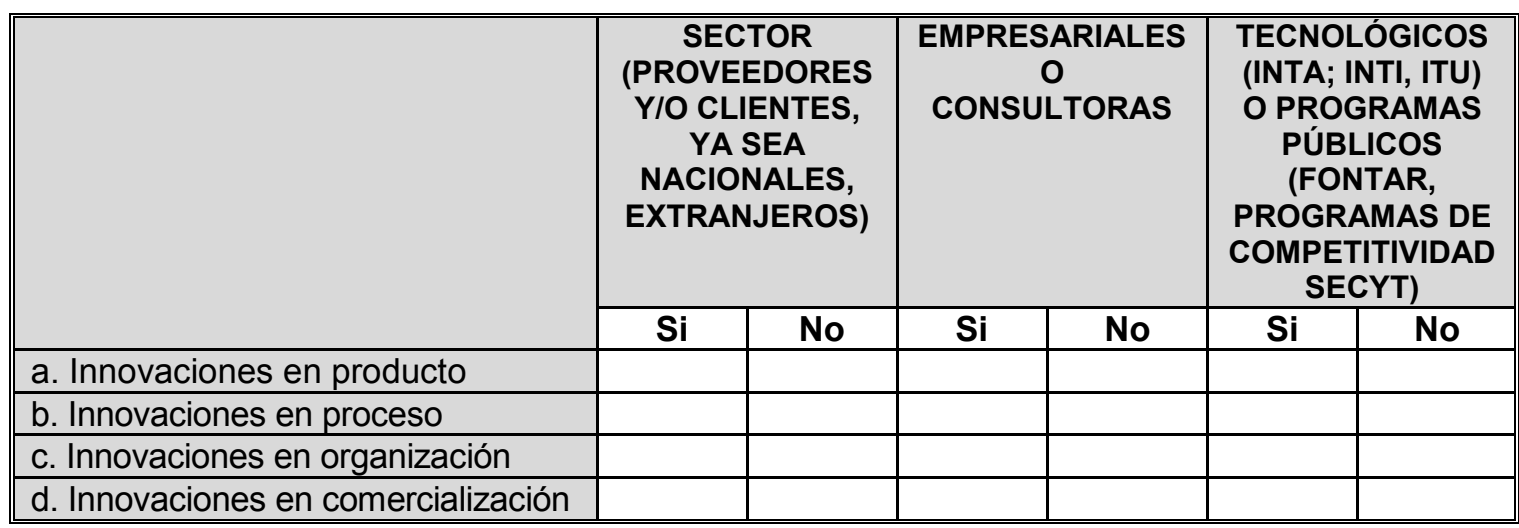

\section{Exclusivo para terminales}

204. ¿Recibió asistencia técnica en alguna de las siguientes temáticas? En caso positivo indique el tipo de agente/s involucrado/s en dicha asistencia.

\begin{tabular}{|l|l|l|l|l|l||}
\hline NO & Si & $\begin{array}{c}\text { OTRAS } \\
\text { EMPRESAS } \\
\text { DEL SECTOR } \\
\text { (PROVEEDORE } \\
\text { S YIO } \\
\text { CLIENTES, } \\
\text { NACIONALE, } \\
\text { EXTRANJEROS } \\
\text { ) }\end{array}$ & $\begin{array}{c}\text { CAMARAS O } \\
\text { ASOCIACION } \\
\text { ES } \\
\text { EMPRESARIA } \\
\text { LES Y } \\
\text { CONSULTOR } \\
\text { AS }\end{array}$ & $\begin{array}{c}\text { UNIVERSIDADES, } \\
\text { CENTROS } \\
\text { TECNOLÓGICOS } \\
\text { (INTA; INTI, ITU) } \\
\text { PROGRAMAS } \\
\text { PÚBLICOS (FONTAR, } \\
\text { PROGRAMAS DE } \\
\text { COMPETITIVIDAD } \\
\text { SECYT) }\end{array}$ \\
\hline $\begin{array}{l}\text { A. DISEÑO } \\
\text { B. PRODUCTO }\end{array}$ & & & & & \\
\hline $\begin{array}{l}\text { C. PROCESO } \\
\text { PRODUCTIVO }\end{array}$ & & & & & \\
\hline $\begin{array}{l}\text { D. GESTIÓN DE LA } \\
\text { CALIDAD }\end{array}$ & & & & & \\
\hline $\begin{array}{l}\text { E. } \\
\text { COMERCIALIZACIÓN }\end{array}$ & & & & & \\
\hline $\begin{array}{l}\text { F. RECURSOS } \\
\text { HUMANOS }\end{array}$ & & & & & \\
\hline $\begin{array}{l}\text { G. OTROS } \\
\text { (ESPECIFIQUE) }\end{array}$ & & & & \\
\hline
\end{tabular}

Si no recibió asistencia técnica, pase a la pregunta 207.

205. ¿Qué ventajas/vinculaciones se generaron a partir de esta asistencia técnica?

\begin{tabular}{|c|c|c|c|c|c|c|}
\hline \multirow[t]{2}{*}{ Manifestaciones } & \multicolumn{2}{|c|}{$\begin{array}{c}\text { Otras Empresas } \\
\text { del Sector } \\
\text { (Proveedores } \\
\text { ylo Clientes, } \\
\text { Nacionales, } \\
\text { Extranjeros) }\end{array}$} & \multicolumn{2}{|c|}{$\begin{array}{c}\text { Cámaras o } \\
\text { Asociaciones } \\
\text { Empresariales y } \\
\text { Consultoras }\end{array}$} & \multicolumn{2}{|c|}{$\begin{array}{c}\text { Universidades, } \\
\text { Centros } \\
\text { Tecnológicos } \\
\text { (INTA; INTI, ITU) o } \\
\text { Programas } \\
\text { Públicos (Fontar, } \\
\text { Programas de } \\
\text { Competitividad } \\
\text { Secyt) }\end{array}$} \\
\hline & Si & No & Si & No & Si & No \\
\hline a. Nuevas relaciones comerciales & & & & & & \\
\hline
\end{tabular}




\begin{tabular}{|l|l|l|l|l|l|l||}
\hline $\begin{array}{l}\text { b. Desarrolló nuevos } \\
\text { productos/servicios o procesos } \\
\text { conjuntamente }\end{array}$ & & & & & & \\
\hline c. Se convirtió en asesor técnico & & & & & & \\
\hline $\begin{array}{l}\text { d. Le permitió acceder a otros } \\
\text { contactos para resolver problemas } \\
\text { técnicos }\end{array}$ & & & & & & \\
\hline $\begin{array}{l}\text { e. Mejoró la calidad de los } \\
\text { productos/servicios ofrecidos }\end{array}$ & & & & & & \\
\hline f. Cultivó una relación de amistad & & & & & & \\
\hline g. Otros. Aclare. & & & & & & \\
\hline
\end{tabular}

a) Incorporó como proveedor o cliente, lo contactó con nuevos proveedores o clientes

206. ¿Cuáles son las razones por las que eligió a estos agentes para recibir la asistencia técnica mencionada?

\begin{tabular}{|c|c|c|c|c|c|c|}
\hline \multirow[t]{2}{*}{ Razones } & \multicolumn{2}{|c|}{$\begin{array}{c}\text { Otras } \\
\text { Empresas del } \\
\text { Sector } \\
\text { (Proveedores } \\
\text { y/o Clientes, } \\
\text { Nacionales, } \\
\text { Extranjeros) } \\
\end{array}$} & \multicolumn{2}{|c|}{$\begin{array}{c}\text { Cámaras o } \\
\text { Asociaciones } \\
\text { Empresariales } \\
\text { y Consultoras }\end{array}$} & \multicolumn{2}{|c|}{$\begin{array}{c}\text { Universidades, Centros } \\
\text { Tecnológicos (INTA; INTI, ITU) o } \\
\text { Programas Públicos (Fontar, } \\
\text { Programas de Competitividad } \\
\text { Secyt) }\end{array}$} \\
\hline & Si & No & $\mathbf{S i}$ & No & $\mathbf{S i}$ & No \\
\hline a. Relación comercial pres & & & & & & \\
\hline $\begin{array}{l}\text { b. Reputación del cuerpo } \\
\text { técnico }\end{array}$ & & & & & & \\
\hline $\begin{array}{l}\text { C. Recomendación de } \\
\text { terceros }\end{array}$ & & & & & & \\
\hline $\begin{array}{l}\text { d. Experiencia previa con } \\
\text { problemas similares }\end{array}$ & & & & & & \\
\hline $\begin{array}{l}\text { e. Relaciones personales } \\
\text { (parentesco, amistad, } \\
\text { compañeros de estudio, } \\
\text { vecinos) }\end{array}$ & & & & & & \\
\hline f. Otros (especifique) & & & & & & \\
\hline
\end{tabular}

\section{Para proveedores y agropartistas}

207. ¿En los últimos tres años alguien ${ }^{\mathrm{a}}$ lo consultó por algún problema técnico que tenía?

$\mathrm{No} \square \mathrm{Si} \square \quad$ ¿Podría identificarlos?

\begin{tabular}{|c|c|c|c|}
\hline & Tipo de Problema & Tipo de Empresa ${ }^{\text {al }}$ & Localidad \\
\hline 1 & & & \\
\hline 2 & & & \\
\hline 3 & & & \\
\hline
\end{tabular}

a/ Proveedores, Compradores, Matriz, Empresa competidora (o en el mismo ramo).

Si no brindó asistencia técnica, pase a la pregunta 210.

\section{Exclusiva para proveedores agropartistas}

208. ¿Qué ventajas/vinculaciones se generaron a partir de esta consulta técnica?

\begin{tabular}{l|l|l|}
\hline Manifestaciones & Si & No \\
\hline
\end{tabular}




\begin{tabular}{|l|l|l|}
\hline a. Nuevas relaciones comerciales & & \\
\hline $\begin{array}{l}\text { b. Desarrolló nuevos productos/servicios } \\
\text { o procesos conjuntamente }\end{array}$ & & \\
\hline c. Se convirtió en asesor técnico & & \\
\hline $\begin{array}{l}\text { d. Le permitió acceder a otros contactos } \\
\text { para resolver problemas técnicos }\end{array}$ & & \\
\hline $\begin{array}{l}\text { e. Mejoró la calidad de los } \\
\text { productos/servicios ofrecidos }\end{array}$ & & \\
\hline f. Cultivó una relación de amistad & & \\
\hline
\end{tabular}

a) Incorporó como proveedor o cliente, lo contactó con nuevos proveedores o clientes

209. ¿Cuáles son las razones por las que considera que acudieron a usted?

\begin{tabular}{||l|c|c||}
\hline \multirow{2}{*}{\multicolumn{1}{||}{ Razones }} & \multicolumn{2}{c||}{$\begin{array}{c}\text { Agentes } \\
\text { comerciales }\end{array}$} \\
\cline { 2 - 3 } & Si & No \\
\hline a. Relación comercial previa & & \\
\hline b. Reputación del cuerpo & & \\
técnico & & \\
\hline $\begin{array}{l}\text { c. Recomendación de } \\
\text { terceros }\end{array}$ & & \\
\hline $\begin{array}{l}\text { d. Experiencia previa con } \\
\text { problemas similares }\end{array}$ & & \\
\hline $\begin{array}{l}\text { e. Relaciones personales } \\
\text { (parentesco, amistad, } \\
\text { compañeros de estudio, } \\
\text { vecinos) }\end{array}$ & & \\
\hline f. Otros (especifique) & & \\
\hline
\end{tabular}

\section{Para proveedores y agropartistas}

211. ¿Podría indicar si mantiene con otros colegas conversaciones informales? No Si

En caso positivo indique si en esas conversaciones tratan alguno de los siguientes temas.

\begin{tabular}{|c|c|c|}
\hline Temas & Si & No \\
\hline a. Situación general del país y/o regional & & \\
\hline b. Estrategias de comercialización en el mercado interno & & \\
\hline c. Posibilidades de financiamiento, relaciones con los bancos & & \\
\hline d. Dificultades relacionadas con aspectos laborales & & \\
\hline e. Temas/problemas vinculados cámaras empresariales & & \\
\hline f. Estrategias de comercialización en mercados externos & & \\
\hline $\begin{array}{l}\text { g. Racionalización del proceso productivo, problemas } \\
\text { vinculados con la gestión de calidad/gestión de la empresa }\end{array}$ & & \\
\hline $\begin{array}{l}\text { h. Temas/ problemas vinculados a la infraestructura urbana } \\
\text { local }\end{array}$ & & \\
\hline $\begin{array}{l}\text { i. Forma de aprovechar la cercanía geográfica para aumentar } \\
\text { las conexiones productivas }\end{array}$ & & \\
\hline j. Búsqueda de socios para realizar acuerdos & & \\
\hline k. Desarrollo de programas de capacitación compartidos & & \\
\hline
\end{tabular}


I. Posibilidad de efectuar un desarrollo compartido de productos y proceso

m. Otros. Aclare.

\section{LAS ACTIVIDADES INNOVATIVAS E INVERSIÓN}

301. ¿Podría indicar si durante los últimos tres años (2004-2006) en la empresa se realizaron esfuerzos y se destinaron recursos orientados a?

\begin{tabular}{|c|c|c|}
\hline Actividad & Si & No \\
\hline \multicolumn{3}{|c|}{$\begin{array}{l}\text { a. Compra de bienes de capital relacionados con productos y/o procesos } \\
\text { nuevos o mejorados }\end{array}$} \\
\hline \multicolumn{3}{|c|}{ b. Adquisición de licencia de fabricación } \\
\hline \multicolumn{3}{|l|}{ c. Incorporación de software de producción } \\
\hline \multicolumn{3}{|l|}{ d. Desarrollo de software de vinculación comercial y producción } \\
\hline \multicolumn{3}{|l|}{ e. Consultoría } \\
\hline \multicolumn{3}{|l|}{ f. Programas de mejora continua } \\
\hline \multicolumn{3}{|l|}{ g. Diseño y Desarrollo de productos } \\
\hline \multicolumn{3}{|l|}{ h. Diseño y Desarrollo de canales de comercialización } \\
\hline \multicolumn{3}{|l|}{ i. Desarrollo de procesos } \\
\hline \multicolumn{3}{|l|}{ j. Cambio organizacional } \\
\hline \multicolumn{3}{|l|}{ k. Capacitación orientada a la innovación } \\
\hline I. Investigación y/o exploración de oportunidades científicas & & \\
\hline
\end{tabular}

En caso de que todas las respuestas sean negativas, pase a la pregunta 303

302. ¿Podría estimar a cuánto ascendieron los gastos relacionados con estas actividades, en el año $2006 ?$

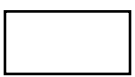

303. Indique aproximadamente la participación de la inversión sobre ventas efectuada en equipamiento en el año 2006

304. ¿Realizó inversiones en las siguientes áreas en el periodo 2004-2006? En caso afirmativo, indique en qué estado de avance se encuentran.

\begin{tabular}{||l|l|l|l|l||}
\hline & NO & SI & $\begin{array}{c}\text { INVERSIONES } \\
\text { PLANEADAS }\end{array}$ & $\begin{array}{c}\text { INVERSIONES } \\
\text { CONCRETADAS }\end{array}$ \\
\hline a. Plantas completas & & & & \\
\hline b. Líneas de productos & & & & \\
\hline c. Secciones productivas & & & & \\
\hline $\begin{array}{l}\text { d. Maquinarias y equipos } \\
\text { aislados }\end{array}$ & & & \\
\hline
\end{tabular}

305. Indique la participación del equipamiento programable o automatizado en el total de equipamiento

\begin{tabular}{||l|l||}
\hline \multicolumn{1}{|c|}{ AÑO } & $\%$ \\
\hline a. 2003 & \\
\hline b. 2006 & \\
\hline
\end{tabular}


306. ¿Cómo calificaría el estado de la maquinaria que interviene directamente en el proceso productivo? Marque sólo una opción

\begin{tabular}{||l|l|}
\hline \multicolumn{1}{|c|}{ ANTIGUEDAD } & OPCIONES \\
\hline a. De punta & \\
\hline b. Moderno & \\
\hline c. Antiguo & \\
\hline
\end{tabular}

307. ¿Qué porcentaje de su equipamiento considera que debería ser renovado?

308. Estime el nivel de utilización de su capacidad productiva en los siguientes períodos:

\begin{tabular}{||l|l||}
\hline \hline & $\begin{array}{c}\text { UTILIZACIÓN } \\
\text { CAPACIDAD } \\
\text { PRODUCTIVA (\%) }\end{array}$ \\
\hline a. 2003 & \\
\hline c. 2006 & \\
\hline d. Estimación 2007 & \\
\hline
\end{tabular}

309. Indique el grado de aplicación de los siguientes ítems de control de proceso y producto y/o servicio.

\begin{tabular}{||l|l|l|l||}
\hline \multicolumn{1}{|c|}{ Control del proceso, producto o servicio } & Si & Parcial & No \\
\hline $\begin{array}{l}\text { a. ¿Existen especificaciones de las materias } \\
\text { primas e insumos críticos? }\end{array}$ & & & \\
\hline $\begin{array}{l}\text { b. ¿Están identificadas las características críticas } \\
\text { del proceso, producto y/o servicio? }\end{array}$ & & & \\
\hline $\begin{array}{l}\text { c. ¿Están documentadas las características } \\
\text { críticas del proceso, producto y/o servicio? }\end{array}$ & & & \\
\hline $\begin{array}{l}\text { d. ¿Están controladas las características críticas } \\
\text { del proceso, producto y/o servicio? }\end{array}$ & & & \\
\hline e. ¿Existe trazabilidad? & & & \\
\hline
\end{tabular}

310. Indique si existen en su firma algunas de las siguientes actividades.

\begin{tabular}{||l|l|l|l||}
\hline \multicolumn{1}{|c|}{ Cultura hacia la calidad } & Si & No & Parcial \\
\hline $\begin{array}{l}\text { a. ¿Existe una Política de Calidad definida y } \\
\text { comunicada a todo el personal? }\end{array}$ & & & \\
\hline $\begin{array}{l}\text { b. ¿Están definidos y se exhiben públicamente los } \\
\text { indicadores clave de calidad? }\end{array}$ & & & \\
\hline $\begin{array}{l}\text { c. ¿Existen equipos para solucionar problemas o lograr } \\
\text { mejoras en el proceso? }\end{array}$ & & & \\
\hline d. ¿Se realizan auditorías internas? & & & \\
\hline $\begin{array}{l}\text { e. ¿Existe algún sistema para mantener el orden y } \\
\text { limpieza? }\end{array}$ & & & \\
\hline $\begin{array}{l}\text { f. ¿Existen comunicaciones periódicas con los clientes } \\
\text { para detectar cambios en los requerimientos? }\end{array}$ & & & \\
\hline $\begin{array}{l}\text { g. ¿Se utilizan estas comunicaciones para modificar el } \\
\text { producto y/o servicio? }\end{array}$ & & & \\
\hline $\begin{array}{l}\text { h. ¿Existen comunicaciones periódicas con los } \\
\text { proveedores? }\end{array}$ & & & \\
\hline $\begin{array}{l}\text { i. ¿Se utilizan estas comunicaciones para modificar el } \\
\text { producto y/o servicio? }\end{array}$ & & & \\
\hline j. ¿Hay algún sistema de reconocimiento de ideas o & & & \\
\hline
\end{tabular}




\section{1. ¿Podría indicar si se utilizan las siguientes herramientas y métodos} sistemáticos de análisis?

\begin{tabular}{|c|c|c|c|}
\hline \multicolumn{4}{|c|}{ Métodos sistemáticos para mejora e innovación } \\
\hline 1. Utilización de herramientas & Si & No & $\begin{array}{c}\text { Alguna } \\
\text { vez }\end{array}$ \\
\hline \multicolumn{4}{|l|}{ a. Diagrama de causa y efecto } \\
\hline \multicolumn{4}{|l|}{ b. Diagrama de Pareto } \\
\hline \multicolumn{4}{|l|}{ c. Histogramas } \\
\hline \multicolumn{4}{|l|}{ d. AMFE / FMEA 1/ } \\
\hline \multicolumn{4}{|l|}{ e. Gráficos de control estadístico de procesos } \\
\hline \multicolumn{4}{|l|}{ 2. Otras herramientas (especifique): } \\
\hline & $<10 \%$ & 10 y $50 \%$ & $>50 \%$ \\
\hline $\begin{array}{l}\text { 3. Cantidad de personal que utiliza estas } \\
\text { herramientas ( } \% \text { del total de la dotación) }\end{array}$ & & & \\
\hline
\end{tabular}

1/ AMFE: Análisis Modal de Fallas y Efecto o FMEA: Failure Mode and Effect Análisis.

312. ¿Los productos, procesos productivos y/o servicios que usted ofrece cumplen con alguna norma de calidad? Indique el código de la norma.

\begin{tabular}{||l|l|l|l|l||}
\hline \multicolumn{4}{|c||}{ Certificación de normas de calidad (1) } \\
\hline \multicolumn{1}{||c||}{ NORMA } & $\begin{array}{c}\text { N } \\
\text { O Si }\end{array}$ & $\begin{array}{c}\text { Nombre de la } \\
\text { norma }\end{array}$ & $\begin{array}{c}\text { Proporción de } \\
\text { implementación }\end{array}$ \\
\hline $\begin{array}{l}\text { a. Normas ISO de aseguramiento de la } \\
\text { calidad }\end{array}$ & & & & \\
\hline b. Normas ambientales & & & & \\
\hline c. Normas sectoriales (especifique) & & & & \\
\hline
\end{tabular}

(1) Certificada: indicar fecha de 1er. certificación - Implementando: Indicar \% de avance.

313. Para los períodos indicados podría señalar:

a. Si realizó innovaciones en productos, procesos, comercialización y organización del trabajo.

b. Si recibió apoyo externo y la importancia del mismo para realizar esas actividades (últimas tres columnas).

\begin{tabular}{|c|c|c|c|c|c|c|c|}
\hline \multirow{3}{*}{ TIPO DE INNOVACIÓN } & \multicolumn{4}{|c|}{ REALIZÓ } & \multicolumn{3}{|c|}{ APOYO A LA INNOVACIÓN } \\
\hline & \multicolumn{2}{|c|}{$\begin{array}{c}2001- \\
2003\end{array}$} & \multicolumn{2}{|c|}{ 2004-2006 } & \multirow{2}{*}{$\begin{array}{l}\text { Carácter } \\
\text { del apoyo } \\
\text { externo a/ }\end{array}$} & \multirow{2}{*}{$\begin{array}{c}\text { Importancia } \\
\text { del apoyo } \\
\text { externo b/ }\end{array}$} & \multirow{2}{*}{$\begin{array}{c}\text { Fuente } \\
\text { principal }\end{array}$} \\
\hline & $\mathrm{Si}$ & No & Si & No & & & \\
\hline \multicolumn{8}{|l|}{ a. En Producto/ ${ }^{1}$} \\
\hline \multicolumn{8}{|l|}{ b. En Procesos $/ 2$} \\
\hline \multicolumn{8}{|l|}{ c. En organización/3 } \\
\hline d. En comercialización /4 & & & & & & & \\
\hline
\end{tabular}

a/ 1) Financiero, 2) Técnico, 3) Informativo; b/ 1) baja, 2) mediana, 3) alta, 4) muy alta; c/ 1) Instituciones de apoyo, 2 Consultores, 3 Otras empresas, 4 Otras empresas del grupo, 5 Casa matriz, 6 Núcleo de la red a la que pertenece.

$I^{1}$ Son productos técnicamente nuevos o con características significativamente mejoradas (incluye mejoras significativas en calidad). $I^{2}$ Alude a la utilización de técnicas de fabricación o procedimientos nuevos o significativamente mejorados (incluye automación). $I^{3}$ Mejoras en cómo se organiza y articula el trabajo de las distintas áreas de la empresa, por ejemplo una reducción de niveles de decisión, una 


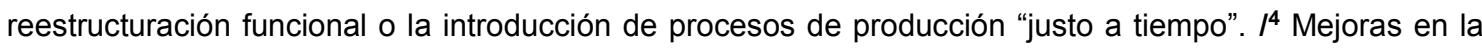
forma cómo se vincula la empresa con sus clientes y con el mercado, por ejemplo la llegada a nuevos mercados o el establecimiento de nuevas formas de acceso, a través de socios o franchising.

314. ¿Podría decir si, en los últimos tres años se lograron resultados derivados de las actividades de innovación y aseguramiento de la calidad en los siguientes planos? En los casos positivos indique en qué se manifestaron estos resultados.

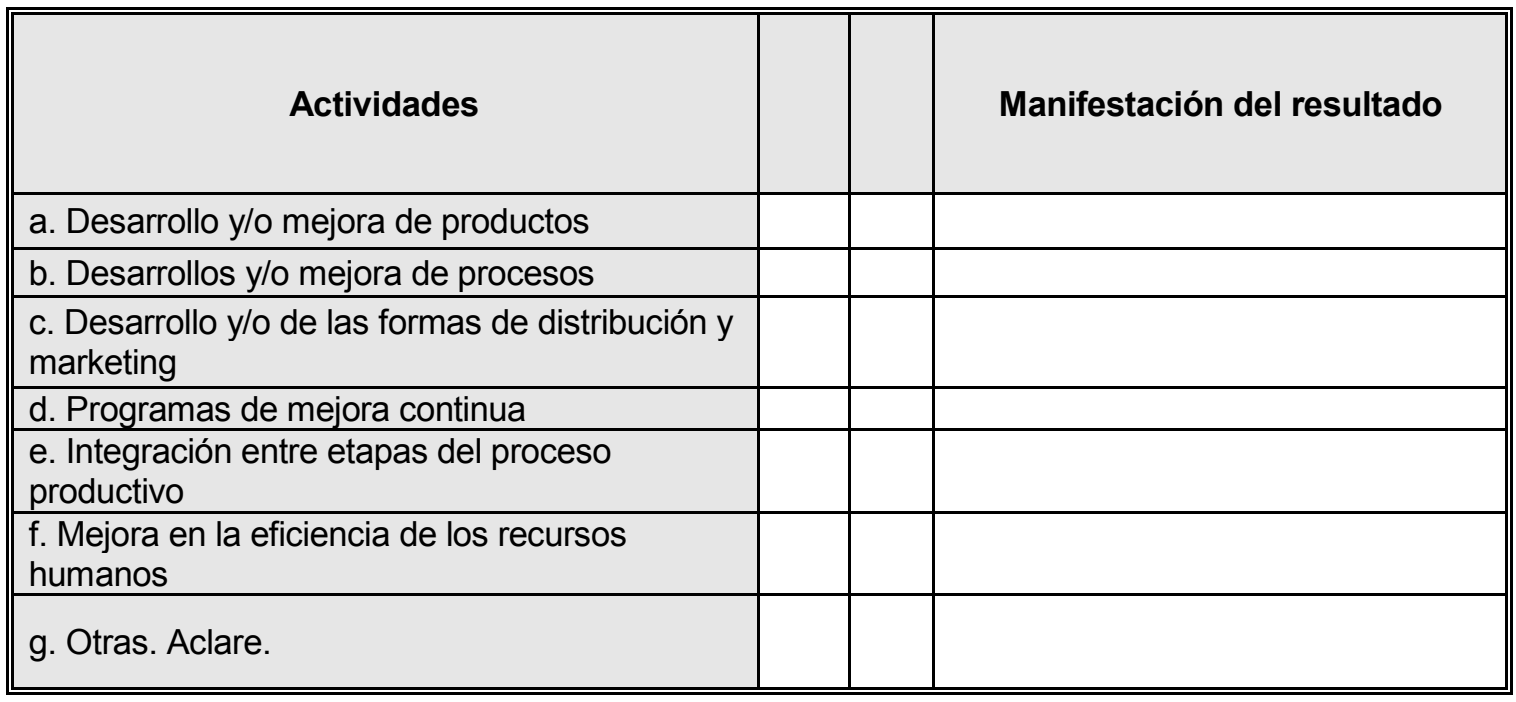

315. Indique los cambios más significativos en términos de empleo derivados de los resultados mencionados

\begin{tabular}{||l|c|c||}
\hline \hline & NO & SI \\
\hline a. Requirió más trabajadores & & \\
\hline b. Requirió menos trabajadores & & \\
\hline c. Requirió trabajadores con mayores calificaciones & & \\
\hline $\begin{array}{l}\text { d. Requirió trabajadores con menores } \\
\text { calificaciones }\end{array}$ & & \\
\hline \hline
\end{tabular}

\section{C.I. DESARROLLO Y MEJORA DE PRODUCTOS, DOCUMENTACIÓN Y COMUNICACIÓN}

316. ¿Podría identificar un grupo que lleve a cabo las actividades de innovación?

\begin{tabular}{||l|l|l|l||}
\hline \hline FORMAL & INFORMAL & AMBOS & NINGUNO \\
\hline & & & \\
\hline
\end{tabular}

En caso de marcar 'ninguno', pase a la pregunta 321.

317. ¿Podría indicar el número de personas que lo integraban en el año 2006 ?

318. Indique que proporción del personal involucrado en estas actividades son exclusivos

319. Indique si este grupo constituye un departamento de investigación y desarrollo No Si $\square$

320. Si existe ¿De qué área funcional de la empresa depende este departamento?

\begin{tabular}{||l|l|l||}
\hline & No & Si \\
\hline a. De ninguna en especial & & \\
\hline
\end{tabular}




\begin{tabular}{||l|l|l||}
\hline b. De producción & & \\
\hline c. De marketing & & \\
\hline d. De la dirección general & & \\
\hline e. Otros. Aclare. & & \\
\hline
\end{tabular}

321. En el período 2001-2006 ¿ha incorporado a la planta de recursos humanos alguno de los siguientes perfiles para el desarrollo y mejora de productos?

\begin{tabular}{||l|l|l||}
\hline & 2001-2002 & Desde el 2003 \\
\hline a. Ingenieros & & \\
\hline b. Técnicos especializados & & \\
\hline c. Arquitectos & & \\
\hline d. Diseñadores de comunicación visual/gráficos & & \\
\hline e. Diseñadores industriales & & \\
\hline
\end{tabular}

322. ¿Utiliza alguna de las siguientes fuentes de información para el desarrollo de nuevos productos?

\begin{tabular}{||l|l|l||}
\hline & NO & SI \\
\hline a. Visitas a ferias sectoriales y exposiciones & & \\
\hline b. Revistas, libros, páginas web & & \\
\hline c. Visitas a plantas/empresas en el exterior & & \\
\hline d. Visitas a plantas/empresas en el país & & \\
\hline e. Institutos Tecnológicos y Universidades & & \\
\hline f. Consultorías & & \\
\hline g. Proveedores de equipos & & \\
\hline h. Proveedores de insumos y materias primas & & \\
\hline i. Clientes & & \\
\hline j. Competidores & & \\
\hline k. Otros. Aclare & & \\
\hline
\end{tabular}

324. a) La imitación de sus productos ¿es un limitante a la innovación de importancia? Alta $\square$ Media $\square$ Baja $\square$ Irrelevante $\square$

325. Indique cuál es la forma de protección más frecuente de los productos/servicios desarrollados por su empresa.

\begin{tabular}{|c|c|c|}
\hline & NO & SI \\
\hline a. Marca & & \\
\hline b. Modelo industrial & & \\
\hline c. Diseño industrial & & \\
\hline d. Modelo de utilidad & & \\
\hline e. Patentes & & \\
\hline $\begin{array}{l}\text { f. Derechos de autor (software, contenidos, } \\
\text { etc..) }\end{array}$ & & \\
\hline g. Mecanismos tecnológicos de apropiación & & \\
\hline h. Controlar las redes de distribución & & \\
\hline i. Llegar primero al mercado & & \\
\hline j. Secreto & & \\
\hline $\begin{array}{l}\text { k. Naturaleza del producto o proceso difícil de } \\
\text { imitar }\end{array}$ & & \\
\hline
\end{tabular}

En caso de respuesta negativa en los ítems a) a e), pase a la pregunta327 
326. ¿Ha licenciado productos y/o marcas a terceros? No $\square \mathrm{Si}$

327. ¿Cuáles de los siguientes atributos considera que permiten que su producto/servicio se diferencie de otros ya existentes (tomar como referencia a los competidores más cercanos)?

\begin{tabular}{|c|c|c|c|c|}
\hline & NO & SI & NO CORRESPONDE \\
\hline \multicolumn{5}{|c|}{ a. Servicio posventa } \\
\hline \multicolumn{5}{|c|}{ b. Calidad de producto o servicio } \\
\hline \multicolumn{5}{|c|}{ d. Precio } \\
\hline \multicolumn{5}{|c|}{ e. Cuidado del medio ambiente } \\
\hline \multicolumn{5}{|c|}{ f. Marca } \\
\hline \multicolumn{5}{|c|}{ g. Potencia del equipo } \\
\hline \multicolumn{5}{|c|}{ h. Funcionalidad del producto o servicio } \\
\hline \multirow[t]{4}{*}{ Tractores } & h.1. Presión hidráulica & & & \\
\hline & h.2 Transmisión ( $n^{\circ}$ de marchas) & & & \\
\hline & h.3 Peso & & & \\
\hline & h.4. Otras & & & \\
\hline \multirow[t]{6}{*}{ Cosechadoras } & h.5. Supresión de perdidas de grand & & & \\
\hline & h.6. Mejora tratamiento residuos & & & \\
\hline & h.7. Capacidad de tolva. & & & \\
\hline & h.8. Capacidad corte (ancho cabeza & & & \\
\hline & h.9. Monitoreo y trazabilidad & & & \\
\hline & h.10. Otras & & & \\
\hline \multirow[t]{6}{*}{ Sembradoras } & h.11. Mayor Ancho de labor & & & \\
\hline & h.12. Dosificación de semilla & & & \\
\hline & h.13. Capacidad de tolva. & & & \\
\hline & h.14. Menor distancia entre surcos & & & \\
\hline & h.15. Sistemas de inoculación & & & \\
\hline & h.16. Monitoreo y trazabilidad & & & \\
\hline \multirow[t]{6}{*}{ Pulverizadoras } & h.17. Sistema de traslado y suspens & & & \\
\hline & h.18. Capacidad/modo de carga tan & & & \\
\hline & h.19. Filtros y bombas & & & \\
\hline & h.21. Sistema de requlación de cau & & & \\
\hline & h.22. Monitoreo y registro de datos & & & \\
\hline & n.23. Utros & & & \\
\hline
\end{tabular}

328. ¿Podría mencionar si su empresa tiene restricciones tecnológicas o productivas para el desarrollo de nuevos productos? No $\square$ Si $\square \quad$ En caso positivo indique cual es la restricción.

329. ¿Efectúa una evaluación de sus nuevos productos en el mercado? No

332. ¿Realizan investigaciones de mercados potenciales en el contexto local y/o global? No $\square$ Sí

333. ¿Qué porcentaje de las ventas de 2006 representan los nuevos productos o servicios desarrollados a partir de 2005 ? 
334. Indique el grado de impacto que las actividades de desarrollo de productos y diseño tuvieron en las siguientes dimensiones de la empresa (2006).

\begin{tabular}{||l|l|l|l||}
\hline & $\begin{array}{c}\text { Nulo o poco } \\
\text { significativo }\end{array}$ & Significativo & $\begin{array}{c}\text { Muy } \\
\text { Significativo }\end{array}$ \\
\hline a. Incremento de la facturación & & & \\
\hline b. Cambio en la organización interna & & & \\
\hline c. Aumento de las exportaciones & & & \\
\hline $\begin{array}{l}\text { d. Aumento en la participación de } \\
\text { mercado (market share) }\end{array}$ & & & \\
\hline e. Rentabilidad & & & \\
\hline f. Productividad & & & \\
\hline
\end{tabular}

\section{GESTION DE RECURSOS HUMANOS}

401. ¿Podría señalar la cantidad aproximada de personal que trabaja en la empresa bajo las siguientes modalidades en los períodos que se detallan?

\begin{tabular}{||l|l|l||}
\hline \hline & $\begin{array}{c}\text { Total } \\
\mathbf{2 0 0 3}\end{array}$ & $\begin{array}{c}\text { Total } \\
\mathbf{2 0 0 6}\end{array}$ \\
\hline $\begin{array}{l}\text { a. Contrato por tiempo } \\
\text { indeterminado }\end{array}$ & & \\
\hline b. Contrato por tiempo determinado & & \\
\hline c. Personal de agencia (eventuales) & & \\
\hline d. Pasantías & & \\
\hline $\begin{array}{l}\text { e. Sin relación de dependencia } \\
\text { (monotributistas) }\end{array}$ & & \\
\hline f. Total & & \\
\hline
\end{tabular}

402. ¿Podría indicar la cantidad del personal de su empresa en 2003 y 2006 según las siguientes categorías?

\begin{tabular}{||l|l|l||}
\hline & 2003 & 2006 \\
\hline a. Profesionales & & \\
\hline b. Técnicos & & \\
\hline c. Operarios calificados & & \\
\hline d. Operarios no calificados & & \\
\hline
\end{tabular}

403.¿En el último año ha incorporado personal en las siguientes categorías? En cuál de éstas ha tenido inconvenientes para conseguir personal con las calificaciones requeridas por la empresa?

\begin{tabular}{||l|l|c|c|c||}
\hline \multicolumn{1}{|c|}{ Categoría ocupacional } & \multicolumn{2}{c||}{ Incorporó } & \multicolumn{2}{c||}{ Inconveniente } \\
\cline { 2 - 5 } & No & Sí & No & Sí \\
\hline a. Profesionales & & & & \\
\hline b. Técnicos aplicados a producción & & & & \\
\hline c. Operarios calificados & & & & \\
\hline d. Operarios no calificados & & & & \\
\hline e. Total & & & & \\
\hline
\end{tabular}

404. ¿Qué elementos son de mayor importancia a la hora de decidir la contratación del personal? (Marque no más de tres en cada categoría de empleado)

\begin{tabular}{||l|l|c|c|}
\hline \hline & Profesional & $\begin{array}{c}\text { Técnico } \\
\mathbf{s}\end{array}$ & Operarios \\
\hline
\end{tabular}




\begin{tabular}{||l|l|l|l||}
\hline a. Sexo & & & \\
\hline b. Edad & & & \\
\hline c. Nivel de instrucción & & & \\
\hline d. Experiencia en puestos similares & & & \\
\hline e. Experiencia en la rama de actividad & & & \\
\hline f. Disponibilidad horaria & & & \\
\hline g. Lugar de residencia & & & \\
\hline
\end{tabular}

405. Indique si la empresa implementa alguna/s de las siguientes modalidades de rotación, aclarando si la misma es o no planificada.

\begin{tabular}{||l|l|l|l|l||}
\hline \hline & NO & SI & $\begin{array}{c}\text { PLANIFICA } \\
\text { DA }\end{array}$ & $\begin{array}{c}\text { ESPONTÁ } \\
\text { NEA }\end{array}$ \\
\hline $\begin{array}{l}\text { a. Rotación de los empleados entre } \\
\text { puestos de complejidad similar }\end{array}$ & & & & \\
\hline $\begin{array}{l}\text { b. Rotación de los empleados entre } \\
\text { funciones de diferente complejidad }\end{array}$ & & & & \\
\hline $\begin{array}{l}\text { c. Rotación de los empleados entre } \\
\text { diferentes áreas }\end{array}$ & & & \\
\hline
\end{tabular}

406. Indique las competencias más importantes requeridas al personal operativo (marque las tres más importantes)

\begin{tabular}{||l|l||}
\hline \multicolumn{2}{|l||}{} \\
\hline a. Conocimientos técnicos específicos & \\
\hline $\begin{array}{l}\text { b. Capacidad para comunicarse o relacionarse } \\
\text { con otros }\end{array}$ & \\
\hline c. Capacidad para trabajar en equipo & \\
\hline d. Autonomía e independencia & \\
\hline e. Creatividad & \\
\hline f. Flexibilidad/capacidad de adaptación & \\
\hline g. Capacidad de resolución de imprevistos & \\
\hline h. Coordinar acciones con los pares & \\
\hline
\end{tabular}

407. Frente a los problemas que aparecen frecuentemente en las actividades de producción, ¿cuál es el comportamiento típico de los operarios? Marque sólo la opción más frecuente

\begin{tabular}{||l|c||}
\hline \multicolumn{1}{|c||}{ Comportamiento } & Opción \\
\hline a. Llamar al supervisor para que lo resuelva. & \\
\hline b. Antes de emprender la solución, consultar al supervisor & \\
\hline c. Resolverlo y luego comunicarle la novedad al supervisor & \\
\hline $\begin{array}{l}\text { d. Resolverlo sin que sea necesario comunicar que ha sido } \\
\text { resuelto }\end{array}$ & \\
\hline $\begin{array}{l}\text { e. Buscar la solución y prevenir los problemas para que no } \\
\text { vuelvan a repetirse }\end{array}$ & \\
\hline f. Otros. Aclare. & \\
\hline
\end{tabular}

408. Indique si personal operativo desarrolla las siguientes funciones

\begin{tabular}{||l|l||}
\hline \multicolumn{1}{|c||}{ Funciones } & Opción \\
\hline a. Sólo operativas y de Programación y puesta a punto de & \\
\hline $\begin{array}{l}\text { b. Operativas y } \\
\text { Máquinas }\end{array}$ & \\
\hline c. Operativas y mantenimiento de primer nivel & \\
\hline d. Todas las anteriores & \\
\hline
\end{tabular}


409. ¿Cuál es el grado de flexibilidad predominante en la asignación de tareas en la gestión productiva? (escoja sólo una respuesta)

\begin{tabular}{||l|l||}
\hline \multicolumn{1}{|c||}{ Concepto } & Opción \\
\hline $\begin{array}{l}\text { a. Se organiza el trabajo de manera individual y se le asigna a las mismas personas } \\
\text { las mismas tareas, los puestos son fijos. }\end{array}$ & \\
\hline $\begin{array}{l}\text { b. Se organiza el trabajo de manera individual y se rota regularmente a las personas } \\
\text { en los distintos puestos. }\end{array}$ & \\
\hline $\begin{array}{l}\text { c. Se organiza el trabajo en células/equipos y dentro de cada equipo los puestos son } \\
\text { fijos }\end{array}$ & \\
\hline $\begin{array}{l}\text { d. Se organiza el trabajo en células/equipos, dentro de cada célula la gente rota entre } \\
\text { las tareas. }\end{array}$ & \\
\hline e. Otros: & \\
\hline
\end{tabular}

411. ¿Las negociaciones con los trabajadores se realizan?

\begin{tabular}{||l|l|l||}
\hline \multicolumn{1}{|c|}{ Forma de realización de las negociaciones } & No & Si \\
\hline a. Entre la Empresa y el sindicato & & \\
\hline $\begin{array}{l}\text { b. En forma directa con los representantes gremiales en la } \\
\text { empresa }\end{array}$ & & \\
\hline c. En forma directa con cada trabajador en particular & & \\
\hline d. Otros. Aclare. & & \\
\hline
\end{tabular}

412. ¿Cuáles son los aspectos que se incluyen en las negociaciones entre la empresa y los sindicatos y/o trabajadores?

\begin{tabular}{||l|l|l||}
\hline \multicolumn{1}{|c||}{ Ítems Negociados } & & \\
& & \\
\hline a. Organización y contenido del trabajo & & \\
\hline b. Salarios y remuneraciones & & \\
\hline c. Premios e incentivos & & \\
\hline d. Jornada, pausas y tiempo de trabajo & & \\
\hline e. Formación profesional & & \\
\hline f. Planes de carrera ocupacional & & \\
\hline g. Categorías & & \\
\hline h. Condiciones y medio ambiente de trabajo & & \\
\hline i. Otros. Aclare. & & \\
\hline \hline
\end{tabular}

413. ¿Qué proporción del salario de los operarios es variable (no considerando las horas extras)?

\begin{tabular}{||l|l||}
\hline & OPCIÓN \\
\hline a. $0 \%$ & \\
\hline b. Menos del $20 \%$ & \\
\hline c. Entre el 20 y el $35 \%$ & \\
\hline d. Más del $35 \%$ & \\
\hline
\end{tabular}

414. ¿Podría indicar el salario medio neto aproximado correspondiente al sector operativo y supervisión

415. Por favor indique cómo es el nivel de salarios de los operarios de su empresa en relación al salario promedio sectorial teniendo en cuenta el siguiente detalle: 
a. Al menos un $15 \%$ superiores al promedio del sector

b. Similares al salario promedio del sector

c. Al menos un $15 \%$ inferiores al promedio del sector

\section{E. CAPACITACION}

501. ¿Posee una estructura propia y diferenciada de las siguientes tareas vinculadas con estas actividades?

\begin{tabular}{||l|l|l||}
\hline & SI & NO \\
\hline a. Diagnóstico & & \\
\hline b. Planificación & & \\
\hline c. Desarrollo & & \\
\hline
\end{tabular}

502. ¿Podría indicar si su empresa realiza u organiza recurrentemente actividades de capacitación para sus empleados?

Si $\square \mathrm{No} \square$

\section{En caso negativo, pase a la pregunta 505}

503. En caso positivo, indique si estuvieron dirigidas a:

\begin{tabular}{||l|c|c|c||}
\hline \multicolumn{1}{|c|}{ DIRIGIDAS A: } & $\begin{array}{c}\text { SÓLO A NUEVOS } \\
\text { EMPLEADOS }\end{array}$ & $\begin{array}{c}\text { A MENOS DEL 50\% } \\
\text { DEL PERSONAL }\end{array}$ & $\begin{array}{c}\text { A MÁS DEL 50\% } \\
\text { DEL PERSONAL }\end{array}$ \\
\hline a. Operarios & & & \\
\hline b. Mandos intermedios & & & \\
\hline
\end{tabular}

504. ¿Realizaron cursos de capacitación en las siguientes temáticas?

\begin{tabular}{||l|l|l||}
\hline & NO & SI \\
\hline a. Supervisión de producción & & \\
\hline b. Gestión de la calidad & & \\
\hline c. Tecnología de producto o proceso & & \\
\hline d. Materiales & & \\
\hline e. Software específicos & & \\
\hline f. Marketing & & \\
\hline g. Informática & & \\
\hline h. Idiomas & & \\
\hline $\begin{array}{l}\text { i. Lectoescritura, matemática y/o geometría } \\
\text { básica, cálculos }\end{array}$ & & \\
\hline j. Otros. Aclare & & \\
\hline
\end{tabular}

505. ¿Cómo se capacita a la gente en sus puestos? Señale la modalidad más frecuente en cada grupo 


\begin{tabular}{|c|c|c|c|c|}
\hline & \multicolumn{2}{|c|}{ Operarios } & \multicolumn{2}{|c|}{$\begin{array}{c}\text { Mandos } \\
\text { intermedios }\end{array}$} \\
\hline & No & Si & No & Si \\
\hline a. Cada jefe inmediato forma a su propi & & & & \\
\hline b. Se asigna la tarea de capacitar al que & & & & \\
\hline c. Se forman tutores o líderes & & & & \\
\hline d. Se forman grupos de entrenamiento & & & & \\
\hline e. Otros (especifique) & & & & \\
\hline
\end{tabular}

\section{F. ADOPCION DE TICS (Exclusivo para empresas terminales)}

601. La maquinaria que la empresa fabrica, ¿incluye alguno de los siguientes dispositivos? (marque con una cruz los que correspondan)

\begin{tabular}{|l|l|l|l|}
\hline \multicolumn{1}{|c|}{ Dispositivos } & $\begin{array}{c}\text { Desarrollo } \\
\text { propio }\end{array}$ & $\begin{array}{c}\text { Desarrollo } \\
\text { terceros }\end{array}$ & Importado \\
\hline a. Monitor de Rendimiento & & & \\
\hline b. Monitor de Siembra & & & \\
\hline c. Monitor de Pulverización & & & \\
\hline d. Monitor controlador/registrador & & & \\
\hline e. Monitor de proteína, grasa, aceite, humedad u otros & & & \\
\hline f. Dosificador Variable de insumos/fertilizantes & & & \\
\hline g. GPS & & & \\
\hline h. Banderillero Satelital & & & \\
\hline i. Guía Automática & & & \\
\hline j. Sensores remotos & & & \\
\hline k. Sensores electrónicos $\left(1^{\circ}\right)$ & & & \\
\hline
\end{tabular}

(1) Indice Verde, Proteínas, Nitrógeno, Flujo, humedad, temperatura, etc.

602. Aquellos dispositivos que no incluye, ¿por qué no los incluye? Señale las razones principales

\begin{tabular}{||l|l||}
\hline Razones & Marque con una cruz \\
\hline Porque se lo agrega a pedido del cliente & \\
\hline Porque no es rentable & \\
\hline Porque la demanda no lo requiere & \\
\hline Porque resulta caro importarlos & \\
\hline Porque no hay recursos humanos para desarrollarlos & \\
\hline & \\
\hline Otra razón (especificar) & \\
\hline \hline
\end{tabular}

603. ¿Tienen pensado agregar estos dispositivos a su oferta en el corto plazo? Sí __ _ No_

604. ¿Cuál es el origen de los sistemas de software que utilizan estos dispositivos? (marcar con una cruz lo que corresponda)

\begin{tabular}{|l|c|c||}
\hline \hline & $\begin{array}{c}\text { Embebido en } \\
\text { dispositivos }\end{array}$ & $\begin{array}{c}\text { Recepción/análisis } \\
\text { de datos (en PC) }\end{array}$ \\
\hline a) Nacional & & \\
\hline Desarrollo propio & & \\
\hline \hline
\end{tabular}




\begin{tabular}{||l|l|l||}
\hline \hline Tercerizado completo & & \\
\hline Tercerizado con adaptaciones propias & & \\
\hline ¿Cuáles? Nombre de la empresa proveedora & & \\
\hline & & \\
\hline b) Extranjero & & \\
\hline Importación de paquete cerrado & & \\
\hline Importación con adaptaciones locales & & \\
\hline $\begin{array}{l}\text { ¿Cuáles? Nombre de la empresa } \\
\text { proveedora }\end{array}$ & & \\
\hline \hline
\end{tabular}

613. ¿Podría indicar aproximadamente el monto de ventas totales de la empresa y el número total de ocupados de la empresa en los siguientes años?

\begin{tabular}{||l|c|c||}
\hline \multicolumn{1}{|c|}{ Año } & $\begin{array}{c}\text { Ventas (miles de } \\
\text { pesos) }\end{array}$ & Ocupados \\
\hline a. 2001 & & \\
\hline b. 2003 & & \\
\hline c. 2006 & & \\
\hline
\end{tabular}

DATOS DEL ENCUESTADOR

\begin{tabular}{|l|l||}
\hline APELLIDO Y NOMBRE: & \\
\hline Código de encuestador: & \\
\hline Fecha/s de visita a la empresa & \\
\hline Duración de la/s entrevista/s: & \\
\hline Observaciones: & \\
\hline
\end{tabular}

